\title{
Model Documentation Report: Commercial Sector Demand Module of the National Energy Modeling System
}

January 1998

\section{RECEIVED \\ JAN 271998. \\ OSTI}

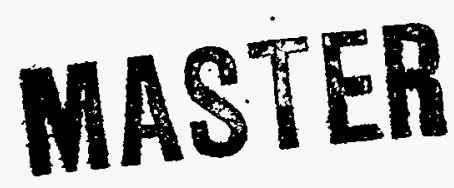

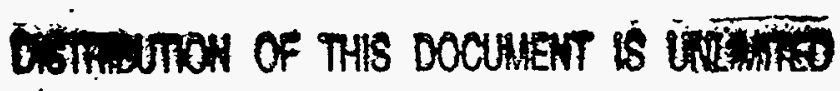

Office of Integrated Analysis and Forecasting

Energy Information Administration

- U.S. Department of Energy

Washington, DC 


\section{UPDATE INFORMATION}

This updated version of the NEMS Commercial Module Documentation includes changes made to the commercial module for the production of the Annual Energy Outlook 1998.

Released for Printing: January 1998 


\section{DISCLAIMER}

This report was prepared as an account of work sponsored by an agency of the United States Government. Neither the United States Government nor any agency thereof, nor any of their employees, makes any warranty, express or implied, or assumes any legal liability or responsibility for the accuracy, completeness, or usefulness of any information, apparatus, product, or process disclosed, or represents that its use would not infringe privately owned rights. Reference herein to any specific commercial product, process, or service by trade name, trademark, manufacturer, or otherwise does not necessarily constitute or imply its endorsement, recommendation, or favoring by the United States Government or any agency thereof. The views and opinions of authors expressed herein do not necessarily state or reflect those of the United States Government or any agency thereof. 


\section{DISCLAIMER}

Portions of this document may be illegible electronic image products. Images are produced from the best available original document. 


\section{Model Documentation Report: Commercial Sector Demand Module of the National Energy Modeling System}

January 1998

Office of Integrated Analysis and Forecasting Energy Information Administration

U.S. Department of Energy

Washington, DC

This repoit was prepared by the Energy. Information Administration, the independent statistical and analytical agency within the Department of Energy. The information contained herein should be altributed to the Energy Information Administration and should not be construed as advocating or reflecting any policy position of the Department of Energy or of any other organization. 


\section{Contents}

1. Introduction $\ldots \ldots \ldots \ldots \ldots \ldots \ldots \ldots \ldots \ldots \ldots \ldots \ldots \ldots \ldots \ldots \ldots \ldots \ldots \ldots$ i

Purpose of this Report $\ldots \ldots \ldots \ldots \ldots \ldots \ldots \ldots \ldots \ldots \ldots \ldots \ldots \ldots \ldots \ldots \ldots \ldots, \ldots \ldots \ldots, \ldots \ldots \ldots$

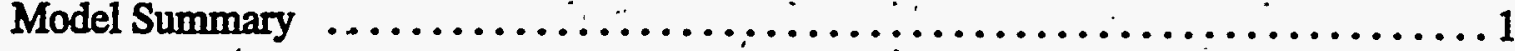

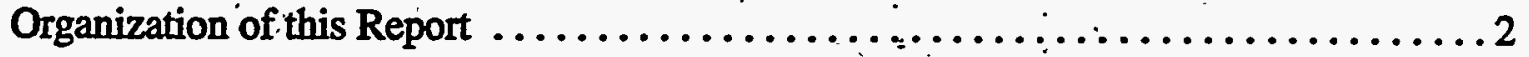

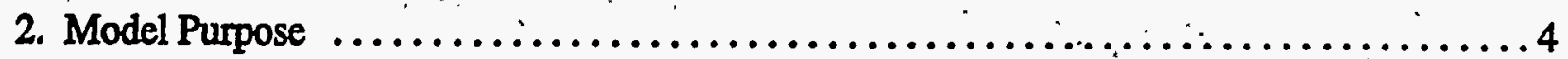

Model Objectives ................................................4

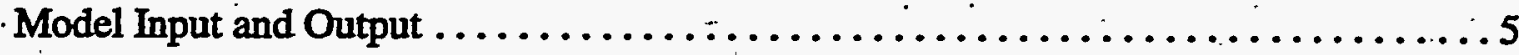

Relationship of the Commercial Module to Other NEMS Modules .............9

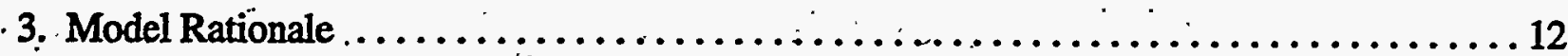

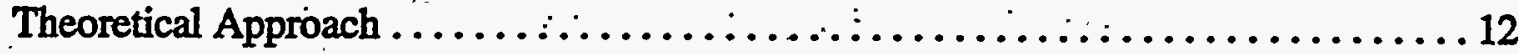

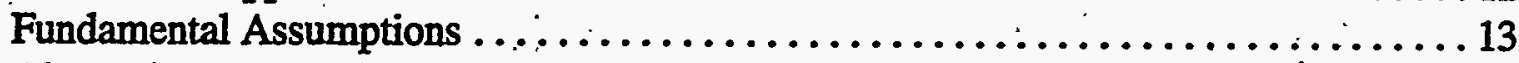

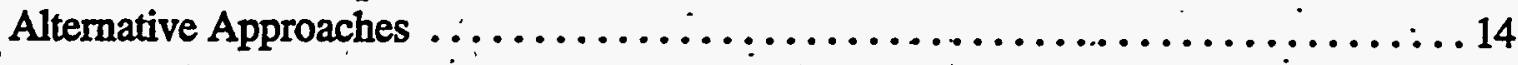

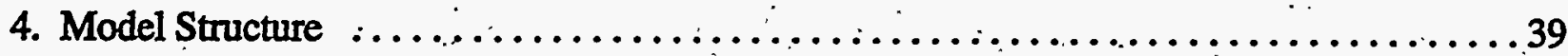

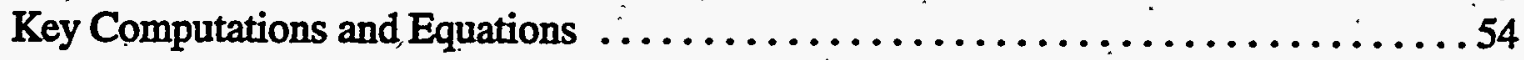

\section{Appendices}

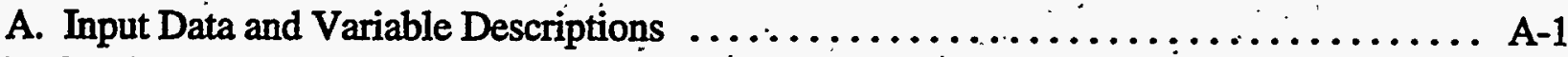

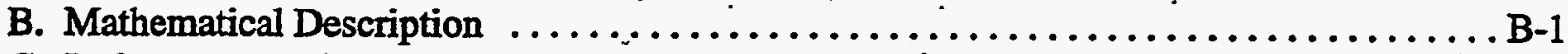

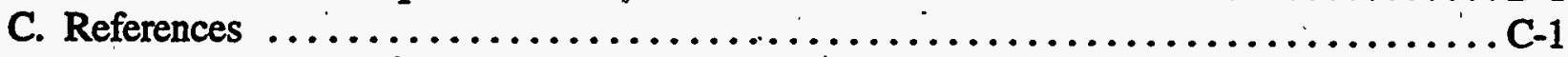

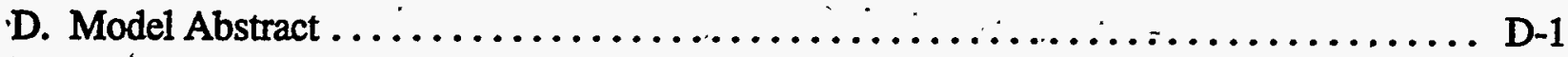

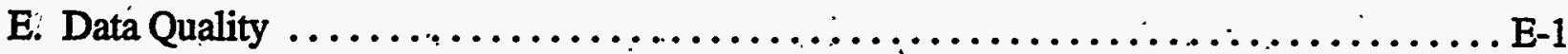

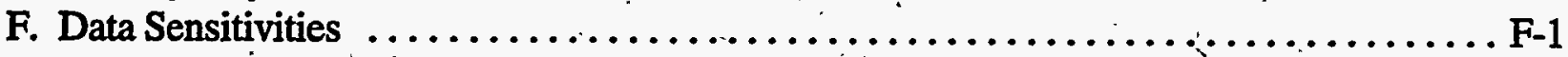




\section{Tables and Figures}

Tables

Table 1. Dimensions Spanned by Commercial Module Variables . . . . . . . . . . . ...8

Table 2. BEEM and NEMS Commercial Models: Conceptual Tasks . . . . . . . . . . . . 16

Table 3. COMMEND and NEMS Commercial Models: Conceptual Tasks . . . . . . . . . . 22

Table 4. ORNL and NEMS Commercial Models: Conceptual Tasks . . . . . . . . . . . . 26

Table 5. CEDMS and NEMS Commercial Models: Conceptual Tasks . . . . . . . . . . . 29

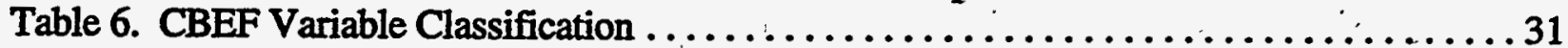

Table 7. CBEF and NEMS Commercial Models: Conceptual Tasks . . . . . . . . . . . 33

Table 8. CSEM and NEMS Cómmercial Models: Conceptual Tasks . . . . . . . . . . ... 36

Table 9. Energy Consumption Calculation Example $\ldots \ldots \ldots \ldots \ldots \ldots \ldots \ldots \ldots \ldots \ldots \ldots \ldots$

Table 10. Array of Technology Choices and Consumer Behaviors . . . . . . . . . . . . . 67

Table 11. Floorspace Ownership and Occupancy .......................69

Table 12. Consolidating Service Demand Segments $\ldots \ldots \ldots \ldots \ldots \ldots \ldots \ldots \ldots \ldots$

Figures

Figure 1. Commercial Sector Demand Module's Relationship to Other NEMS Modules . . . . 11

Figure 2. Commercial Module Structure \& Fundamental Process Flow $\ldots \ldots \ldots \ldots \ldots \ldots \ldots 45$

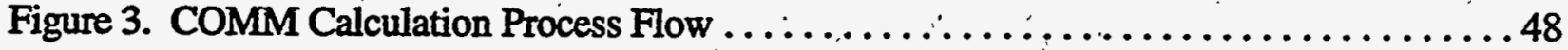

Figure 4. COMFloorspace Calculation Process Flow . . . . . . . . . . . . . . . . . . . . 49

Figure 5. COMServiceDemand Calculation Process Flow . . . . . . . . . . . . . . . . 50

Figure 6. COMTechnologyChoice Calculation Process Flow . . . . . . . . . . . . . 51

Figure 7. COMConsumption Calculation Process Flow $\ldots \ldots \ldots \ldots \ldots \ldots \ldots \ldots \ldots \ldots \ldots$

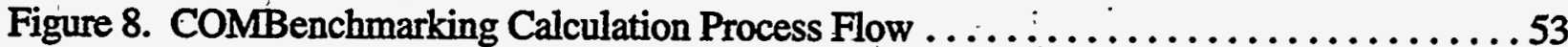

Figure 9. Floorspace Survival Function Sensitivity to Average Building Lifètimes . . .....56

Figure 10. Alternative Gamma Assumptions and Results . . . . . . . . . . . . . . . 57 


\section{Introduction}

\section{Purpose of this Report}

This report documents the objectives, analytical approach and development of the National Energy Modeling System. (NEMS) Commercial Sector Demand Module. The report catalogues and describes the model assumptions, computational methodology, parameter estimation techniques, model source code, and forecast results generated through the synthesis and scenario development based on these components.

This document serves three purposes. First, it is a reference document providing a detailed description for model analysts, users, and the public. Second, this report meets the legal requirement of the Energy Information Administration (EIA) to provide adequate documentation in support of its models (Public Law 93-275, section 57.b.1). Third, it facilitates continuity in model development by providing documentation from which energy analysts can undertake model enhancements, data updates, and parameter refinements as future projects.

\section{Model Summary}

The NEMS Commercial Sector Demand Module is a simulation tool based upon economic and engineering relationships that models commercial sector energy demands at the nine Census Division level of detail for eleven distinct categories of commercial buildings. Commercial equipment selections are performed for the major fuels of electricity, natural gas, and distillate fuel, for the major services of space heating, space cooling, water heating, ventilation, cooking, refrigeration, and lighting. The market segment level of detail is modeled using a constrainedlife-cycle cost minimization algorithm that considers commercial sector consumer behavior and time preference premiums. The algorithm also models demand for the minor fuels of residual oil, liquefied petroleum gas, steam coal, motor gasoline, and kerosene, the renewable fuel sources of wood and municipal solid waste, and the minor services of office equipment (with a separate breakout of personal computers) and "other" in less detail than the major fuels and services. Numerous specialized considerations are incorporated, including the effects of changing building shell efficiencies, the relationship between nonutility generation of electricity and the relative prices of fuels, and consumption to provide district services.

As a component of the National Energy Modeling System integrated forecasting tool, the NEMS Commercial Module generates mid-term forecasts of commercial sector energy demand. The model facilitates policy analysis of 
energy markets, technological development, environmental issues, and regulatory development as they impact commercial sèctor energy demand.

\section{Archival Media}

NEMS-98 (Part of the National Energy Modeling System archive package for the Annual Energy Outlook 1998, DOE/EIA-0383(98)).

\section{Model Contact}

Erin Boedecker

Office of Integrated Analýsis and Forecasting

Energy Demand and Integrated Analysis Division

Energy Demand Analysis Branch

United States Department of Energy, James Forrestal Building

1000 Independence Avenue, SW

Washington, D.C. 20585

\section{Telephione}

(202) $586-4791$

\section{Organization of this Report}

Section 2 of this report discusses the purpose of the model, detailing its objectives, primary input and output quantities, and the relationship of the Commercial Module to the other modules of the NEMS system. Section 3 of the report describes the rationale behind the model design, providing insights into further assumptions utilized in the model development process to this point. Section 3 also reviews alternative commercial sector modeling methodologies drawn from existing literature, providing a comparison to the chosen approach. Section 4 details the . model structure, using graphics and text to illustrate model flows and key computations.

The Appendices to this report provide supporting documentation for the input data and parameter files currently residing on the EIA computing platform. Appendix A lists and defines the input data used to generate parameter estimates and endogenous forecasts, along with the parameter estimates and the outputs of most relevance to the NEMS system and the model evaluation process. A table referencing the equation(s) in which each variable appears is also provided in Appendix A. Appendix B contains a mathematical description of the computational algorithms, '. including the complete set of model equations and variable transformations, Appendix $C$ is a bibliography of 
réference materials used in the development process. Appendix $\mathrm{D}$ provides the model abstract. Appendix $\mathrm{E}$ discusses data quality and estimation methods, and Appendix F consists of results illustrating the sensitivity of the model outputs to variations in the inputs 


\section{Model Purpose}

\section{Model Objectives}

The NEMS Commercial Sector Module serves three objectives. First, it develops mid-term forecasts of commercial sector energy demand, currently spanning a forecast horizon of thirty-one (31) years, from 1990 through $2020^{1}$, as a component of the NEMS integrated forecasting system. The resulting forecast is incorporated into the Annual Energy Outlook, published annually by the Energy Information Administration of the U.S. Department of Energy. Second, it is a policy andlysis tool to assess the impacts of changes in energy markets, building and equipment technologies, environmental considerations and regulatory initiatives on commercial sector energy consumption. Third, as an integral component of the NEMS system, it provides inputs to the Electricity Market Module, Coal. Market Module, Natural Gas Transmission and Distribution Module, and Petroleum Market Module of NEMS, contributing to the calculation of the overall energy supply and demand balance of the U.S. energy market.

The Commercial Sector Demand Module projects commercial sector energy demands in four sequential steps.

- These steps produce forecasts of new and surviving commercial building floorspace, demands for energy-consuming services in those buildings, technology choices to meet the service demands, and consumption of electricity, natural gas, and distillate oil by the equipment chosen. ${ }^{2}$ These forecasts are based on energy prices and macroeconomic variables from the.NEMS system, combined with external data sources.

Forecasted commercial sector fuel demands generated by the Commercial Sector Demand Module are used by the NEMS system in the calculation of the supply and demand equilibrium state. In addition, the NEMS supply modules referenced previously use the commercial sector outputs in conjunction with other projected sectoral demands to determine the patterns of consumption and the resulting amounts and prices of energy delivered to the commercial sector.

The base year for the Commercial Module is currently 1992, corresponding to the last available energy consumption survey of commercial buildings. Dynamic forecasts dependent on feedback from the rest of NEMS are made for the years 1993 through 2020, whereas results reported for $1990^{\circ}$ through 1992 are historical.

${ }^{2}$ The End-Use Consumption Module accounts for commercial sector consumption of five minor fuels. These fuels - do not account for enough commercial sector consumption to justify modeling at.the same level of detail as the three major fuels (distillate fuel oil, natural gas, and electricity). The five minor fuels are residual fuel oil, liquefied petroleum gas (LPG), coal, motor gasoline and kerosene: 
Of equal importance, the NEMS Commercial Sector Model is relevant to the analysis of current and proposed legislation, private sector initiatives and technological developments. The flexible model design provides a policy analysis tool able to accommodate a wide range of scenario developments. Both the input file structure and the model source code have been specially developed to facilitate "what if" analyses of energy markets, technology characterizations, market initiatives, environmental concerns; and regulatory policies such as demand-side management (DSM) programs. Examples of specific policy analyses that can be addressed using this model include assessing the potential impacts of:.

- New end-use technologies (for example, compact fluorescent light bulbs or ground source heat pumps)

New energy supply technologies (for example, solar thermal heating or fuel cells)

Federal, state and local government policies, including:

- changes in fuel prices due to tax policies

- changes in building shell or equipment energy efficiency standards

- financial incentives for energy efficiency or renewable energy investments

- information programs

- environmental standards

- Utility demand-side management programs

\section{Model Input and Output}

\section{Inputs}

The primary inputs to the Commercial Sector Demand Module include fuel prices, commercial building floorspace growth, interest rates; and technology characteristics. The technology characteristics used by the model include . years of availability for purchase, market shares of equipment existing in 1992, installed capital costs per unit of service demand, operating and maintenance costs per unit of service demand, equipment efficiencies, removal/disposal cost factors, building réstrictions, service provided, fuel used, expected equipment lifetimes, and cost trend parameters. Additional detail on model inputs is provided in Appendix A. The major inputs by model component are summarized as follows:

\section{Iniputs to Floorspace Component}

Existing distribution of commercial building floorspace stock for 1992

Median construction year of existing commercial buildings by type, vintage, and location

Building survival parameters 
Commercial building floorspace growth

Inputs to Service Demand Component

Energy Use Intensities (EUI) for 1992.

Commercial technology characterizations

market shares of equipment existing in 1992

equipment efficiencies

- building restrictions

service provided

funel used

Building shell efficiency indices for new floorspace

Building shell efficiency improvement over the forecast for existing and new floorspace

Market penetration forecasts for office equipment and "other" end-use category

Steam EUIs to provide District Services in 1992

Efficiencies of boilers providing District Services in 1992

Fuel shares of District Service steam production in 1992

Renewable fuel consumption forecast

Short-run price elasticities of service demand

Historical and average heating and cooling degree days :

Differences in serviced floorspace proportions between existing and new floorspace

\section{Inputs to Technology Choice Component}

Consumer behavior rules

Consumer time preference premium segments

Minor service efficiency improvement projections

Building end-use service capacity utilization factors

DSM program options

Commercial Technology characterizations

years of availability for purchase

market shares of equipment existing in 1992

installed capital costs per unit of service demand

operating and maintenance costs per unit of service demand

equipment efficiencies

removal/disposal cost factors

building restrictions 
service provided

fuel used

expected equipment lifetimes

cost trend parameters

Expected fuel prices

\section{Inputs to End-Use Fuel Consumption Component}

Short Term Energy Outlook (STEO) consumption forecast

State Energy Data System.(SEDS) consumption information

Components of SEDS data attributable to other sectors

Historical cogeneration of electricity data

\section{Cogeneration of electricity parameters}

Minor fuel regression parameters

\section{Outputs}

The primary output of the Commercial Sector Demand Module is a forecast of commercial sector energy consumption by fuel type, end-use, building type, Census Division, and year. The module also provides forecasts of the following for each of the forecast years:

construction of new commercial floorspace by building type and Census Division

surviving commercial floorspace by building type, year of construction, and Census Division

equipment market shares by technology, end-use, fuel, building type, ánd Census Division

cogeneration of electricity, and quantities of fuel consumed for cogeneration

consumption of fuels to provide District Services

nonbuilding consumption of fuels in the commercial sector

Average efficiency of equipment mix by end-use and fuel type

\section{Variable Classification}

The NEMS demand modules are required to exchange information with the supply modules at the nine Census Division level of detail spatially, and average annual level temporally. Information exchanged between the Commercial Demand Module and the Electricity Market Module is also required at the end-use service level of detail. The input data available from the Commercial Buildings Energy Consumption Survey (CBECS) performed by EIA (which forms the basis for the Commercial Sector Demand Module) and other sources are designed to be 
statistically significant at various levels, some of which are above the nine Census Division level. Commercial Sector Demand Module variables are resolved at a relatively fine level of detail in order to capture heterogeneous effects that manifest themselves at a high level of aggregation, yet which originate from variations at a disaggregate level. The primary dimensions across which key variables vary are set forth in Table 1 , below, together with the notation generally used to represent the dimensions in this repoit:

Table 1. Dimensions Spanned by Commercial Module Variables

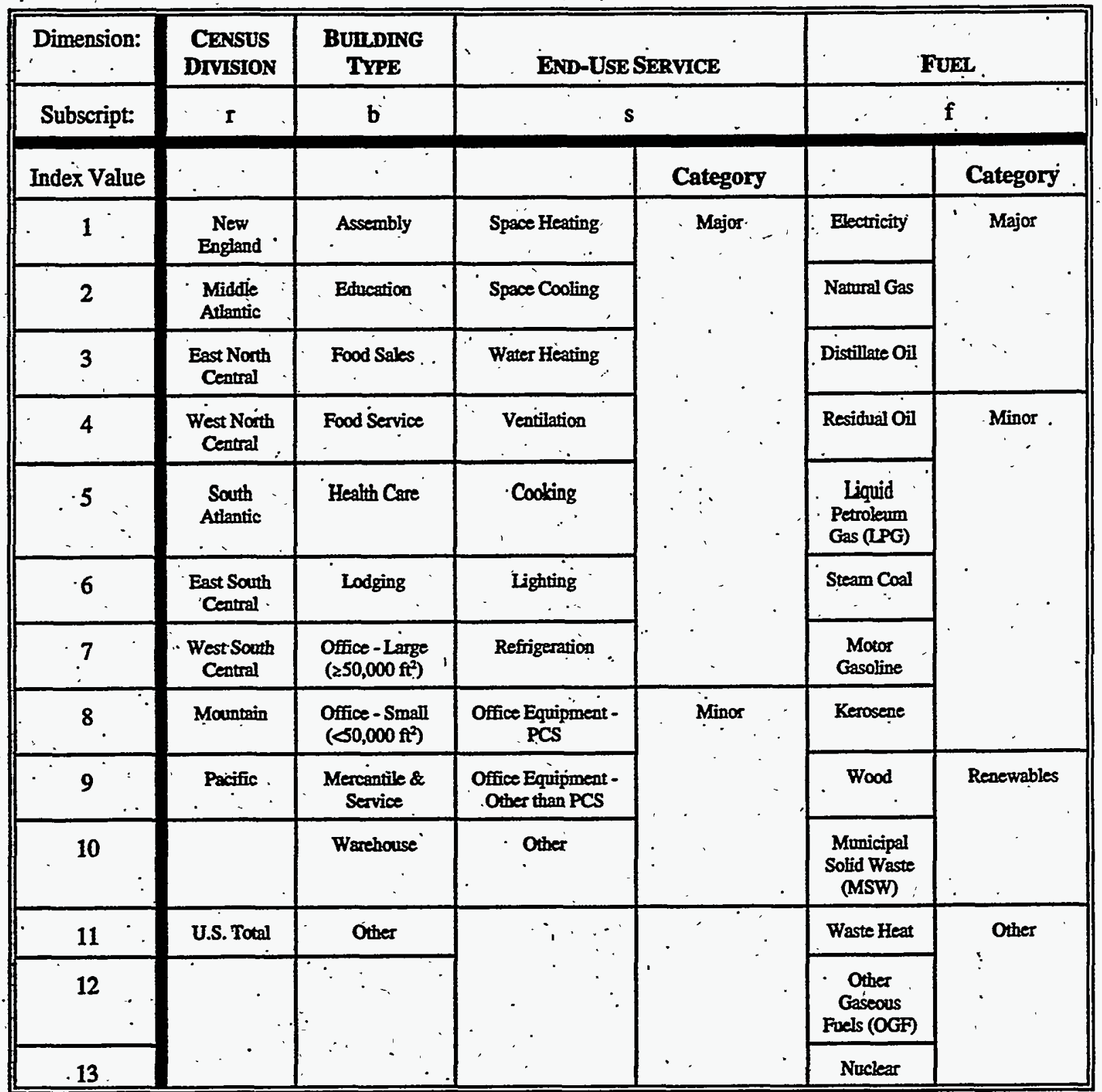


In addition to the dimensions shown in Table 1, over which most Commercial Module yariables vary, there are several other domains of variation considered by certain classes of variables. Of course, time is a dimension spanned by most Commercial Module variables, and is generally represented by the subscript $y$, which is indexed so that a - value of 1 corresponds to the year 1990 and a value of 31 corresponds to 2020.

Consumer time preference premium segments are represented by the subscript $p$, and represent the percent increment to the risk-free interest rate in the current year, used to segment commercial consumer behavior patterns. The model currently uses a discrete distribution of six (6) consumer time preference premiums to characterize the commercial consumer decisionmaking population. These six discount premia, and the proportion of consumers attributed to each, vary both regionally and with end-use. Additional detail is provided in Chapter 4 of this report.

Equipment defined in the Commercial Sector Technology Characterization Database, KTECH, is represented through the use of two subscripts, namely $t$ and $v$. The existence of a particular pair of indexed values of $t$ and $v$ indicates that a representative piece of equipment within a technology class $(t)$ is available in one or more models $(v)$ for competition in Technology Choice Submodule. The current Technology Choice Submodule allows for a maximum of 11 vintages for each piece of representative equipment. An example of two different vintages for the same technology class would be: 1) an electric resistance water heater with energy factor of 0.80 , available in 1995 and 2) an electric resistance water heater with an energy factor of 0.91 , available in 2000 and beyond. Vintage 2) represents an updated model in this example.

The,Major Service end-uses listed in Table 1 are modeled in the Technology Choice Submodule described in Chapter 4 of this report. Minor end-uses are forecast using equipment efficiency and market penetration trends. Forecasted energy demand for the Major fuels listed above takes into account the price elasticity of service demand and takeback effects as described in Chapter 4 below. Minor fuel demands do not incorporate price elasticity of demand impacts, although they are correlated with fuel prices and amount of floorspace.

\section{Relationship of the Commercial Module to Other NEMS Modules}

The Commercial Module receives input data from the Macroeconomic Activity Module and the energy supply modules. The commercial floorspace forecast and ten-year Treasury bond interest rates generated by MAM are used to calculate annual new additions to floorspace and annualized technology capital cósts respectively. Energy prices generated by the supply modules, specifically the end-use service electricity prices from the Electricity Market. Module (EMM); the natiral gas prices from the Natural Gas Transmission and Distribution Module (NGTDM), and the petroleum prices from the Petroleum Market Module (PMM) are primary drivers for the technology cost 
comparison, the forecast of commercial sector cogeneration, and price foresight scenarios. The Commercial Module provides energy consumption forecasts by Census Division and fuel to the supply modules listed above, from which supply resources and capacity plans are developed.

This relationship of the Commercial Module to other components of NEMS is depicted schematically in Figure 1. As shown, all exchanges of information between the modules takes place through the NEMS Global Data Structure. Not shown is the NEMS Integrating Module, which directs the activation of the sectoral modules, thus controlling. the sequence and iteration of modeled considerations at the sector level. For a more detailed description of the approach taken by the Integrating Module within the NEMS general equilibrium solution to interactions between the U.S. energy markets and the economy, the reader is referred to the Integrating Module Documentation Report ${ }^{3}$ and the NEMS Overview"

${ }^{3}$ Energy Information Administration, NEMS Integrating Module Documentation Report, DOEIEIA-M057 (Washington, DC, May 1997).

${ }^{4}$ Energy Information Administration, NEMS-An Overview, DOE/EIA-0581 (Washington, DC, March 1996) 
Figure 1. Commercial Sector Demand Module's Relationship to Other NEMS Modules

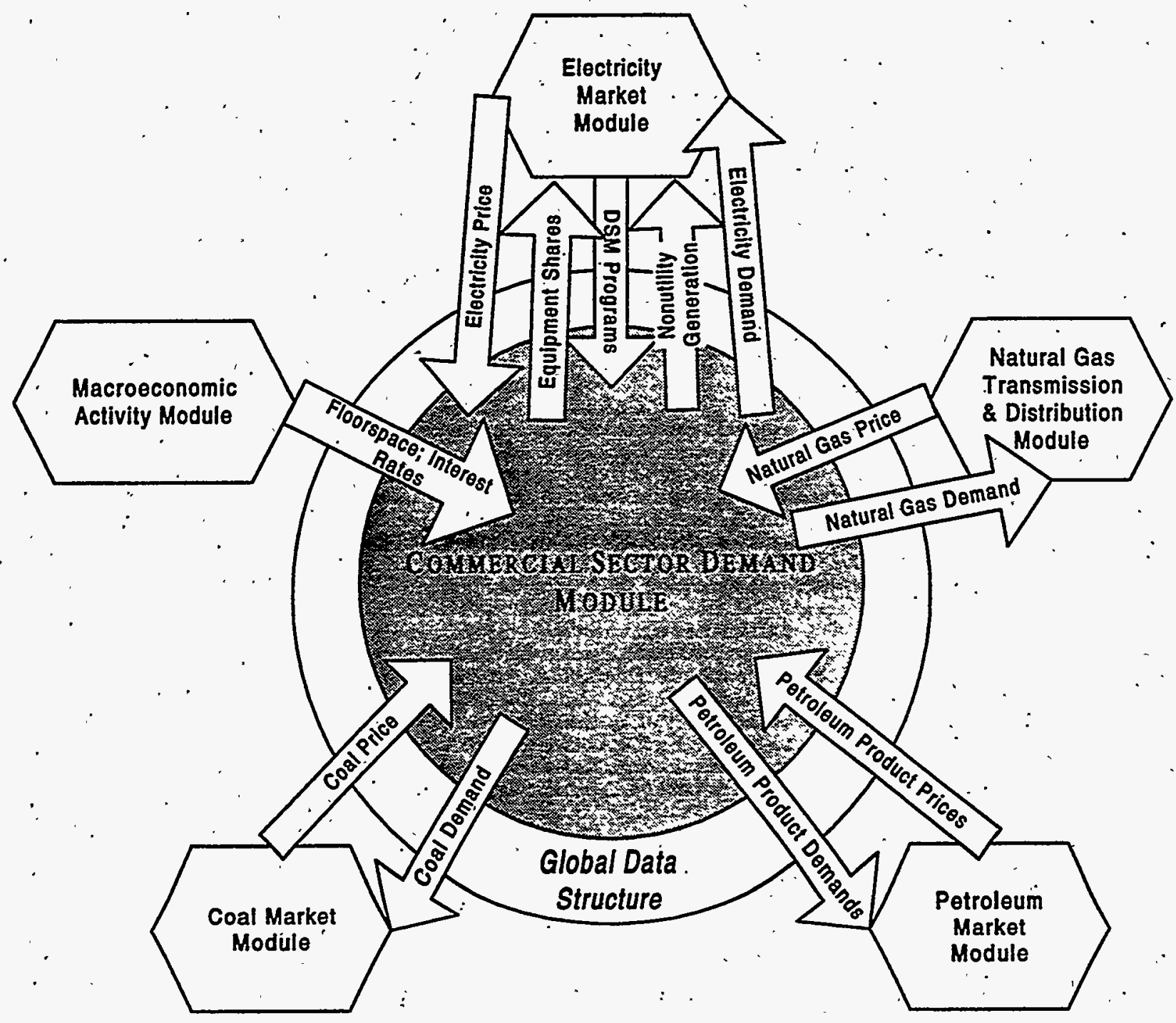

Energy Information Administration NEMS Commercial Demand Module Documentation Report 


\section{Model Rationale}

\section{Theoretical Approach}

The Commercial Module utilizes a simulation approach to project energy demands in commercial buildings. A simulation approach represents the characteristics of one system through the use of another system. The specific approach of the Commercial Module involves explicit economic and engineering-based analysis of the building energy end uses of space heating, space cooling, water heating, ventilation, cooking, lighting, office equipment, refrigeration, and "other" energy-consuming equipment. These end-uses are modeled for eleven distinct categories of commercial buildings at the Cenșus Division level of detail.

As described previously in this report, the model is a sequentially structured system of algorithms, with succeeding computations utilizing the outputs of previousiy-executed routines as inputs. For example, the building square footage projections developed in the Floorspace routine are used to calculate demands of specific end-uses in the Service Demand routine. Calculated service demands provide input to the Technology Choice subroutine, and subsequently contribute to the development of end-use consumption.

In the default mode, the Commercial Module assumes myopic foresight with respect to energy prices, using only currently-known energy prices in the annualized cost calculations of the technology selection algorithm. The model is capable of accommodating the alternate scenarios of adaptive foresight and perfect foresight within the NEMS. system.

A key assumption that is integrated into the technology characterization data base that forms the basis of the technology selection process is that the equipment efficiency standards described in the Energy Policy Act of 1992 (EPACT) become operative market choices in the year 1994. This is modeled in the data base by the elimination of noncompliant equipment choices and introduction of compliant equipment choices by the year 1993. Through this data base, the Commercial Module is able to model equipment efficiency legislation as it continues to evolve.

There are several documented models of commercial sector energy demand. Some of these predecessor models employ simulation techniques, while others employ hybrids of econometric, engineering, and simulation approaches. Selected commercial sector modeling initiatives, including predecessor EIA models, are discussed and compared to the selected approach further in this section. 


\section{Fundamental Assumptions}

\section{Floorspace Submodule}

The existing stock, geographic and building usage distribution, and vintaging of floorspace at the beginning of the dynamic portion of the model run is assumed to be the floorspace stock published as a result of the 1992 Commercial Buildings. Energy Consumption Survey (CBECS)s.

New additions to the floorspace stock through the forecast period are assumed to conform to building standards as described in End-Üse Energy Consumption Estimates for U.S. Commercial Buildings, 1989, Pacific Northwest Laboratory, PNL-8946; November 1993.

\section{Service Demand Submodule}

The average equipment efficiency of the existing ștock of equipment is assumed in each service to produce the CBECS 1992 energy consumption when the Energy Use Intensities (EUIs) derived from the CBECS 1992 data are applied.

The model currently assumes a simplification of the equipment retirement function that sets the proportion of equipment of a specific technology class and model that retires annually equal to the reciprocal of that equipment's expected lifetime expressed in years.

Service Demand Intensity (SDI) is assumed constant over the forecast period (for a given service, building type and vintage, and Census Division), and EUIs and average equipment efficiencies, which are the primary components of the SDI calculation, which change over the forecast, are assumed to change in such a manner as to preserve the SDI.

The market for the largest major services is assumed to be saturated. No increase in market penetration for the services of space conditioning, water heating, ventilation, refrigeration, and lighting is modeled.

Energy Information Administration, Commercial Buildings Characteristics 1992, DOE/EIA-0246(92), GPO Stock No. 061-003-00850-0 (Washington, DC, April 1994). 


\section{Technology Choice Submodule}

The technology selection approach employs explicit assumptions regarding commercial consumer choice behavior. Consumers are assumed to follow one of three behavioral rules: Least Cost, Same Fuel, or Same Technology. The proportions of consumers that follow each behavioral rule are developed based upon quantitative assessment and specific assumptions that are referenced in Table A-2, Appendix A to this report.

The technology selection is performed using a discrete distribution of consumer time preference premiums. These premiums are developed based on analysis of survey results and additional literature, employing specific assumptions to consumer behavior in order to quantify these concepts for inclusion in the model. Documentation of these assumptions is referenced in Table A-2 of Appendix A to this report.

Myopic foresight is assumed in the default mode of the model operation. In other words, current energy prices are used to develop the annualized fuel costs of technology selections in the default mode.

Energy efficiency and continuing market penetration for minor services (office equipment and "other" services) is forecast to increase over the forecast period based on published sources that are further referenced in Table A-2, Appendix A to this report. Minor services are assumed to consume only electricity, and fuel switching is not addressed.

\section{Alternative Approaches}

Building-level simulation is one approach that is applicable to the analysis of commercial sector energy demands. Additional approaches exist and have been adopted by previous modelers for such institutions as EIA, Electric. Power Research Institute (EPRI), Oak Ridge National Laboratory (ORNL), and the California regulatory establishment. Selected alternative approaches are discussed below. Versions of all models discussed are those which existed in 1993; the comparison has not been updated to reflect changes made since that time in either the NEMS Commercial Sector Demand Module or the alternative approaches.

\section{Building Energy End-Use Model (BEEM): EIA}

The BEEM model is designed to forecast annual commercial building energy consumption for the four Census Regions through 2010. The BEEM methodology and the NEMS Commercial Model methodology are contrasted in Table 2. 
BEEM divides the commercial sector into seven building types according to primary building activity. The categories are office, food saleș/service, warehouse, retail, education, continuous uses, and miscellaneous. Six energy-consuming services are modeled: space heating, space cooling, water heating, cooking, lighting, and other services. The fuels consumed to meet the service demand are electricity, natural gas, distillate fuel, and various minor fuels. The model's base year is 1986, determined from the 1986 EIA Nonresidential Building Energy Consumption Survey (NBECS-86), which provides much of the initial data for energy consumption and building characteristics.

Building energy consumption changes over time in response to commercial floorspace growth and improvements in . sheli integrity and equipment efficiency. The range of forecasted energy consumption depends on the variation of floorspace growth and on consumer choices among energy-using equipment. The BEEM commercial model is composed of five modules: floorspace, service demand, service capacity, technology choice, and a calibration modúle.

Floorspace. BEEM measures building stock by square footage of floorspace, for the seven building types and four: Census Regions. 'Floorspace growth is composed of the combined effect of floorspace construction and attrition of ' existing stock. Base yéar floorspace is based on NBECS-86. This floorspace declines annually at constant attrition rates by region, while new floorspace is added each year. Total new constriction for the period 1980-86 (divided by seven to obtain a yearly average, or no growth in yearly construction) is used as a proxy for the 1987 new construction pattern by building type. The 1987 estimate is then extrapolated annually by region, at the same rate of growth as regional employment growth. 'The module then computes total floorspace by adding existing and new floorspace by region and building type.

Service Demand. The service demand module tracks the energy required for each type of service (space heating, space cooling, etc.) and building type. Energy consumed for each service (in energy consumption per square foot) is multiplied by corresponding floorspace. Energy efficiency of building shells improve over time relative to 1986 stock, reducing the demand for heating and cooling services. Thus, a shell efficiency index is used as an adjustment factor to capture the reduction in service demand. Service demand is also adjusted to account for renewable energy consumption. Renewable energy contributions are exogenously estimated for geothermal consumption, which reduces space cooling service demand, and solar and other renewables, which reduces heating service demand. 
Table 2. BEEM and NEMS Commercial Models: Conceptual Tasks

\begin{tabular}{|c|c|c|}
\hline Conceptual Task & BEEM Methodology & $\begin{array}{l}\text { NEMS Commercial Model } \\
\text { Methodology }\end{array}$ \\
\hline $\begin{array}{c}\text { Forecast floorspace additions } \\
0 \\
\end{array}$ & $\begin{array}{l}\text { Increase additions (for every } \\
\text { building type) proportionally with } \\
\text { change in national employment; } \\
\text { shares of building type constant } \\
\text { throughout forecast period }\end{array}$ & $\begin{array}{l}\text { Forecast by building type and } \\
\text { Census Division, based on NEMS } \\
\text { MAM floorspace forecast }\end{array}$ \\
\hline Retire floorspace & $\begin{array}{l}\text { Retire constant proportion for all } \\
\text { building type, regions, and vintages }\end{array}$ & $\begin{array}{l}\text { Retire based on vintage, using } \\
\text { convolutional decay }\end{array}$ \\
\hline $\begin{array}{l}\text { Measure and forecast service } \\
\text { demand and demand penetration } \\
\vdots\end{array}$ & $\begin{array}{l}\text { Measure service demand as, energy } \\
\text { consumption in base year (indexed } \\
\text { to consumption data) }\end{array}$ & $\begin{array}{l}\text { Measure service demand in Btu of } \\
\text { delivered energy; include short-term } \\
\text { price sensitivity. Forecast } \\
\text { penetration based on assumptions } \\
\text { and market data }\end{array}$ \\
\hline $\begin{array}{l}\text { Retire service demand } \\
\qquad \begin{array}{c}. \\
.\end{array} . .\end{array}$ & $\begin{array}{l}\text { Retire service demand by retiring } \\
\text { equipment energy consumption }\end{array}$ & $\begin{array}{l}\text { Retire service demand by retiring } \\
\text { delivered energy, use data on age } \\
\text { and efficiency distribution of } \\
\text { equipment stock }\end{array}$ \\
\hline $\begin{array}{l}\text { Choose equipment to meet } \\
\text { service demand }\end{array}$ & $\begin{array}{l}\text { Use logit function based on cost } \\
\text { minimization; assume initial } \\
\text { equipment shares, fixed discount } \\
\text { rate, and inertia factor }\end{array}$ & $\begin{array}{l}\text { Use } 3 \text { behavioral assumptions, } \\
\text { resulting in constrained } \\
\text { optimization (cost minimization); } \\
\text { use variation in consumer discount } \\
\text { rate, price expectations, and inertia } \\
\text { factor. }\end{array}$ \\
\hline Calculate energy consumption & $\begin{array}{l}\text { Multiply service demand by } \\
\text { equipment share-weighted inverse } \\
\text { efficiency }\end{array}$ & $\begin{array}{l}\text { Weight share of equipment chosen } \\
\text { by inverse of average efficiency for } \\
\text { each fuel and apply to service } \\
\text { demand }\end{array}$ \\
\hline
\end{tabular}

The relative magnitude of the service demand associated with the current stock of buildings declines gradually over the forecast period and the characteristics of newer buildings become progressively more important in determining consumption levels as the older and more energy intensive buildings retire.

Service demand is adjusted for equipment efficiency, and expressed in terms of energy output requirements. The service capacity module determines how these requirements are met (capacity) and consequently how much energy will be consumed. In the model, retiring equipment reduces existing service capacity. Replacement capacity refers to equipment that must be purchased to replace retired equipment. Eventually, equipment reaches then end of its useful lifetime and must be replaced. 
Technology Choice. Each year, equipment is chosen to meet.new and replacement service demand: Equipment technology is chosen based on life-cycle cost criteria. The life-cycle cost for a technology is simply the capital cost plus the present value of the operating and maintenance costs for the life of the equipment (discounted at 20 percent). Ceterus paribus, the technology with the minimum life-cycle cost is chosen. The life-cycle cost is indexed to 1986. A 1986 market share corresponds to each technology option. A logit choice definition of the market share strategy is based on initial technology shares, and a price sensitivity $(\gamma=-7)$. Since the life-cycle costs are indexed to 1 in 1986, initial market shares are identical to the 1986 market shares. Therefore, the shares for each service add to 1. Market shares change over time, based on the effects of fuel prices on life-cycle cost relative to 1986 . Since $\gamma$ is negative, a'higher or lower fuel price respectively decreases or increases the share a technology receives of the investment in new capacity.

The impact on life-cycle technology choice on energy consumption is dampened by allowing the chosen technologies to penetrate only $20 \%$ of the market for new and.replacement equipment. The remaining $80 \%$ of new/replacement demand is met by equipment that has the same efficiency as the equipment stock in the previous year.

Benchmarking. Equipment energy consumption is then passed through a series of calibration adjustments. The difference between State Energy Data System (SEDS) fuel consumption and forecast consumption in 1988 is the SEDS difference. In 1991, the model forecast plus the 1988 SEDS difference adjusted by a building growth rate factor is compared to the 1991 Short-Term Energy Outlook (STEO) value, yielding a STEO adjustment factor. Final consumption is computed in two steps. First, the SEDS adjustment is added to the model resuits. Second, this total is then adjusted by the STEO factor to produce the resulting forecast of commercial sector electricity, natural gas, and distillate fuel oil consumption.

Minor fuel consumption. Forecasts for residual oil, liquefied petroleum gas, cỏal, motor gasoline, and kerosene, are obtained by extrapolating historical consumption for each of these fuels:

Reasons for Differences between BEEM and NEMS Modeling Approaches. The NEMS Commercial Module floorspace forecast represents an enhancement over BEEM, as the new forecast varies by both building type and Census Division over time. In addition, forecasted building type shares vary over time in the NEMS Commercial Module. In addition, the NEMS model applies a logistic decay function to calculate retiring floorspace; which is an . improvement over the proportional building retirement utilized in BEEM.

The NEMS model calculates service demands and service-demand market penetration based upon assumptions and market-specific data. Short-term price elasticity of demand for major fuels is considered in this calculation. This is 
an enhancement to the simplified indexing of service demand to energy consumption that is used by BEEM. Both models retire service demand using simplified assumptions regarding equipment retirement.

The NEMS Commercial Module Technology Choice algorithm is significantly more sophisticated than the costminimizing logit function approach contained in BEEM. The NEMS model applies a more comprehensive approach to equipment selection, incorporating nonmonetary considerations such as natural gas availability and consumer preferences in the behavioral rule structure of the algorithm. In addition, the NEMS model uses variable time preference premium discount rates (compared to the fixed discount rate in BEEM) and price expectations. The NEMS model incorporates detailéd technology characterization information (e.g., cost and performance attributes) that correspond to explicit pieces of equipment, achieving a fine level of disaggregation in the selection process.

The NEMS model computes energy consumption based upon the equipment-specific disaggregation of technology selections, achieving a fine level of computational resolution. This methodology is an enhancement to the level of detail that is modeled in BEEM, which does not disaggregate heterogeneous equipment that meets a given service.

\section{Commercial End-Use Model (COMMEND): EPRI}

EPRI developed the COMMEND model to forecast commercial sector energy demands by end-use. ${ }^{6}$ Within each building type and end-use segment, COMMEND forecasts fuel choice, equipment efficiency, and usage level decisions. The primary equation used in COMMEND is:

$$
\text { Sales }_{f}=\sum_{v} U_{f, v} E_{f, v} S_{f, v} \dot{F}_{y}
$$

where:

$$
\begin{aligned}
\text { Sales } & =\text { Sales of fuel } \mathrm{f} \text { in energy units } \\
U & =\text { Utilization (usage) rate for fuel } \mathrm{f} \text {, building vintage } \mathrm{v} \\
E & =\text { End-Use Intensity in base year for fuel } \mathrm{f} \text {, building vintage } v \\
S & =\text { Share of building vintage v using the fuel } \\
F & =\text { Floorspace of building vintage } v
\end{aligned}
$$

The four components of this energy equation are projected using economic relationships and parameters.

${ }^{6}$ Regional Economic Research, Commercial End-Use Data Development Handbook: COMMEND Market Profiles and Parameters, Vol.1: COMMEND Profiles and Model Structure, EPRI EM-5703, April 1988, Ch. 4. 
COMMEND requires the following data:

(1) exogenous forecasts of macroeconomic indicators such as interest rafes or employment, commercial sector. drivers, fuel prices, floorspace inputs, weather, operating hours, etc.

(2) market profiles - base year values for EUI, share, and floorspace.

(3) technology data - equipment type (i.e., heat pump), capital cost, elasticities, efficiency trends, interaction parameters, etc.

(4) economic data - decision maker data, discount rate, thermal shell parameters, demand side management data, and building and equipment energy efficiency standards.

Fuel shares and end-use intensities reflect the outcome of choices among energy technologies. Once floorspace is measured and equipment is in place, changes in usage levels reflect daily decisions about the frequency and intensity of equipment use as determined by the behavior of building managers and occupants. COMMEND uses a variety of approaches to model these decisions.

Floorspace. COMMEND develops vintage profiles for floorspace stock and new additions. This computation requires input data on floorspace in a distant base year, annual additions to the current base year, and a set of survival functions to link new construction to changes in the stock.

COMMEND uses a logistic survival function with a 45 -year mean building lifetimes to retire floorspace built since 1940 , and a geometric or exponential survival function to retire older buildings. These survival functions are used to construct time series of floorspace additions. The additions time series can also be created using a demographic approach, where a key variable such as employment or population is used to estimate additions. A mixed approach combining demographic and historical additions is used in the COMMEND model. This mixed approach involves 5 steps:

(1) Estimate 1967 stock by working backward from 1985, using additions data and assuming an average (logistic) survival rate.

(2) Estimate 1940 stock by working backward from 1967, using data generated by a proportional demographic variable, such as square footage per employee.

(3) Compute average additions for each time interval (between 1940 and 1967) corresponding to each of the proportional variable's values, if the relationship to the proportional variable has changed over time. 
(4) Re-estimate average survival rate to make stock and additions series consistent with additions assumptions and proportional variable assumptions.

(5) Repeat the first four steps using the new survival rate.

When these steps are completed, the additions and stock series are consistent with 1985 stọck data, available additions data, the demographic variable, and the retirement functions.

Once the current composition of the building stock is established, it is necessary to forecast growth and change in the composition of the stock. The COMMEND model provides a general framework for forecasting floor stock growth. Users of COMMEND may use a flow appioach, forecasting building additions directly and arriving at total floorspace by retiring existing stock. However, the COMMEND user's guide advises that this approach is difficult to implement, and the forecasts tend to be ill-behaved.

As an alternative approach, stock can be forecasted directly. Using this approach, stock and additions are . determined by a simultaneous equation model. Floorspace stock in the forecast year is a function of exogenous variables including stock in the previous year. Additional exogenous variables may include commercial output, floorspace prices; prices of other commercial inputs such as labor, equipment, and energy. Regional income, population, and employment are often used as a proxy for commercial output. Additions in the forecast year are a function of the current stock less stock surviving from previous years.

EPRI recommends that users opt for a single variable proportional model. Employment is commonly used as the explanatory variable. This approach assumes that labor and floorspace are complementary inputs. Both increase proportionally if the commercial sector has fixed-coefficient, homogenous production functions, if relative input prices do not change over time, and if technological change is neutral. This model does not capture investment's lagged response to the business cycle.

End-Use Intensity (EUI) is expressed as energy consumption per square foot. It is based on conditional demand analysis of EIA's NBECS-86 data. Since aggregate consumption depends on average efficiency, EUIs will change as efficiency changes. In COMMEND, average equipment efficiency changes as a result of technology choice microsimulation modules (for heating, ventilation and air conditioning (HVAC) equipment choices), or elasticity parameters (for water heating, cooking, refrigeration, lighting, and other). Average usage can change based on elasticity parameters (for all services), and fuel shares can change based on microsimulation results and penetration rate'assumptions.' 
COMMEND assumes that consumers use different decision riles for heating, ventilation and air conditioning (HVAC) equipment as compared to other end-use equipment. The HVAC equipment is chosen sequentially. First an optimal system point is chosen for each technology on its technology curve (a plot of the relationship between energy efficiency and capital intensity for the technology, where it is assumed that energy and capital are substitutes). This is a function of price expectations and the individual's discount rate. A user-defined distribution of consumers' discount rates is entered which yields a distribution of optimal systems for each technology. The distribution of discount rates is used to prevent an unrealistic outcome: a single dominant technology choice. The discount rate is the only parameter for which COMMEND assumes consumers deviate from cost-minimizing behavior.

In the second step of the COMMEND decision process for HVAC equipment, the least cost points for each technology supply curve are compared between technologies. The least cost technologies are compared for consumers with the same discount rates. This generates a distribution of technology selections corresponding to the distribution of discount rates.

The decision simulation for non-HVAC equipment is less detailed. It assumes an existing stock of equipment with constant (average) end-use intensity. New equipment with a lower (marginal) end-use intensity is gradually weighted with the existing stock as overall demand increases. The efficiency of the new equipment for these equipment types is approximated by an elasticity response to fuel price changes. 
Table 3. COMMEND and NEMS Commercial Models: Conceptual Tasks

\begin{tabular}{|c|c|c|}
\hline Conceptual Task & $\begin{array}{c}\text { COMMEND Methodology } \\
\vdots\end{array}$ & $\begin{array}{l}\text { NEMS Commercial Model } \\
\text { Methodology }\end{array}$ \\
\hline $\begin{array}{c}\text { Forecast floorspace additions } \\
\begin{array}{ccc}\cdot & & \\
& & \ddots\end{array}\end{array}$ & $\begin{array}{l}\text { Choice of: } \\
\text { - Flow Approach } \\
\text { - Simultaneous Equation estimation } \\
\text { using lagged dependent and } \\
\text { exogenous macroeconomic } \\
\text { variables } \\
\text { - Proportional approach to one } \\
\text { variable, e.g., employment. }\end{array}$ & $\begin{array}{l}\text { Forecast by building type and } \\
\text { Census Division, based on NEMS } \\
\text { MAM floorspace forecast. }\end{array}$ \\
\hline Retire floorspace : & $\begin{array}{l}\text { Retire based on vintage, using } \\
\text { logistic decay. }\end{array}$ & $\begin{array}{l}\text { Retire based on vintage, using } \\
\text { convolutional decay. }\end{array}$ \\
\hline $\begin{array}{l}\text { Measure and forecast service } \\
\text { demand and demand penetration }\end{array}$ & $\begin{array}{l}\text { Forecasts dependent on } \\
\text { microsimulation (HVAC), or . } \\
\text { elasticity estimates. Penetration } \\
\text { assumptions based on market data. }\end{array}$ & $\begin{array}{l}\text { Measure service demand in Btu of } \\
\text { delivered energy; include short-term } \\
\text { price sensitivity. Forecast } \\
\text { penetration based on assumptions } \\
\text { and market data. }\end{array}$ \\
\hline Retire service demand & $\begin{array}{l}\text { Retire service demand by retiring } \\
\text { equipment energy consumption. }\end{array}$ & $\begin{array}{l}\text { Retire service demand by retiring } \\
\text { delivered energy; use data on age } \\
\text { and efficiency distribution of } \\
\text { equipment stock. }\end{array}$ \\
\hline $\begin{array}{l}\text { Choose equipment to meet } \\
\text { service demand }\end{array}$ & $\begin{array}{l}\text { Uses cost minimization. HVAC } \\
\text { modeled separately using a } \\
\text { consumer discount rate distribution. }\end{array}$ & $\begin{array}{l}\text { Use } 3 \text { behavioral assumptions, } \\
\text { resulting in constrained } \\
\text { optimization (cost minimization); } \\
\text { use variation in consumer discount } \\
\text { rate, price expectations, and inertia } \\
\text { factor. }\end{array}$ \\
\hline $\begin{array}{l}\text { Calculate energý consumption } \\
0\end{array}$ & $\begin{array}{l}\text { Multiply utilization rate by EUI and } \\
\text { share of building vintage and } \\
\text { floorspace vintage using fuel. Sum } \\
\text { over fuels. }\end{array}$ & $\begin{array}{l}\text { Weight share of equipment chosen } \\
\text { by inverse of average efficiency for } \\
\text { each fuel and apply to service } \\
\text { demand. }\end{array}$ \\
\hline
\end{tabular}

Reasons for Differences between COMMEND and NEMS Modeling Approaches. The availability of commercial floorspace forecasts by building type from the NEMS Macroeconomic Activity Module eliminated the need to model, future floorspace trends in the Commercial Module. The Commercial Module does adopt a flow methodology, though, using the MAM floorspace forecasts to develop annual new additions to floorspace. Both models retire commercial floorspace using a logistic decay function, backcasting current floorspace stock to original construction year stock. 
Both models incorporate short-term price sensitivity into the calculation of service demands. COMMEND relies upon microsimulation of major services, similar to the level of detail modeled in NEMS. Both models also address the issue of market penetration for energy consuming services. COMMEND retires service demand by retiring energy consumption, while NEMS retires delivered energy, since delivered energy needs are a central concept to the technology selection process modeled in the NEMS model.

The technology selection processes of both models share certain features, specifically, an equipment-specific methodology and a distribution of consumer discount rates. COMMEND uses a cost minimization algorithm, while the NEMS model considers nonmonetary factors such as natural gas availability and consumer preferences for the same or similar equipment currently installed (inertia).

COMMEND develops energy consumption projections by aggregating the results of the technology selection process and applying building vintage shares and EUIs. This methodology flows directly from the structure of the . calculations performed previously by COMMEND, and would not be applicable to the NEMS model, since building vintage shares are not computed. The NEMS model utilizes the market shares and average equipment efficiencies developed in the Technology Choice algorithm to weight equipment shares and apply these to service demands to arrive at consumption.

\section{Oak Ridge National Laboratory (ORNL) Commercial Demand Model}

The ORNL model develops annual forecasts of commercial sector energy consumption through the year 2000. These forecasts are based upon economic and engineering parameter estimates, including equipment utilization rates, fuel choices, and capital-to-energy substitution. Technological factors used in the model inciude equipment efficiency and building thermal characteristics (shell efficiencies). The ORNL model has been validated using the period of 1970 to 1975 , incorporating the energy price shock that occurred during that time.

The ORNL model considers energy demand for ten building types: finance and other office-related, retail-wholesale, auto repair and garage, warehouse, educational, public administration, health care, religious, hotel-motel, miscellaneous commercial. Services demanded in the commercial sector are disaggregated.into five end use categories: space heating, space cooling, water heating, lighting, and other. Refrigeration energy consumption is modeled within the space cooling service. Four fuels are modeled: electricity; natural gas, oil, and other, and individual equipment types are not explicitly modeled. Most of the data in the ORNL model is developed from Edison Electric Institute, American Gas Association, and Bureau of Mines sources (available source citations provided in Appendix C to this report). 
Short-run commercial sector energy demands are modeled as a function of the utilization rate of equipment and the equipment stock, where the utilization is dependent on the price of fuel providing the service. The price of the service in turn is a function of the equipment and efficiency characteristics as well as the fuel price. This relationship, is modeled as, .

$$
Q_{f, s}=U(P)_{f, s} \times S_{f s}
$$

where,

$Q_{f s^{*}}$ is the total consumption by fuel and service,

$U(P)_{f s}$ is the utilization rate for each fuel and service which is dependent on price,

$S_{f s} \quad$ is the stock of equipment measured in terms of potential energy use.

The equipment stock is described as a function of the potential energy use to service each square foot of floorspace times the share of the floorspace by fuel and service. This is expressed as,

$$
S_{f, s}=e_{f, s} \times a_{f, s} \times F
$$

where,

$e_{f s} \quad$ is the potential energy use to service each square foot of floorspace by fuel,

$a_{f s}$ is the share of floorspace for a service and fuel and,

$F$ is total floorspace.

Total floorspace is determined by new additions and a decay function applied to existing stock to obtain surviving floorspace. The decay function used is,

$$
f(t)=1-\frac{1}{1+e^{(\alpha+\beta(t))}}
$$

where,
$f(t)$ is surviving floorspace,
$\alpha, \beta \quad$ are parameters, and
(t) is the.age of the floorspace.

This decay function assumes an average building lifetime of 45 years. 
Forecasted utilization factors are simply adjusted by the change in the price of the fuel weighted by the unit energy requirements for the time period times the fuel-specific own-price elasticity as taken from a study on price elasticities by Baughman and Joskow.? This allows the utilization rate to respond to a change in prices and a change in the efficiency change from one time period to another. The model discounts the any change in the utilization as a response to prices by any gains in efficiency from one time period to another.

Some assumptions are made in determining the floorspace share of each service. Floorspace is assumed to be $100 \%$ lit. The "other services" category is composed primarily of electromechanical devices, which are assumed to have an annual unit energy requirement of $2.5 \%$ (based on estimates from Arthur D. Little, Inc., cited in Appendix C to this report). According to research conducted by Westinghouse, space cooling is assumed to increase by $1.5 \%$ annually for existing buildings, and new additions to commercial floorspace are assumed to have $90 \%$ space cooling saturation:

The fraction of floorspace served by each fuel for each end use is estimated in two steps as follows:

1. The adjusted fuel-choice equations from Baughman \& Joskow are used initially to determine fuel shares. The following equation estimates the floorspace share for each end-use and fuel combination:

$$
a_{f}=\frac{S_{f} / e_{f}}{\sum_{f=1}^{4}\left(S_{f} / e_{f}\right)}
$$

where,

$$
\begin{aligned}
& a_{f} \quad \text { is the share of floorspace for fuel } f \\
& S_{f} \quad \text { is the fuel share }(f) \text { for the end-use } \\
& e_{f} \quad \text { is the energy use index for fuel } f \text {. }
\end{aligned}
$$

2. Additions to floorspace stock are determined as a function of the price of floorspace, the prices of other inputs and the level of commercial output. Commercial output is in turn a function of the demand for commercial products. The stock of floorspace is estimated as a function of per capita income and population. School enrollment is used instead of population data to forecast educational floorspace.

${ }^{7}$ Baughman, M.L. and P.L. Joskow, "Energy Consumption and Fuel Choice by Residential and Commercial Consumers in the United States," Energy Systems and Policy, Vol. 1, No. 4, 1976. 
Table 4. ORNL and NEMS Commercial Models: Conceptual Tasks

\begin{tabular}{|c|c|c|}
\hline Conceptual Task & ORNL Methodology & $\begin{array}{l}\text { NEMS Commercial Model } \\
\text { Methodology }\end{array}$ \\
\hline Forecast floorspace additions & $\begin{array}{l}\text { Forecasted using prices of floorspace, prices } \\
\text { of other inputs, and the level of commercial } \\
\text { output, where demand for commercial output } \\
\text { is a function of income and population. }\end{array}$ & $\begin{array}{l}\text { Forecast by building type and Census : } \\
\text { Division, based on NEMS MAM floospace } \\
\text { forecast. }\end{array}$ \\
\hline Retire floorspace & Retire based on vintage, using logistic decay. & $\begin{array}{l}\text { Retire based on vintage, using convolutional } \\
\text { decay. }\end{array}$ \\
\hline $\begin{array}{l}\text { Measure and forecast service demand } \\
\text { and demand penetration } \\
\qquad . .\end{array}$ & $\begin{array}{l}\text { Assumed constant penetration rates for most } \\
\text { services. Lighting assumed at } 100 \% \text { of } \\
\text { floorspace. }\end{array}$ & $\begin{array}{l}\text { Measure service demand in Btw of deliveired } \\
\text { energy, inchude short-term price sensitivity. } \\
\text { Forecast pepetration based on assumptions } \\
\text { and market data. }\end{array}$ \\
\hline Retire service demand & $\begin{array}{l}\text { Retire service demand by retiring equipment } \\
\text { exergy consumption. }\end{array}$ & $\begin{array}{l}\text { Retire service demand by retiring delivered } \\
\text { energy, use data on age and efficiency } \\
\text { distribution of equipment stock. }\end{array}$ \\
\hline $\begin{array}{l}\text { Choose equipment to meet service } \\
\text { demand }\end{array}$ & $\begin{array}{l}\text { Equipment types not chosen. Charactétistics } \\
\text { of equipment population determined by } \\
\text { potential energy use, changes in efficiency, } \\
\text { and prices. }\end{array}$ & $\begin{array}{l}\text { Use } 3 \text { behavioral assumptions, resulting in } \\
\text { constrained optimization (cost minimization); } \\
\text { use variation in consumer discount rate, price } \\
\text { expectations, and inertia factor. }\end{array}$ \\
\hline Calculate energy consumption & $\begin{array}{l}\text { Multiply utilization rate for each fuel and } \\
\text { service by stocit of equipment measured in } \\
\text { terms of potential energy use. }\end{array}$ & $\begin{array}{l}\text { Weight share of equipment chosen by inverse } \\
\text { of average efficiency for each fuel and apply } \\
\text { to service demand. }\end{array}$ \\
\hline
\end{tabular}

Reasons for Differences between ORNL and NEMS Modeling Approaches. As discussed in conjunction with the COMMEND model, the availability of detailed commercial floorspace forecasts from the NEMS

Macroeconomic Activity Module eliminates the need to project building-level floorspace trends. Also similar to the discussion of the COMMEND model, both ORNL and the NEMS model retire floorspace using a logistic decay function. While the ORNL model makes simplifying assumptions regarding service penetration rates and lighting, the NEMS model enhances the service demand approach using EUI data from CBECS 1989 and penetration projections from Lawrence Berkeley. Laboratory (LBL) studies (available citations provided in Appendix C to this report).

Similar to COMMEND, the ORNL model retires service demand based on retiring energy consumption, while the NËMS approach retires delivered energy, since it is delivered energy that must be met in the subsequently-executed Technology Choice algorithm.

Specific pieces of equipment are not characterized and competed in the ORNL model. As an alternative, the characteristics of the equipment stock that meets required service demand are determined based on the composite of 
energy efficiency trends, fuel prices, and service demand patterns. The NEMS model incorporates a more detailed approach, considering nonmonetary factors such as commercial consumer behavior, fuel switching, and the introduction of new technologies in the marketplace.

\section{Commercial Energy Demand Model Service (CEDMS): Jerry Jackson and Associates}

CEDMS has been used by utilities, power pools and state agencies since 1983 to forecast commercial energy use. The system provides commercial energy demand forecasts in addition to a microsimulator for prototypical buildings. The microsimulator models individual building energy requirements based upon user-specified input parameters. This capability enables the model user to develop micro-level parameter estimates for regional demand forecasting.

Microsimulation emulates a single agent in the commercial market. The process begins by defining characteristics about the decision-maker. These characteristics are the payback time period requirement, operating hours of the equipment, and the fuél preferences of the consumer. The agent then selects the equipment with the minimum payback period cost. The microsimulation uses DOE's ASEAM (A Simplified Energy Analysis Model) to define a prototypical building and its energy characteristics. Microsimuiation is the primary determinant of saturation and efficiency choices.

The payback period cost equation is estimated using the maximum-likelihood method. The equation is,

$$
\left.\begin{array}{c}
\text { Payback } \\
\text { period } \\
\text { equip. cost }
\end{array}=\text { Equip. }_{\text {Cost }}^{\text {Install. }}+\text { cost }_{\text {corice }} \times E U I+\beta_{f, b}\right) \times \underset{\text { req. }}{\text { Payback }}
$$

where the subscript $f$ refers to fuel, and $B$ is a random variable.determined outside of the model run with mean of $b$ and measure of dispersion $D$. Additional terms used in Equation (6) are further defined in this section.

Utilization changes by equipment vintage over the forecast according to the following equation,

$$
U_{t}=U_{t-1} \times\left(1.0+\frac{\ddot{P}_{f, t}-P_{f, t-1}}{P_{f, t}}\right) \times \frac{U \text { Utiliz. }}{\text { elast. }}
$$

where the $t$ subscript refers to the time dimension, and the other subscripts are as previously defined for this model. 
CEDMS uses a disaggregated appliance stock approach to determine energy by service, fuel and building type. The primary equation to accomplish this is,

$$
\text { Consump }_{s, f, b}=\begin{aligned}
& \text { Total bldg. } \\
& \text { floorspace }
\end{aligned} \times \text { Satur. rate } \times \text { EUI }
$$

where the energy use intensity (EUT) is described as,

$$
E U I=E U I_{t_{0}} \times E f f i c i e n c y \text { index } \times \text { Utilization } \text { index }
$$

$t_{0}$ refers to the base year of the forecast, and Satur. rate is the appliance saturation rate.

CEDMS relies upon annual floorspace vintage information to monitor buildịng shell and equipment efficiencies.

Floorspace is retired through a logistic decay function. Appliances are replaced at average lifetimes or earlier if the new appliance payback period cost is less than the existing appliance operating cost over the same period.

The energy use equation in its final form is then,

$$
\text { Consumption }_{f, s, b, v}=A \times d \times S A T \times E U I_{t_{0}} \times E^{\prime} \times U
$$

where,
A is new floorspace constructed,
d is the floorspace retirement parameter based on the logistic decay function,
SAT is the saturation rate for equipment,
$\mathrm{EUT}_{\text {to }}$ is the base year energy use intensity,
E is the energy efficiency index,
$\mathrm{U}$ is the energy using equipment utilization index.

Space heating and water heating fuel choices are determined through a building simulation subroutine within the model framework. CEDMS estimates parameters using historical data through either simulation methods or utilization elasticities. 
Table 5. CEDMS and NEMS Commércial Modelṣ: Conceptual Tasks

\begin{tabular}{|c|c|c|}
\hline Conceptual Task & CEDMS Methodology & $\begin{array}{l}\text { NEMS Commercial Model } \\
\text { Methodology }\end{array}$ \\
\hline Forecast floorspace additions & Exogenous flocispace foriecast. & $\begin{array}{l}\text { Forecast by building type and Census } \\
\text { Division, based on NEMS MAM floorspace. } \\
\text { forecast. }\end{array}$ \\
\hline Retire flocrspace & $\begin{array}{l}\text { Recire based on constant rate of historical } \\
\text { demolition data in region. }\end{array}$ & $\begin{array}{l}\text { Retire based on vintage, using convolutional } \\
\text { decay. }\end{array}$ \\
\hline $\begin{array}{l}\text { Measure and forecast service demand } \\
\text { and demand peactration }\end{array}$ & $\begin{array}{l}\text { Samration (fuel choice) rebationships are } \\
\text { determined by microsimulations or efficiency } \\
\text { elasticities. }\end{array}$ & $\begin{array}{l}\text { Measure service demand in Btu of delivered } \\
\text { energy; include short-term price sensitivity. } \\
\text { Forecast penetration based on assumptions } \\
\text { and market data. }\end{array}$ \\
\hline Retire service demand & $\begin{array}{l}\text { Retire service demand by retiring equipment } \\
\text { energy consumption. }\end{array}$ & $\begin{array}{l}\text { Retire service demand by retiring delivered } \\
\text { energy, use data on age and efficiency } \\
\text { distribution of equipment stock. }\end{array}$ \\
\hline $\begin{array}{l}\text { Choose equipment to meet service } \\
\text { demand }\end{array}$ & $\begin{array}{l}\text { Microsimulation process estimates the } \\
\text { payback period of the equipment to determine } \\
\text { equipment choice. }\end{array}$ & $\begin{array}{l}\text { Use } 3 \text { behavional assumptions, resulting in } \\
\text { constrained optimization (cost minimization); } \\
\text { use variation in consumer discount rate, price } \\
\text { expectations, and inertia factor. }\end{array}$ \\
\hline Calculate energy consumption & $\begin{array}{l}\text { Multiply total building floorspace by } \\
\text { saturation rate and EUT. }\end{array}$ & $\begin{array}{l}\text { Weight share of equipment chosen by inverse } \\
\text { of average efficiency for each fuel and apply } \\
\text { to service demand. }\end{array}$ \\
\hline
\end{tabular}

Reasons for Differences between CEDMS and NEMS Modeling Approaches. Both CEDMS and the NEMS model utilize exogenous forecasts of commercial floorspace. The NEMS model requires some additional processing of the DRI forecast received from the NEMS Macroeconomic Activity Module, specifically, to develop new additions to floorspace by the eleven building types required for the flow model approach discussed previously in this report. The NEMS methodology of retiring floorspace based on vintaging and a logistic decay function is more sophisticated than the simplifying assumption made by CEDMS that retirements are a constant proportion based on historical demolitions.

The CEDMS model microsimulates fuel choice relationships to determine service demands that must be met through technology selections. Equipment payback periods are then simulated, in order to determine equipment choices.

The NEMS Commercial Module has as its starting point the CBECS 1989 data base of floorspace, fuel consumption, fuel shares and market shares, which effectively eliminates the need to microsimulate fuel proportions or market shares in the base year. The technology selection algorithm of the NEMS model effectively computes relative 
technology costs based on a distribution of discount rates, microsimulating building equipment choices. The NEMS model takes into account both monetary and nonmonetary factors in the decision process.

CEDMS relies upon the equipment saturations calculated in the service demand algorithm to develop end-use consumption. CEDMS also applies EUIs to projected commercial floorspace in this calculation. The NEMS Commercial Module does not explicitly calculate equipment saturations: Instead, the primary outputs of the NEMS Technology. Choice algorithm are fuel proportions of service demand and inverse average equipment efficiencies. These outputs are applied to calculated service demands to develop end-use consumption.

\section{Commercial Building Energy Demand Forecast Model (CBEF): California Energy Commission (CEC)}

CBEF was developed to address operating and policy issues relevant to the California energy establishment. The theoretical basis and structure of CBEF is similar to the Jackson model described previously in this section.

CBEF determines end-use consumption based on total commercial floorspace, the proportion of floorspace receiving an end-use energy service and the building type, efficiericy, and use of equipment. CBEF uses the Jackson-type equation to forecast consumption for all services except miscellaneous. Miscellaneous consumption is forecasted using assumed growth rates for office equipment and other miscellaneous consumption. The office equipment growth rates vary over building type and time, and other miscellaneous consumption is assumed to grow continually at two percent per year.

CBEF applies two sets of engineering simulation results to incorporate internal load adjustments for office equipment in the space heating and space cooling services. The simulations are for prototypical buildings in Fresno and San Francisco to account for differing climate regions.

The seven major utility planning areas of California are modeled. These appear in Table 6 below. CBEF forecasts energy consumption for eleven building types, ten end-uses, and three fuels, also listed in Table 6.

Price Responsiveness. The utilization rate, which is specified by fuel, end-use, building type and vintage, is a function of equipment efficiency, fuel price, and utilization short-run price elasticities. CBEF forecasts a short-run response to price changes in the utilization rate of energy consuming equipment. In addition, a price increase will induce the installation of higher efficiency units for new floorspace and for replacement of retiring equipment. CBEF does not explicitly address retrofits. 
Table 6. CBEF Variable Classification

\begin{tabular}{|c|c|c|c|}
\hline Building Types & Planning Areas & Fuels & End-uses \\
\hline $\begin{array}{l}\text { Office-small } \\
\text { Office-large } \\
\text { Restaurants } \\
\text { Retail Stores } \\
\text { Food/Liquor } \\
\text { Stores } \\
\text { Warehouses } \\
\text { Schools } \\
\text { Colleges/Trade } \\
\text { Health Care } \\
\text { Hotel/Motel } \\
\text { Miscellaneous }\end{array}$ & $\begin{array}{l}\text { Pacific Gas \& . } \\
\text { Electric } \\
\text { L.A. Dept. of } \\
\text { Water \& Power. } \\
\text { Sacramento } \\
\text { Municipal Utility } \\
\text { District } \\
\text { San Diego Gas \& } \\
\text { Electric } \\
\text { Southern. } \\
\text { California Edison } \\
\text { Burbank, } \\
\text { Glendale, } \\
\text { Pasadena } \\
\text { Other }\end{array}$ & $\begin{array}{l}\text { Electricity } \\
\text { Natural Gas } \\
\text { Other }\end{array}$ & $\begin{array}{l}\text { Space Heat } \\
\text { Space Cooling } \\
\text { Ventilation } \\
\text { Water Heating } \\
\text { Cooking } \\
\text { Refrigeration' } \\
\text { Lighting -Indoor } \\
\text { Lighting - } \\
\text { Outdoor . } \\
\text { Office } \\
\text { Equipment } \\
\text { Miscellaneous }\end{array}$ \\
\hline
\end{tabular}

Equipment. CBEF improves upon its predecessor models by using an end-use equipment vintaging algorithm. The CBEF Model applies a Weibull distribution function to compute the surviving share of an equipment vintage in any given year. The function is expressed as, :

$$
g_{t}=e^{-(t L) * b}
$$

where,

$g_{i}$.. is the survival fraction, .

$t$ is the age of the equipment, and

$L, b$ are parameters determining the shape of the function.

This function is used to decay all equipment after the 1964 base year. The 1964 stock is composed of all previous surviving vintages. Therefore the composition of the 1964 stock is determined assuming that the stock of appliances is in equilibrium and normally distributed. By applying the same type of decay function, the 1964 stock is the sum of .. all surviving stock from previous years.

${ }^{8}$ This vintaging algorithm is a potential enhancement to the NEMS model that is currently under consideration. 
- Floorspace. Commercial floorspace forecasts are generated by a mixed use of stock demand and constant stock ratio approaches. The resultant stock adjustment model is described by the log-log equation,

$$
\ln \left(\frac{l_{t}}{T_{z}}\right)=b_{1}+b_{1} * \ln \left(\frac{l_{12}}{I_{1}}\right)+b_{1} * \ln (M)+b_{1} * \ln (P C I)+b \mid * \ln \left(\frac{I_{t-1}}{T_{t-1}}\right)
$$

where,

$$
\begin{aligned}
& Y / X_{t} \text { is floorspace stocks over by a commercial output proxy (e.g. employment, taxable sales, } \\
& \text { etc.),. } \\
& P F / P o_{z} \quad \text { is the price of floorspace, as measured by the construction materials price index over the } \\
& \text { average hourly earnings per worker by sector, } \\
& \mathbf{M}_{\mathbf{2}} \text {. . is the money supply, } \\
& \mathrm{PCl}_{4} \text { is per capita income, } \\
& Y_{t-P} \cdot \dot{X}_{\ell \cdot 1} \quad \text { is the dependent variable lagged one period, and } \\
& b_{i} \quad \text { for } I=0, . .4 \text { are regression coefficients. }
\end{aligned}
$$

The equation is estimated using OLS for ten building types and seven regions. Floorspace stock data is included from various state agency sources connected with the regulation of specific sectors. These agencies include the California State Health Planning and Development and the California State Department of Education. New additions to commercial floorspace are developed based on F.W. Dodge data.

The share of any particular vintage of building stock survives according to the following logistic decay function which is taken from the Jackson Model,

$$
\begin{aligned}
& \text { Surviving Share } \\
& \text { of building vintage } e_{t}=\frac{1}{1+e^{6.91-0.126 \cdot t}}
\end{aligned}
$$

This function assumes a mean building lifetime of 55 years whereas the Jackson Model uses a 45 year average building lifetime. This implies that the increase of new and more efficient building shell technology and equipment is more gradual than the Jackson Model.

Energy Use Intensity. Prototype buildings are developed for two climate regions: Northern and Southern." California. Within each climate region prototypes are simulated for each building.type. 
Fuel Saturations. Three vintages are used in determining fuel saturations. The vintages are pre-1965, 1966-1974, and post-1975. Estimations are made for each vintage for both space heating and cooling.

Price Elasticities. The CBEF utilizes a Nguyen and Chen algorithm to estimate price elasticity of demand. The model explains a range of variations in demand per square foot. The following explanatory variables are included in the model:

- output of commercial services, :

- fuel prices, specifically electricity and natural gas prices,

- $\quad$ heating degree days; and

- $\therefore$ cooling degree days.

Table 7. CBEF and NEMS Commercial Models:" Conceptual Tasks

\begin{tabular}{|c|c|c|}
\hline Conceptual Task & CBEF Methodology & $\begin{array}{l}\text { NEMS Commercial Model } \\
\text {-Methodology }\end{array}$ \\
\hline $\begin{array}{c}\text { Forecast floorspace additions } \\
\text { : }\end{array}$ & $\begin{array}{l}\text { Floorspace forecasted using a mixture of stock } \\
\text {.demand and constant stock ratio approaches. }\end{array}$ & $\begin{array}{l}\text { Forecast by building type and Census } \\
\text { Division, based on NEMS MAM floorspace } \\
\text { forecast. }\end{array}$ \\
\hline Retire floorspace & Retire based on vintage, using logistic decay. & $\begin{array}{l}\text { Retire based on vinnge, using convohutional } \\
\text { decay. }\end{array}$ \\
\hline $\begin{array}{l}\text { Measure and forecast service demand } \\
\text { and demand penetration }\end{array}$ & $\begin{array}{l}\text { EUIs are developed using prototypical } \\
\text { buildings in two climate regions. }\end{array}$ & $\begin{array}{l}\text { Measure service demand in Btw of delivered } \\
\text { energy; include short-term price sensitivity. } \\
\text { Forecast penetration based on assumptions } \\
\text { and market data. }\end{array}$ \\
\hline Retiré service demand & $\begin{array}{l}\text { Retire service demand by retiring equipment } \\
\text { energy consumption using equipment decay } \\
\text { rates. }\end{array}$ & $\begin{array}{l}\text { Retire service demand by retiring delivered } \\
\text { epergy, use data on age and efficiency } \\
\text { distribution of equipment stock. }\end{array}$ \\
\hline $\begin{array}{l}\text { Choose equipment to meet service } \\
\text { demand }\end{array}$ & $\begin{array}{l}\text { Equipment efficiency and utilization rate are } \\
\text { forecasted. Individual equipment technologies } \\
\text { are noc modeled. }\end{array}$ & $\begin{array}{l}\text { Use } 3 \text { behavioral assumptions, resulting in } \\
\text { constrained optimization (cost minimization); } \\
\text { use variation in consumer discount rate, price } \\
\text { expectations, and inertia factor. }\end{array}$ \\
\hline $\begin{array}{c}\text { Calculate exergy consumption } \\
\text { ? }\end{array}$ & $\begin{array}{l}\text { Multiply utilization rate by EUI and } \\
\text { floospace. }\end{array}$ & $\begin{array}{l}\text { Weight share of equipment chosen by inverse } \\
\text { of average efficiency for each fivel and apply } \\
\text { to service demand. }\end{array}$ \\
\hline
\end{tabular}

Reasons for Differences between CBEF and NEMS Modeling Approaches. Both CBEF and NEMS utilize - building stock vintaging information to develop forecasted floorspace, but the NEMS model uses a flow methodology to project new additions to floorspace while CBEF uses a constant stock ratio algorithm. The NEMS approach is potentially more dynamic in nature than the CBEF method. Floorspace is retired in both models through a logistic decay function.

Energy Information Administration NEMS Commercial Demand Module Documentation Report 
Both CBEF and NEMS utilize EUIIs based on specific building parameters, CBEFs developed from microsimulation of prototypical buildings and NEMS' based on CBECS 1989 survey data. CBEF employs an equipment decay rate algorithm to compute retiring service demand; while NEMS currently assumes proportional service demand retirement. The CBEF methodology is a potential enhancement to the NEMS treatment of retiring service demand.

CBEF does not explicitly model individual technologies. Instead, composite equipment efficiencies and utilization - factors are forecasted. Projected utilization rates are then multiplied by EUIs to obtain consumption forecasts. In contrast, the NEMS model characterizes specific equipment and selects this equipment based upon behavioral assumptions for each decision type. The resulting equipment market shares and the equipment efficiencies that correspond to each market share are then used in conjunction with calculated service demands to project end-use consumption. The NEMS approach results from the treatment of service demand at the Census Division, building, and service level of detail. This approach complements the detailed treatment of technology selection, enabling the results of the service demand calculation to be used to compute exid-use consumption.

\section{Commercial Sector Energy Model (CSEM): Energy Information Administration .}

CSEM is a product of EIA's Office of Energy Markets that was a component of the PC-AEO (spreadsheet) model. The PC-AEO system was used to produce the Annual Energy Outlook prior to the development of BEEM. CSEM generates annual commercial sector demand forecasts through the year 2000 . Forecasts are developed for the major fuels of electricity, natural gas, and distillate fuel along with minor fuels (e.g., residual fuel oil). CSEM models the commercial sector at the four Census Region level of detail.

CSEM projects commercial floorspace using the 1983 NBECS. 1983 new additions to floorspace are estimated as one-tenth of NBECS floorspace constructed between 1974 and 1983. The base year of the forecast is then set to 1983. Base year floorspace is multiplied by regional population growth rates and lagged GNP to obtain floorspace additions. Annual surviving floorspace is determined using a constant survival rate applied to existing vintages.

Energy use intensities are developed for new and surviving floorspace. Capital stock energy use is calculated using new and surviving floorspace as weights. Fuel price effects are assumed to be zero.

Price-impacted energy intensity is then computè as,

$$
q=\exp \left(e \times \ln \left(p / p_{83}\right)\right) \times q^{\prime}
$$


where,
q . is the price impacted energy intensity,
p is the fivel price,
- $P_{83}$ is the fuel price in the base year,

$q^{\prime}$ is the capital stock energy intensity independent of price, identical to the weighted sum of 1983

NBECS.energy consumption rates in new and surviving floorspace using a relative price index with a 1983 base year.

Total energy forecasts are generated by multiplying the price-affected energy intensity estimates by the total floorspace forecast.

Reasons for Differences between CSEM and NEMS Modeling Approaches. As discussed in the comparison of COMMEND and NEMS, the availability of exogenous projections of commercial floorspace in NEMS eliminates the need to explicitly forecast building-level annual new additions. Instead, NEMS apportions new additions into the elevén CBECS 1989 building types. CSEM utilizes NBECS 1983 floorspace stock and macroeconomic driver variables to forecast commercial floorspace, using an approach that is conducive to developing a simulation based on the survey data. CSEM retires existing floorspace based on a constant survival rate, which does not consider floorspace vintaging and building lifetimes. The NEMS Commercial Module backcasts the base year floorspace stock to the original years of construction and applies a logistic decay function to model more accurately the shape of the building retirement function.

Both CSEM and the NEMS Commercial Module employ price impacts in the service demand calculation. CSEM computes price-affected EUIs to account for fuel price impacts and energy consumption patterns in newer buildings. NEMS explicitly includes short-run price elasticity of demand estimates for the major fuels of electricity, natural gas, and distillate. The NEMS approach uses finely disaggregated EUIs based on CBECS 1989, which were not àvailable when CSEM was developed. Retiring service demand is not treated in CSEM. In contrast, the NEMS Commercial Module retires a portion of delivered energy each forecast year that corresponds to retiring commercial floorspace.

As discussed previously in this section, the NEMS Commercial Module technology selection procedure incorporates numerous cost-based and nonmonetary decision factors in the determination of equipment market shares and the resulting inverse average equipment efficiency. The results of this selection process and the aggregating calculations are directly input to the calculation of end-use consumption. The CSEM approach directly uses the price-affected EUIs to the floorspace forecast to obtain consumption values, not considering explicit equipiment choices. The

Energy Information Administration NEMS Commercial Demand Module Documentation Report 
NEMS approach provides a finer level of resolution in selecting individual technologies and calculating consumption based on the specific equipment mix.

\section{Table 8. CSEM and NEMS Commercial Models: Conceptual Tasks}

\begin{tabular}{|c|c|c|}
\hline Conceptual Task & CSEM Methodology & $\begin{array}{c}\text { NEMS Commercial Model } \\
\text { Methodology } \\
\end{array}$ \\
\hline $\begin{array}{c}\text { Forecast floorspace additions } \\
\qquad \begin{array}{c}\cdot \\
\end{array}\end{array}$ & $\begin{array}{l}\text { Forecast based on NBECS } 1983 \\
\text { stock data and multiplying by } \\
\text { lagged GNP and population growth } \\
\text { rates. }\end{array}$ & $\begin{array}{l}\text { Forecast by building type and Census } \\
\text { Division, based on NEMS MAM } \\
\text { floorspace forecast. }\end{array}$ \\
\hline Retire floorspace & $\begin{array}{l}\text { Retire based on a constant survival } \\
\text { rate of existing floorspace. }\end{array}$ & $\begin{array}{l}\text { Retire based on vintage, using } \\
\text { convolutional decay. }\end{array}$ \\
\hline $\begin{array}{l}\text { Measure and forecast service } \\
\text { demand and demand } \\
\text { penetration }\end{array}$ & $\begin{array}{l}\text { EUIs assume to higher for } \\
\text { electricity and gas in newer. } \\
\text { buildings. 'Price affected intensity } \\
\text { computed using fuel prices and } \\
\text { weighted sum of NBECS } \\
\text { consumption rates in new and } \\
\text { surviving floorspace.' }\end{array}$ & $\begin{array}{l}\text { Measure service demand in Btu of } \\
\text { delivered energy; include short-term } \\
\text { price sensitivity. Forecast } \\
\text { penetration based on assumptions and } \\
\text { market data. } \\
\end{array}$ \\
\hline $\begin{array}{c}\text { Retire service demand } \\
:\end{array}$ & none & $\begin{array}{l}\text { Retire service demand by retiring } \\
\text { delivered energy; use age and } \\
\text { efficiency distribution of equipment } \\
\text { stock data. }\end{array}$ \\
\hline $\begin{array}{l}\text { Choose equipment to meet } \\
\text { service demand }\end{array}$ & none & $\begin{array}{l}\text { Use } 3 \text { behavioral assumptiòns, } \\
\text { resulting in constrained optimization } \\
\text { (cost minimization); use variation in } \\
\text { consumer discount rate, price } \\
\text { expectations, and inertia factor. }\end{array}$ \\
\hline Calculate energy consumption & $\begin{array}{l}\text { Multiply price affected energy } \\
\text { intensity by total floorspace. } \\
\text { forecast. }\end{array}$ & $\begin{array}{l}\text { Weight share of equipment chosen by } \\
\text { inverse of average efficiency for each } \\
\text { fuel and apply to service demand. }\end{array}$ \\
\hline
\end{tabular}




\section{Summary of Reasons for Selecting NEMS Commercial Model Approach over Alternative Approaches Adopted in Previous Commercial Models}

\section{BEEM}

The BEEM floorspace forecast does not address variation of floorspace by Census Division and building type over time. The NEMS approach incorporates this consideration. The BEEM service demand algorithm is a simple indexing of service demand to energy consumption. The NEMS approach is much more sophisticated, treating such considerations as district services, service demand price elasticity, and office equipment market penetration. The BEEM technology choice algorithm is a simplified logit function that minimizes life-cycle costs. The NEMS - Technology Choice algorithm is much more sophisticated and flexible, and considers a myriad of issues such as equipment availability, energy efficiency standards, technology competition, retrofit decisions, and technological breakthroughs that introduce new classes of equipment to the marketplace.

\section{COMMEND}

COMMEND models only two regions, and NEMS models nine Census Divisions, incorporating extensive Census Division level data. COMMEND utilizes à cost-minimization algorithm to compute technology selections. NEMS applies a highly sophisticated Technology Choice algorithm that considers numerous facets of the consumer choice process as described previously. COMMEND applies building vintage shares and EUI information to the technology selection results to develop end-use consumption. The NEMS Technology Choice algorithm incorporates a finer level of detail that allows for numerous types of aggregations to be performed to calculate enduse consumption at several desired levels of aggregation.

\section{ORNL}

ORNL makes simplifying assumptions regarding service penetration rates and lighting. NEMS enhances the service demand approach by employing detailed EUI data developed from CBECS 1989, along with office equipment market penetration studies performed by Lawrence Berkeley Laboratory. In addition, NEMS treats lighting as a major service and models bulb competition in the Technology Choice algorithm. ORNL does not characterize and compete specific classes of equipment, relying instead upon characterizations developed from energy efficiency trends, fuel prices and service demand patterns. The NEMS approach competes specific technology classes to enable a finer level of disaggregation of the choice calculation that is central to the model. 


\section{CEDMS}

CEDMS employs the simplifying assumption that floorspace retirements are a constant proportion based on historical demolitions. NEMS applies a convolution algorithm that reconstructs floorspace back to the original construction vintage, and evolves existing and new floorspace stock throughout the forecast period.

\section{CBEF}

CBEF is a regional model based upon seven distinct areas of the state of California. NEMS models nine Census Divisions. NEMS employs a more dynamic modeling structure for the convolution of commercial floorspace over the forecast period. CBEF does not explicitly model individual technology classes, relying instead upon composite efficiencies and utilization rates across classes of technologies. NEMS models distinct technology classè, enabling a finer tracking of equipment selections and resultant.average equipment efficiencies.

\section{CSEM}

CSEM retires existing floorspace based on a constant survival rate, while NEMS incorporates variation through the convolutional approach to floorspace retirement. The EUI estimates employed in the CSEM model are not as finely disaggregated as the EUIs used in NEMS, enabling a greater level of disaggregation in NEMS. CSEM does not treat retiring service demand, and NEMS does. CSEM does not incorporate a technology choice procedure, and instead directly uses price-adjusted EUIs and forecasted floorspace to compute end-use consumption. This approach does not consider a plethora of factors that impact final consumption, such as those considered in the NEMS Technology Choice Submodule. 


\section{Model Structure}

\section{Structural Overview}

The commercial sector encompasses business establishments that are not engaged in industrial or transportation activities. Commercial sector energy is consumed primarily within buildings. ${ }^{9}$ Energy consumed in commercial buildings is the sum of energy required to provide specific energy services using selected technologies. The model structure carries out a sequence of four basic steps for each forecast year. The first step is to forecast commercial sector floorspace. The second step is to forecast the energy services (e.g., space heating, lighting, etc.) required by that building space. The third step is to select specific technologies (e.g., gas furnaces, fluorescent lights, ètc.) to meet the demand for energy services. The last step is to determine how much energy will be consumed by the equipment chosen to meet the demand for energy services. New construction, surviving floorspace, and equipment choices forecast for previous time periods largely determine the floorspace and equipment in place in future time periods. General considerations involved in each of these processing steps are examined below. Following this overview, flow diagrams are provided and the calculations performed by each of the forecasting components are described in detail.

\section{Commercial Building Floorspace Forecast.}

Commercial sector energy consumption patterns depend upon numerous factors, including the composition of commercial building and equipment stocks, and regional climate and building construction variations. The NEMS Commercial Sector Demand Module first develops a forecast of commercial floorspace construction and retirement by type of building and Census Division. Floorspace is forecast for the following 11 building types:

- Assembly

- Education

- Food Sales

- Food Services
- Health Care

- Lodging :

- Office - large

- Office - small
- Mercantile and Service

- Warehouse

- Other

There is a small amount of commercial energy consumption (from uses such as street lights), that is not attributed to buildings. This is discussed in the End-Use Consumption section. 


\section{Service Demand Forecast}

Once the building inventory is projected, the model then develops a forecast of demand for energy-consuming services within buildings. Consumers do not demand energy per se, but the services that energy provides. ${ }^{10}$ This demand for delivered forms of energy is measured in units of Btu out by the Commercial Module, to distinguish it from the consumption of fuel, measured in Btu in, necessary to produce the useful services. The following ten services, based in part on the level of detail available from published survey work discussed further in this report, are tracked:

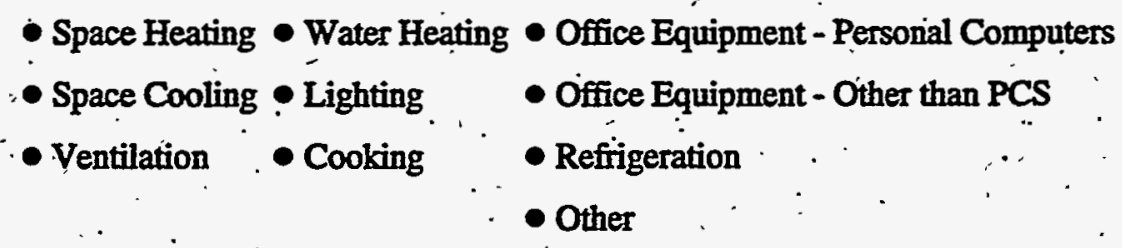

The energy intensity of usage, measured in Btu/sq ft, differs across service and building type. For example, health care facilities typically require more space heating per square foot than warehouses. Intensity of usage also varies across Census Divisions. Educational buildings in the New England Census Division typically require more heating services than educational buildings in the South Atlantic Census Division. As a result, total service demand for any service depends on the number, size, type, and location of buildings.

In each forecast year, a proportion of energy-consuming equipment wears out in existing floorspace, leaving a gap between the energy services demanded and the equipment available to meet this demand. The efficiency of the equipment that is chosen to replace this equipment, along with the efficiency of equipment chosen for new floorspace, is reflected in the calculated average efficiency of the equipment stock.

Consumers may increase or decrease their level of usage of a service in response to a change in energy prices. The model accounts for this behavioral impact by adjusting service demand forecasts using price elasticity of demarid estimates for the major fuels of electricity, natural gas, and distillate fuel ${ }^{11}$. For electricity, the model uses a

\footnotetext{
${ }^{10}$ Lighting is a good example of this concept. It is measured in units which reflect consumers' perception of the level of service received: lumens.

${ }^{11}$ The calculation described is actually performed on the fuel consumption forecast by the End-Use Consumption Submodule, making use of the direct proportionality between consumption and service demand. This is necessary because the fuel shares of provided services are not determined until after selection of the equipment mix by the Technology Choice Submodule.
} 
weighted-average price for each end-use service and Census division. For each of the other major fuels; the model uses a single average annual price for each Census division. In performing this adjustment, the model also takes into account the effects of changing technology efficiencies and building shell efficiencies on the marginal cost of the service to the consumer, resulting in a "takeback effect" modification of pure price elasticity."

\section{Equipment Choice to Meet Service Needs}

Given the level of energy services demanded, the algorithm then projects the class and model of equipment selected to satisfy the demand. Commercial consumers purchase energy-using equipment to meet three types of service demand:

- New - service demand in newly-constructed buildings (constructed in the current year of the forecast),

- Replacemenit - service demand formerly met by retiring equipment (equipment that is at the end of its useful life and must be replaced),

- Retrofit - service demand formerly met by equipment at the end of its economic life (equipment with a remaining useful life that is nevertheless subject to retirement on economic grounds):

Thus, consumers must choose equipment to meet service demand under three conditions, as mentioned above. Each condition is referred to as a "decision type".

One possible approach to describe consumer choice behavior in the commercial sector would require the consumer to choose the equipment that minimizes the total expected cost over the life of the equipment. However, there is empirical evidence that suggests that traditional cost minimizing models do not adequately account for the full range of economic factors that influence consumer behavior. ${ }^{12}$ Using a similar methodology, the NEMS Commercial Model is coded to allow the use of several possible assumptions about consumer behavior. The consumer behavior assumptions are:

- Buy the equipment with the minimum life-cycle cost;

- Buy equipment that uses the same fuel as existing or retiring equipment, but minimizes life-cycle costs $\because$ : under that constraint;

.

${ }^{12}$ See Jon Koomey, "Energy Efficiency Choices in New Office Buildings: An Investigation of Market Failures and Corrective Policies," Dissertation, University of California at Berkeley, April 1990; and U.S. Congress, Office of Technology Assessment, Building Energy Efficiency, OTA-E-518, Washington DC: U.S. Government Printing Office, May 1992, pp. 73-85. 
Buy (or keep) the same technology as the existing or retiring equipment, but choose between models with different efficiency levels based upon minimum life-cycle costs.

These-behavior rules are designed to represent empirically the range of economic factors which influence the consumer's decision. The consumers who minimize life-cycle cost are the most sensitive to energy price changes, thus, the price-sensitivity of the model depends in part on the share of consumers using each behavior rule. The proportions of consumers in each behavior rule segment vary by building type, the end-use service under consideration, and decision type, for the three decision types of new construction, replacement of worn-out equipment, or retrofitting of "economically obsolete" equipment. ${ }^{13}$.

The model is designed to choose among a discrete set of technologies that are exogenously characterized by commercial availability, capital costs, operating and maintenance (O\&M) costs, removal and disposal costs, efficiencies, and lifetime. The menu of equipment depends on technological innovation, market development and policy.intervention. The design is capable of accommodating a changing menu of technology choices, recognizing that changes in energy prices and consumer demand may significantly change the set of relevant technologies which the model user wishes to consider.

\section{Energy Consumption}

Following the choice of equipment to satisfy service demands, the model computes the total amount of energy consumed. To calculate energy consumption, the fuel shares of service resulting from the selected mix of equipment, together with the average efficiency of that mix, are applied to service demand. An example of this calculation is shown in Table 9. If 100 million Btu (MMBtu) of heating service demand in new office buildings in New England is required, then the calculations proceed as follows: allocate service demand according to the share of a given fuel (Table 9, Column 3); divide service demand (3) by the average efficiency (4) to derive fuel consumption by fuel type.

${ }^{13}$ Additional detail regarding the derivation of the choice proportions is provided in Appendix $A$ to this report. 
Table 9. Energy Consumption Calculation Example.

\begin{tabular}{|c|c|c|c|c|}
\hline \multicolumn{3}{|c|}{$\begin{array}{l}\text { Service Demand } \\
\text { (100 MMBtu out) }\end{array}$} & \multirow[b]{2}{*}{$\begin{array}{l}\text { Average efficiency } \\
\text { (But out/Btu } \\
\text { consumed) } \\
(\mathbf{4})\end{array}$} & \multirow{2}{*}{$\begin{array}{c}\text { Fuel Consumption } \\
(M M B(w) \\
(5)=(3)(4)\end{array}$} \\
\hline $\begin{array}{c}\text { Fuel } \\
\text { (1) }\end{array}$ & $\begin{array}{c}\text { Proportion of } \\
\text { Service } \\
\text { Demand } \\
\text { (2) }\end{array}$ & $\begin{array}{l}\text { Amount of Service } \\
\text { 'Delivered } \\
\text { (MMBtu out) } \\
(3)=(2) \neq 100\end{array}$ & & \\
\hline Distillate Fuel Oil & $\cdot 0.5$ & $\quad 50.0$ & 0.75 & 66.7 \\
\hline Electricity & 0.3 & 30.0 & 0.87 & 34.5 \\
\hline Natural Gas & 0.2 & 20.0 & 0.80 & 25.0 \\
\hline Total & & & 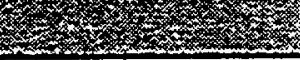 & 126.2 \\
\hline
\end{tabular}

Forecasted building energy consumption is then benchmarked to the State Energy Data System (SEDS) historical commercial sector consumption, applying an additive correction term to ensure that simulated model results correspond to published SEDS historical values. This benchmarking adjustment accounts for nonbuilding . commercial sector energy consumption (e.g., radio transformer towers). and provides a consistent starting point for the forecast. The benchmarking procedure is further discussed in the last section of the main text of this report.

\section{Flow Diagrams}

Figure 2 illustrates the general model flow of the NEMS Commercial Sector Demand Module. The flow proceeds sequentially, with each succeeding Submodule utilizing as inputs the outputs of preceding Submodules. In other words, the outputs of the Floorspace Submodule are used as inputs to the Service Demand Submodule, the outputs of the Service Demand Submodule are used as inputs to the Technology Choice Submodule, and the outputs of the Technology Choice Submodule are used as inputs to the End-Use Consumption Submodule. The basic processing flow used by the Commercial Module to generate its forecast of fièl demands consists of five steps:

1. A forecast of commercial building floorspace is generated based upon input from the Macroeconomic Module and results from previous years. (COMFloorspace Submodule).

2. Demands for various services are calculated for that distribution of floorspace (COMServiceDemand Submodule).

3. Equipment is chosen to satisfy the demands for services (COMTechnologyChoice Submodule). 
4. Fuel consumption is calculated based on the chosen equipment mix, and additional commercial sector consumption components such as those resulting from nonutility cogeneration of electricity and district services are accounted for. Commercial sector airborne emissions associated with the consumption forecast are also calculated (COMConsumption Submodule).

5. Results by fuel and Census Division are adjusted to match the 1990 through 1994 State Energy Data System (SEDS) historical data, and optionally the 1995-1996 forecasts of the Short Term Energy Outlook (STEO) (COMBenchmarking Submodule), 
Figure 2. Commercial Module Structure \& Fundamental Process Flow

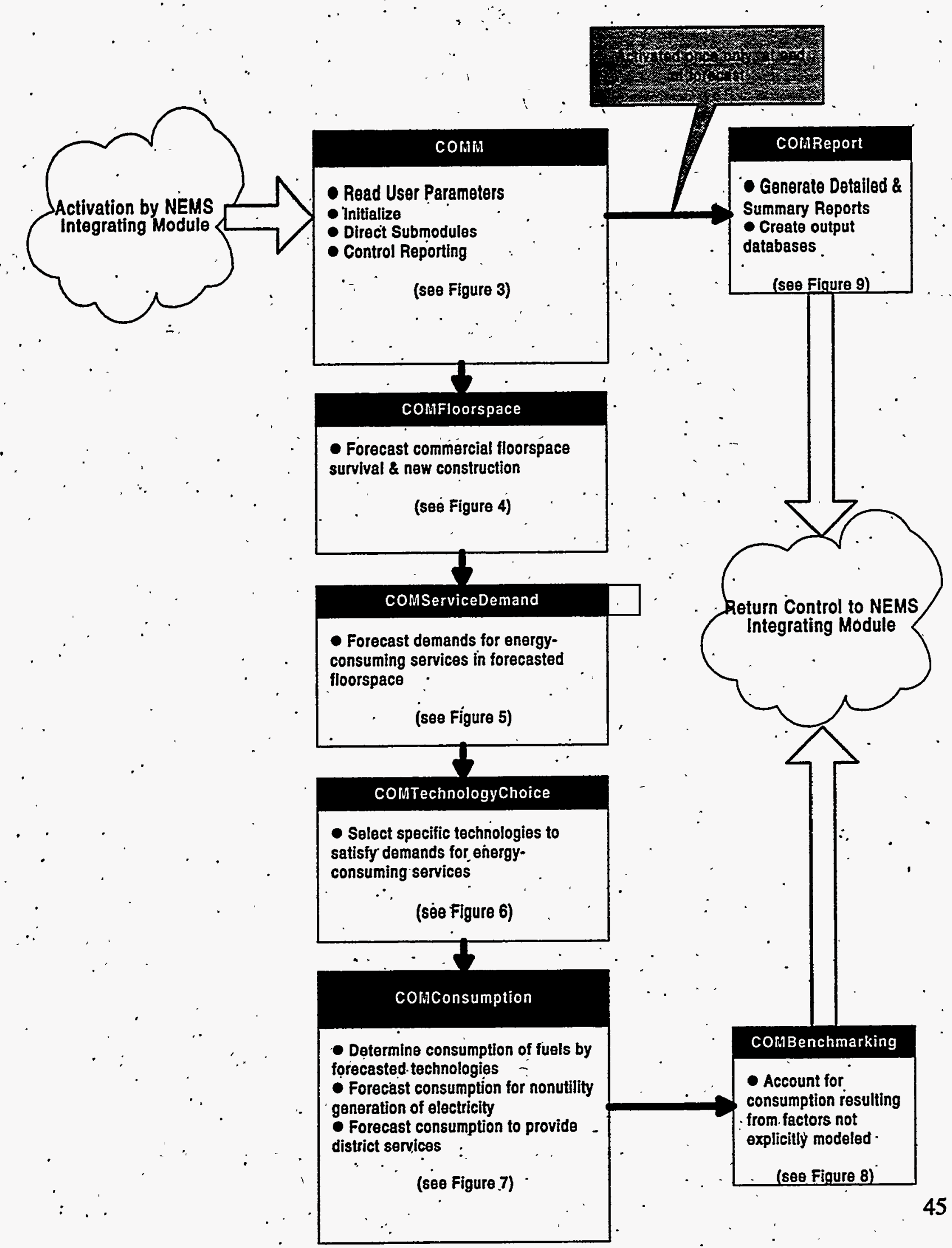


The Commercial Module is activated one or more times during each year of the forecast period by the NEMS Integrating Module. On each occurrence of module activation, the processing flow follows the outline shown in figure 2. Details of the processing flow within each of the Commercial Module's submodules, together with the input data sources accessed by each, are shown in figures 3 through 9, and summarized below. The precise calculations performed at the program subroutine level are described in the next section.

Figure 3 illustrates the filow within the controlling component of the Commercial Module, COMM. This is the component that determines whether a dynamic forecast for the current year is warranted, retrieves user-specified options and parameters, performs certain initializations, and directs the processing flow through the remaining submidules. It also detects the occurrence of the conclusion of the forecast period, and directs the generation of printed reports and output databases to the extent specified by the user.

Figure 4 illustrates the processing flow within the Floorspace Component of the model, COMFloorspace. The Floorspace Submodule requires the NEMS Macroeconomic Activity Module (MAM) total commercial floorspace forecast by Census Division, building type, and year. In addition, base year building stock characteristics and building survival.parameters developed based on analysis of CBECS 1992 and additional sources (further referenced in Table A-2 of Appendix A to this report) are used by the Fioorspace Submodule to evolve the existing stock of floorspace into the future.

Figure 5 illustrates the processing flow within the Service Demand Component of the model, COMServiceDemand. The surviving and new floorspace results generated by the Floorspace Submodule are accepted as inputs by the Service Demand Submodule, along with additional inputs such as base year (1992) Energy Use Intensities (EUIs), renewable energy service demands, office equipment market penetration forecasts, base year equipment market shares and stock efficiencies, equipment survival assumptions, building shell efficiencies, weather data, and district service information. The Service Demand Submodule forecasts demands for the 10 modeled end-uses in each of the 11 building types and nine Census Divisions separately for newly-constructed commercial floorspace, surviving floorspace with unsatisfied service demands due to equipment failure, and surviving floorspace with currently functioning equipment.

Figure 6 illustrates the processing flow within the Technology Choice Component, COMTechnologyChoice. The service demands produced by the Service Demand Submodule, combined with equipment-specific inputs, consumer behavior characterization and time preference segmentation information specific to the Commercial Module, and NEMS system outputs including Treasury Bill rates from the Macroeconomic Activity Module (MAM) and fuel prices from the Electricity Market Module, Natural Gaș Transmission and Distribution Module, and Petroleum Market Module, are required by the Technology Choice Submodule. The result of processing by this submodule is a 
forecast of equipment market shares of specific technologies retained or purchased for servicing new floorspace, replacing failed equipment, or retrofitting of economically obsolete equipment. Also calculated are the corresponding fuel shares and average equipment efficiencies by énd-use service and other dimensions.

Figure 7 illustrates the processing flow within the Consumption Component, COMConsumption. The average equipment efficiency and fuel proportions output by the Technology Choice Submodule are combined with the service demand forecast generated by the Service Demand Component to produce the forecast of major fuel consumption by building type, Census Division, and end-use. Several additional considerations are incorporated into the final forecast, including fuel consumption for the purposes of electricity cogeneration and providing District Services. Demands for the five minor fuels are also forecast by this component using the floorspace forecast together with fuel prices and input regression parameters.

Figure 8 illustrates the Benchmarking Component of the fuel consumption forecast, COMBenchmarking. Data input from the State Energy Data System (SEDS), and, at the user's option; fuel consumption forecasts produced for the Short Term Energy Outlook (STEO), are compared with the basic Cormmercial Module fuel consumption forecast. during the period of time over which they overlap, in an attempt to calculate energy consumption in the Commercial Sector not attributable to the building end-uses explicitly modeled in the Commercial Module. If desired, the calculated nonbuilding consumption is evolved in one of several methods chosen by the user and added to the basic Commercial Module forecast.

A final reporting subroutine, COMReport, generates detailed documentation on the Final Control and Reporting Loop of the last forecast year. Numerous subcategories and additional considerations are handled by the model for each of the broad process categories given above. These are described below under the headings of the applicable subroutines, and explicitly stated in mathematical form in Appendix B. 
Figure 3. COMM Calculation Process Flow

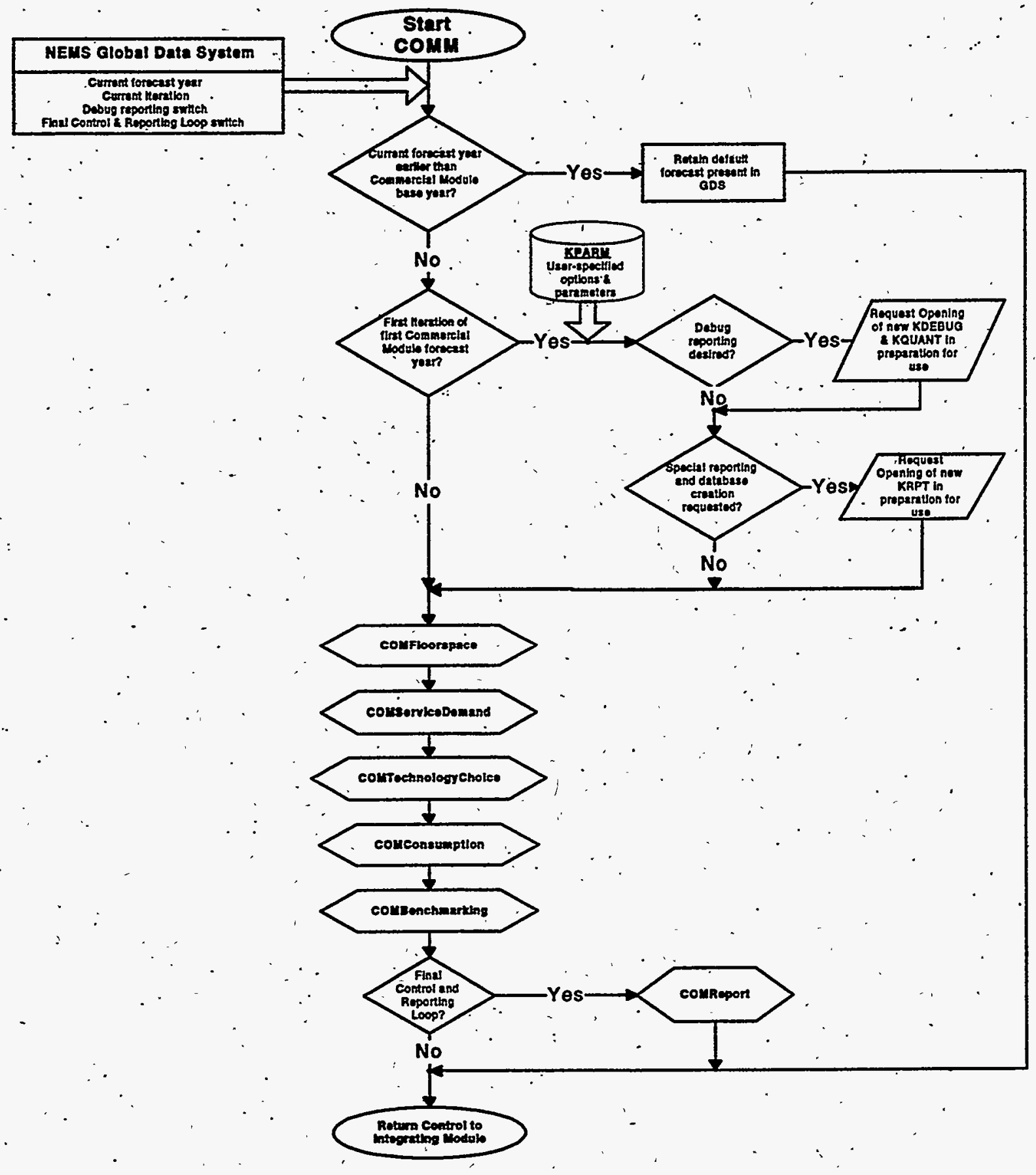


Figure 4. COMFloorspace Calculation Process Flow

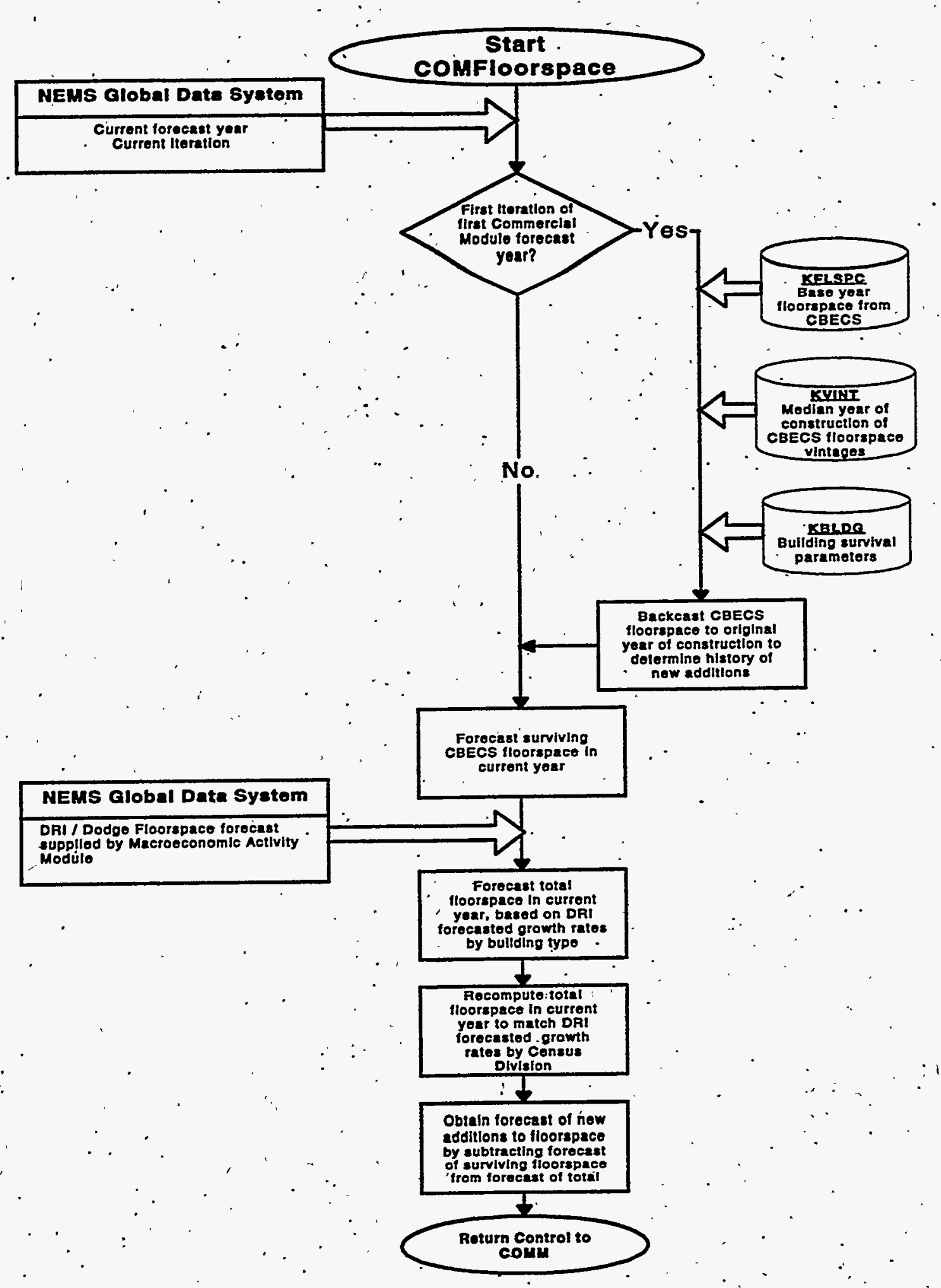

Energy Information Administration

NEMS Commercial Demand Module Documentation Report 
Figure 5. COMServiceDemand Calculation Process Fiow

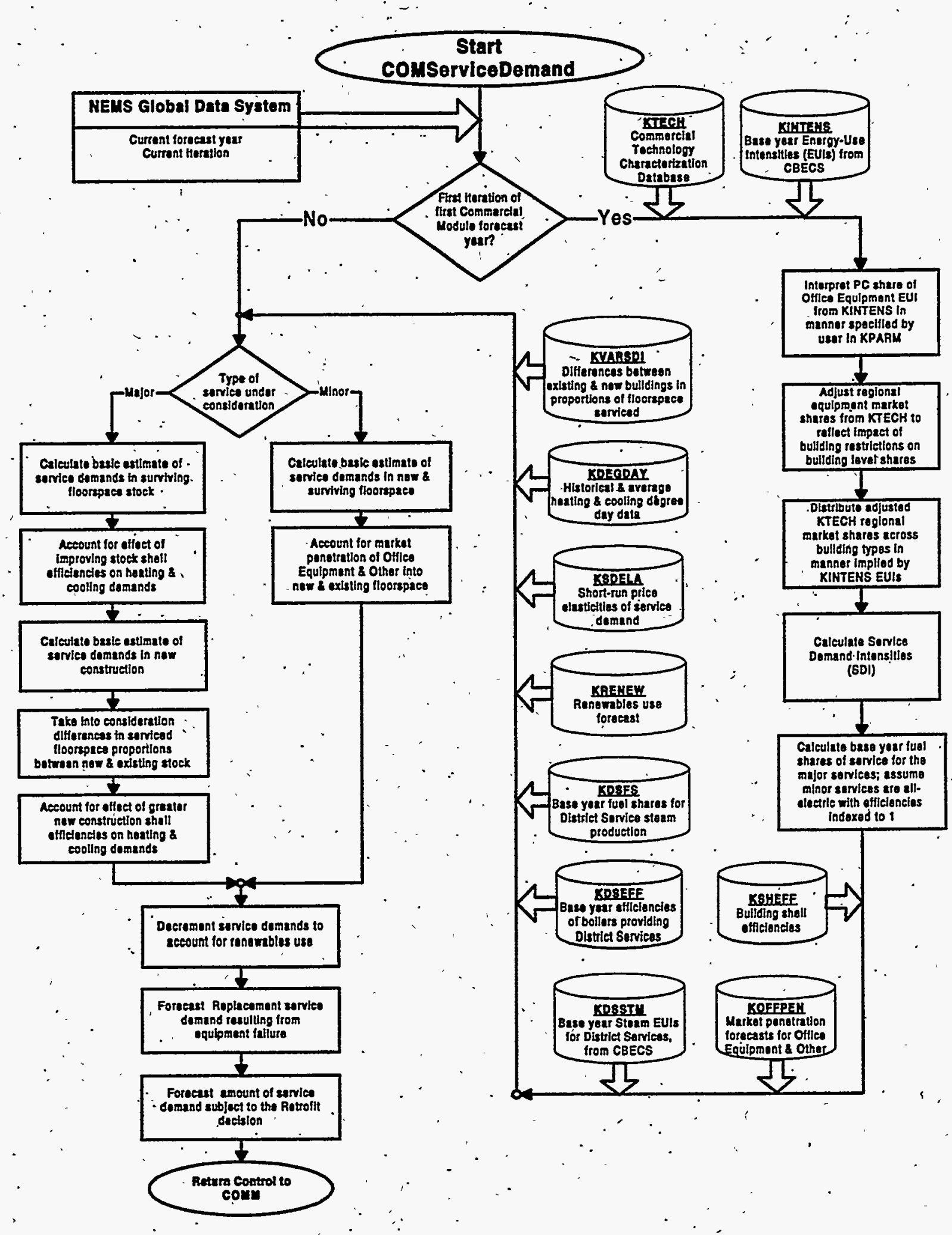

Energy Information Administration NEMS Commercial Demand Module Documentation Report 


\section{Figure 6. CoMTechnologychoice Calculation Process Flow}

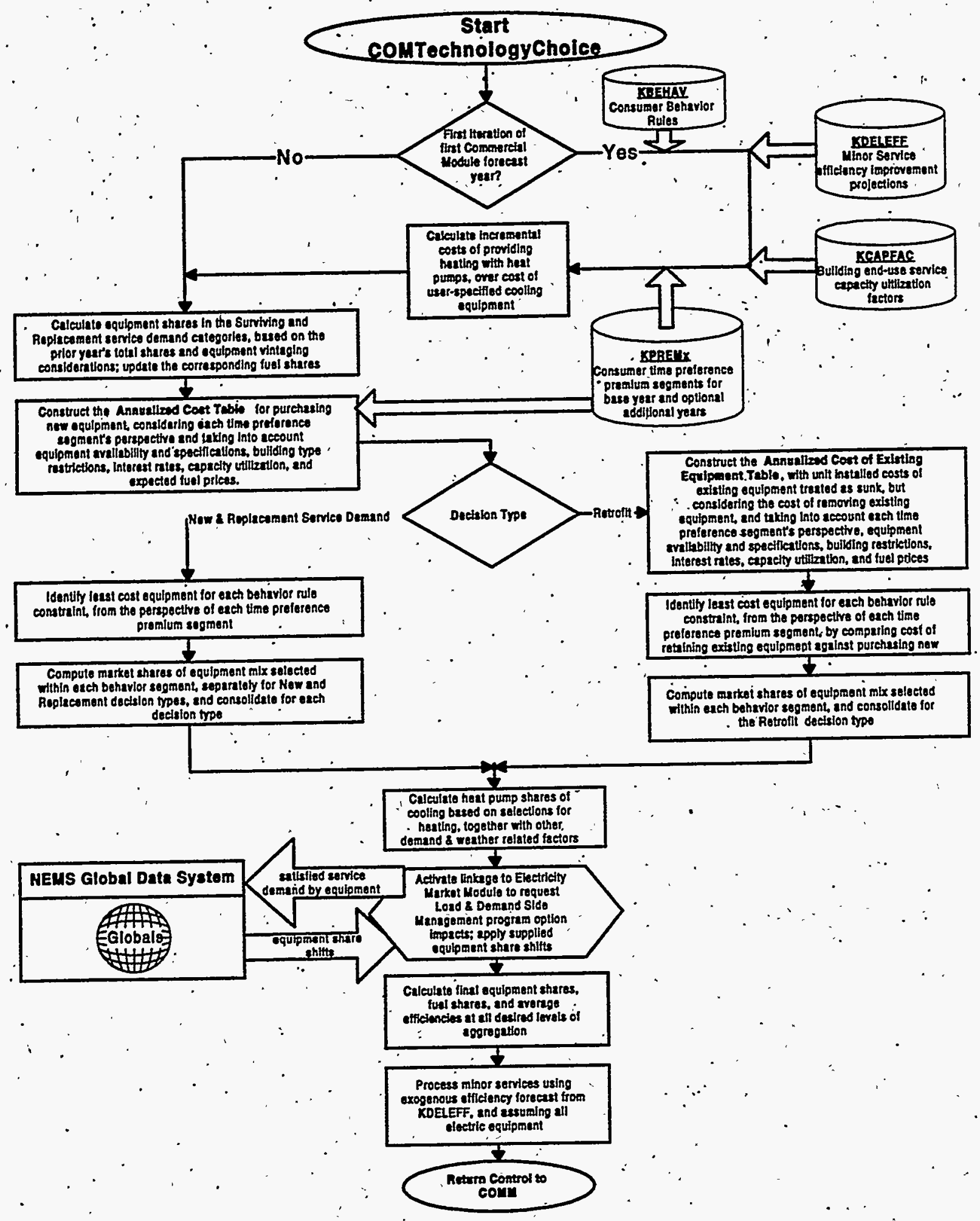

Energy Information Administration NEMS Commercial Demand Module Documentation Report 
Figure 7. COMConsumption Calculation Process Flow

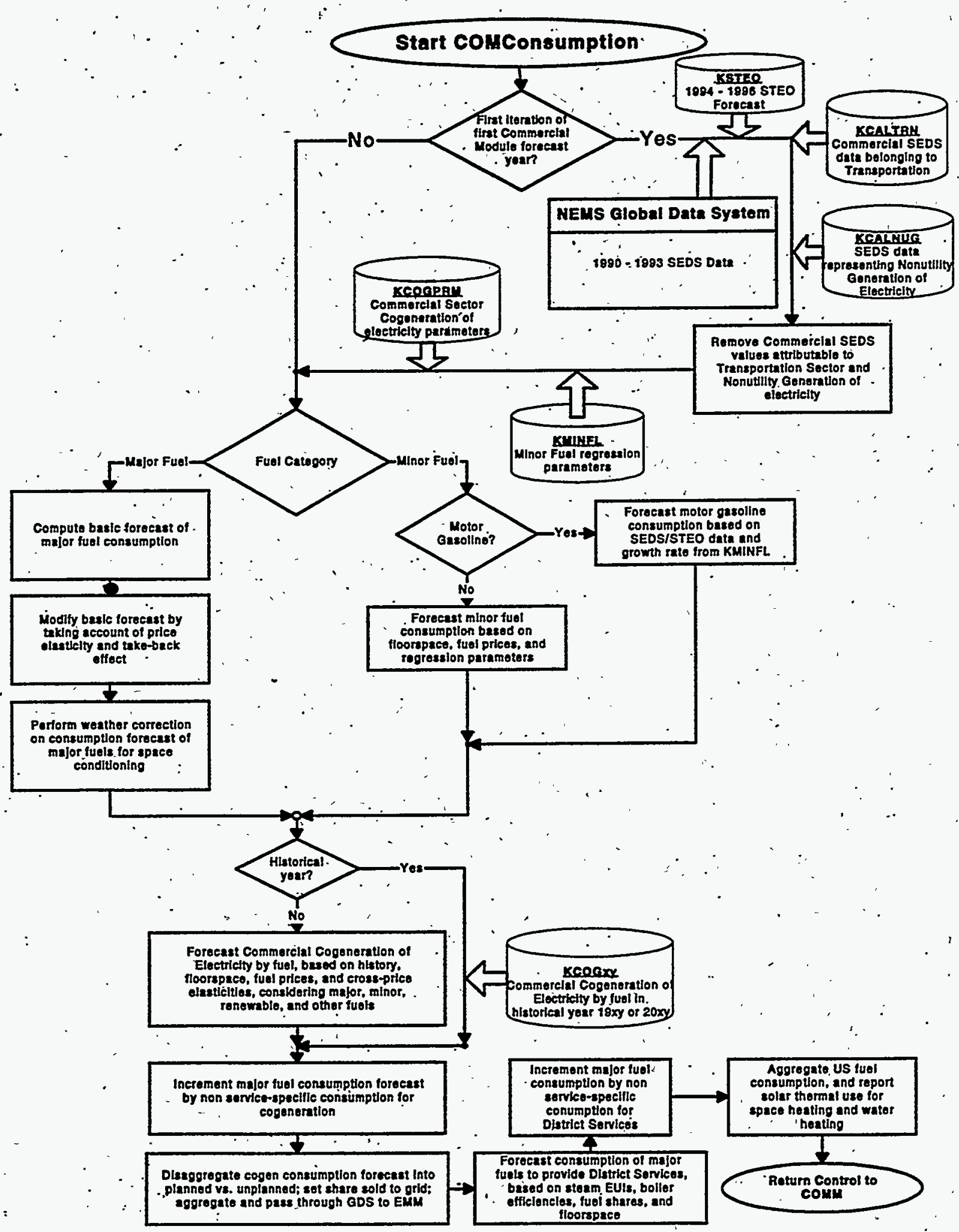

Energy Information Administration NEMS Commercial Demand Module Documentation Report 


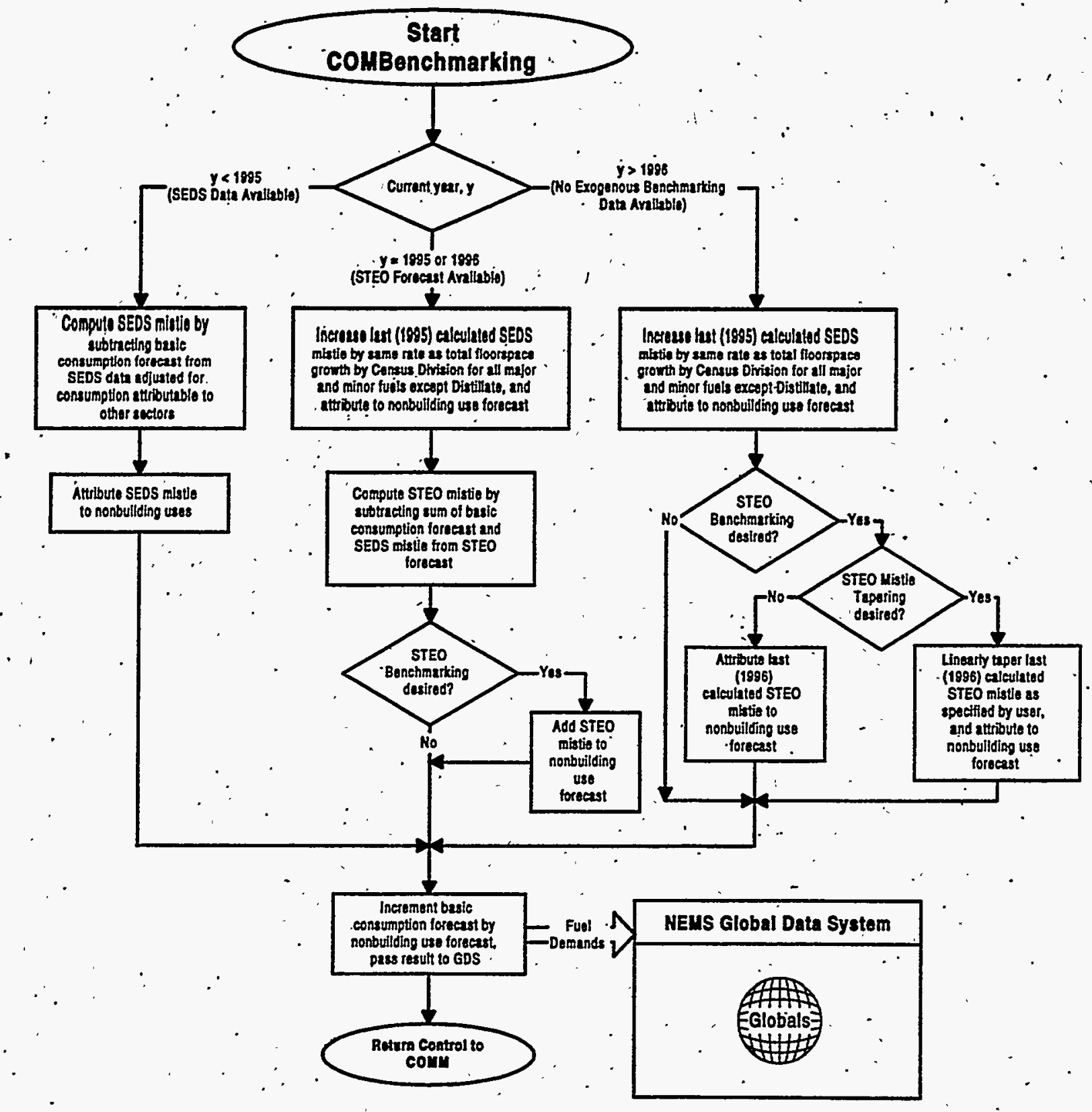

Energy Information Administration 


\section{Key Computations and Equations}

This section provides detailed solution algorithms arranged by sequential submodule as executed in the NEMS Commercial Sector Demand Module. General forms of the fundamental equations involved in the key computations are presented, followed by discussion of the numerous details considered by the full forms of the equations provided in Appendix B.

\section{Floorspace Submodule}

The Floorspace Submodule utilizes the Census Division level building-specific total floorspace forecast from the NEMS Macroeconomic Activity Module (MAM) as its primary driver. Many of the parameter estimates used in the Commercial Module, including base year (1992) commercial sector floorspace, are developed from the 1992 Commercial Building Energy Consumption Survey (CBECS) data base. Forecasted total commercial floorspace is provided by the MAM through the MC_COMMILSP member of the NEMS Global Data Structure (GDS). Commercial floorspace from the MAM is specified by the 14 building categories forecast by F.W. Dodge of McGraw-Hill, Inc. and supplied through the underlying proprietary model developed by Data Resources. Incorporated (DRI). To distinguish the Commercial Module floorspace forecast ultimately produced within the Commercial Module from that provided by the MAM, the latter is referred to as the DRI floorspace forecast in this report.

The Floorspace Sübmodule first backcasts the 1992 CBECS floorspace stock to its original construction years, and then simulates building retirements by convolving the time series of new construction with a logistic decay function. New floorspace construction during the forecast period is calculated in a way that causes total floorspace to grow at the rate indicated by the MAM forecast. In the event that the new additions computations produce a negative value for a specific building type, new additions are set to zero.

Correspondence with the analysts responsible for the MAM floorspace forecast provided values for the average building lifetime between 40 and 80 years, based on the F.W. Dodge/DRI data provided for the MAM floorspace forecast. The building retirement function used in the Floorspace Submodule depends upon the values of two user inputs: average building lifetime, and gamma. The average building lifetime refers to the median expected lifetime of buildings of a certain type; that is, the period of time after construction when half of the bivildings have retired, and half still survive. The gamma parameter, $\gamma$, corresponds to the rate at which buildings retire near their median expected lifetime. The current values for these model inputs are 59 years and 5.3 respectively. The proportion of buildings of a certain type built at the same time that are surviving after a given period of time has passed is referred 
to as the survival rate. The survival rate is modeled as assuming a logistic functional form in the Commercial Module, and is given by equation B-1 in appendix B. This survival function, also referred to as the retirement function, is of the form:

$$
\text { Surviving Proportion }=\frac{! \cdot 1}{1+\left(\frac{\text { Building Age }}{\text { Median Lifetime }}\right)^{\gamma}}
$$

Existing floorspace retires over a longer time period if the median building lifetime is increased or over a shorter time as the average lifetime is reduced as depicted in Figure 9. The user-specified gamma parameter partly determines the shape of the survival rate function that defines the acceleration of the rate of retirement around the average building lifetime. The larger the value of gamima, the steeper the survival cirve near the median lifetime. This implies greater numbers of buildings retiring at or very near the average lifetime. Large values of gamma . should be avoided, as this implies that a vintage of buildings will retire almost entirely at its average lifetime. The converse is true as well: Small gamma values will retire floorspace more evenly over the range of lifetimes. Negative values of gamma will not produce a decay or retirement function but rather a penetration function with increasing values. A gamma value of zero yields a straight horizontal line at the $50 \%$ share mark. This function implies that immediately after construction only half the floorspace remains, but it survives forever, and therefore has no realistic economic meaning. Hence, gamma must be restricted to values greater than zero for the purposes of the NEMS Commercial Module. 
Figure 9. Floorspace Survival Function Sensitivity to Average Building Lifetimes.

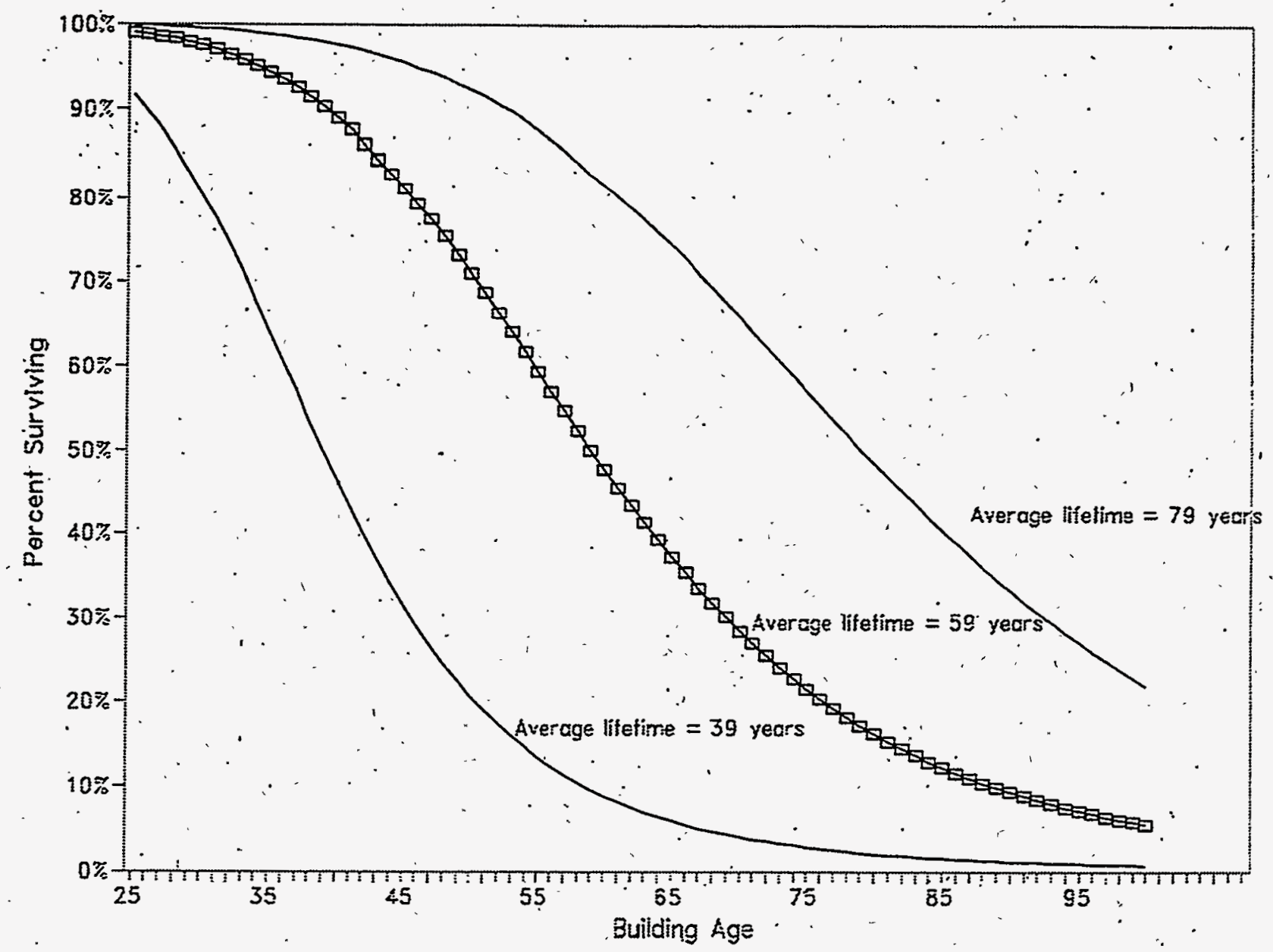

The gamma parameter impacts final energy consumption by determining how gradually the floorspace vintage is retired. A large gamma causes nearly all of the vintage to retire within a few years of the average building lifetime, which in turn results in replacement of the retiring floorspace with new construction in an equally uneven manner. Uneven retirement and construction results in rapid escalation of average equipment efficiencies as large amounts of new equipment are rapidly introduced, resulting in an erratic consumption time path. 


\section{Figure 10. Alternative Gamma Assumptions and Results.}

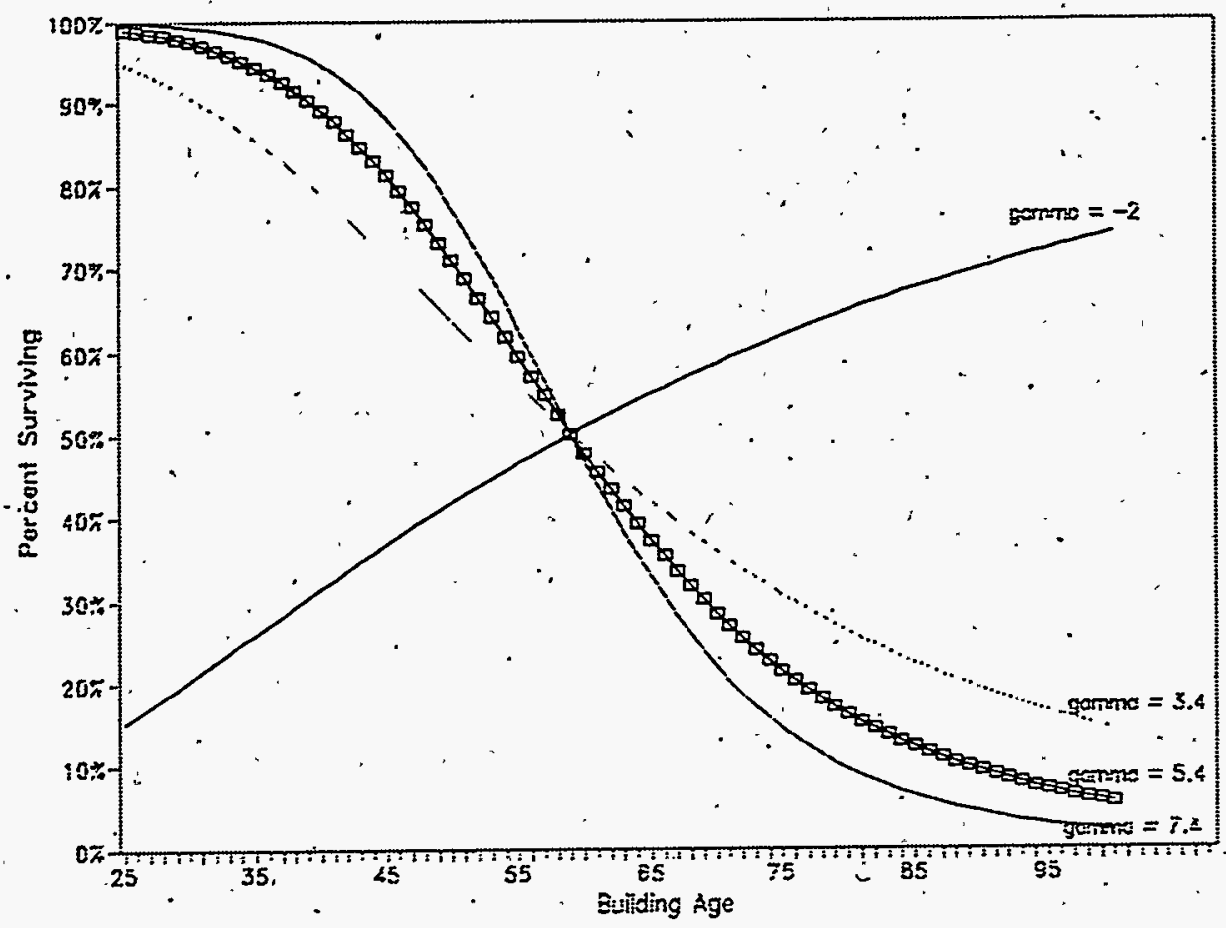

Average building lifetimes are positively related to consumption; the longer the average building lifetime, the more slowly new construction with it's associated higher-efficiency equipment enters the market, prolonging the use of the lower-efficiency equipment in the surviving stock. This scenario results in a higher level of energy consumption than in the case of accelerated building retirements and phase-in of riew construction.

The NEMS Commercial Sector Demand Module is designed to accept user inputs for gamma and median building lifetime, by building type. This flexibility enables the Module to reflect the distinguishing characteristics of the different building types. 
Surviving floorspace from previous years depends on both the composition of the base year (1992) CBECS stock and all new floorspace added between 1992 and the current year of the forecast. In addition, survival characteristics . vary among building types. Specifically, in order to calculate the surviving fioorspace in a given year, it is necessary to consider the amounts and building types of all floorspace by vintage range, as well as the correspionding survival parameters. This is accomplished in the Commercial Module using a convolutional approach as follows:

1. During the first pass through the algorithm, existing CBECS floorspace by building type, Census Division, and vintage range, is input from file KFLSPC.

2. The median year of construction for each vintage range is input from file KVINT. These values also vary with building type and Census Division.

3. The key building survival parameters discussed above are input from file KBLDG. These include the median lifetime for each building type, and a shape parameter (gamma) that characterizes the shape of the Logistic Building Survival Function used to represent the surviving propiortion of original floorspace as a function of time, for each building type. The mathematical expression of the Logistic Building Survival Function is given by Equation B-1 in Aṕpendix B.

4. Based on the building parameters described in step 3., base year CBECS floorspace is backcast to new floorspace in the original year of construction: Conceptually, this is simply the inverse building retirement, and is performed using Equation B-2 of Appendix B. Basically, if the age of a given amount of floorspace is known, then the original year of construction and the surviving proportion as given by Equation 15 or B-1 are also known. The relationship of these quantities is given by:

$$
\text { Surviving Stock }=(\text { Original Stock }) \cdot(\text { Surviving Proportion })
$$

Dividing the surviving stock by the surviving proportion gives the original stock in the year of construction. This time series of new floorspace is spliced to the new floorspace obtained from the DRI forecast (described below) to produce a total history of new additions to floorspace, starting with the original stock of the oldest CBECS vintage (currently 1825). Surviving floorspace in any given year is then calculated by using the appropriate survival parameters to determine the proportion of original stock that survives from -each prior year into the current year of the forecast. This is accomplished using the mathematical process known as "convolution," where , for each building type, the time series of new construction is convolved . with the survival furction to produce the time series of surviving floorspace, which is evaluated for the current year.; This calculation is shown by Equation B-3 in Appendix B. 
'In order to calculate new additions to floorspace in the current forecast year, the surviving floorspace calculated above is combined with the DRI total floorspace forecast provided by MAM as follows:

1. Within each Census Division, the total amount of floorspace for each CBECS building type is calculated so as to change from the prior year to the current year by the same proportion exhibited by the corresponding combination of DRI building types. The mapping from the DRI building types to the CBECS building types is represented by a transformation matrix named DRItoCBECS. The fourteen building types forecasted in the MAM are: Amusement, Automotive, Dormitory, Education, Health, Hotel, Manufacturing, Warehouse, Miscellaneous, Office, Public Service, Religious, Store, and Warehouse. New additions are obtained by subtracting the surviving floorspace forecast from the total CBECS floorspace forecast. For reasons described below, this is merely the first estimate of new additions to CBECS floorspace. The calculation is illustrated by Equations B-4 and B-6. Equation B-5 simply prevents negative new additions by replacing such occurrences with zero.

2. Due to differences between the CBECS and DRI data sources, the results obtained in the previous step do not guarantee that the total floorspace growth rate for each entire Census Division will be in agreement. Therefore, the growth rates by building type obtained in the previous step are uniformly modified within each Census Division is such a way that Census Division level growth rate agreement between the Commercial Module and the DRI forecast is achieved. This is accomplished using Equations B-7 and B-8.

3. New additions to floorspace for each CBECS building type are obtained by subtracting the floorspace forecast as surviving into the current year from the total floorspace in the current year calculated in step 2 , as shown by Equations B-8 and B-9, completing the forecast of new floorspace. The final value obtained for total floorspace is then given by Equation B-10.

This approach is necessary because the DRI floorspace forecast read from the NEMS Macroeconomic Activity Module is not available as separate forecasts for new additions and existing floorspace stock.

\section{Service Demand Submodule}

Aś indicated in Table 1, the Commercial Module partitions energy-consuming activities in the commercial sector into ten services. For reference, these are: 


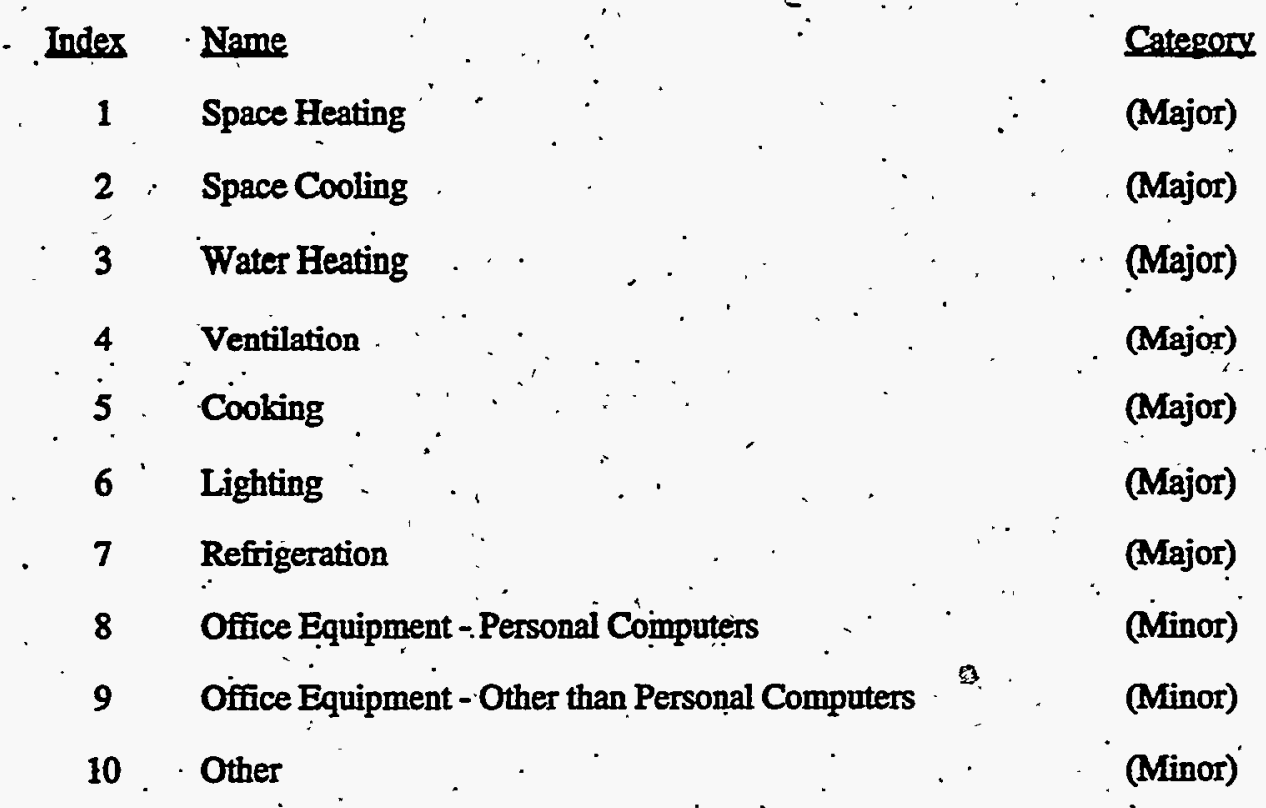

The Service Demand Submodule accounts for the delivered energy for each end-use service demanded. The service demand is sensitive to a variety of input's including base year (1992) energy use intensities (EUIs), base year efficiencies of equipment, efficiencies of building shells; short-term price elasticities, and weather ${ }^{14}$. Service demands for District Services and solar thermal applications are considered separately.

The base year EUIs represent the average amount of energy required to obtain a given service for a defined area. Currently the model uses EUI estimates developed from conditional demand analysis of the CBECS 1992 , consumption survey disaggregated by service, fuel type, building type, and Census. Division. The concept that fuel is consumed in commercial buildings in order to satisfy demands for the services enumerated above is central to the model. Service demand is defined as Btus out (amount of DELIVERED energy). Equipment efficiency or equipment Coefficient of Performance (COP) of the technologies that meet required service demands, together with the distribution of that equipment and the levels of service demanded, determines the fuel consumption, or Btu input. Efficiency is defined as the ratio of Btus out to Btus in for a closed system, which is a system that does not. draw from external sources for Btis transference. The COP is a more appropriate measure of equipment performance where the system is more open, as in the case of a heat pump. In the case of the heat pump, a small amount of energy is consumed in moving a larger amount of heat between the interior and exterior of a structure, making the COP greater than one, the theoretical maximum value for closed-system efficiency. The terms efficiency and COP are

14 Impacts on service demands due to price elasticity, weather, and the "rebound" effect are calculated by the End-Use Consumption Submodule, based on the direct proportionality between fuel consumption and service demand. This is necessary because the fuel shares of provided service are not known until after the selection of the equipment mix by the Technology Choice Submodule.

60 
used interchangeably in this report when referring to the ratio of delivered to consumed energy. These terms are also used where either ventilation or lighting is the service, although the actual measure used in the model for ventilation is cubic feet per minute of ventilation air delivered to Btus in and that used for lighting is efficacy, defined as lumens delivered per watt of electricity consumed.

Sërvice Demand Intensity (SDI), defined as, the demand for a service per square foot of floorspace, varies with service, building type and location; but is assumed to remain constant for a given service in a given building type and location. The service demand obtained by multiplication of the SDI with the floorspace is, however, subject to. modification by various factors such as shell efficiency and fuel price elasticity, as described below.

The service demand intensities are computed for the major services by applying the composite average equipment efficiency for the service to the EUI. This provides a more realistic picture of the energy needed to provide an enduse service since energy losses occur during conversion to a consumable service. The base year EUI for a given service is related to the SDI and the average efficiency of the base year equipment mix as follows:

$$
S D I\left(\frac{B t u \text { out }}{f t^{2}}\right):=E U I\left(\frac{B t u \text { in }}{f t^{2}}\right) \cdot C O P_{\text {iverage }}
$$

The actual calculation of SDI in the model involves several additional considerations, such as buildings from which specific equipment is restricted, base year equipment market shares, and the distribution of Census Division level equipment market shares across, the different building types. In addition, since the model accommodates fuel switching, the total SDI for the service must be calculated, rather than an SDI corresponding to each fuel used in 1992. The basic calculation illustrated by Equation 17 is carried out by evaluation of Equations B-11 through B-19 in Appendix B for each major service.

Minor services of Office Equipment and "Other" are modeled at a level of detail coarser than that performed for the major services. In particular, specific discrete minor service technologies are not characterized; instead, the efficiency of the composite mix of technologies for a given minor service is modeled as evolving relative to its base year. (1992) level. The actual base year average efficiency of the minor service equipment mix is indexed to equal one, resulting in the minor service SDI and EUI values being equal, as indicated by Equation B-20.

The basic computation of service demand for a given service in a given category of floorspace (new or surviving) is the same for major and minor services, namely: 


$$
\text { Service Demand }(\text { Btu out })=S D I\left(\frac{B t u \text { out }}{f t^{2}}\right) \cdot \text { Floorspace }\left(f t^{2}\right)
$$

The computation illustrated above is accomplished in the Commercial Module by evaluating Equations B-21, B-26, B-31, and B-32.

Building shell efficiencies for new construction are user inputs that can be modified to generate scenarios to reflect a variety of conservation policy options such as increased insulation or weather-stripping or new highly energyefficient construction-materials. Building shell improvements are assumed to affect service demands for both space heating and space cooling. However, Commercial buildings are typically not as "shell-driven" as residential buildings (they have less surface area per conditioned cubic volume), and as commercial building shell efficiency improves, more internally generated heat (from lighting, computer equipment, people, etc.) must be removed by air conditioning equipment. These two factors often cause shell improvements to increase cooling loads while heating loads are reduced. As a result, an average cooling load change is calculated based on the heating shell efficiency index. The source of data for calculating the differential cooling effect is a report developed for the U.S. Department of Energy by Lawrence Berkeley National Laboratory: 15

The present shell efficiencies are indexed to the average 1992 values by building type and Census Division. The heating shell efficiency indices are modeled as increasing to user-specified values in 2015 with improvement continuing to 2020 at the same rate. For AEO98, floorspace surviving from the base-year floorstock is assumed to improve a maximum of 4 percent over the 1992 stock average by 2015, and new floorspace is assumed to improve 6 percent by 2015 relative to the efficiency of new construction in 1992 ( 5 and 7 percent improvement, respectively, by 2020). Heating shell efficiencies are then translated into cooling shell efficiencies using coefficients based on averaging the changes in cooling loads caused by an improvement to the thermal integrity of the shell. Changing shell efficiencies impact the demands for Space Heating and Space Cooling services in the following fashion:

Service Demand $=($ Service Demand with 1992 shell $) \cdot($ Shell efficiency index $)$

\footnotetext{
${ }^{15}$ Sezgen, O., E.M. Franconi, J.G. Koomey, S.E. Greenberg, A. Afzal, and L. Shown, Lawrence Berkeley National Laboratory, Technology Data Characterizing Space Conditioning in Commercial Buildings: Application to End-Use Forecasting with COMMEND 4.0, LBL-37065, (Berkeley, CA, December 1995). 
The calculations involved in computing the appropriate shell efficiency index and evaluating the expression illustrated by Equation 19 are accomplished using Equations B-22 through B-24 and Equations B-27 through B-29.

The 1992 CBECS data indicated several differences in the proportions of biilding floorspace receiving services for several major services. The most pronounced differences occurred between newer and older buildings. This effect has been captured, and is accounted for using equation B-30.

While the market for major services is assumed to be saturated, additional penetration of the minor services of Office Equipment (both PC and NonPC) and "Other" is modeled. Forecasts of continuing market penetration are prepared offline as described in Appendix A, and incorporated into the service demand forecast for these minor services using equations B-33 and B-34.

The portion of service demand satisfied by solar space heating, solar water heating, and daylighting is computed using exogenous forecasts for renewable-energy for the commercial sector. The penetration of solar energy changes the amount of service demand, affecting the end-use consumption for the major services. The incorporation of solar services in this manner provides a useful method for policy analysis. By varying adoption of these technologies in response to policy mandates or incentive programs, the effects on consumption of conventional fuels can be determined. The calculations involved in modeling the penetration of solar services are performed by Equations B35 and B-36.

The short term price elasticity of demand is currently provided for space heating, space cooling, water heating, ventilation, cooking, and lighting. The parameters currently included in the Commercial Module are set to -0.15 for these services. These values are representative of estimates provided in the literature as first referenced in Table A2. The elasticities represent the short-term price responsiveness of the aforementioned service demands in the model. The values for the elasticities must necessarily be nonpositive since the services are normal goods, meaning that, as fuel prices increase, the quantity demanded of energy services declines. In order to capture the effect of fuel price changes on demands for services satisfied by equipment using the affected fuel, the service demand elasticity. calculation is postponed until after the final determination of the current year equipment mix as calculated by the Technology Choice Submodule. Because of the linear relationship between service demand and fuel consumption, as illustrated in Equation 17 above, a proportional change in service demand results in the same proportional change in fuel consumption. The service demand elasticity computation is illustrated by Equation B-88. Equation B-88 also illustrates the modification of pure price elasticity to account for the fact that improving equipment and shell efficiencies reduce the actual cost of meeting certain service demands. Incorporation of this "take-back" or "rebound" effect, and the weather correction (described in the End-Use Consumption Submodule section), is also . postponed until the calculation of fuel consumption. 
The final responsibility of the Service Demand Submodule is to determine the amount of service demanid in surviving floorspace that becomes unsatisfied in the current forecast year due to failure of equipment. A simplified equipment vintaging scheme is employed, where each year a proportion of each type of equipment fails, with the proportion given by the reciprocal of the expected equipment lifetime expressed in years. Thus, if the expected - lifetime for a particular piece of equipment were 10 years, the Commercial Module assumes that each year one tenth of the total amount of that equipment fails. This relationship is used to split the total amount of service demand in surviving floorspace into the portion in need of equipment replacement and the surviving portion, for satisfaction by appropriate decisions in the Technology Choice Submodule. The calculation of this split.is performed by Equations

B-37 and B-38.

\section{Technology Choice Submodule}

The Technology Choice Submodule models the economic decision-making process by which commercial agents choose equipment to meet their end-use demands. One feature of the current approach that distinguishes it from alternative modeling approaches is its representation of the heterogeneity of agents in the commercial sector. The NEMS Commercial Sector Demand Module segments commercial agents using three behavior rules and six distinct time preference premium categories. This type of segmentation incorporates the notion that all agents do not consider the same set of parameters in the optimization within the commercial sector. Some participants may display specific behavior due to existing prejudices regarding certain equipment types or fuels. In addition, the distribution of time preference premiums represents a variety of commercial agents' attitudes about the desirability of current versus future expenditures with regard to capital, $O \& M$, and fuel costs.

Each one of the above market segments is faced by one of three decisions, 1) to purchase new equipment for new buildings, 2) to purchase replacement equipment for retiring equipment in existing buildings or, 3) to purchase retrofit equipment or retain existing equipment for existing buildings. Within each market segment, the commercial agent will search the available.technology menu for the least cost alternative within the constraints of the applicable behavior rule.

Choosing the least cost alternative within a market segment involves a tradeoff among capital cost, fuel cost, and operating and maintenance (O\&M) cost. In the case of renewable energy-consuming equipment, costs may also include the cost of backup equipment. The relative importance of each cost component is a function of consumer time preference. The NEMS Commercial Sector Demand Module sets all other attributes of a technology constant across choices, and these other attributes do not influence the technology choice decision modeled by the algorithm. 
Each technology is modeled with constant returns to scale. This means that there is a proportional response between capital, fuel and O\&M inputs and the service output for these technologies. In addition, the technology costs are represented for comparison in such a way that, for a given total cost, a dollar increase in capital cost must imply more than a dollar decrease in fuel and O\&M costs since the dollar spent today for capital is worth more than any future dollar. Therefore, a tradeoff in the form of additional reduction in other costs is necessary in order for the perceived total cost to remain constant. In addition to this tradeoff, this component allows for optional expectations modeling, in that price expectations can be used to determine the fuel costs over the expected economic lifetime of the equipment.

The algorithm is designed to choose among a discrete set of available technologies for each decision. The Technology Choice Submodule computes the annualized equipment cost per unit of delivered service as the method of weighting the attributes (capital cost, fuel cost, etc.) to develop a composite score for the technology. Choices among the technologies are then made by minimizing the annualized cost. The annualized cost represents the discounted flow of all O\&M, capital, and fuel costs of the technology over its lifetime. The technology is chosen by minimizing the annualized cost per unit service demand (subject to constraints on the set of potential technologies represented by the behavior rules discussed below). The discount rate is embedded in this annualized cost through a factor that converts the one time capital and installation costs into an equivalent annuity of equal annual payments over the equipment lifetime. The basic form of the expression for equipment cost used in the Commercial Sector Demand Module is:

$$
\begin{aligned}
\frac{\text { Annualized cost }}{\text { unit of delivered service }}= & \text { (annuitized purchase \& installation cosst component) } \\
& +(\text { yearly } O \& M \text { component) } \\
& +(\text { expected yearly fuel cost component) }
\end{aligned}
$$

The unit of service demand referred to above that is used in the Commercial Module calculations is thousand Btu delivered per hour for all end-use services except lighting and ventilation. The unit of service demand used for lighting is thousand lumens delivered and that used for ventilation is thousand cubic feet per minute of air delivered. Consideration of the building capacity utilization factor is.necessary because, unilike the purchase and installation costs, the yearly O\&M and fuel costs will vary depending on the intensity of equipment use.

The Commercial Sector Demand Module contains the option to use a cost function to estimate the unit installed capital cost of equipment as a function of time during the interval of equipment availability, rather than limiting technologies to specific models with constant costs during the model years of availability: The choice to enable the 
cost trend function is specified through the Commercial Module user parameter CostTrendSwitch. Currently, cost trends represented are of logistic functional form and are separated into three categories corresponding to technology maturity: Infant, emerging or future technologies; Adolescent, existing technologies with significant potential for further market penetration and price decline; and, Mature, technologies not expected to decline further in cost. The Adolescent and Infant categories require specification of the initial year of price decline, the year of inflection in the price trajectory, the ultimate price reduction as a proportion of initial cost, and a shape parameter, gamma, governing the rate of price decline. The Mature category corresponds to the previous constant-cost representation. The cost trend function is enabled in the default mode of model operation, although lighting is the only service to use technologies specified as Adolescent or Infant at the current time. The calculation of unit costs using the cost trend function is presented in equation B-45.

The electricity prices used to develop the annualized fuel costs; in the default mode, are end-use specific prices developed by weight-averaging time-of-day rates by expected time-of use patterns. The incorporation of prices relevant to a particular end-use service accommodates the move to competitive marginal pricing expected as a result of the deregulation of electricity markets. Average annual prices by Census division are used to develop the annualized fuiel costs for the other major fuels.

The actual calculation of the annualized cost for comparison of candidate technologies is performed using Equation B-48. For decisions regarding space heating and cooling equipment, the calculation includes a shell efficiency' factor, incorporating the effects that building shell improvements have on annual fuel costs. The shell efficiency. factor, illustrated in Equations $B-46$ and $B=47$, uses the same shell efficiency indices calculated in the Service Demand Submodule.

The costs that are relevant to the consumers and the menu of technologies vary for different consumers and different choices. Therefore, a distribution of technologies, rather than a single technology, is chosen when the decisions of various consumers for various decisions are consolidated. A distribution is more representative of consumer response than a forecast which assumes all consumers choose the same technology. There are nine combinations of commercial consumer behavior riles and decision types with which technology choice decisions are made in the Commercial Module. These are presented in Table 10 and described in greater detail below. 


\section{Table 10. Array of Technology Choices and Consumer Behaviors}

\begin{tabular}{|c|c|c|c|}
\hline & +4 & (3) & 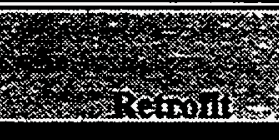 \\
\hline 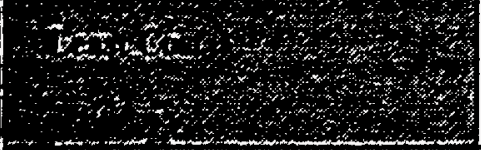 & $\begin{array}{l}\text { New Equipment, } \\
\text { Least Cost Rule }\end{array}$ & $\begin{array}{l}\text { Replacement } \\
\text { Equipment, Least Cost } \\
\text { Rule }\end{array}$ & $\begin{array}{l}\text { Retrofit Decision, } \\
\text { Least Cost Rule } \\
\text {. }\end{array}$ \\
\hline 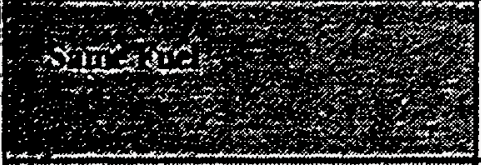 & $\begin{array}{l}\text { New Equipment, } \\
\text { Same Fuel Rule }\end{array}$ & $\begin{array}{l}\text { Replacement } \\
\text { Equipment, Same Fuel } \\
\text { Rule }\end{array}$ & $\begin{array}{l}\text { Retrofit Decision, } \\
\text { Same Fuel Rule }\end{array}$ \\
\hline 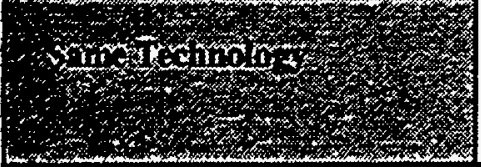 & $\begin{array}{l}\text { New Equipment, } \\
\text { Same Technology } \\
\text { Rule }\end{array}$ & $\begin{array}{l}\text { Replacement } \\
\text { Equipment, Same } \\
\text { Techmology Rule }\end{array}$ & $\begin{array}{l}\text { Retrofit Decision, } \\
\text { Same Technology } \\
\text { Rule }\end{array}$ \\
\hline
\end{tabular}

Behavior Rules .

The NEMS Commercial Sector Demand Module simulates this range of economic factors influencing consumer purchase decisions by assuming that consumers use one of three behavior rules in their technology choice decisions. These behavior rules are:

- Least Cost Rule - Purchase the equipment with the smallest annualized cost without regard to currently installed technologies or fuels used;

- Same Fuel Rule -- Purchase equipment that uses the same fuel as existing or retiring equipment, but within that constraint minimize costs;

- Same Technology Rule - Purchase (or keep) the same class of technology as the existing or retiring equipment, but choose the model within that technology class that minimizes the annualized costs.:

The same basic decision logic'applies to all of these rules, but the behavior rule determines the set of technologies . from which the selection is made. A consumer following the least cost behavior rule chooses from all available technologies and all available fuels. A consumer following the same fuel behavior rule chooses from a more restrictive array of technologies. A consumer following the same technology behavior rile would select from one class of technologies, choosing among all available models of equipment in that class.

As discussed above, the Commercial Sector Demand Module segments consumers into three behavior rule categories. Ideally, survey data would provide an indication of what proportion of the commercial sector follows 
each rule. The Technology Choice Submodule currently incorporates proportions by building type and decision type based on an analysis of data from CBECS 1992. Data regarding the ownership and occupants of commercial building forms the basis of proportions of the market that act according to each behavior rule for each decision type. Special considerations and interactions between the behavior rules and decision types are described in the section on decision types. The CBECS 1992 data is combined with other data characterizing consumer behavior obtained from published literature to develop the behavior.rule proportions incorporated in the Module. Changing these proportions impacts final consumption estimates.

Supporting data from CBECS 1992 includes building stock ownership patterns for 1992. This data is presented in Table 11. The categories provided are:

- Total Floorspace of All Buildings

- Total Floorspace of All Nongovernment Owned Buildings

- Owner Occupied

- Nonowner Occupied

Specific ownership categories are developed from this data, including but not limited to:

Nongovernment, Non-owner Occupied, which is the difference between Total Nongovernment Owned and Nongovernment Owner Occupied; and

Government Owned, which is the difference between Total Floorspace and Nongovernment Owned. 


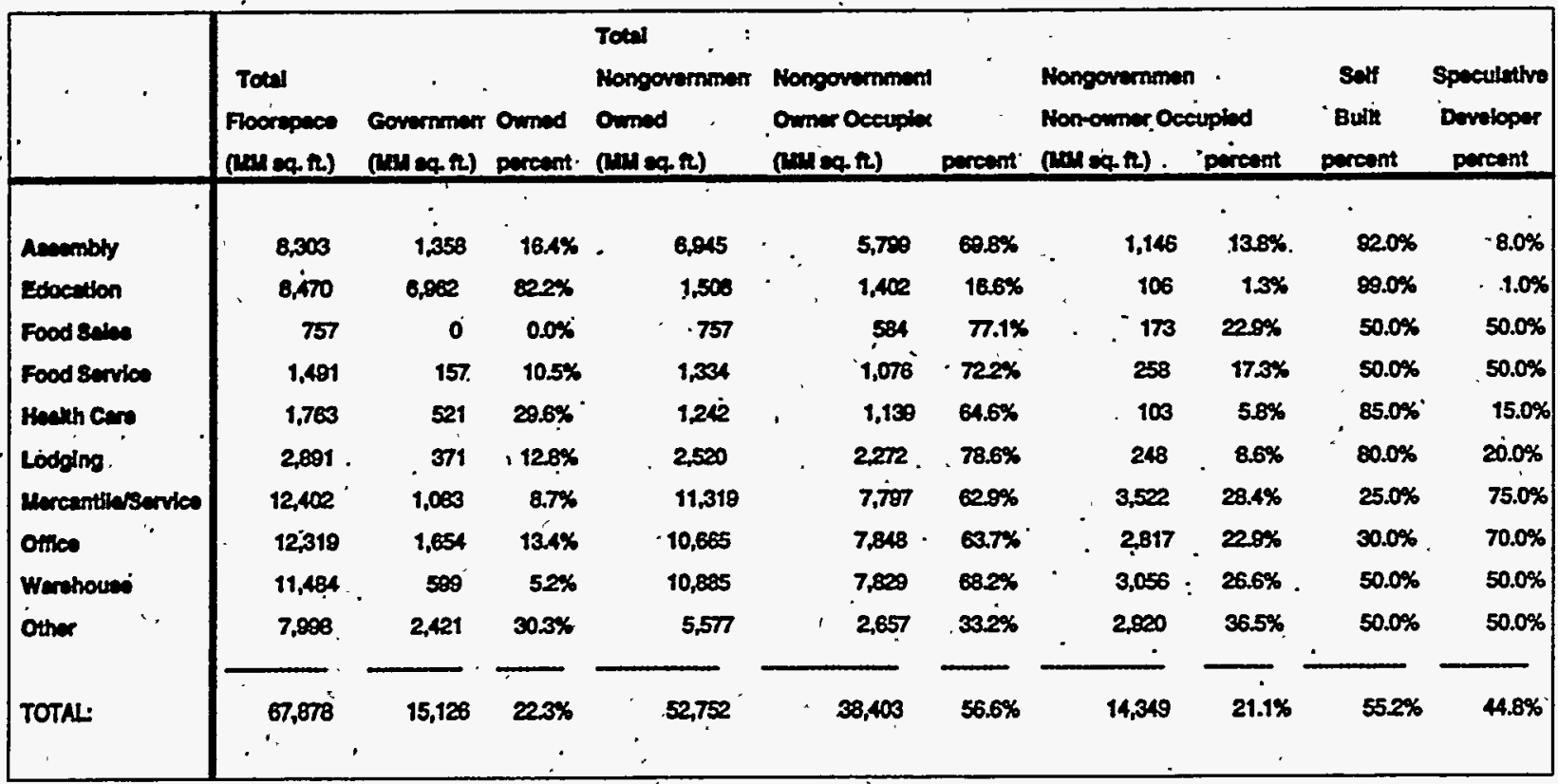

This disaggregation, combined with analysis of consumer behavior literature, results in the behavior rule proportions. The methodology to develop these proportions is described below. The three issues that are examined to determine which behavior rule applies are construction, ownership, and occupancy. Äppendix A provides additional documentation and sources for the information in Table 11 and this discussion.

The behavior rule that applies when constructing new buildings is sensitive to the party that is financing the construction. The behavior in selecting equipment in new construction is assumed to differ between those projects that are self-built and those that are built by speculative developers. For each building type, a proportion of self-built to developer-built is assumed.

The ownership and occupancy of buildings provides some insight into the proportions for the replacement and retrofit decision types. In a replacement decision case, it is assumed that government and owner occupied building will replace most equipment with either the same technology or a technology that uses the same fuel. Owner occupied floorspace is likely to have similar proportions between same technology and same fuel rules. . Renter . occupied floorspace is most likely to simply replace the existing technology with the same technology.

The general description of the technology choice procedure given above does not mean that all consumers simply minimize the costs that can be measured. There is a range of economic factors that influence technology choices. 
which cannot be measured. For example, a hospital adding a new wing has an economic incentive to use the same

fuel as in the existing building. There are also economic but non-measurable costs associated with gathering information for purchase decisions, and managerial attention.

\section{Decision Types and Their Relationship to Behavior Rules.}

Besides providing behavior rules to determine how consumers select technologies to meet their service demands, the model must furnish a rationale for purchasing the equipment in the first place. The reasons for purchasing equipment are referred to as decision types and described below. There are three equipment purchase decision types for commercial sector consumers. These decision types are:

- New - Choose equipment for new buildings;

- Replacement - Choose replacement equipment for retiring equipment in existing buildings;

- Retrofit-Choose retrofit equipment to replace equipment that continues to function in existing buildings, or leave existing equipment in place.

Previously, the Service Demand Submodule computed the total amount of service demand falling into each of the three Decision Type categories given above. The Technology Choice Submodule must first determine the mix of equipment and corresponding fuel shares represented in the Replacement and Retrofit Decision Types. This is accomplished by Equations B-39 through B-43 given in Appendix B.

For new buildings, consumers using the least cost behavior rule choose from among all current technologies and all fuels. Identification of the least cost equipment from the perspective of each consumer time preference segment is made using Equation B-50. Consumers using the same fuel behavior rule chóose from among current technologies which use the same fuel as in surviving buildings (buildings that do not retire). Identification of the least cost. equipment for each fuel from the perspective of each consumer time preference segment is made using Equation B-

51. Proportions of consumers in this category who choose each fuel are assumed to equal the overall fuel shares that prevailed in existing buildings during the previous year, which is reflected in the.individual terms of Equation B-54. Similarly, the identification of least cost models for each technology for the consumers following the same technology rule is illustrated by Equation B-52. As with the same fuel rule, the proportions of consumers within this . segment that stick with each particular technology class is assumed to equal the overall market share distribution of those technologies within existing buildings during the previous year, as reflected in the individual terms of Equation B-56.

- For equipment replacement decisions, consumers using the least cost behavior rule choose from among all current technologies, as illustrated again by Equation B-50. Consumers using the same fuel behavior rule choose from 
among current technologies which use the same fuel as was used by the retiring equipment. The proportions of consumers within the same fuel rule attempting to preserve the use of each fuel are equal to the fuel shares represented in aggregate by the equipment in need of replacement, as reflected in the individual terms of Equation B55. Consumers using the same technology behavior rule choose the least costly vintage of the same technology as the technology in need of replacement. As with the same fuel rule, the proportions of consumers within the same technology category attempting to retain equipment within each technology class are equal to the market shares of retiring equipment classes within the aggregate service demand in need of replacement' as reflected in the individual terms of the right side of Equation B-57.

For the retrofit decision, which involves the choice of retaining equipment that continues to function, or replacing it with equipment in order to reduce costs, the costs of purchasing new equipment as described above must be compared against the cost of retaining existing equipment. In order to make this comparison, the existing equipment capital costs are considered'sunk costs, meaning that these costs are set to zero. If retrofit equipment is purchased, the decision maker must pay the capital and installation costs of both the existing equipment and the retrofit . equipment. If existing equipment is retained, the decision maker continues to pay just the capital and installation costs of the existing equipment. Therefore, the capital and installation costs of existing equipment are netted out, since it is irrelevant to the retrofit decision. (This analysis assumes zero salvage value for existing equipment). The cost calculation is similar to that illustrated by Equation 20 above, except without the purchase and installation component. However, the cost of removing and disposing of existing equipment must be considered. This cost is expressed in the Commercial Sector Demand Module technology characterization database as a specified fraction of the original purchase and installation cost, and is annualized over the equipment lifetime. The resulting calculation of annualized cost of retaining existing equipment is given by Equation B-60. As in the calculation of the annualized cost of new equipment, the annualized cost of retaining existing space heating or cooling equipment includes the shell efficiency factor illustrated in Equations B-46 and B-47, incorporating the effects that building shell improvements have on fuel costs.

For the equipment retrofit decision, consumers using the least cost behavior rule choose from among all current technologies, comparing the cost of each as expressed by Equation B-48 against the cost of retaining the existing equipment as expressed by Equation B-60, and choosing the least cost result, as illustrated by Equation B-61. Consumers using the same fuel behavior rule choose from among current technologies which use the same fuel as is currently used by the existing equipment, again comparing the cost of each against the cost of retaining the existing equipment,' and choosing the least costly alternative, as indicated by Equation B-62. Two options are available in the Commercial Sector Demand Module to represent the choice behavior of consumers using the same technology behavior rule for the equipment retrofit decision. One option, used in the AEO98 reference case, is to allow selection from among available models in the same technology class, comparing the cost of each against the cost of 
retaining the existing equipment, and choosing the least costly alternative, as illustrated by Equation B-63. Alternatively, all consumers using the same technology behavior rule may be assumed to retain their existing equipment, as indicated by Equation B-66. The choice of methods is specified through the Commercial Module user parameter named STRetBehav.

The equipment selections made for each of the decision types and behavior rules described above will vary according to the time preference held by the consumer: These time preferences are discussed below in preparation for the description of consolidation of equipment choices to obtain the final equipment market shares.

\section{Time Preferences}

Consumers have different preferences on the value of money over time (the value of money now versus the value of money at some future time). Consumers' discount rates can betied to many attributes of personal preference or in .. many cases to age cohort. For example, older consumers may have a higher time preference premium because they may have a shorter expected time over which they expect to enjoy the money.

This distribution is a function of factors aside from the market interest rate that render current dollars preferable to future dollars. The Commercial Sector Demand Module is designed to accept a distribution of time preferences as input. This is a discrete distribution; it takes the form of a list of real time preferences (premiums to the risk-free interest rate), and a proportion of commercial consumers corresponding to each time preference. The time preference distribution is modeled independently of the behavior rules. The time preference results in differences in consumer preferences between capital costs (paid initially) and fuel and O\&M costs (incurred over the lifetime of the equipment). The value of the consumer's time preference interest rate premium influences the annualized installed capital cost through an annuity payment financial factor based on the 10-year Treasury bond rate and expected physical equipment lifetime.

: The distribution of the consumer's interest rate premium impacts results in several aspects. If the distribution is denser at the high premiums, the annualized cost of capital for all new equipment will rise. Higher annualized capital cost implies that fewer buildings will be retrofitted and that equipment that has a higher' installed capital cost is less likely to be chosen over a technology with a lower initial cost and higher operating and fuel costs. Typically, those technology and vintage combinations with high installed capital costs are high efficièncy pieces of equipment, so that the indirect effect of this scenario is that fuel consumption is likely to be higher. The values currently used in the Commercial Sector Demand Module have been developed using case stúdies on the payback period or time preferences regarding the adoption of a specific technology. For AEO98, the distribution of consumer time preference premiums is assumed constant over the forecast horizon. However, the model allows variation in the 
distribution on an annual basis to accommodate simulation of policy scenarios targeting consumers' implicit discount rates. The module currently uses expected physical equipment lifetime as the discount horizon.

\section{Consolidate Choices From Segments}

Once the technology choices have been made for each segment represented for a given end-use service; these choices must be consolidated in order to obtain equipment market shares by building type, Cenșis Division, and decision type for the end-use. From these market shares, average efficiencies of the equipment mix and fuel shares may be obtained, with which the Consumption Submodule calculates fuel consumption.

The first step in consolidation involves combining the results obtained from the perspective of each consumer time preference segment to calculate market shares of equipment within each behavior rule segment of each decision type. Since a given time preference segment makes only one equipment selection for a given decision type and behavior rule, the market share of a given equipment type is computed for that decision type and behavior rule segment by simply adding up the proportions of consumers contained in each time preference segment that selected that equipment. This is the calculation performed by Equations B-53 through B-57 and B-64 through B-66, with the factors associated with same fuel and samé technology proportions described previously. :

Table 12. Consolidating Service Demand Segments

\begin{tabular}{|l|l|}
\hline \multicolumn{1}{|c|}{$\begin{array}{l}\text { Variable by Which Service Demand } \\
\text { was Segmented }\end{array}$} & Weighting Variable for Consolidating Segments \\
\hline $\begin{array}{l}\text { Behavior Rule } \\
\text { Consumer's Time Value of Money Preference }\end{array}$ & $\begin{array}{c}\text { 'Behavior rule service demand proportions } \\
\text { Consumer time preference proportions }\end{array}$ \\
\hline
\end{tabular}

The next step in the consolidation process is to calculate the market shares of equipment within each decision type, consolidated across the behavior rule segments. This is done using Equations B-58, B-59, and B-67 to obtain equipment market shares for the new, replacement, and retrofit decisions, respectively. This and the previously- . described consolidation may be viewed as weighted sums, using as weights the quantities described in Table 12.

After this point, all equipment used to provide the major services receives identical treatment, but the calculation of equipment market shares described above differs for the case of heat pumps, and deserves separate mention. The purchase decision of heat pumps is integrated to provide both space heating and space cooling: This is desirable because selection of the same heat pump for two services is not realistically accomplished using two independent 
decisions. Furthermore, if the utility of the heat pump for providing additional services is not considered during the purchase decision, then the total heat pump cost may appear unreasonably high in comparison with other equipment providing the service under consideration. Both of these considerations have been resolved in the current version of the Commercial Module using the following approach:

First, heat pumps are assumed to be purchased primarily during the course of satisfying demands for space heating. Heat pumps compete with other available space heating equipment in the normal fashion during the technology choice process with one notable exception: The installed capital cost of the heat pump for heating is not the total cost of purchasing and installing the heat pump, but rather the incremental cost of doing so over and above the cost .of purchasing and installing a standard cooling equipment selection specified by the user. This captures the fact that the heat pump provides both space heating and space cooling, yet has only one purchase and installation cost. This adjustment to the installed capital cost retrieved from the technology characterization database is performed using Equation B-44.

During the technology choice process for satisfying space cooling service demands, heat pumps are excluded from selection. Instead, market shares of cooling service demand satisfied by the heat pumps selected to provide space heating are explicitly computed. This is accomplished by assuming that the ratio of cooling to heating delivered by a heat pump over the course of the forecast year is equal to the ratio of cooling degree days to heating degree days for the Census Division under consideration. From this assumption, the amount of cooling service demand satisfied by heat pumps is calculated, and hence their market shares of cooling service demand. This calculation is performed by Equation B-68. In order to account for the fact that equipment shares of cooling equipment other than heat pumps apply only to that portion of cooling service demand not satisfied by heat pumps, a final correction of the non heat pump market shares is then performed by Equations B-69 through B-71.

Fuel shares of service demand for the major services and fuels are calculated in a straightforward manner, by simply summing the equipment market shares of service demand of equipment using a given fuel. This is the calculation performed by Equation B-72 within the decision type segments by end-use, fuel type, building type, and Census Division, and by B-74 consolidated across decision types. Equations B-80 through B-82 calculate the fuel shares' by decision type, end-use, fuel type, and Census Division consolidated across building type.

Average efficiencies of the equipment mixés within various segments are calculated using the inverse weighted efficiency approach exhibited by Equations B-73, B-76 through B-79; and nationally by end-use and fuel using Equation B-83. The particular form of the averaging is necessary because efficiencies possess units of delivered to consumed energy, whereas the equipment market shares ussed as weights are proportions of delivered energy. Only if 
the equipment.market shares were expressed as proportions of consumed energy would the average efficiency of the equipment mix be obtained using a simple weighted sum of market shares and corresponding efficiencies.

Finally, fuel shares and average efficiencies are determined for the minor services, without consideration of individual equipment choices given to the major services. As described previously, the 1992 average efficiencies for the minor services are indexed to unity, and an exogenous forecaśt of minor service efficiency improvement is. employed. Minor service average efficiency for the current year is calculated from the value for the previous year. The exogenously-specified efficiency growth rate is shown in Equation B-84. Minor services are further assumed to use only electricity, and to possess identical average efficiencies for all decision types and buildings within a given Census Division and year, as illustrated by Equation B-85.

\section{Technology Menu}

Equipment availability, installed capital costs, removal and disposal cost proportions' of installed capital costs, operating and maintenance costs, building restrictions, energy efficiencies, lifetimes and technology cost trend parameters are specified exogenousiy. Equipment availability pertains to the set of technologies currently in the marketplace during a particular forecast year, not all available technologies are economically feasible, and therefore may not be selected. The menu of potential technologies includes technologies which are currently under development to be introduced over the forecast period. Equipment supply is assumed to be unlimited for commercially available technologies, with unit costs either fixed or declining according to the appropriate cost trend function. The other equipment characteristics are assumed fixed for a given technology and vintage once it is commercially available.

These technology characterizations are important, since improper estimation can cause substantial aberrations in . market behavior over the forecast period. As an example, assume that a new high efficiency piece of equipment becomes available in a specific forecast year. If the costs of the new piece of equipment are too low relative to other equipment for the service then too many new, replacement, and retrofit decisions will be directed to this equipment, in turn unrealistically reducing overall energy consumption and increasing the average equipment efficiency, although the behavior rule proportions dampen this effect. For the case of certain prototypical or "design-stage" technologies currently not available in the marketplace (or currently not in production), engineering specifications form the basis of the technology characterization. These costs may differ-markedly from the actual technology costs when the equipment is introduced to the real-world marketplace over the forecast horizon.

The 1992 initial historical market shares are based on an analysis of CBECS 1992 data. The.years of equipment availability are based on current market conditions and research as well as mandated federal efficiency standards. This window in which each technology is available constrains the technology choice menu for all decision types. For 
example, a distillate-fuel fired furnace currently available may no longer be available in 1998 due to federally . mandated minimum equipment efficiency standards.

\section{End-Use Consumption Submodule}

The End-Use Consumption Submodule models the consumption of fuels to satisfy the demands for end-use services computed in the Service Demand Submodule. Additionally, the End-Use Consumption Module forecasts the consumption of fuels to provide district services and cogeneration of electricity in the commercial sector, and accounts for the use of solar thermal energy to provide space heating and water heating.

The primary inputs to the End-Use Consumption Module are the service demands calculated by the Service Demand Submodule, and the fuel shares and average efficiencies forecast.by the Technology Choice Submodule. Together, these quantities allow a basic calculation to be made for consumption of the major fuels that has the same form for both the major and minor services. This calculation, given by equation B-86, makes use of the definition of average efficiency to obtain the forecast of consumption by fuel, end-use, building type and year, by simply dividing that portion of the end-use service satisfied by a given fuel by the average efficiency of equipment using that fuel. A value of zero for the average efficiency indicates that no equipment consuming the given fuel is used to satisfy the service, and in this case the corresponding consumption forecast is explicitly' set to zero. Because the units carried for lighting service demand and efficacy differ from those of the other services, a special conversion factor must be applied to the lighting result, as shown by equation B-87.

The basic estimate of fuel consumption described above is that projected to occur if all conditions other than the amount of floorspace, the building shell efficiency, and the equipment mix were identical to those found in the base year (1992), and consumers were only concerned with fuel prices in so far as they impacted the equipment purchase decisions. Since conditions other than those mentioned above vary with time, and consumers are also concerned. with fuel prices when using the equipment they have purchased, the basic estimate is subject to modification by several considerations.

First, a price elasticity of service demand may alter the consumer's demand for a service as a result of a change in the fuel price. As an example, an increase in the price of distillate heating oil may cause the consumer to maintain the floorspace at a somewhat cooler temperature in the winter than would have been the case without a price increase. While this consideration should logically be made where service demands are calculated in the Service Demand Submodule, it is not possible at that point because the mix of equipment using each fuel is not calculated until the Technology Choice Submodule has completed its forecaist. However, the calculation is easily made by the End-Use 
Consumption Module because of the direct proportionality between service demand and fuel consumption, as can be seen in equation B-86; that is, a percentage change in service demand corresponds to the same percentage change in. fuel consumption. The first term in equation B-88 shows the calculation and application of the short-run price elasticity of demand to modify the basic consumption estimate obtained by equation B-86. This is done for the enduse services of space heating, space cooling, water heating, ventilation, cooking, and lighting.

\section{Another consideration that affects the consumer's demand for services is known as the "rebound," or "täkeback"} effect. While fuel price increases can be expected to reduce demand for services; this can be partially offset by other factors which cause a decrease in the marginal cost of providing the service. Two such factors modeled by the EndUse Consumption Submodule are the responses to increased average equipment efficiency and improved building shell efficiency. The proportional change in the marginal cost of service provision due to movement in each of the aforementioned factors relative to their base year values is calculated, and combined with the price elasticity of service demand parameters to yield the computed effect on fuel consimption, as shown by the second and third terms of equation B-88. Because these modifications to the basic consumption estimate are each multiplicative, equation B-88 is capable of accommodating independent changes in each of the underlying driver variables (fuel price, average equipment efficiency, and building shell efficiency) regardiess of the directions of movement. While the rebound effect due to equipment efficiency improvement is considered for the end-use services of space heating, space cooling, water heating, ventilation, cooking, and lighting, the effect due to building shell improvement is considered only for space heating and space cooling.

A final modification to the basic estimate of fuel consumption is made in the form of a weather correction, which accounts for known weather abnormalities during historical years of the forecast period, and differences between the base year (1992) weather and "average" weather anticipated for future years. The basis for the weather correction is the number of heating and cooling degree days by Census Division for the years 1990 through 1995, together with the long term average of each. Because 1992 is the base year for the key Commercial Module parameters, the basic forecast for consumption in other years to provide space heating and space cooling is modified by considering the heating and cooling requirements in that year relative to those prevailing in 1992. This is accomplished using a multiplicative factor equal to the ratio of the appropriate degree days, as shown by equation B-89. Values for 1997 have been extrapolated using data through August of that year. Years after 1997 are assumed to exhibit the longterm average number of heating and cooling degree days, by Census Division.

Applying the price elasticity and-rebound effect considerations, together with the weather correction, to the basic estimate of fuel consumption by end-use provides an enhanced forecast of demand for the major fuels of electricity, natural gas, and distillate by equipment directly satisfying the 10 basic end-use services. Consumption of the minor fuels of residual oil, liquid petroleum gas, steam coal, motor gasoline, and kerosene is calculated using a different 
approach, as is consumption for purposes not yet explicitly modeled. These include consumption for the cogeneration of electricity, consumption'to provide district services, and "non-building" consumption (consumption in the commercial sector not attributable to end-uses within buildings, such as street lighting).

With the exception of motor gasoline, consumption of the minor fiels is forecast using elasticities derived from historical minor fuel consumption and pricing data. The historical data, obtained from the State Energy Data System (SEDS), spans the 23 year period from 1970 to 1992, for each Census Division. The estimated elasticities are applied to the forecasted minor fuel price to yield a forecasted minor fuel EUI. Combining this EUI with the forecasted commercial floorspace produces the forecast of minor fuel consumption. The entire calculation is given by equation B-94.

Motor gasoline consumption is forecast by replicating SEDS data for the years 1990 through 1994, followed by the Short Term Energy Outlook (STEO) forecast for 1995 through 1998, after which a growth rate derived from the . SEDS historical analysis is applied to obtain the forecast for future years. The approach is shown by equations B-95 and $B-96$.

The End-Use Consumption Submodule also forecasts the amount of planned and unplanned nonutility generation of electricity by the commercial sector (cogeneration), together with the incremental quantities of fuels consumed in order to provide the cogeneration. The baseline forecast of cogenerated electricity by fuel and Census Division for the years 1993 and 1994 is derived from processing of form EIA-867 survey results. Corresponding quantities for future years are forecast by considering floorspace growth and fuel prices, together with cross-price elasticities between the major and minor fuels and electricity, as shown by equation B-97. In addition, several fuels are involved with the cogeneration process for which cross-price elasticities are unavailable or not applicable. These : additional fuels are the renewable fuels together with cogenerating fuels not considered elsewhere in the NEMS Commercial Sector Demand Module, and include hydroelectric power, geothermal, municipal solid waste, biomass, solar, other gaseous fuels, nuclear, and wind energy sources. Equation B-98 shows the cogenerated electricity. calculation for these fuels, indicating the assumption that their use for commercial sector cogeneration grows proportionately with commercial floorspace. The forecast of total electricity cogeneration is disaggregated into planned and unplanned components for reporting purposes using an input historical ratio, as shown by equations B99. and B-100. For production of the AEO98, the proportion of cogenerated electricity that is unplanned was calculated using an historical ratio of .3298 . In addition, an assumption is made that all cogenerated electricity is sold to the grid, as indicated by equation B-101.

- Having obtained the forecast of electricity produced by cogeneration, the next step involves the calculation of the incremental quantities of fuels consumed during the cogeneration process. The fuel consumption is referred to as 
incremental because equipment used for cogeneration usually serves another function, which would require fuel consumption even in the absence of cogeneration of electricity. The assumption that the electricity cogeneration is a byproduet of the generation of only that amount of thermal energy that would be needed in the absence of cogeneration is used, together with an input ratio of generated thermal energy to cogenerated electricity, to compute . the amount of useful thermal energy produced. An additional input parameter characterizing the difference in equipment efficiency when producing useful thermal energy in cogeneration mode as opposed to noimal operation; by fuel, is used to compute the incremental fuel consumed during the cogeneration process. Specifically, the parameter is equal to the difference between the reciprocal of the efficiency of cogenerating equipment in generating thermal energy only and the reciprocal of the efficiency of comparable equipment which is only used to meet a : service demand, by fuel. The calculation of fuel use is given by equation B-102. Equation B-103 simply reflects the accounting for electricity cogeneration fuel consumption in the total forecast by the End-Use Consumption Submodule.

The final component of the forecast asseribled by the End-Use Consumption Submodule is an estimation of the quantities of fuel consumed in order to provide the district services of space heating, space cooling, and water heating. District services involve the localized production of steam energy that is used to provide distributed end-use services over a wide area, such as a campus environment. Estimates of the steam energy EUI by Census Division, building type, and end-use service for district services were prepared separately from those previously described for the standard end-use services. These are used in conjunction with typical efficiencies and fuel shares for the boilers providing district services, together with the floorspace forecast, to produce the forecast of fuel consumption for district services, as shown by equation B-104.

The consumption forecast by Census Division; fuel, and building type is incremented by the district service consumption estimate just described, as shown by equation B-106. Aggregation of this result across building types yields the forecast of fuel consumption by fuel and year at the Census Division level required by the other NEMS modules, as shown by equation B-108. Another aggregation across fuels and Census Divisions is performed to obtain the national-level forecast of total energy consumption by building type, to which is added the use of solar thermal energy for space heating and water heating, as shown by equation B-109. Additional results are also aggregated in various ways to satisfy reporting requirements, as illustrated by the End-Use Consumption equations not discussed. One final consumption component, that of nonbuilding consumption, is calculated in the Benchmarking Submodule, described in the next section. 


\section{Benchmarking Submodule}

The Benchmarking Submodule reconciles the fuel consumption forecast produced by the End-Use Consumption Submodule with data from the State Energy Data System (SEDS). SEDS represents the collection of historical fuel consumption data chosen to serve as a.standard for the NEMS system over the historical period of the forecast. Additionally, the Benchmarking Submodule provides an option for considering results from EIA's Short Term Energy Outlook (STEO) for the near term immediately beyond the last year of SEDS data availability. Definitional differences between SEDS and the Commercial Buildings Energy Consumption Survey (CBECS), upon which the Commercial Sector Demand Module is based, are used to construct a forecast of commercial sector fuel consumption not atributable to end-uses within buildings.

Equation B-110 illustrates the calculation of the "SEDS mistie," or discrepancy between the End-Use Consumption Submodule results and SEDS data, during years for which SEDS data exist. The SEDS data is first corrected for certain components of the commercial data that the NEMS system attributes to other sectors.. These components are represented by the variables TranFromSEDS, which is commercial sector transportation-related consumption, such as that by AMTRAK (modeled by the NEMS Transportation Module), and NUGFromSEDS, which is consumption for nonutility generation (modeled by the NEMS Electricity Market Module).

Because SEDS data are estimates of all consumption by the commercial sector, whereas CBECS applies only to consumption within commercial buildings, the difference between the End-Use Consumption 'Submodule's CBECSbased fuel consumption forecast and the adjusted SEDS data is attributed to fuel consumption for nonbuilding uses, as shown by equation B-111. This assignment is performed during each year of the forecast period for which SEDS data is available. The use of the SEDS data through the year indexed as MSEDYR+1 in these calculations reflects the fact that reliable estimates of SEDS data are available for an additional year beyond the latest published SEDS results, and are used in the same manner as published SEDS data.

After the final year of SEDS data availability, fuel consumption for nonbuilding uses is forecast to grow at the same rate as commercial floorspace. This expectation follows from the observation that, while not representing fuel consumption within buildings, the nonbuilding uses are generally asseciated with commercial buildings, as in the case of exterior lighting of parking lots. The forecast of SEDS-based consumption of major and minor fuels other than distillate oil for nonbuilding uses beyond the last year of SEDS data availability is shown by equation B-113. Nonbuilding use of distillate oil is not expected to grow at the same rate as commercial floorspace, but instead to remain at a relatively constant level, as illustrated by equation B-115. 
An option is present in the Commercial Sector Demand Module to activate benchmarking to that portion of the STEO forecast immediately following the last year of SEDS data. This is accomplished through the setting of a NEMS system-wide parameter named STEOBM. If selected, the benchmarking is incremental; that is, it is calculated based on the forecast produced after benchmarking to SEDS. For years covered by the short-term STEO forecast, the calculation of the discrepancy between the SEDS-benchmarked forecast and STEO is given by equation B-112 for the major and minor fuels except distillate oil. Equation B-114 gives the corresponding calculation for distillate oil. Equation B-116 shows the addition of the STEO-based incremental component of nonbuilding consumption to the component based on SEDS.

In the event the STEO benchmarking option is chosen, one of two options for avoiding a discontinuity in the benchmarked forecast beyond the last year of STEO data must also be selected. The simplest option is to retain the STEO component of nonbuilding use calculated for the last year of STEO data availability, and apply it to all future years of the forecast period. Alternatively, the STEO component of nonbuilding use can be ramped down to zero over a specified time period following the last year of STEO data. The choice of methods is specified through the Commercial Module user parameter named DecayBM. Calculation of a time-dependent decay factor based on the selection of the various options is illustrated by equation B-117. B-118 illustrates the optional addition of a STEObased component of nonbuilding consumption to that based on SEDS, for forecast years after the final year of STEO data availability.

Addition of the forecast of fuel consumption for nonbuilding uses to that produced by the End-Use Consumption Submodule for end-uses within buildings completes the forecast of commercial sector fuel consumption, as shown by equation B-119. 


\section{[This page intentionally left blank]}




\section{Appendix A}

\section{Introduction}

This Appendix describes the input data, parameter estimates, variables, and data calibrations that currently reside on EIA's computing platform for the execution of the NEMS Commercial Module. These data provide a detailed representation of commercial sector energy consumption and technology descriptions that support the module. Appendix A also discusses the primary module outputs.

Table A-1 references the input data, parameter estimates, variables, and module outputs documented in this report. For each item, Table A-1 lists an equation reference to Appendix B of this report, a subroutine reference, the item definition and dimensions, a subroutine reference, the item classification, and units. Note that all variables classified as "Calculated Variable" can also be considered to fall into the "Output" classification, as they are located in common blocks accessible to other NEMS modules and external programs. Following Table A-1 are profiles of the data items. Each profile describes the data sources, analytical methodologies, and parameter estimates corresporiding to the table.

The remainder of Appendix A contains supporting discussion including data selection and calibration procedures, required transformations, levels of disaggregation, and model inpụt files. . 
Table-A-1. NEMS Commerclal Module Inputs and Outputs

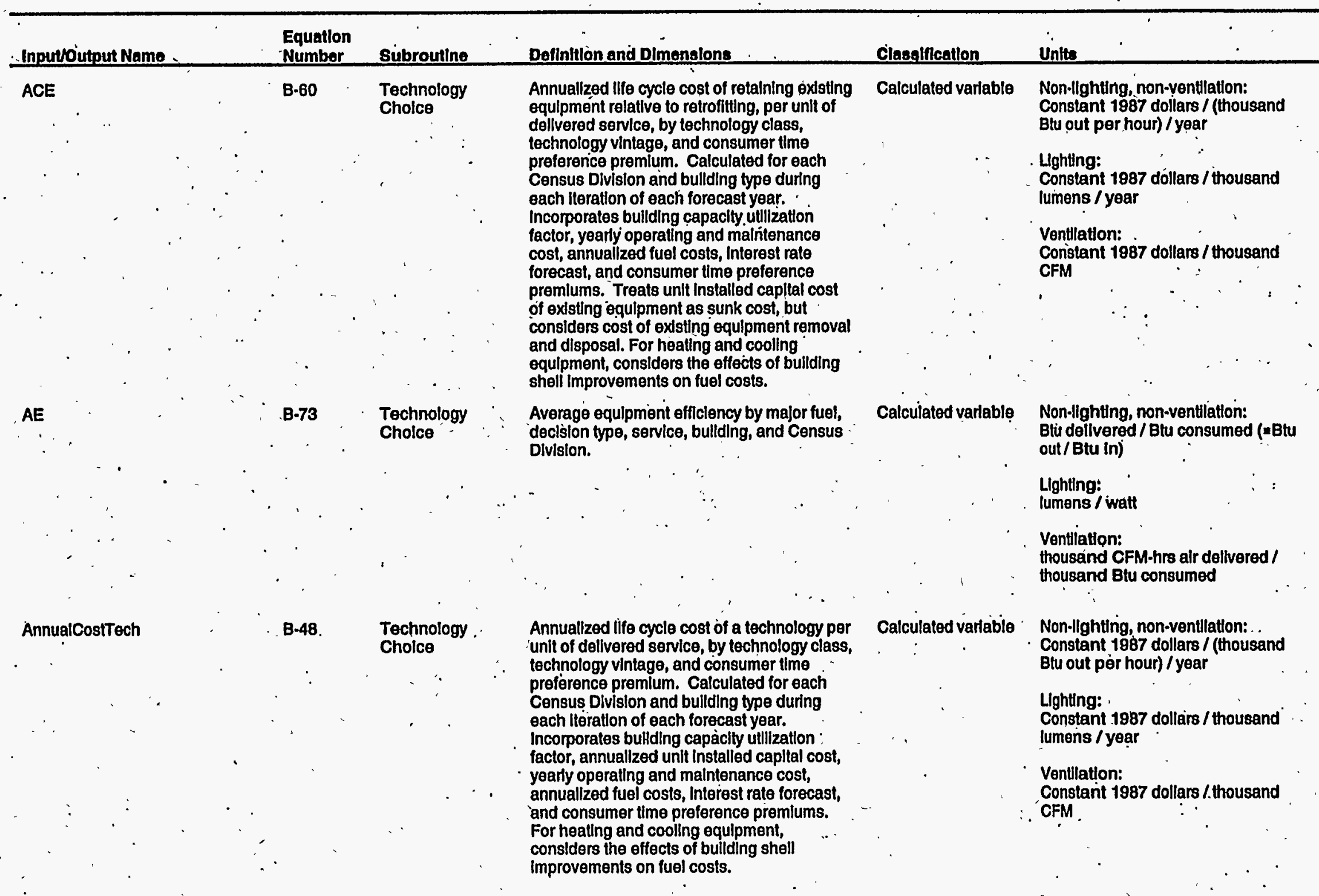


Table A-1. NEMS Commerclal Module Inputs and Outputs (Continued)

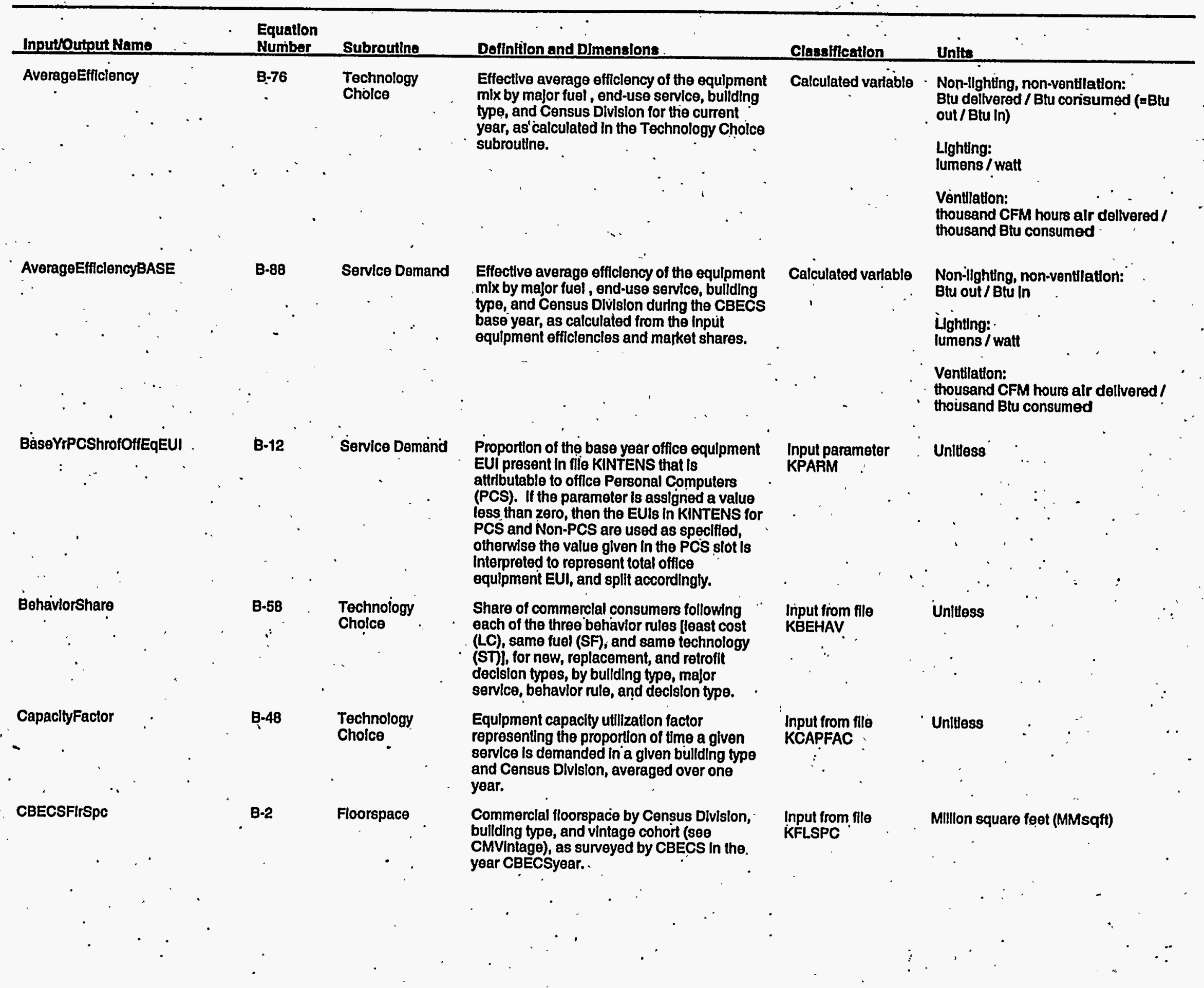


Table A-1. NEMS Commercial Modụle Inputs and Outputs (Continued)

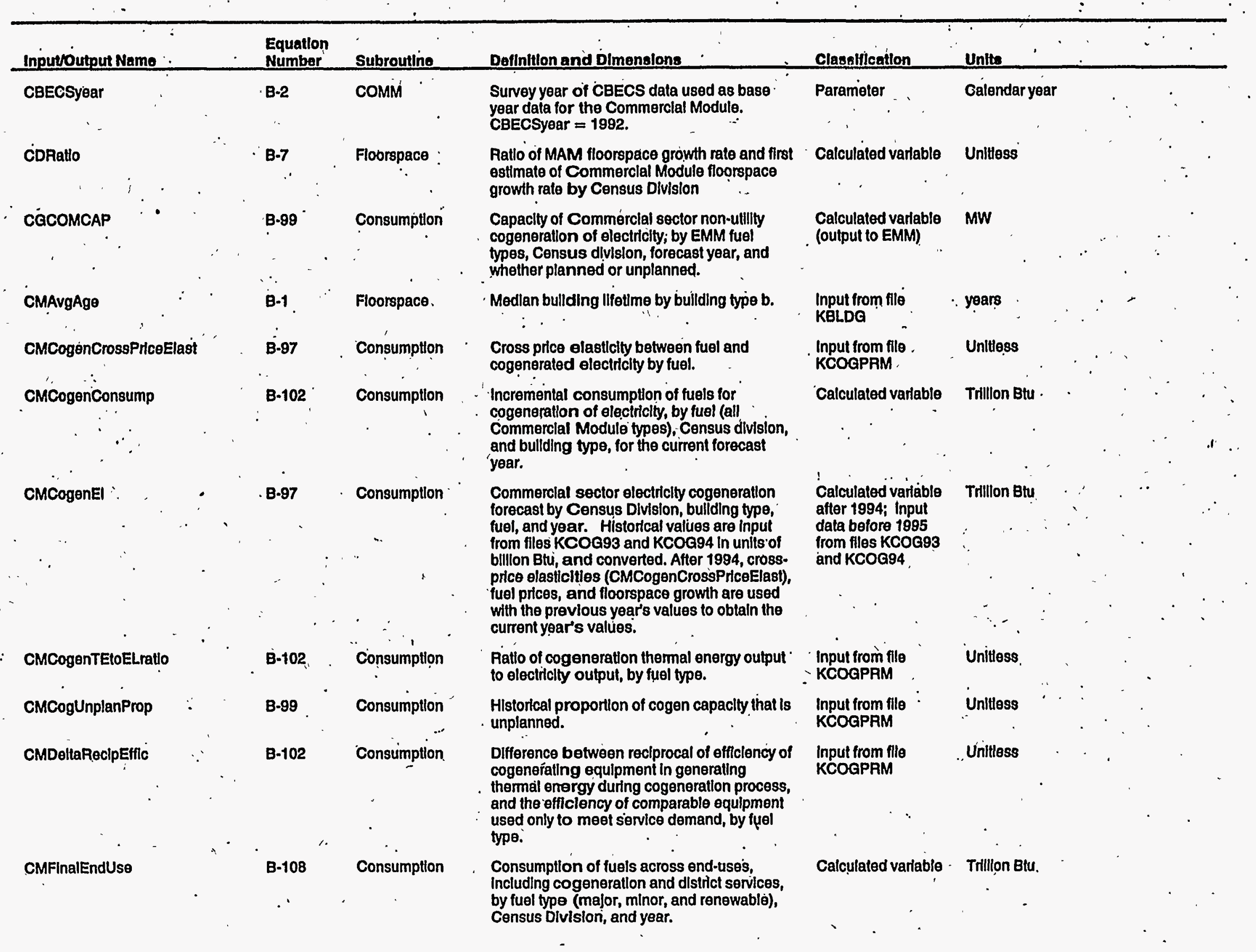


Table A-1. NEMS Commerclal Module Inputs and Outputs (Continued)

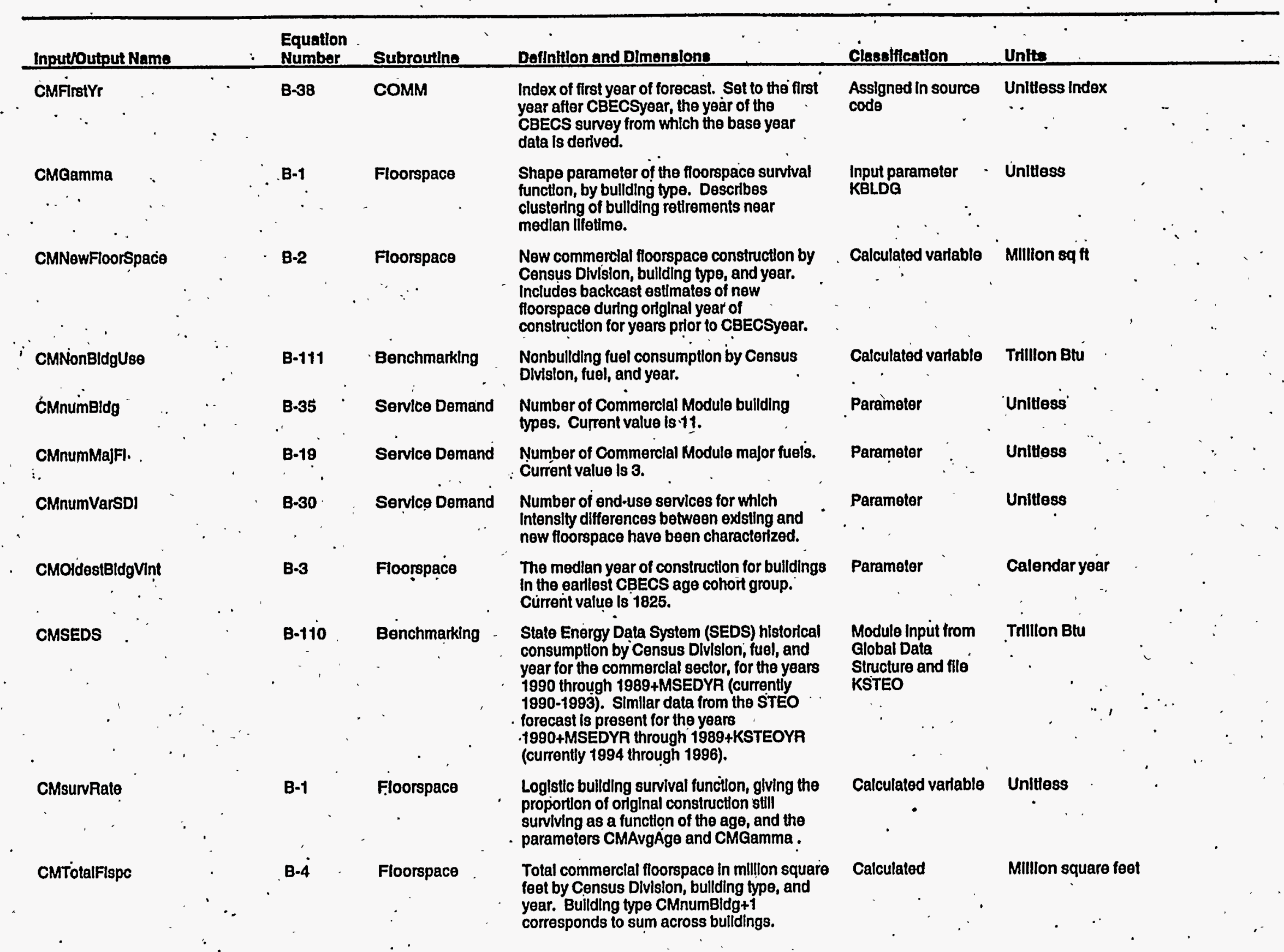


Table A-1. NEMS Commercial Module Inputs and Outputs (Continued)

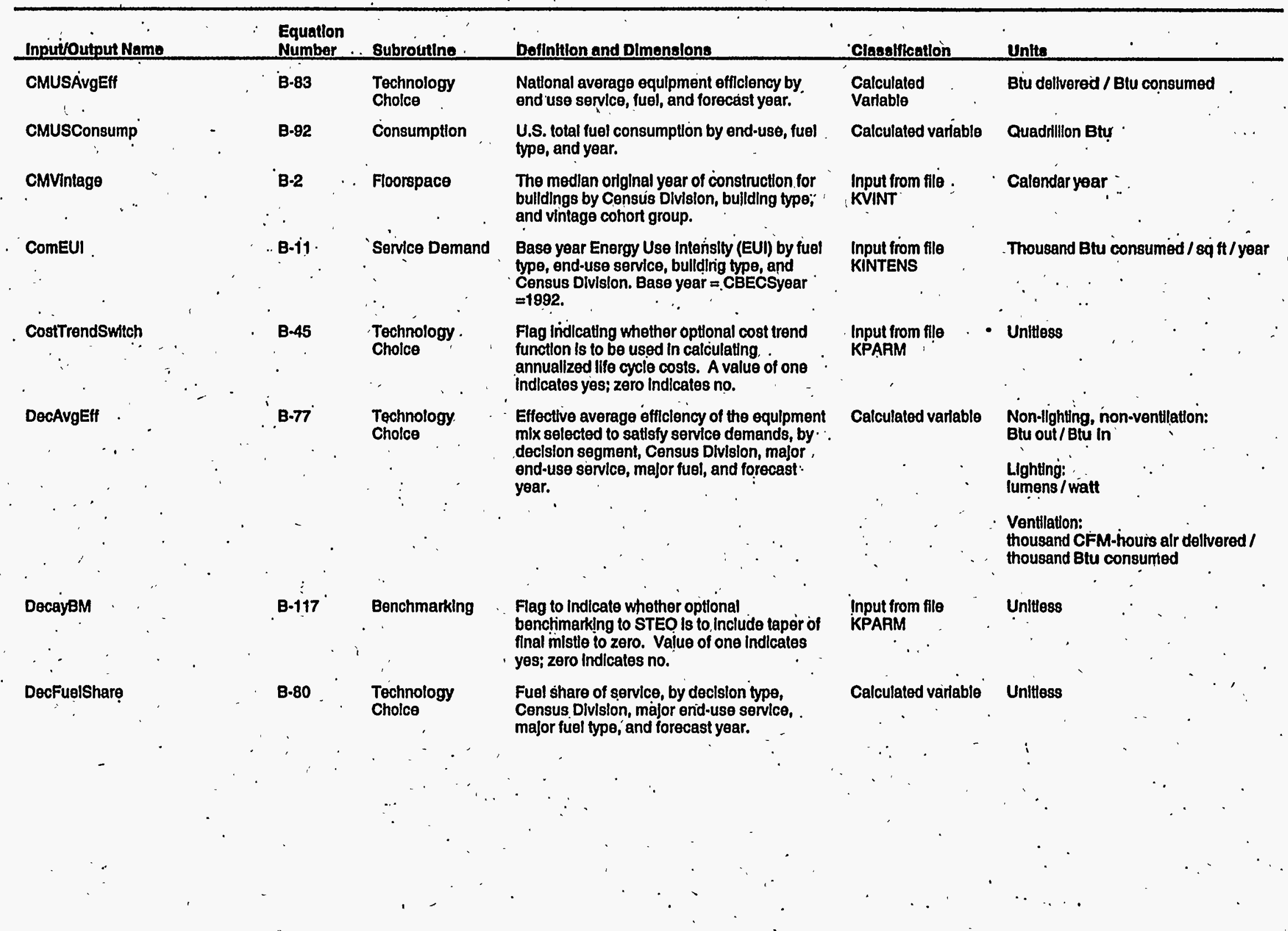


Table A-1. NEMS Commerclal Module Inputs and Outputs (Continued)

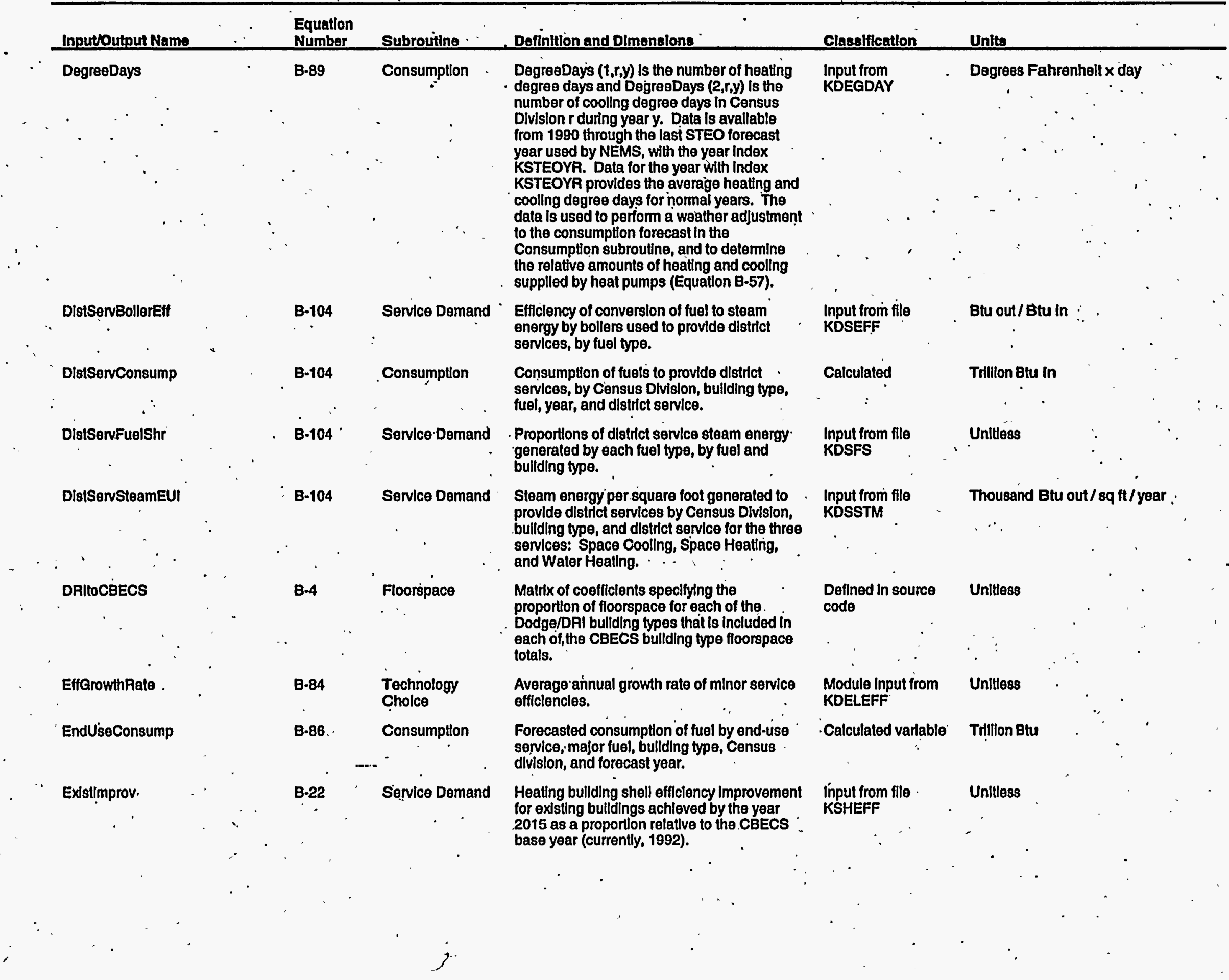


Table A-1. NEMS Commerclal Module Inputs and Outputs (Continued)

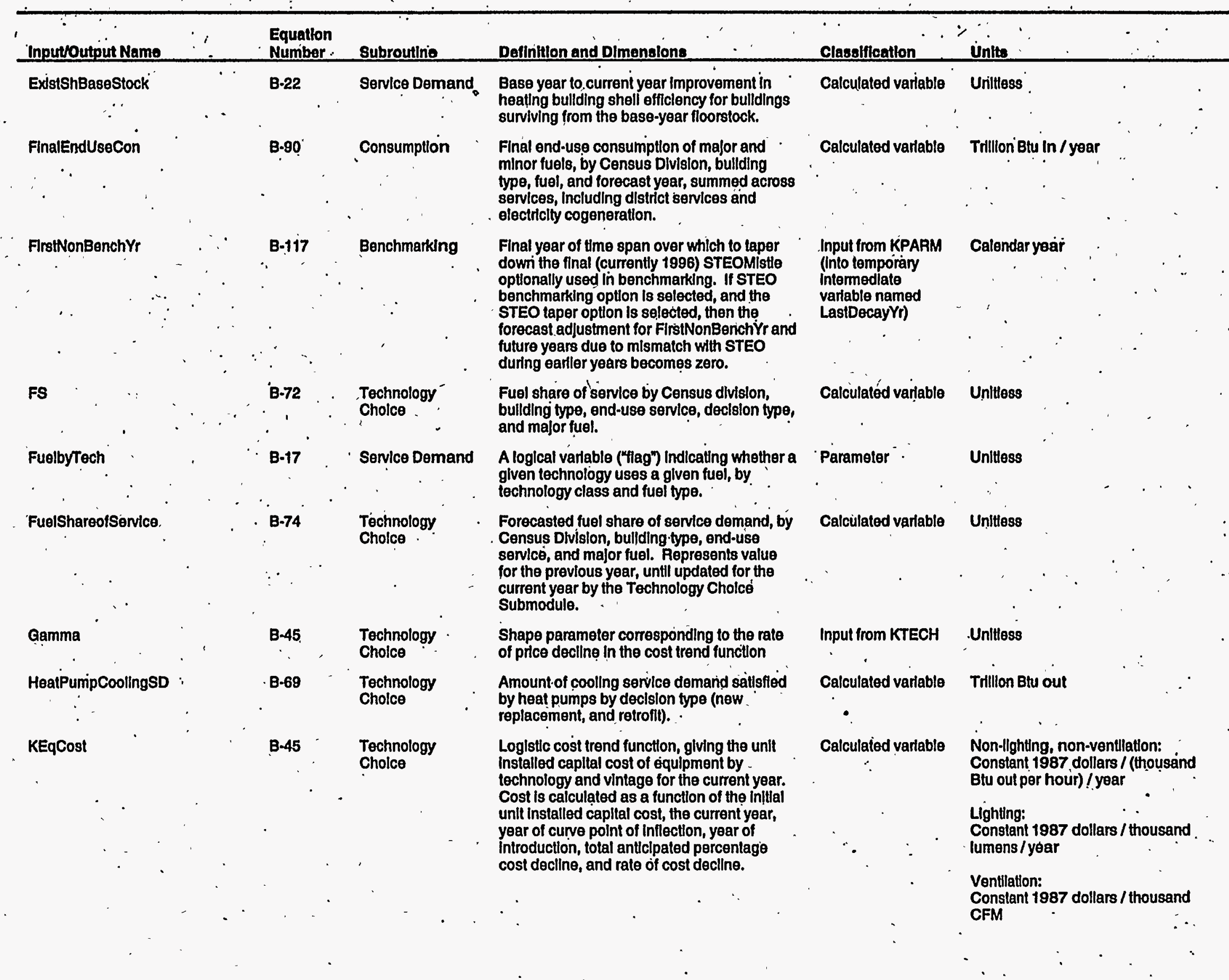


Table A-1: NEMS Commerclai Module Inputs and Outputs (ContInued)

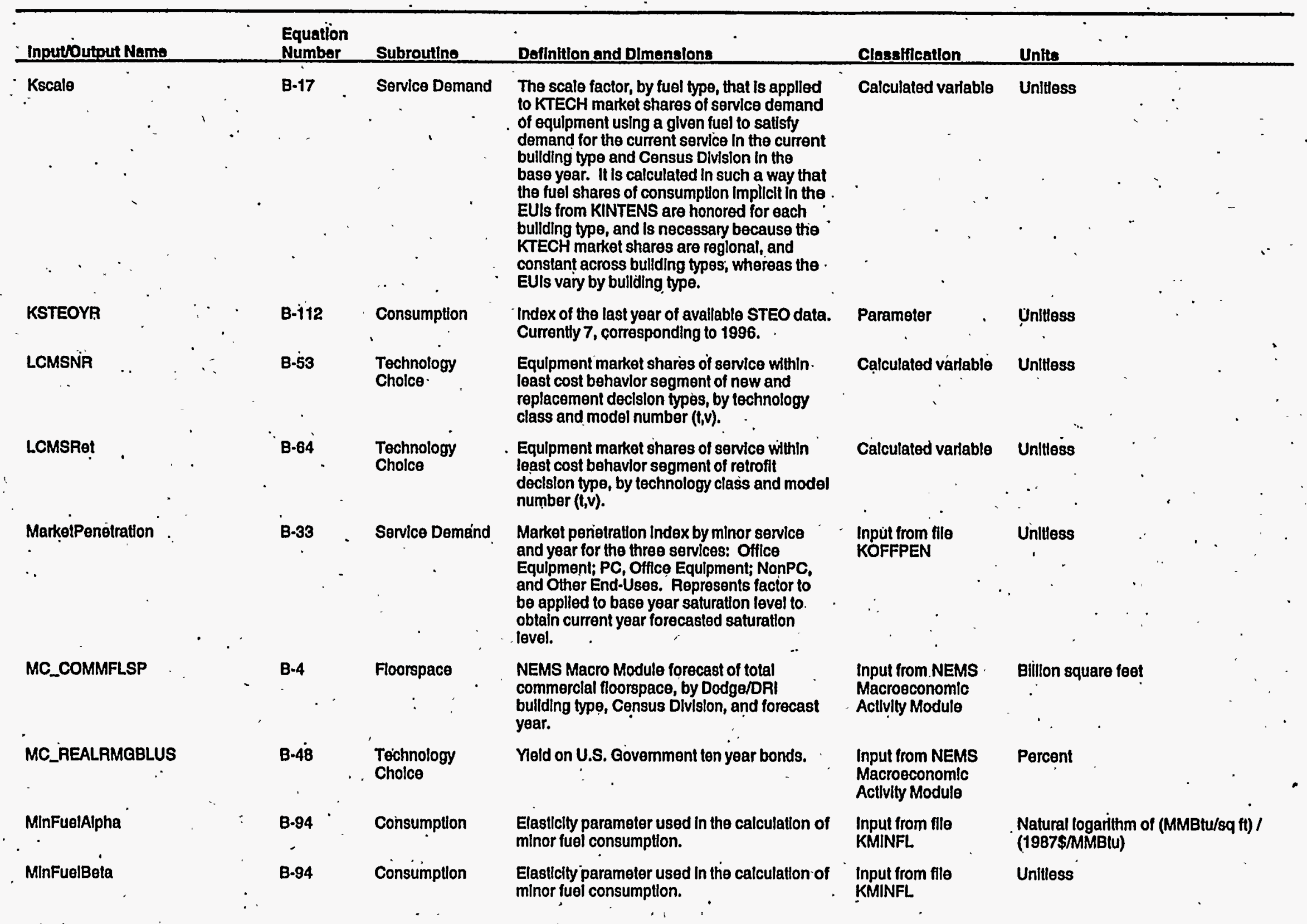


Table A-1. NEMS Commorclal Module Inputs and Outputs (Contlinued)

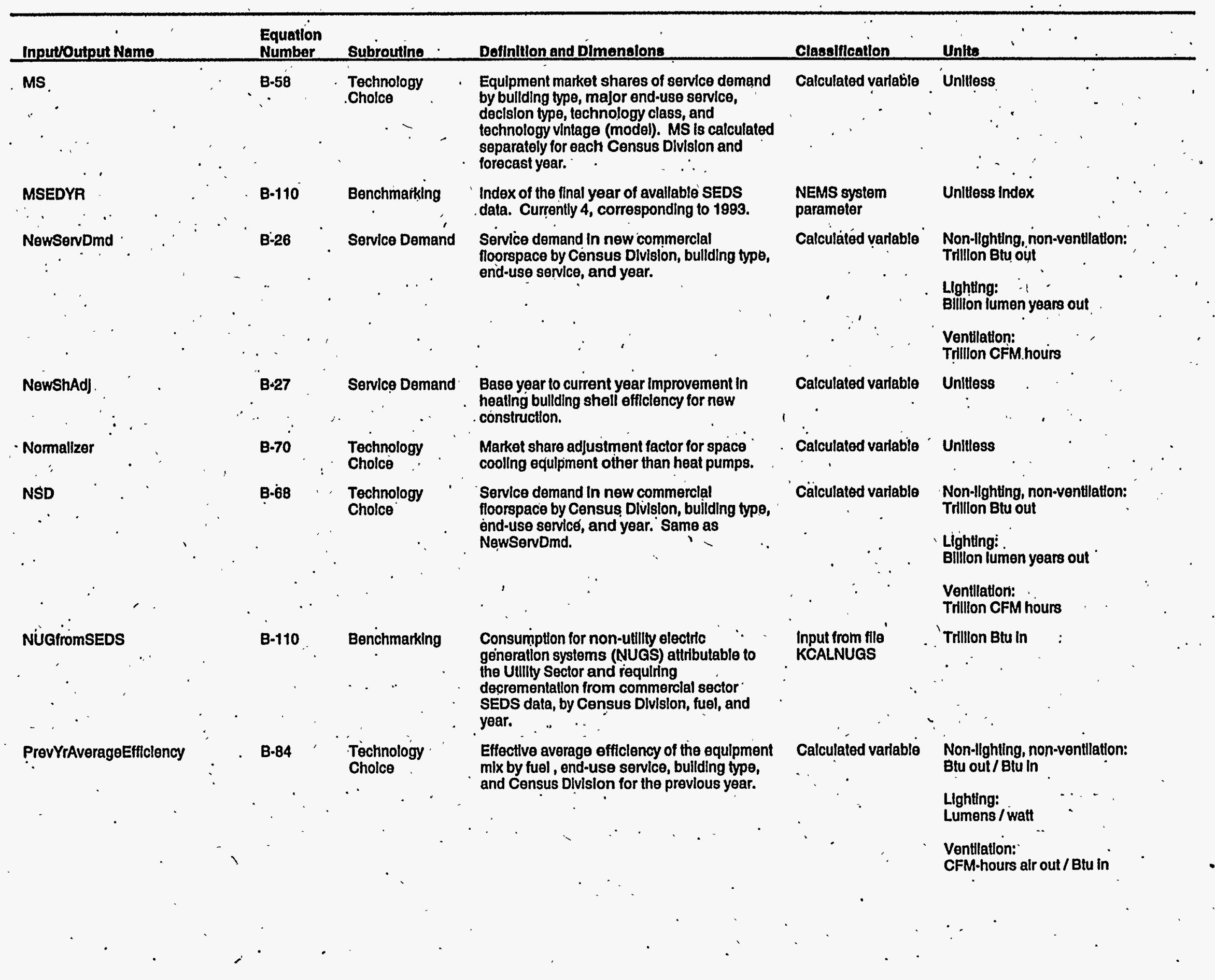


Tablo A-1. NEMS Commerclal Module Inputs and Outputs (Continued)

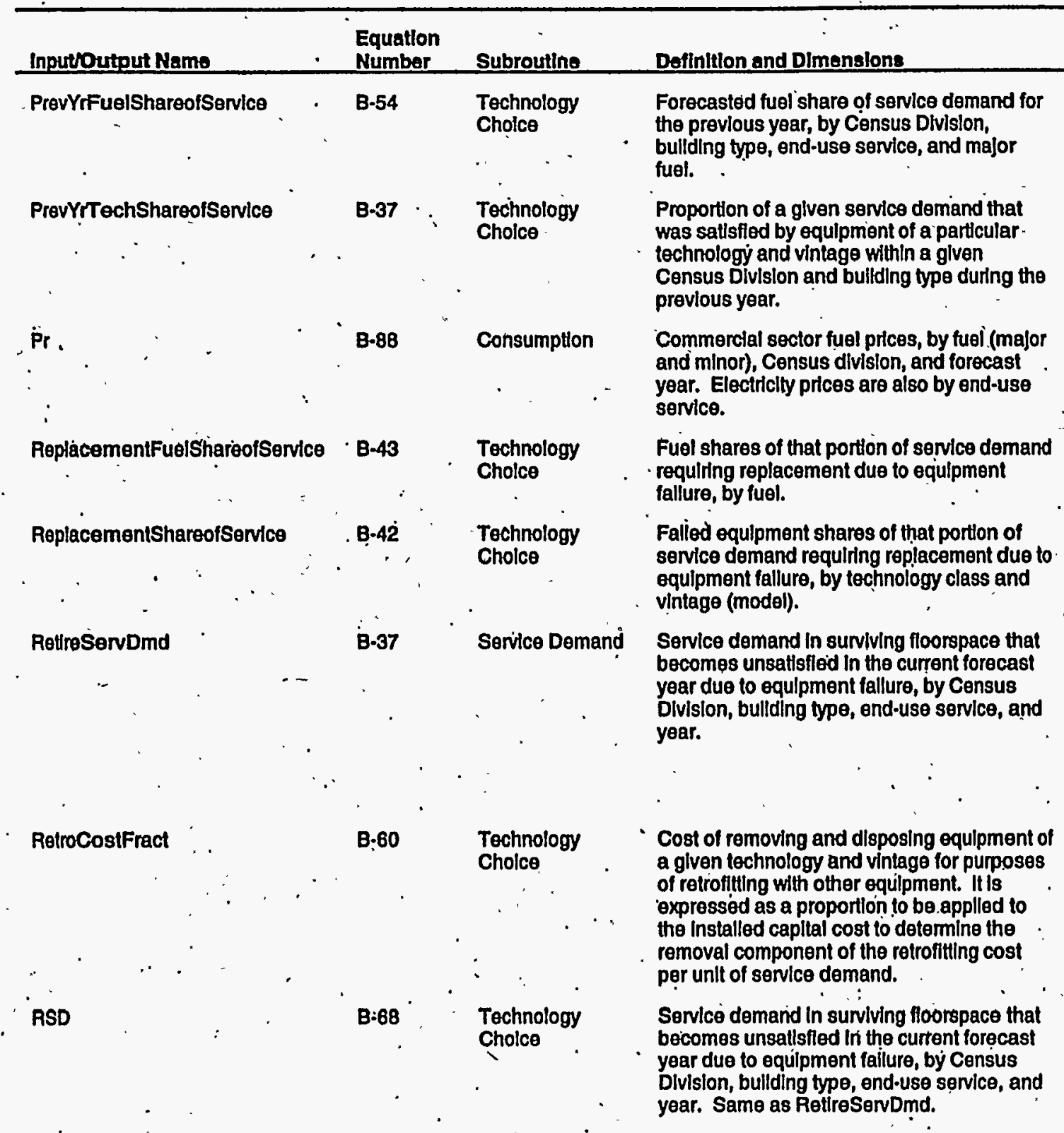

Classification

Units

Calculated variable Uniliess

Calculated variable Unittess

Input from

appropriate NEMS

supply soctor

modules.

Calculated

Unittess

Calculäted . . Unitiess

Calculated varlable

Non-llghting, non-ventllation: Trillion Btu out

Llghting:

Billion lumen years out

Ventliation:

Trillon CFM hours

Input from KTECH

Unittess

Calculated varlable

Non-llghting, non-veritllation: Trillon Blu out

$\begin{array}{ll} & \text { Lighting: } \\ \text { - . } & \text { Ellilon lumen years out } \\ \text {. Ventliation: } \\ \text { Trlilion CFM hours }\end{array}$


Table A-1. NEMS Commerclal Module Inputs and Outputs (Contlnued)

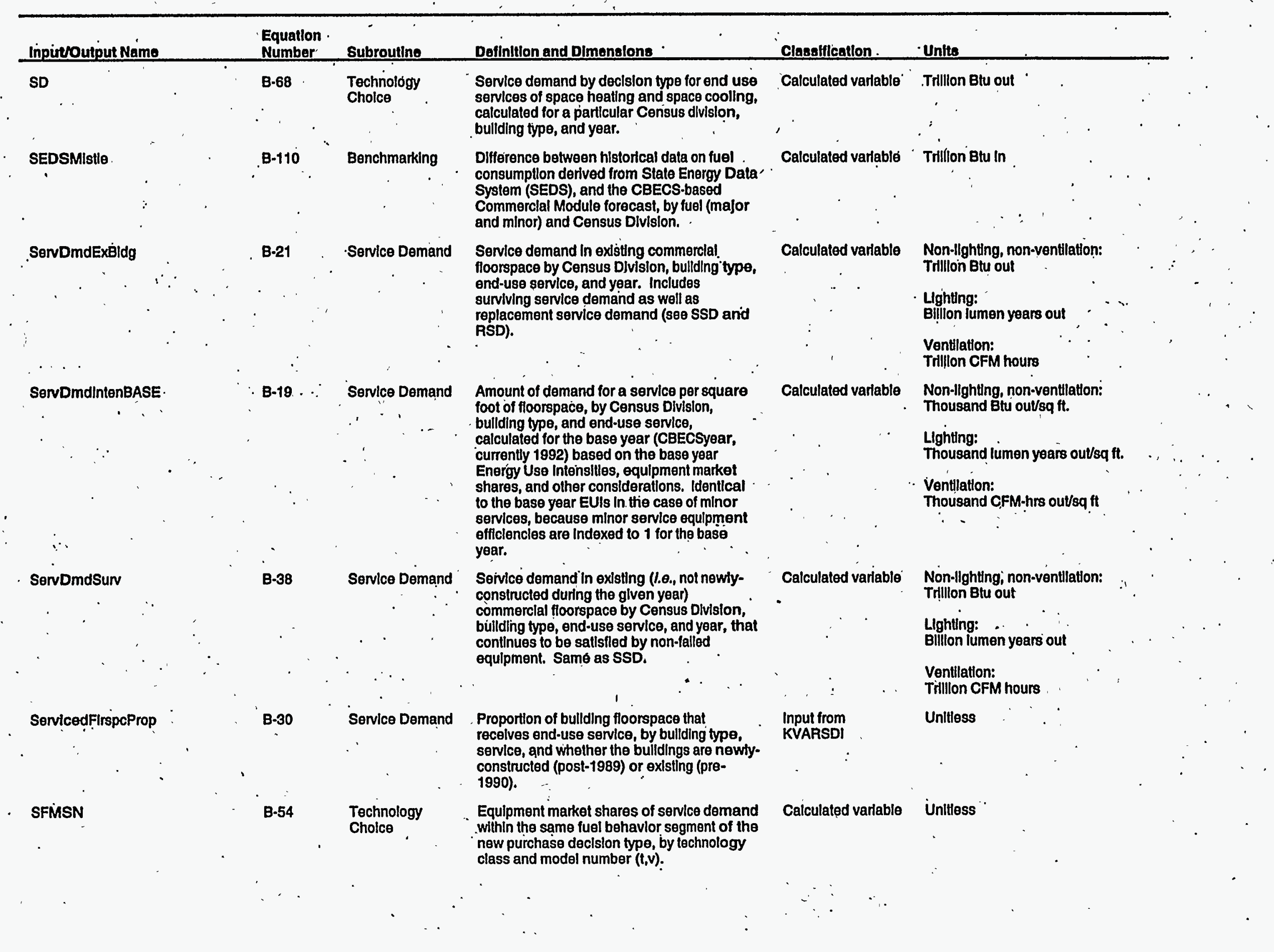


Tablo A-1. NEMS Commerclal Module Inputs and Outputs (Continued)

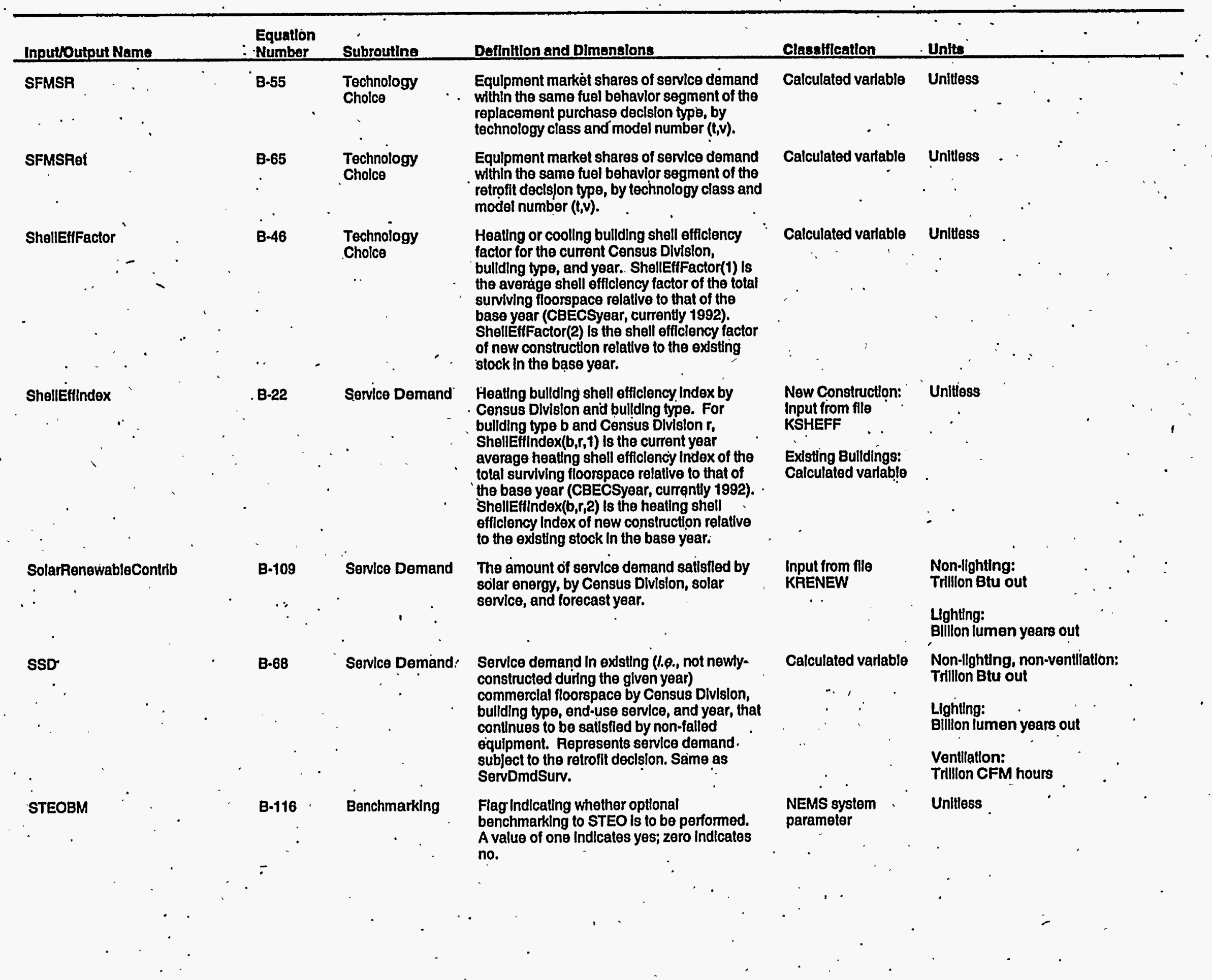




\section{Table A-1. NEMS Commerclal Module Inputs and Outputs (Continued)}

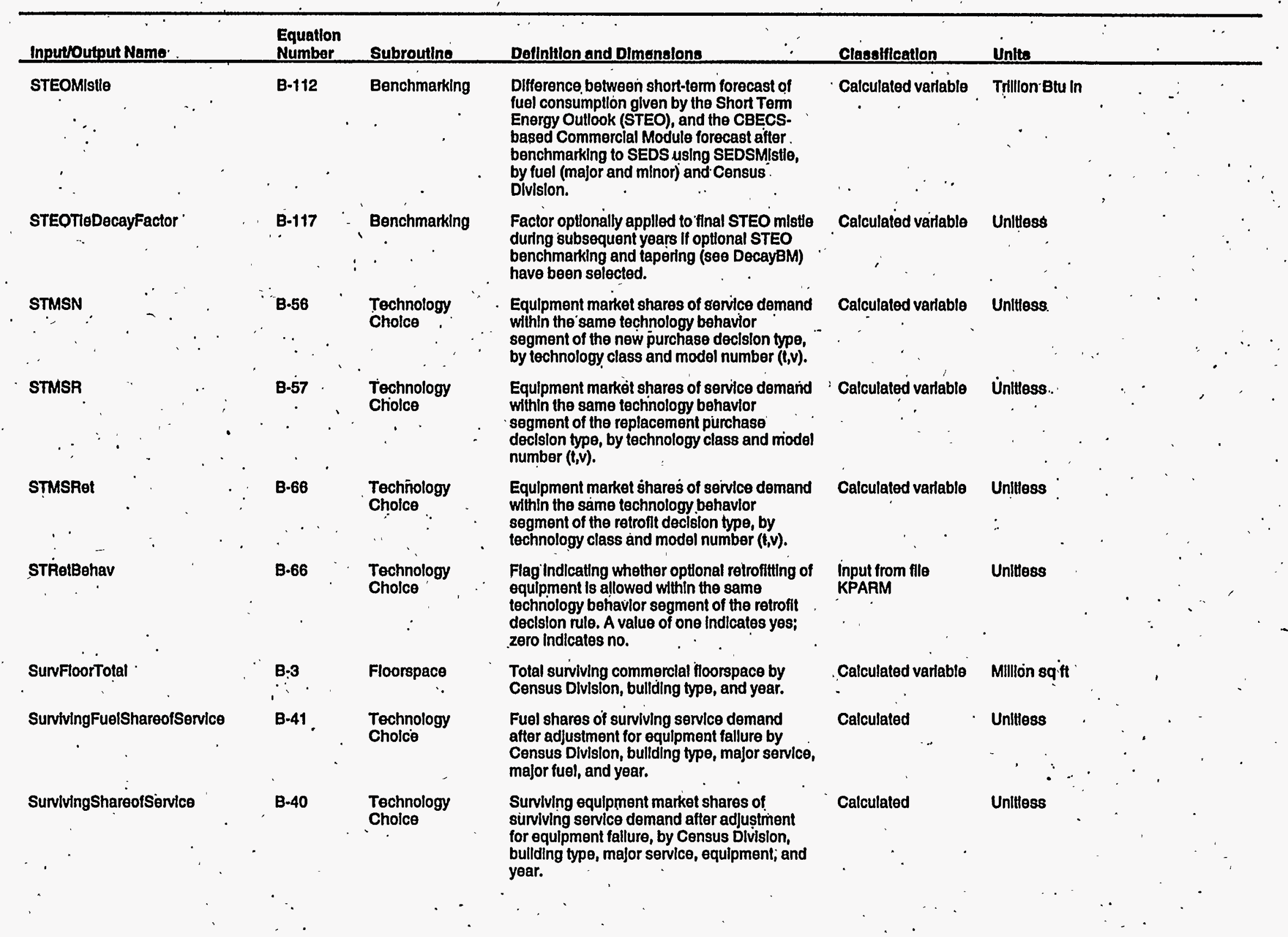


Table A-1. NEMS Commerclal Module Inputs and Outputs (Continued)

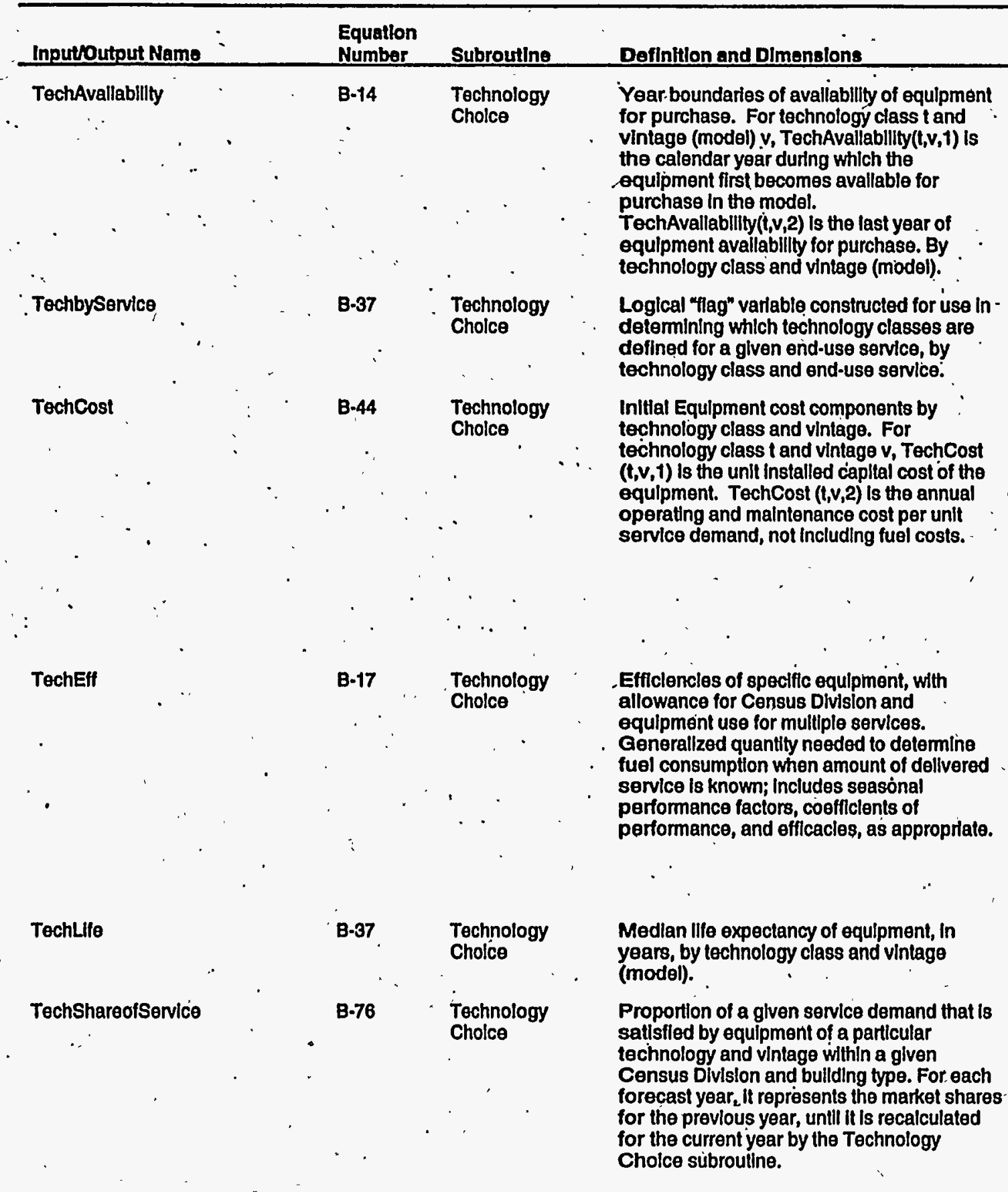

Classiflcation

Unite

Input from KTECH Calendar yoar

Calculated varlable (based on KTECH

- Input)

Input from KTECH

Non-lighting, non-ventlation:

Constant 1987 dollars / (thousand Btu out per hour) / year

Lighting:

Constant 1987 dollars / thousand lumens/yeai

Ventlation:

Constant 1987 dollars / thousand CFM.

Input from KTECH

Non-llghting, non-ventilation: Btu dellvered / Btu consumed (nBtu out / Blu In)

Llghting:

lumens / watt

Ventilation:

thousand CFM-hrs alr delivered/

thousand Btu consumed

Module input from

KTECH

Years; Unittess where used as exponent

Calculated variable 
Table A-1. NEMS Commerclal Module Inputs and Outputs (Continued).

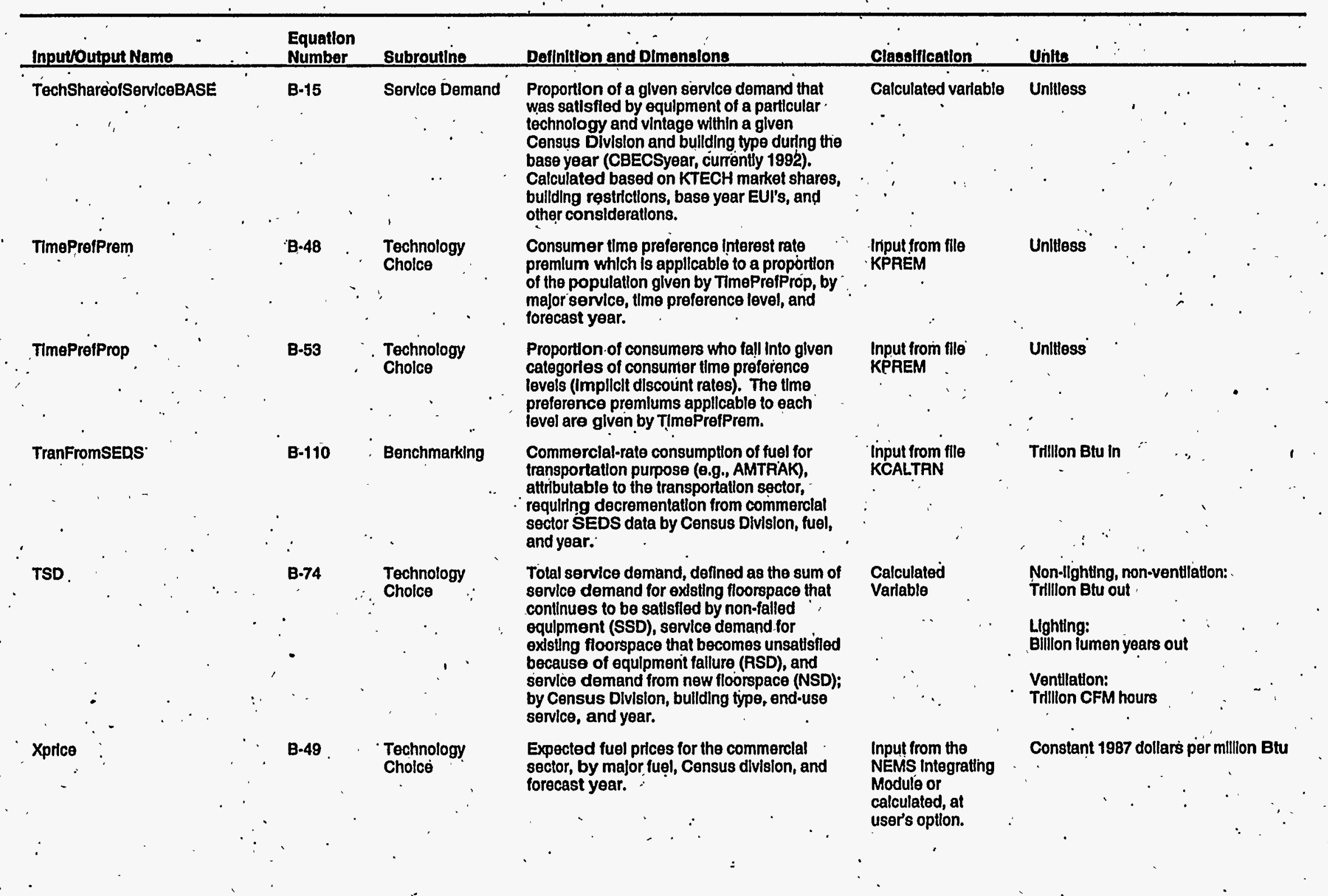


MODELINPUT:

YARIABLENAME:

MODEL COMPONENT:

DEEINTTON:

CLASSIEICATION:
Proportion of base year office equipment EUI attributable to PC use

- BaseYrPCShrofOffÉqEUI

Service Demand

PCS proportion of base year office equipment EUI

Inpirt parameter (KPARM)

\section{DISCUSSTON:}

The 1992 Commercial Buildings Energy Consumption Survey (CBECS 92) provides data on energy consumption by building, and includes data on the number of PCS present in each building surveyed...Pacific Northwest Laboratory (PNL) provides CBECS-derived estimates of the end-use intensities (EUIs) by building type, fuel type, and Census division for the end-use services modeled by the NEMS Commercial Sector Demand Module, by a combination of engineering simulation and Conditional Demand Analysis approaches. This results in estimates for the office equipment EUIs, but without a separate breakout into personal computers (PCS) and other office equipment.

A representative national estimate of the 1992 proportion of office equipment EUI attributable to PC use has been developed by EIA analysts, based on the CBECS data and studies referenced below. Because this estimate is based partly on expert judgement, it is placed in the Commercial Module parameter file, KPARM, where it can be easily updated by other specialists. There is also a mechanism for automatically disabling its use should specific PC EUIs be developed and placed in the EUI input file, KINTENS.

\section{SOURCES:}

J. G. Koomey, M. Cramer, M. Piette, and J. H. Eto. Efficiency Improvements in U. S. Office Equipment: Expected Policy Impacts and Uncertainties. Lawrence Berkeley Laboratory, December, 1995, LBL-37383.

Belzer, D. L. et al, unpublished update to-Belzer, D., L. Wrench and T. Marsh, End-Use Energy Consumption Estimates for U.S. Commercial Buildings, 1989, Pacific Northwest Laboratory; PNL-8946, UC-350, November 1993.

Original work by Eugene Burns and Kristine Mćskimming of the U:S. Department of Energy, Energy . Information Administration. Use Data Diskettes.

Energy Information Administration. Commercial Buildings Consumption and Expenditures 1992, Public 
MODEL INPUT:

VARIABLENAME:

MODEL COMPONENT:

DEEINTTON:

\section{CLASSIEICATION:}

Consumer behavior rule proportions

BehaviorShare

Technology Choice

Proportions of commercial consumers using the least cost, same fuel, and same technology behavior rules for decision type $d$ in building type' $b$

Input from file KBEHAV .

\section{DISCUSSTON:}

These parameters are designed to facilitate model calibration to historical data, so precise specifications are not expected. Nevertheless, professional judgement is applied to éstimate initial values for the proportions by decision type and building type which are consistent with the commercial sector. Building type is used here as a proxy to distinguish different types of commercial sector decision makers, and decision type represents the different economic situations under which technology choice decisions are made.

The judgement estimates are made separately for all government, privately.owned and rented floorspace for the replacement and retrofit decision types. The proportions of floorspace by government, private and rented space from Commercial Buildings Characteristics 1992 are utilized to weight these estimates by building type to yield -replacement and retrofit behavior rule proportions by building type. Similarly, judgement estimates are made for self-built and speculative developer floorspace for the new decision type. These consider estimates of the proportions of self-built and speculative developer floorspace for each by building type to yield new building behavior rule proportions by building type.

\section{SOURCES:}

Decision Analysis Corporation of Virginia and Science Applications International Corporation. Alternative Methodologies for NEMS Building Sector Model Development, draft report, prepared under Contract No. DE-AC0192EI21946, August 3, 1992, p. 14.

Energy Information Administration. Commercial Buildings Characteristics 1992. Washington DC, April 1994, DOE/EIA-0246(92), GPO Stock No. 061-003-00850-0

Koomey, Jonathan G. Energy Efficiency Choices in New Office Buildings: An Investigation of Market Failures and Corrective Policies, Ph. D. Dissertation, University of California at Berkeley, 1990.

'Feldman, S. 'Why is it So Hard to Sell 'Savings' as a Reason for Energy Conservation?" Energy Efficiency: Perspectives on Individual Behavior, Willett Kempton and Max Neiman eds., American Council for an -Energy-Efficient Economy, Washington DC, 1987, pp. 27-40.

Office of Technology Assessment. Building.Energy Efficiency. 'OTA-E-518, U.S. Government Printing Office, Washington' DC, May 1992.

Komor, P. And L. Wiggins. "Predicting Conservation Choice: Beyond the Cost-Minimization Assumption." Energy, Yol. 13, No. 8, 1988, pp. 633-645.

Komor, P. And R. Katzev. "Behavioral Determinants of Energy Use in Small Commercial Buildings: 
Implications for Energy Efficiency." Energy Systems and Pólicy, Vol. 12, 1988, pp. 2333-242.

Vine, E. And J. Harris. "Implementing Energy Conservation Programs for New Residential and Commercial Buildings." Energy Systems and Policy, Vol. 13, No. 2, 1989, pp. 115-139.

Lamarre, L. "Lighting the Commercial World" EPRI Journal, December 1989, pp. 4-15.

Lamarre, L. “New Push for Energy Efficiency." EPRI Joumal, April/May 1990, pp. 4-17. 
MODEL INPUT:

VARTABLENAME:

MODEL COMPONENT:

DEETITION:

CLASSIEICATION:

\section{Equipment Capacity Factor}

CapacityFactor

Technology Choice

Capacity factor of equipment to meet service $s$ in Census Division $r$ in building type $b$.

Input from file KCAPFAC

\section{DISCUSSION:}

The capacity factor is the ratio of actual annual equipment output to output if equipment were run $100 \%$ of the time at full capacity. Space conditioning capacity factors are developed by Census Division, service, and building type from the ratio of average daily load to peak load for space heating and space cooling at 44 selected cities in the EPRI source cited below. The averages for the cities in each Census Division are weighted by population to compute the capacity factors used by the NEMS Commercial Sector Demand Module. Lighting capacity factors vary by building type and are based upon the ratio of average hours of operation to total hours from Lighting in Commercial Buildings. Capacity factors for the remaining services are derived by service and building type from the ratio of operating hours to total hours in the building load profiles in the EPRI source.

\section{SOURCES:}

Decision Focus, Inc. TAG Technical Assessment Guide, Vol. 2: Electricity End Use; Part 2: Commercial Electricity Use -- 1988. Palo Alto CA, Electric Power Research Institute, October 1988, pp. 4-5 to 4-29, 9-10 to 927.

Energy Information Administration. Energy Consumption Series: Lighting in Commercial Buildings. DOE/EIA-0555(92)/1. Washington DC, March 1992. p. 38. 
MODEL INPUT:

VARIABLENAME:

MODEL COMPONENT:

DEEINITION:

CLASSIFICATION:
Base year commercial floorspace

\section{CBECSFIrSpc}

Floorspace

Commercial floorspace by building type $b$ in Census Division $r$ for 1992

Input from file KFLSPC

\section{Discussron:}

A straightforward aggregation of weighted survey data from CBECS 92 was used to compute 1992 levels of commercial floorspace for each of the 11 building categories and nine age ranges ("vintage cohorts" - see

CMVintage) in each Census division. The mapping used to transfer from the CBECS building classifications to the building type classification scheme used by the NEMS Commercial Sector Demand Module is shown in the table below:

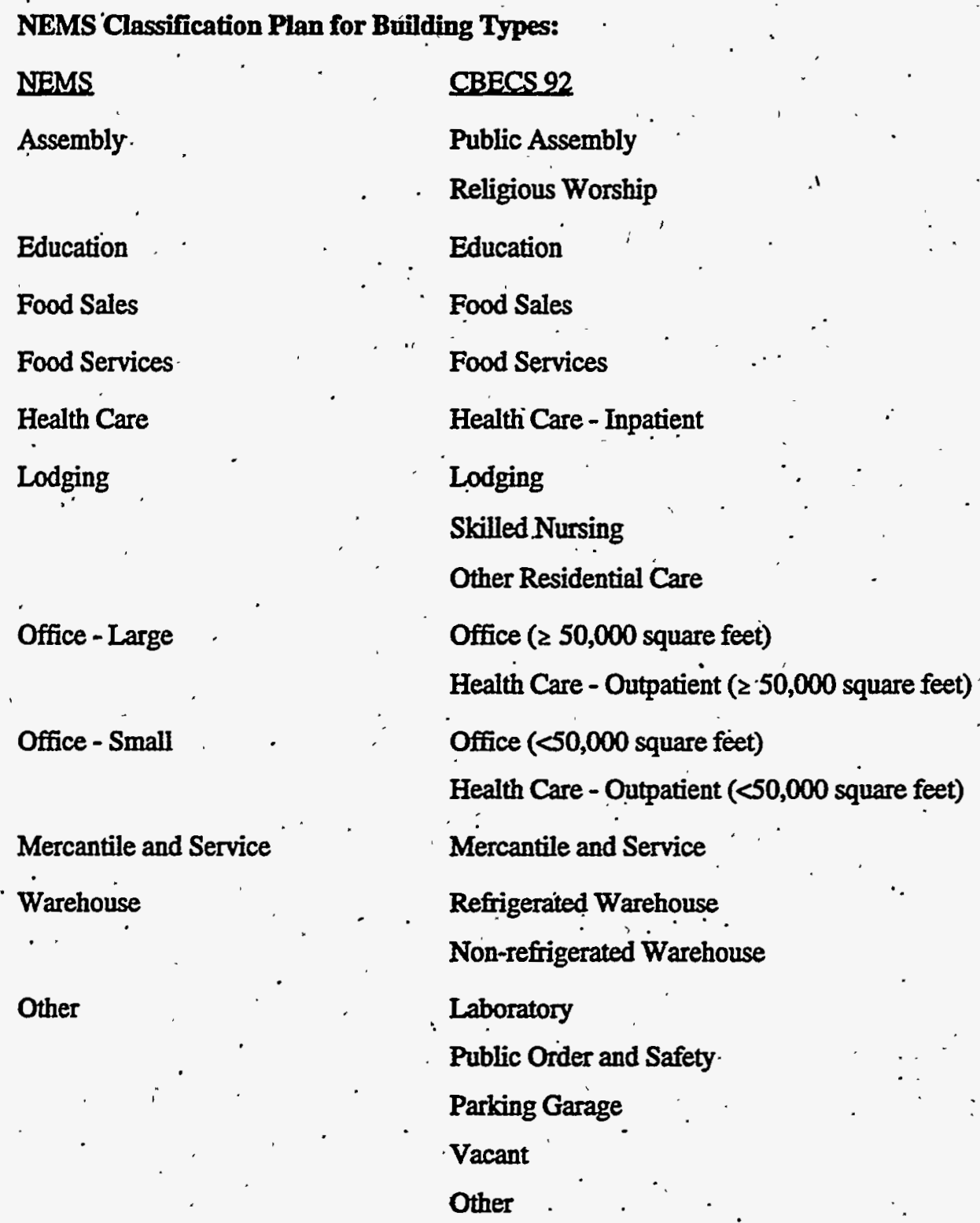

Other

Laboratory

Public Order and Safety.

Parking Garage

Vacant

Other 


\section{SOURCES:}

Energy Information Administration. Commercial Buildings Consumption and Expenditures 1992, Public Use Data Diskettes:

Energy Information Administration. Commercial Buildings Characteristics 1992. Washington DC, April 1994, DOE/EIA-0246(92), GPO Stock No. 061-003-00850-0 
MODEL TNPUT:

YARIABLENAME:

MODEL COMPONENT:

DEEINITION:

CLASSIITCATION:
Expected building lifetimes

\section{CMAvgAge}

Floorspace.

Median building lifetime by building:type $b$

Input from file KBLDG

\section{DISCUSSION:}

The sources cited below provided various estimates of average building lifetimes for the building types considered by the NEMS Commercial Sector Demand Module. Where estimates differed between the sources, a simple average value was used. In some cases, NEMS analysts' judgement provided building lifetimes that overrode the published values because of differing interpretations of the concept of "useful". lifetimes, and the need to insure that the particular building survival function used performed in accordance with historical data. Insufficient data addressing median expected commercial building usage lifetimes were available to enable disaggregation to the Census division level; consequently, a characterization at the national level was developed based on the following sources:

\section{SOURCES:}

Hazilla, M., and R. Kopp. "Systematic Effects of Capital Service Price Definition on Perceptions of Input Substitution." Journal of Business and Economic Statistics. April, 1986, pp. 209-224.

Electric Power Research Institute. Commercial End-Use Data Development Handbook: COMMEND Market Profiles and Parameters, Vol. 2: COMMEND Data and Parameter Development Techniques. Regional Economic Research, Inc. San Diego, California. EM5703, April.1988, p. 2.24. 
MODET INPUT:

YARIABLENAME:

MODEL COMPONENT:

DEEINTHON:

CLASSIEICATION:
Cross price elasticities

CMCogenCrossPriceElast

Consumption

Cross price elasticity between fuel and cogenerated electricity by fuel Input from file.KCOGPRM

\section{DISCUSSTON:}

Cross price elasticities were developed by model calibration conducted in such a way that historical cogeneration results surveyed with Form EI-867 were closely matched when corresponding fuel prices were used.

\section{SOURCES:}

Energy Information Administration. Form El-867 Survey of Independent Power Producers Public Usè Data Diskéttes. 
MODEL INPUT:

VARTABLENAME:

MODEL COMPONENT:

DEEINITION:

CLASSIGICATION:
Cogeneration of electricity by commercial sector facilities

CMCogenEl

End-Use Consumption

Commercial sector cogeneration forecast by fuel $f$ to meet service demand $s$ in Census Division $r$

Calculated variable after 1994; Input from files KCOG93 and KCOG94 prior to 1995

\section{DISCUSSION:}

Historical data for commercial sector SIC codes from the EI-867. Survey of Independent Power Producers for the years 1993 and 1994 forms the basis for the forecast of cogenerated power by fuel and Census Division. The EI-867 surveys generating facilities of $5 \mathrm{MW}$ or more, and.with $1 \mathrm{MW}$ or more, at two different levels of detail (less detail is provided for producers smaller than $5 \mathrm{MW}$ ). The data base covers only those facilities generating $1 \mathrm{MW}$ or greater. that sell power to utilities. Commercial buildings with smaller capacity and those that produce electricity for selfconsumption are excluded, so this source is not exhaustive.

For forecast years after 1994 , the baseline forecast of cogeneration by source fuel is set at the prior year's level per square foot of floorspace, with a price sensitivity component that uses the percent changes from the prior year electricity prices and generating fuel prices.

\section{SOIURCES:}

\section{Data Diskettes}

Energy Information Administration. Form EI-867, Survey of Independent Power. Producers Public Use

Energy Information Administration, "Nonutility Power Producers," Electric Power Monthly, April 1995. 


\section{MODEL INPUT:}

VARIABLENAME:

MODEL COMPONENT:

DEEINTTION:

CLASSIFICATION:
Ratio of useful thermal energy to cogenerated electricity

\section{CMCogenTEtoElsatio}

\section{Consumption}

Ratio of cogeneration thermal energy output to electricity output by fuel type Input from file KC̣ỌGPR

\section{DISCUSSION:}

The ratio of useful thermal energy produced by cogenerating equipment to the amount of electricity produced is a key parameter used by the NEMS Commercial Sector Demand Module to determine the incremental fuel - : consumption during the cogeneration process. A value given in the EPRI TAG for packaged cogeneration systems is used by the model, and assumed to remain constant over the forecast horizon.

\section{SOURCES:}

Decision Focus, Inc. TAG Technical Assessment Guide, Vol. 1: Electricity Supply; Part 2: Commercial Electricity Supply -- 1988. Palo Alto CA, Electric Power Research Institute, October 1988. 
MODELINPUT:

VARIABLENAME:

MODEL COMPONENT:

DEEINTITON:

ChASSIFICATION:

\section{DISCUSSION:}

The amount of commercial sector cogeneration capacity that is classified as unplanned is calculated directly from the

Förm EI-867 survey data collected for 1992, and assumed to remain constant throughout the forecast horizon.

\section{SOURCES:}

\section{Data Diskettes}

Unplanned cogeneration proportion

\section{CMicogUnplanProp}

Consumption

Historical proportion of cogeneration capacity that is unplanned

Input from file KCOGPRM
Energy Information Administration. Form EI-867, Survey of Independent Power Producers Public Use

\section{Diskettes}


MODET INPUT:

VARIABLENAME:

MODEL_COMPONENT:

DEFINTHON:'
Cogeneration equipment efficiency measure

CMDeltaRecipEffic

Consumption

Difference between reciprocal of efficiency of cogenerating equipment and the efficiency of comparable equipment used only to meet service demand, by fuel type

Input from file KCOGPRM

\section{DISCUSSION:}

The NEMS Commercial Sector Demand Module uses two parameters to forecast the consumption of fuels to meet the projected amount of electricity cogeneration. The first of these, CMCogenTEtoEL ratio, is described elsewhere. The second parameter, CMDeltaRecipEffic, characterizes the performance of cogenerating equipment during the electricity cogeneration process. It can be expressed as

$$
\text { CMDeltaEquipEffic }=\left[\frac{1}{C E F E}-\frac{1}{E F E}\right] \text {, }
$$

where CEFE is the efficiency of cogenerating equipment in generating useful thermal energy only, and EFE is the efficiency of equipment comparable to the cogenerating equipment which is used solely to meet a service demand.

The values for CEFE and EFE used to evaluate the expression above were based on base year average equipment efficiencies. CEFE was derived from CMCogenTĖtoELratio and the combined thermal and electric generating efficiency in the EPRITAG. EFE was estimated by averaging the base year average equipment efficiencies for oil and gas boilers - the equipment comparable to packaged cogeneration systems.

\section{SOURCES:}

Decision Focus, Inc. TAG Technical Assessment Güide, Vol. 1: Electricity Supply; Part 2: Commercial Electricity Supply -- 1988. Palo Alto CA, Electric Power Research Institute, October 1988. 
MODEL NNPUT:

VARIABLENAME:

MODEL COMPONENT:

DEEINTTON:

CLASSTITCATION:
Floorspace survival function shape parameter

\section{CMGamma}

Floorspace

Shape parameter for the floorspace survival function

Input parameter from file KBLDG

\section{DISCUSSTON:}

The sources cited below provide data on average building lifetimes, together with expected surviving proportions after various periods of time: The NEMS Commercial Sector Demand Module models.floorspace rétirement using the logistic survival function,

$$
\text { Surviving Proportion }=\frac{1}{1+\left(\frac{\text { current year }- \text { building vintage year }}{\text { median lifetime }}\right)}
$$

It can be seen that half the original floorspace constructed during a particular year is modeled as remaining after a period of time equal to the median building lifetime, regardless of the value used for the building survival parameter, CMGamma. As discussed in the text of the Commercial Model Documentation Report, CMGamma describes the variance of building retirement about the median lifetime, and is calculated so that the documented percentage of buildings remaining one year after construction is obtained.

\section{SOURCES:}

Hazilla, M., and R. Kopp. "Systematic Effects of Capital Service Price Definition on Perceptions of Input Substitution." Joumal of Business and Economic Statistics. April, 1986, pp. 209-224.

Electric Power Research Institute. Commercial End-Use Data Development Handbook: COMMEND Market Profiles and Parameter', Vol. 2: COMMEND Data and Parameter Development Techniques'. Regional Economic Research, Inc. San Diego, California. EMS703, April 1988, p. 2.24. 
MODEL INPUT:

YARTABLENAME:

MODELCOMPONENT:

DEEINUTLN:

\section{CLASSIITCATON:}

Oldest modeled buildings

\section{CMOldestBldgVint}

Floorspace

Median year of construction for buildings in the earliest CBECS age cohort group

Input parameter.

\section{DISCUSSION:}

CBECS 92 building characteristics include the year of building construction. Eight age categories, referred to as "vintage cohorts" are used by CBECS and the NEMS Commercial Sector Demand Module to aggregate average building characteristics. These age cohorts are discussed in the section documenting CMVintage. The median year of construction for the oldest vintage cohort (pre-1900) was determined to be 1875 during processing of the CBECS data set, and is the value currently assigned to the input parameter, CMOldestBldgVint.

\section{SOURCES: ,}

Energy Information Administration. Commercial Buildings Consumption and Expenditures 1992, Public Use Data Diskettes.

Energy Information Administration. Commercial Buildings Characteristics 1992. Washington DC, April 1994, DOE/EIA-0246(92), GPO Stock No. 061-003-00850-0, 
MODEL, NPUT:

YARTABLENAMT:

MODEL,COMPONENT:

DEEINTION:

CLASSIFICATION:
Historical fiuel consumption CMSEDS

Consumption

State Energy Data Sysstem (SEDS) historical energy consumption by Census

Division, fuel; and year for the commercial sector

Module input from Global Data Structure and file KSTEO

\section{DISCUSSION:}

The National Energy Modeling System (NEMS) uses the State Energy Data System (SEDS) historical consumption data as a standard against which the various sectoral module forecasts are benchmarked during the historical portion of the forecast horizon. The SEDS data is provided to the NEMS Commercial Sector Demand Module by the NEMS Integrating Module, and is more fully described in the Integrating Module Documentation Report. Currently, the latest year for which SEDS data is supplied is 1993 . This data is supplemented with projections from the Short Term Energy Outlook (STEO) for the commercial sector for the years 1994 - 1996. STEO data for 1994 is treated by the Commercial Module as if it were SEDS data, which is very likely to become the actual case. STEO data for. 1995 and 1996 is available for optional benchmarking during those years, at the user's discretion.

\section{SOURCES:}

Energy Information Administration. State Energy Data Report 1993 Consumption Estimates. DOE/EIA0214(93). May 1995. 
MODELINPUT:

YARIABLENAME:

MODEL COMPONENT:

DEENITION:

ClassitidCatuON:
Floorspace vintages

CMVintage

Floorspace

Median year of construction of commercial floorspace existing in 1992, by

building type, Census division, and vintage cohort group.

Input from file KVINT

\section{DISCUSSTON:}

The CBECS 1992 data set provides data on ages and numbers of buildings by building type and Census division.

- These data were processed to obtain estimates of the median year of construction for buildings constructed in each of the following vintage cohort groups:
pre-1900
$1900-1919$
$1920-1945$
1946 - 1959
$1960-1979$
$1980-1986$
$1987-1989$
$1990-1992$

The results vary with building type and Census Division, and are organized for input to the Commercial Module in the KVINT file.

\section{SOURCES:}

U.S. Department of Energy, Energy Information Administration, 1992 Commercial Buildings Energy . Consumption Survey, Public Use Data Diskettes. 
MODELINPUT:

YARTABLENAME:

MODEL COMPONENT:

DEEINTION:

CLASSTEICATON:
Energy-use Intensity

\section{ComEUI}

Service Demand

Energy consumed per unit floorspace for service $s$ in building type $b$ in Census Division $r$ in year $y, 1000$ Btu consumed/ft'.

Input from file KINTENS

\section{DISCUSSION:}

Pacific Northwest Laboratory (PNL) provides CBECS-derived estimates of the end-use intensities (EUIs) by building type, fuel type, and Census division for the end-use services modeled by the NEMS Commercial Sector Demand Module, by a combination of engineering simulation and Conditional Demand Analysis approaches. The resulting EUI estimates are subjected to a smoothing procedure and then input to the Commercial Module from the KINTENS input file.

\section{SOURCES:}

Belzer, D. L. et al, unpublishéd update to Belzer, D., L. Wrench and T. Marsh, End-Use Energy Consumption Estimates for U.S. Commercial Buildings, 1989, Pacific Northwest Laboratory, PNL-8946, UC-350, November 1993.

Belzer, D., L. Wrench and T. Marsh, End-Use Energy Consumption Estimates for U.S. Commercial Buildings, 1989, Pácific Northwest Laboratory, PNL-8946, UC-350, November 1993.

Original work by Eugene Burns of the U.S. Department of Energy, Energy Information Administration. 
MODEL NNPUT:

VARIABLENAME:

MODEL COMPONENT:

DEEINTION:

CLASSIEICATION:
Heating and Cooling degree days

DegreeDays

Consumption

Heating and Cooling degree days

Input from file KDEGDAY

\section{DISCUSSION:}

DegreeDays $(1, r, y)$ is the number of heating degree days and DegreeDays $(2, \dot{r}, y)$ is the number of cooling degree days in Census Division r during year $y$. Data is available from 1990 through the last STEO forecast year used by NEMS, currently 1996. Data for the final year (1996) provides the average heating and cooling degree days for normal years. The data is used to perform a weather adjustment to the consumption forecast in the Consumption subroutine to account for historical and 'normal' differences from the base year (1992) weather, and to determine the relative amounts of heating and cooling supplied by heat pumps.

\section{SOURCES:}

U.S. Department of Commerce, National Oceanic and Atmospheric Administration, Historical Climatology Series 5-2, September 1995. 
MODEL INPUT:

YARIABLENAME:

MODEL COMPONENT:

DEFINITION:

CLASSIFICATION:

DISCUSSION:

National average values for typical boiler efficiencies in converting the fuels of electricity, natural gas, and distillate oil to the intermediate products of steam, hot water, and chilled water, were estimated from tabular data presented in the 1992 National Census of District Heating, Cooling, and Cogeneration.

SOURCES:

U. S. Department of Energy. 1992 National Census of District Heating, Cooling, and Cogeneration. Prepared by BMS Management services for U. S. Department of Energy, July, 1993.
District service boiler efficiencies

DistServBoilerEff

Efficiency of conversion of fuel to steam energy by boilers used to provide district services

Input from file $\mathrm{KDSEFF}$
Service Demand 
MODELINPUT:

VARIABLENAME:

MODEL COMPONENT:

DEEINTTON:

CLASSIFICATION:
District service fuel shares

DistServFuelShr

Service Demand

Proportions of district service steam energy generated by each fuel type Input from file KDSFS

\section{DISCUSSTON:}

These shares are based on fuel consumption of district system plants that generate the intermediate products of steam, họt water, and chilled water. They are estimated from data provided in the Assessment of Energy

Consumption in Mültifacility Buildings report and the 1992 National Census of District Heating, Cooling, and .

Cogeneration. The fuel share estimates are input to the NEMS Commercial Sector Demand Module from the file -

KDSFS, by fuel and building type.

\section{SOURCES:}

U.S. Department of Ėnergy. 1992 National Census of District Heating, Cooling, and Cogeneration. Prepared by BMS Management services for U. S. Department of Energy, July, 1993.

Energy Information Administration. Energy Consumption Series: Assessment of Energy Use in Multibuilding Facilities. DOE/EIA-0555(93)/1. August 1993. 
MODEL INPUT:

YARIABLENAME:

MODEL COMPONENT:

DEFINTION:

CLASSIITCATION:
District service steam EUIs

DistServSteamEUI

Service Demand

Steam energy per square foot (MBtw/sqft) generated to provide district services (space heating, space cooling, water heating), by Census division, building type, and district service

Input from file KDSSTM

\section{DISCUSSTON:}

- Steam energy EUI estimates were developed by Pacific Northwest Laboratory and EIA personnel using the CBECS

1992 data set in a manner similar to the development of EUI estimates for other end uses. The steam EUI values are totals by building type and Census division, and are not broken down by generating fuel.

\section{SOURCES:}

Belzer, D. L. et al, unpublished update to Belzer, D., L. Wrench and T. Marsh, End-Use Energy

Consumption Estimates for.U.S. Commercial Buildings, 1989, Pacific Northwest Laboratory, PNL-8946, UC-350, November 1993.

Belzer, D., L. Wrench and T. Marsh, End-Use Energy Consumption Estimates for U.S. Commercial Buildings, 1989, Pacific Northwiest Laboratory, PNL-8946, UC-350, November 1993.

Original work by Eugene Burns and Kristine McSkimming of the U.S. Department of Energy, Energy Information Administration. 
MODEL INPUT:

VARTABLENAME:

MODEL COMPONENT:

DEEINTITON:

- Minor service equipment efficiency annual growth rate

EffGrowthRate

Technology.Choice

Annual efficiency improvement factor for the minor services of office equipment: PCS, Office Equipment: NonPCs, and miscellaneous ("other")

services.

Input from file KDELEFF

\section{CLASSIEICATION:}

\section{DISCUSSTON:}

The estimated efficiency improvement factors for office equipment, subdivided into personal computers (PC) and non personal-computer (NonPC) categories, and miscellaneous or "other" services are developed from the EPRI and LBL sources cited below. The annual improvement factor required to reach the estimated level of efficiency in the year 2010 is obtained by calculating the annual percentage improvement in the equipment stock that must be attained - in order to reach the target energy efficiency improvement for the entire stock by 2010.

\section{SOURCES:}

Koomey, J.G., M. Cramer, M. Piette, J.H. Eto. Efficiericy Improvements in U. S. Office Equipment: Expected Policy.Impacts. and Uncertainties. LBL-37383. Prepared by Lawrence Berkeley Laboratory, December 1995.

Decision Focus, Inc., TAG Technical Assessment Guide, Vol. 2: Electricity End Üse: Part 2: Commercial Electricity Use - 1988, Palo Alto, CA, Electric Power Research Institute, October 1988, pp. 5-48 to 5-84, 6-33, 6-40.

Arthur D. Little, Inc., Technical Memorandum for Technology Advances and Forecasts Residential/Commercial End-Use Equipment, ADL reference 64460-09, prepared for.U.S. Department of Energy, Contract No. DE-AC-21-88, April 1990, pp. 4-3, 8-4, 8-5, 10-5.

Gas Research Institute, Baseline Projection Data Book: GRI Baseline Projection of U.S. Energy Supply and Demand to 2010, 1992 edition, Vol. I, pp. 156-158.

Geller, Howard S., Commercial Building Equipment Efficiency: A State-of-the-Art Review, report prepared for the U.S. Congress, Office of Technology Assessment, Energy \& Materials Program by The American Council for an Energy-Efficient Economy, Washington, DC, May 1988.

Mahoney, Daniel D., Phase I of a Project to Enhance the Commercial Section Analysis of the GRI Baseline Modeling System; Topical Report \#I: Data Enhancements, prepared for the Gas Research Institute under Contract No. 5085-800-1175, DRI Energy Division, Lexington, MA, July 1987, pp.4, 59, 139-140.

U.S. Congress, Office of Tèchnology Assessment, Building Energy Efficiency, OTA-E-518, Washington, DC, U.S. Government Printing Office February 1991, p.122.

U.S. Department of Energy, Energy Information Administration, Lighting in Commercial Buildings, EIA, Washington, DC, March 1992, p. 41.

U.S. Department of Energy, Energy Information Administration, Energy Consumption and Conservation Potential: Supporting Analysis for the National Energy Strategy, EIA, Washington, DC, December 1990, p.52.

U.S. Department of Energy, Energy Information Administration, PC-AEO Forecasting Model for the Annual Energy, Outlook: Model Documentation, EIA, Washington, DC, March 1990, p.III-37 to III-39. 
MODELINPUT:

YARIABLENAME:

MODEL COMPONENT:

DEEINTITON:

\section{CLASSIFICATION:}

Office equipment penetration

MarketPenetration

Service Demand :

Office Equipment (PC, nonPC) and "Other" market penetration index by building type and year

Input from file KOFFPEN

\section{DISCUSSION:}

The Lawrence Berkeley Laboratory sources cited below documents the LBL studies performed to forecast office equipment market penetration. The principal source of commercial base year PC stock data is CBECS 1992. Data on energy consumption (both Energy Star and other) of PCS, monitors and laser printers are from LBL's Efficiency Improvements in U.S. Office Equipment report. This report also provides estimates of sales for PC-related office equipment. Estimates of the enabling rate for Energy Star PCS is taken from an EPA communication. The market penetration index is set to unity in 1992, and the forecast from LBL's Energy Use and Trends report is indexed to the 1992 baise year. The indexed LBL forecast of office equipment market penetration is included in the NEMS Commercial Module calculation of service demand.

\section{SOURCE:}

Koomey, J.G., M. Cramer, M. Piette, J.H. Eto. Efficiency Improvements in U. S. Office Equipmient: - Expected Policy Impacts and Uncertainties. LBL-37383. Prepared by Lawrence Berkeley Laboratory for the U.S. Department of Energy, December, 1995.

Piette, M., J. Eto, and J. Harris, Office Equipment Energy Use and Trends, Energy and Environment Division, Lawrence Berkeley Laboratory, September 1991.

U.S. Environmental Protection Agency, personal communication (facsimile) regarding Energy Star program. June 12, 1995. 
MODEL INPUT:

VARIABLENAMES:

MODEL COMPONENT:

DEFINITUON:

CLASSIFICATION:
Minor fuel consumption elasticity parameters

MinFuelAlpha, MinFuelBeta

Consumption

Elasticity parameters used in the calculation of minor fuel consumption

Input from file KMINFL

\section{DISCUSSION:}

MinFuelAlpha and MinFuelBeta are used as follows:

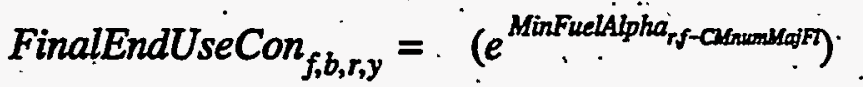

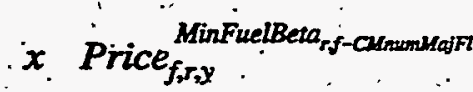

$$
\begin{aligned}
& x, 10^{-6} \\
& \left.x \text { (SurvFloorTotal }_{r, b, y}+\text { CMNewFloorSpace }{ }_{r, b, y}\right)
\end{aligned}
$$

$$
\forall f \in\{\text { MinFuels }\}-\{\text { MotorGasoline }\}, b, r ; y
$$

where FinalEndUseCon is final end-use minor fuel consumption. Minor fuel final end-use consumption is measured in trillion Btu in for $f \in$ \{residual fuel oil, LPG, coal, kerosene $\}$ for Census Division $r$ for year $y$, and is calculated.for all forecast years by the expression above. For motor gasoline, consumption levels are set to the published SEDS historical values by Census Division for the historical portion of the forecast horizon, and subsequently are developed by multiplying the previous year's motor gasoline consumption by the term; $(1+$ MinFuelBeta), which is based upon SEDS historical share growth for motor gasoline consumption. MinFuelBeta and MinFuelAlpha are calculated using the historical data on minor fuel consumption and prices from 1970-1992 provided by SEDS publications.

\section{SOURCES:}

Energy Information Administration. State Energy Data Report: Consumption Estimates, 1960-1990, DOE/EIA-0214(90), Washington'DC, May 1992:

Energy Information Administration. State Energy Price and Expenditure Data System (SEPEDS) Database, 1970-1991.

Energy Information Administration. State Energy Data Report 1992: Consumption Estimates, DOE/EIA0214(92), Washington DC, May 1994. 
MODELINPUT:

VARIABLENAME:

MODEL COMPONENT:

DEFINITION:

CLASSIEICATION:
Adjustment to SEDS to match NEMS sectoral definitions

\section{NUGfromSEDS}

Benchmarking

Commercial-rate energy consumption for nonutility generation systems (NUGS) attributable to the utility sector

Input from file KCALNUGS

\section{DISCUSSION:}

There are several differences between the sectoral classification definitions used by NEMS and those employed for SEDS reporting. In particular, sectoral classification in SEDS is based on supplier classifications of customer accounts, by whatever means suppliers choose to use. As a result, where SEDS quantities include contributions. known to properly belong to NEMS sectors other than the commercial sector, adjustments are made to the SEDS data prior to benchmarking the Commercial Sector Demand Module forecasts. -NUGfromSEDS contains fuel quantities included by SEDS in the commercial sector, because they were purchased at commercial rates, bit which were purchased for nonutility generation of electricity activities outside the commercial sector proper. They are input to the Commercial Module from file KCALNUGS, and subtracted from corresponding SEDS consumption figures in the appropriate Census divisions.

\section{SOÜRCES:}

Patricia Toner, Energy Information Administration. Personal communication, October 1995. 
MÒDELINPUT:

VARIABLENAME:

MODEL COMPONENT:

DEFINITION:

CLASSIFCATION:
Retrofit removal and disposal cost

RetroCostFract

Technology Choice

Cost of removing and disposing equipment of a given technology and vintage for purposes of retrofitting with other equipment

Input from KTECH

\section{DISCUSSTON:}

The cost is expressed as a proportion to be applied to the installed capital cost. Currently, a placeholder value of 0.0 is used throughout the Commercial Sector Demand Module, pending acquisition and analysis of appropriate data.

\section{SOURCES:}

Energy Information Administration: Estimated value. 
MODELINPUT:

VARIABLENAMT:

MODEL COMPONENT:

DEFINTITON:

CLASSIEICATION:
Serviced floorspace variation with building vintage

ServicedFlspcPiop

\section{Service Demand}

Proportion of building floorspace that receives end-use service, by building type, service, and whether the buildings are newly-constructed (post-1989) or existing (pre-1990).

Input from file KVARSDI

\section{DISCUSSION:}

An investigation undertaken to deterinine whether significant variations existed by building age in the proportions of floorspace receiving various end use services found, for several services, a measurable difference between the two broad classes of 'old' and 'new.' For this characterization; 'new' was defined as floorspace constructed after 1989. The NEMS Commercial Sector Demand Module parameters characterizing service demand patterns are derived by considering the entire floorspace stock as sampled by CBECS 92 , and is influenced most heavily by values corresponding to the 'old'. floorspace category. In order to account for service demand differences in new floorspace construction, the model makes use of the different serviced floorspace proportions, as described in the text of the model documentation. The values were derived by processing the individual CBECS survey records.

\section{SOURCES:}

U.S. Department of Energy, Energy Information Administration, 1992 Commercial Buildings Energy. Consumption. Survey, Public Use Data Diskettes. 
MODEL INPUT:

YARTABLENAME:

MODEL COMPONENT:

DEEINITION:

ClassimCatTON:
Building shell efficiency index

SheilEffIndex

Service Demand

Shell efficiency index for buildings constructed in the current year for building type $b$ in Census Division $r$ in year $y$.

Input from file KSHEFF

\section{DISCUUSSTON:}

The 1992 existing stock shell efficiency is indexed to 1.0 for each building type. The building shell efficiency index measures the improvement in the shell integrity of newly-constructed floorspace that must by law adhere to building codes, and the general improvement in overall existing stock shell efficiency that results from the continual : introduction of more shell-efficient new construction.

Regional shell efficiency parameters developed from a 1992 Pacific Northwest Laboratory (PNL) study cited below are included in the model. The PNL study consists of an extensive microsimuiation of buildings closely matching the CBECS 1992 building types across the country. The PNL study analyzes the impacts on shell efficiency based upon three groups of buildings: those built to 1980 building codes, those built to 1992 building codes, and future potential buildings built to 1993 building codes. Regional data from the PNL study enables regional variation to be included in the model. The model currently does not incorporate assumptions regarding the proposed 1998 efficiency standards that may impact future building codes.

\section{SOURCES:}

Koomey, J., Lawrence Berkeley Laboratory, personal communication, June 18; 1992.

Jarnagin R., Pacific Northwest Laboratory, personal communication, August, 1992. .. Energy Information Administration, Commercial Buildings Characteristics 1989, DOE/EIA-0246(89), Washington DC, June 1991.'

- . Gas Research Institute, Baseline Projection Data Book: GRI Baseline Projection of U.S. Energy Supply and Demand to 2010, 1992 edition, Vol. I.

Brodrick, J., Office of Building Technologies, Office of Conservation and Renewable Energy, DOE, personal communication, June 16, 1992. 
MODEL INRUT:

VARIABLENAME:

MODEL COMPONENT:

DEEINITION:
Short-term price elasticity of service demand

ShortRunPriceElasofDmd

Service Demand

Short run price elasticity, (percent change in service demand as result of percent change in energy price) by service demand $s$, for the major fuels of electricity, natural gas, and distillate. This is a composite factor based on fuel proportions of service demand by Census. Division and service.

\section{CLASSIEICATION:}

\section{Input from file KSDELA}

\section{DISCUSSION:}

The following table summarizes a literature review encompassing price response analyses of majôr fuel demands. Composite price elasticity of service demand estimates based upon these sources are included. Input values for the fuel and end-use specific elasticity parameters included in the module are selected from within the range illustrated in this table, to correspond to analyst judgement within the range of empirical values developed. 


\begin{tabular}{|c|c|c|c|c|c|c|c|}
\hline \multirow{2}{*}{ Author } & \multirow{2}{*}{ Sector } & \multirow{2}{*}{$\begin{array}{l}\text { Time } \\
\text { Period }\end{array}$} & \multirow{2}{*}{ - Fuel } & \multicolumn{2}{|c|}{$\begin{array}{c}\text { Price } \\
\text { Elasticities } \\
\end{array}$} & \multicolumn{2}{|c|}{$\begin{array}{c}\text { Income } \\
\text { Elasticities }\end{array}$} \\
\hline & & & & $\begin{array}{c}\text { Short- } \\
\text { run }\end{array}$ & $\begin{array}{l}\text { Long: } \\
\text { run }\end{array}$ & $\begin{array}{c}\text { Short-: } \\
\text { run }\end{array}$ & $\begin{array}{l}\text { Long- } \\
\text { run }\end{array}$ \\
\hline $\begin{array}{l}\text { Balestra \& } \\
\text { Nerlove (1966) }\end{array}$ & $\begin{array}{l}\text { Residential- } \\
\text { Commercial }\end{array}$ & $\begin{array}{l}1957- \\
62\end{array}$ & - Gaś & & -0.63 & & 0.62 \\
\hline $\begin{array}{l}\text { Joskow \& } \\
\text { Baughman. } \\
\text { (1976) }\end{array}$ & $\begin{array}{l}\text { Residential- } \\
\text { Commercial }\end{array}$ & $\begin{array}{l}1968 \\
7.2\end{array}$ & Gas & $-0.15^{\prime \prime}$ & -1.01 & 0.08 & 0.52 \\
\hline $\begin{array}{l}\text { Fuss, Hydman \& } \\
\text { Waverman } \\
\text { (1977) }\end{array}$ & Commercial & $\begin{array}{l}1960- \\
71\end{array}$ & Gas & - & -0.72 & $\therefore$ & . \\
\hline $\begin{array}{l}\text { Berndt \& } \\
\text { Watkins (1977) }\end{array}$ & $\begin{array}{l}\text { Residential- } \\
\text { Commercial }\end{array}$ & $\begin{array}{l}1959 \\
74\end{array}$ & Gaš & $\begin{array}{l}-0.15 \\
. \\
\end{array}$ & -0.68 & 0.04 & 0.133 \\
\hline Griffin (1979) & Commercial & $\begin{array}{l}1960- \\
72 .\end{array}$ & Gas & -0.83 & -1.60 & & $\circ$ \\
\hline $\begin{array}{l}\text { Beierlin, Durin \& } \\
\text { McConnor } \\
\text { (1981) }\end{array}$ & Commercial & $\begin{array}{l}1967- \\
77\end{array}$ & Gas & -0.161 & -1.06 & -0.33 & -2.19 \\
\hline $\begin{array}{l}\text { Beierilin, Dunn \& } \\
\text { McConnor } \\
\text { (1981) }\end{array}$ & $\begin{array}{c}\text { Commercial } \\
\end{array}$ & $\begin{array}{l}1967- \\
77\end{array}$ & Gas & -0.276 & -1.865 & 0.035 & 0.237 \\
\hline $\begin{array}{l}\text { Beierlin, Dunn \& } \\
\text { McConnor } \\
\text { (1981) }\end{array}$ & Commercial & $\begin{array}{l}1967= \\
77\end{array}$ & Gas & -0.366 & -2.258 & 0.034 & 0.210 \\
\hline $\begin{array}{l}\text { Mount, Chapman } \\
\text { \& Tyrrell (1973) }\end{array}$ & Commercial & $\begin{array}{l}1946- \\
70\end{array}$ & Electric & -0.52 & -1.47 & 0.30 & 0.85 \\
\hline $\begin{array}{l}\text { McFadden \& } \\
\text { Puig (1975). }\end{array}$ & Commercial & 1972 & Electric & & -0.54 & ، & 0.80 \\
\hline $\begin{array}{l}\text { Murray, Spann, } \\
\text { Pulley \& } \\
\text { Beauvais (1978) }\end{array}$ & Cömmercial & $\begin{array}{l}1958- \\
73\end{array}$ & Electric & -0.07 & $\begin{array}{c}-0.67 \\
-\end{array}$ & 0.02 & $0.70^{\circ}$ \\
\hline $\begin{array}{l}\text { Chem \& Just } \\
\text { (1982) }\end{array}$ & Commercial & $\begin{array}{l}1955- \\
74\end{array}$ & Electric & $-0 . \dot{47}$ & -1.32 & 0.25 & 0.70 \\
\hline DOE (1978) & Commercial". & $\begin{array}{l}1960- \\
75\end{array}$ & Gas & -0.32 & -1.06 & & \\
\hline Nelson (1975) & $\begin{array}{l}\text { Commercial- } \\
\text { Residential } \\
\end{array}$ & 1971 & $\begin{array}{l}\text { Space } \\
\text { Heating } \\
\end{array}$ & -0.3 & & & \\
\hline Uri (1975) & Commercial & & Electric & -0.34 & -0.85 & 0.79 & 1.98 \\
\hline FEA' (1976) & Commercial & & $\begin{array}{l}\text { Gas } \\
\text { Distlat. }\end{array}$ & $\begin{array}{l}-0.38 \\
-0.55 \\
\end{array}$ & $\begin{array}{l}\text { large } \\
-0.55\end{array}$ & $\begin{array}{l}0.73 \\
0.73 \\
\end{array}$ & $\begin{array}{l}\text { large } \\
0.73 \\
\end{array}$ \\
\hline
\end{tabular}




\section{SOURCES:}

Al-Sahlawi, M., "The Demand for Natural Gas: A Survey of Price and Income Elasticities," The Energy Joumal, vol. 10, no. 1, January 1989.

Balestra, T. and M. Nerlove, "Pooling Cross-Section and Time-Series Data in the Estimation of a Dynamic Model: The Demand for Natural Gas," Econometrica, vol. 34, no. 3, July 1966.

Beierlin, J., J. Dunn, and J. McConnor, Jr., "The Demand for Electricity and Natural Gas in the Northeastern United States," Review of Economics and Statistics, vol. 64, 1981.

Berndt, E. and G. Watkins, "Demand for Natural Gas: Residential and Commercial Markets in Ontario and. British Columbia," Canadian Joumal of Economics, vol. 10, February 1977.

Chern, W. and R. Just, "Assessing the Need for Power: A Regional Econometric Model," Energy Economics, vol. 10, no. 3, 1982, pp. 232-239.

Federal Energy Administration; 1976 National Energy Outlook, Washington, DC, 1976. Company, 1979.

Griffin, J., Energy Consumption in the OECD: 1880-2000, Cambridge, Mass., Ballinger Publishing

Halvorsen, $\dot{R}$., "Demand for Electric Energy in the United States," Southern Economic Journal, vol. 42, no. 4,1975 , pp. 610-625.

Joskow, P. and M. Baughman, "The Future of the U.S. Nuclear Energy Industry," Bell Journal of Economics, vol. 7, Spring 1976.

McFadden, D. and C. Puig, Economic Impact of Water.Pollution Control on the Steam Electric Industry, Chapter 3, Report EED-12, Teknekron Inc., Berkeley, California, 1975.

Mount, T., L. Chapman \& T. Tyrrell, Electricity Demand in the United States: An Econometric Analysis, National Technical Information Service No. ORNL-NSF-EP-49, Springfield, Virginia, 1973.

Murray, M., R. Spann, L. Pulley, \& E. Beauvais, "The Demand for Electricity in Virginia," The Review of Economics and Statistics, vol. 60, no. 4, 1976, pp. 585-660: pp.508-512.

Nelson, J., "The-Demand for Space Heating Energy," Review of Economics and Statistics, November 1975,

Uri, N., A Dynamic Demand Analysis for Electrical Energy by Class of Consumer, Working Paper No. 34, Bureau of Labor Statistics, January 1975. .

Westley, G., The Demand for Electricity in Latin America: A Survey and Analysis, Economic and Ścial Development Department, Country Studies Division, Methodology Unit, Washington, DC, February 1989. ' 
MODEL INPUT:

VARTABLENAME:

MODEL COMPONENT:

DEFINTION:

CLASSIFICATION:
Commercial.sector renewable energy consumption forecast

SolarRenewableContrib

Service Demand 、

Contribution of solar thermal energy consumed to meet commercial sector service demánds by service $s$

Input from file KRENEW

\section{DISCUSSTON:}

A baseline projection for solar thermal energy consumption developed by the National Renewable Energy

Laboratory (NREL) is read into the Commercial Module, since forecasts from the NEMS Renewable Fuels Module are not currently available at the level of disaggregation required by the Commercial Module. The renewable energy forecasts for active solar (space heating and water heating) are applied, interpolating to fill in the five-year forecast intervals provided in the white paper.

Commercial sector consumption of geothermal technologies is explicitly modeled by including geothermal heat pumps in the technology characterization menu, allowing geothermal technologies to compete in the marketplace. Consumption of the renewable fuels of wood and municipal solid waste (MSW) in the cogeneration of electricity is . also modeled explicitly; using data from the EI-867 Survey of Independent Power Producers data base.

\section{SOURCES:}

Energy Information Administration, EI-867 Survey of Independent Power Producers data base.

The Potential of Renewable Energy: An Interlaboratory White Paper, a report prepared for the Office of Policy, Planning and Analysis, U.S. Department of Energy, Golden, Colorádo, March 1990. 
MODELINPUT:

YARIABLENAME:

MODEL COMPONENT:

DEEINTION:

\section{CLASSIFICATUON:}

Equipment efficiency

TechEff .

\section{Technology Choice}

Efficiency, Coefficient of Performance, Seasonal Performance Factor, Efficacy

(lighting), of equipment in providing service

Input from file KTECH

\section{DISCUSSION:}

Equipment efficiencies for the services of space heating, space cooling, water heating, ventilation, cooking, lighting, and refrigeration are included in the Technology Characterization Menu of the NEMS Commercial Module. These input data are composites of commercial sector equipment efficiencies of existing and prototypical commercial sector technologies provided in the EPRI, ADL, GRI, OTA, NES, AEO90, and Lighting in Commercial Buildings sources cited below.

\section{SOURCES:}

Decision Analysis Corporation of Virginia, Lighting System Technology Characterization for the NEMS Commercial Sector Demand Module, prepared for Energy Information Administration, Contract No. DE-AC0192EI21946, August 1996.

Decision Analysis Corporation of Virginia, Ventilation System Technology Characterization for the NEMS Commercial Sector Demand Module, prepared for Energy Information Administration, Contract No. DE-AC0192EI21946, August 1996.

Decision Focus, Inc., TAG Technical Assessment Guide, Vol. 2: Electricity End Use; Part 20: Commercial Electricity Use -- 1988, Palo Alto CA, Electric Power Research Institute, October 1988, pp. 5-48 to 5-84, 6-33, 6-40, 7-16,7-19.

Arthur D. Little, Inc., EIA - Technology Forecast Updates, ADL reference 41615, prepared for U.S. Department of Energy, Contract No. DE-AC01-92EL21946, June 1995.

$\because$

Arthur. D. Little, Inc., Technical Memorandum for Technology Advances and Forecasts -

ResidentiaVCommercial End-Use Equipment, ADL reference 64460-09, prepared for U.S. Department of Energy, Contract No. DE-AC-21-88, April 1990, pp. 4-3, 8-4, 8-5, 10-5.

. Arthur D. Little, Inc., Discussion Charts; Task 1: Technology Status; ResidentiaV Commercial End-Use Equipment and Advanced Power Cycles, ADL reference 64460-09, prepared for U.S. Department of Energy, Energy Information Administration, March 1990, pp. 42-49, 58-59.

Gas Research Institute, Baseline Projection Data Book: GRI Baseline Projection of U.S. Energy Supply and Demand to 2010, 1992 edition, Vol. I, p. 158.

Lawrence Berkeley Laboratory, Energy and Environment Division, Energy Analysis Program, Technology Data Characterizing Lighting in Commercial Buildings: Application to End-Use Forecasting with COMMEND 4.0, September 1993.

Pietsch, J., TAG Technical Assessment Guide, Vol. 2: Electricity End Use: Part 2: Commercial Electricity Use - 1992, Dallas, TX, Electric Power Research Institute, December 1992. 
U.S. Congress, Office of Technology Assessment, Building Energy Efficiency, OTA-E-518, Washington DC, U.S. Government Printing Office; May 1992, pp. 51-55.

U.S. Congress, Office of Technology Assessment, Changing by Degrees: Steps to Reduce Greenhouse Gases, OTA-O-482, Washington DC, U.S. Government Printing Office, February 1991, p. 122. : .

Energy Information Administration, Lighting in Commercial Buildings, DOE/EIA-0555(92)/1, Washington DC, March 1992, p. 41.

Energy Information Administration, Energy Consumption and Conservation Potential: Supporting Analysis for the National Energy Strategy, SR/NES/90-02, Washington DC, December 1990, p. 52.

Energy Information Administration, PC-AEO Forecasting Model for the Annual Energy Outlook 1990: Model Documentation, DOE/EIA, Washington DC, March 1990, pp. III-37 to III-39. 
MODEL INPUT:

YARIABLENAME:

MODEL COMPONENT:

DEEINITION:

\section{CLASSITICATION:}

Base year equipment market share

TechShareofServiceBASE

Technology Choice

Current year market share of technology $k$ of vintage $v$ that meets service demand $s$ in building type $b$ in Census Division $r$.

Input from file KTECH

\section{DISCUSSION:}

Base year market shares for the representative technologies included in the technology characterization data base are computed based primarily upon consumption patterns from CBECS 1992 . The computed shares represent the proportion of demand that is satisfied by the particular technology characterized by building type for ventilation and lighting services and by Census division for the other major services. Proportions of floorspace serviced by each alternative technology are used as proxies for the market shares of demand where actual market share data is unavailable. These shares are computed for equipment supplying the major services of space heating, space cooling; water heating, ventilation, cooking, lighting,and refrigeration. Additional sources referenced below provided further breakdown of the overall market shares for certain technology classes developed from CBECS.

\section{SOURCES:}

Energy Information Administration. Commercial Buildings Energy Consumption and Expenditures 1992, Public Use Data Diskettes.

Energy Information Administration. Commercial Buildings Characteristics 1992. Washington DC, April * 1994, DOE/EIA-0246(92), GPO Stock No. 061-003-00850-0.

37.

Energy Information Administration, Lighting in Commercial Buildings, Washington, DC, May 1992, p. 36-

Decision Analysis Corporation of Virginia, Lighting System Technology Characterization for the NEMS Commercial Sector Demand Module, prepared for Energy Information Administration, Contract No. DE-AC0192EI21946, August 1996.

Decision Analysis Corporation of Virginia, Ventilation System Technology Characterization for the NEMS Commercial Sector Demand Module, prepared for Energy Information Administration, Contract No. DE-AC0192EI21946, August 1996.

Decision Focus, Inc.,TAG Technical Assessment Guide, Vol 2: Electricity End Use: Part 2: Commercial Electricity Use -- 1988, Palo Alto, CA, Electric Power Research Institute, October 1988.

Energy Information Administration, Energy Consumption and Conservation Potential: Supporting Analysis for the National Energy Strategy, EIA, Washington, DC, December 1990.

Huang et al., 481 Prototypical Commercial Buildings for Twenty Urban Market Areas, Lawrence Berkeley Laboratory, June 1990. 


\section{YARIABLENAME:}

MODEL NPUT:

MODEL COMPONENT:

DEEINTTON:

CLASSIFICATION:
TimePrefPrem

Consumer time preference distribution data

\section{Technology Choice}

The consumer time preference interest rate premium is a percentage increment to the risk-free commercial sector interest rate. The Module also requires the set of proportions of commercial consumers with each time preference interest rate premium segment.

Input from file KPREM

\section{DISCUSSION:}

The preference distribution data are composites developed using a set of distributions of consumer payback period requirements from the literature. The principal data sources for these inputs are cited below. These sources include Koomey (LBL), DAC/SAIC, four electric utility studies, and an EIA market study. Three of the distributions were performed for specific technologies, and two are generalized to represent all technologies. These data are not sufficient to identify statistically significant differences in commercial sector consumer payback requirement. between classes of technologies. Furthermore, some of the utility sources represent "best guess" rules used to characterize potential demand-side management customers rather than data from a statistical survey. Therefore, since these limited data preclude the development of time preferences as functions of technology characteristics, an average distribution across all technologies is applied.

The average consumer time preference distribution is calculated as follows. Each source lists the proportions of commercial sector consumers with payback requirements by year, from zero to ten years. These payback requirements are first converted to implied internal rates of return for each year of the distribution for each source. ${ }^{1}$ Then the risk-free interest rate (for purposes of the study, the 10 year Treasury bond rate for the year corresponding to the payback study was used) is subtracted, from each implied rate of return to yield a consumer time preference. premium distribution for each source. ${ }^{2}$ Each distribution is discrete, consisting of eleven cells, corresponding to the eleven payback years. These are subjected to a simple arithmetic average across studies to form a composite distribution. ${ }^{3}$ Finally, the resulting average distribution is aggregated to yield a distribution of six time preference segments.

The assumed distribution of consumer time preference premiums is assumed constant over the forecast horizon.

${ }^{1}$ The conversion to implied internal rates of return assumed mid-year payments and a thirty year amortization period.,

${ }^{2}$ The Treasury bond rates were obtained from the Statistical Abstract and from personal communication with EIA's Macro and Financial Information Branch staff.

${ }^{3}$ The proportions for the eleven cells were averaged directly. The consumer time preference premiums for each cell were averaged, weighting by the proportion of consumers. These rates differed slightly because of variations in the zero risk interest rate between sources. 
However, the Commercial Sector Demand Module allows variation in the distribution on an annual basis to accommodate simulation of policy scenarios targeting consumers' implicit discount rates.

\section{SOURCES:}

Koomey, Jonathan G., Energy Efficiency Choices in New Office Buildings: An Investigation of Market Failures and Corrective Policies, Ph.D. Dissertation, University of California at Berkeley, 1990, p..16.

Decision Analysis Corporation of Virginia and Science Applications International Corporation, Alternative Methodologies for NEMS Building Sector Model Development: Draft Report, prepared for EIA under Contract No. DE-AC01-92EI21946, Task 92-009, Subtask 4, Vienna VA, August 3, 1992, p. 14.

U.S. Department of Commerce, Bureau of the Census, Statistical Abstract of the United States 1990 (110th ed.), Washington DC, 1990, p.510. 
VARIABLENAMES:

MODEL INPUT:

MODEL COMPONENT:

DEETNTHON:

CLASSIFICATION:
TechCost, Techlife

Equipment characteristics (see Definition below)

Technology Choice

Installed unit capital cost, annual operating and maintenance cost; and equipment lifetime in years for specific technologies/models

input from file KTECH

\section{DISCUSSION:}

Capital and installation costs are combined to form installed capital costs, based upon availabledata. The

Technology Choice algorithm does not require the separation of capital and installation costs, and currently does not retain information describing absolute equipment capacity. Installed unit capital costs (installed capital cost per thousand Btu/hr output capacity, per 1000 lumens in the case of lighting, or per $1000 \mathrm{cfm}$ for ventilation systems) and the annual unit operating and maintenance costs vary by technology and vintage for the services of space heating, space cooling, water heating, ventilation, cooking, lighting and refrigeration. They are developed from a variety of sources, referenced below.

\section{SOURCES:}

Decision Focus, Inc., TAG Technical Assessment Guide, Vol. 2: Electricity End Use: Part 2: Commercial Electricity Use -- 1988, Palo Alto, CA, Electric Power Research Institute, October 1988, pp. 5-48 to 5-84, 6-33, 640.

Arthur D, Little, Inc., ELA - Technology Forecast Updates, ÁDL reference 41615, prepared for U.S. Department of Energy, Contract No. DE-AC01-92EI21946, June 1995.

Arthur D. Little, Inc., Technical Memorandum for Technology Advances and Forecasts Residential/Commercial End-Use Equipment, ADL reference 64460-09, prepared for U.S. Department of Energy, Contract No. DE-AC-21-88, April 1990, pp. 4-3, 8-4, 8-5, 10-5. MA,-1994.

Chaing, J.H., ed., Means Electrical Cost Data, 17th Annual Edition. R.S. Means Company, Inc., Kingston,

Decision Analysis Coiporation of Virginia, Lighting System Technology Characterization for the NEMS Commercial Sector Demand Module, prepared for Energy Information Administration, Contract No. DE-AC0192E121946, August 1996.

Decision Analysis Corporation of Virginia; Ventilation System.Technology Characterization for the NEMS Commercial Sector Demand Module, prepared for Energy Information Administration; Contract No. DE-AC0192EI21946, August 1996.

Gas Research Institute, Baseline Projection Data Book: GRI Baseline Projection of U.S. Energy Supply and Demand to 2010, 1992 edition, Vol. I, pp. 156-158.

Lawrence Berkeley Laboratory, Energy and Environment Division, Energy Analysis Program, Technology Data.Characterizing Lighting in Commercial Buildings: Application to End-Use Forecasting with COMMEND 4.0, September 1993.

Means Southern Construction Information Network, Means Facilities Construction Cost Data, 1995. 
1995.

Means Southern Construction Information Network, Means Facilities Maintenance and Repair Cost Data,

Pietsch, J., TAG Technical Assessment Guide, Vol. 2: Electricity End Use: Part 2: Commercial Electricity Use -- 1992, Dallas; TX, Electric Power Research Institute, December 1992.

U.S. Congress, Office of Technology Assessment, Building Energy Efficiency, OTA-E-518, Washington, DC, U.S. Government Printing Office February 1991,p.122.

Energy Information Administration, Lighting in Commercial Buildings, DOE/EIA-0555(92)/1, Washington, DC, March 1992, p. 41:

Energy Information Administrātion, Eniergy Consumption and Conservation Potential: Supporting Analysis for the National Energy Strategy, SR/NES/90-02, Washington, DC, December 1990, p.52.

; U.S. Department of Energy, Energy Information Administration, PC-AEO Forecasting Model for the Annual Energy Outlook: Model Documentation, DOE/EIA, Washington, DC, March 1990, p.II-37 to III-39.'

Geller, Howard S., Commercial Building Equipment Efficiency: A State-of-the-Art Review, report prepared for the U.S. Congress, Office of Technology Assessment, Energy \& Materials Program by The American Council for an Energy-Efficient Economy, Washington, DC, May 1988. 
VARIABLENAME:

MODEL TNPUT:

MODEL COMPONENT:

DEEINTTON:

CLASSIEICATION:
TechAvailability

Equipment Availability

Technology Choice

Availability of equipment technology/model by year

Input from file KTECH

\section{DISCUSSION:}

The first year in which technologies become available corresponds to efficiency and cost data in the EPRI, ADL,

GRI, OTA and EIA sources cited below for space heating, space cooling, water heating and lighting technologies. In some cases, where 'typical' future costs were provided for specific years, the first year of availability was adjusted to be somewhat earlier, in order to reflect the time needed to achieve production levels necessary to justify the 'typical' cost. In addition, the National Energy Policy Act of 1992 Title I, Subtitle C, Sections 122 and 12A, provides commercial equipment efficiency standards applicable to units manufactured after January 1,1994. This information is combined with the previously cited sources and professional expectations to estimate the first-available and lastavailable year for each technology that is subject to the standards.

\section{SOURCES:}

Decision Focus, Inc., TAG Technical Assessment Guide, Vol. 2: Electricity End Use; Part 2: Commercial Electricity Use -- 1988, Palo Alto CA, Electric Power Research Institute, October 1988, pp. 5-48 to 5-84, 6-33, 6-40, 7-16, 7-19.

Arthur D. Little, Inc., EIA - Technology Forecast Updates, ADL reference 41615, prepared for U.S. Department of Energy, Contract.No. DE-AC01-92EI21946, June 1995.

Arthur D. Little, Inc., Technical Memorandum for Techinology Advances and Forecasts - . Residential/Commercial End-Use Equipment, ADL reference 64460-09, prepared for U.S. Department of Energy, Contract No. DE-AC-21-88, April 1990, pp. 4-3, 8-4, 8-5, 10-5.

Arthur D. Little,.Inc., Discussion Charts; Task 1: Technology Status - Residential. Commercial End-Use. - Equipmenit and Advanced Power Cycles, ADL reference 64460-09, prepared for U.S. Department of Energy, Energy Information Administration, March 1990, pp. 21, 42-49, 58-59.

Decision Analysis Corporation of Virginia, Lighting System Technology Characterization for the NEMS Commercial Sector Demand Module, prepared for Energy Information Administration, Contract No. DE-AC0192EI21946, August 1996.

- Decision Analysis Corporation of Virginia, Ventilation System Technology Characterization for the NEMS Commercial. Sector Demand Module, prepared for Energy Information Administration, Contract No. DE-AC0192EI21946, August 1996.

Gas Research Institute, Baseline Projection Data Book: GRI Baseline Projection of U.S. Energy Supply and Demand to 2010, 1992 edition, Vol. I,pp. 156-158.

Lawrence Berkeley Laboratory, Energy and Environment Division, Energy Analysis Program, Technology Data Characterizing Lighting in Commercial Buildings: Application to End-Use Forecasting with COMMEND 4.0, September 1993.

Pietsch, J. TAG Technical Assessment Guide, Vol. 2: Electricity End Use; Part 2: Commercial Electricity 
Use - 1992, Dallas, TX, Electric Power Research Institute, Deceimber 1992.

U.S. Congress, Office of Technology Assessment, Building Energy Efficiency; OTA-E-518, Washington DC, U.S. Government Printing Office, May 1992, pp. 51-55.

U.S. Congress, Office of Technology Assessment, Changing by Degrees: Steps to Reduce Greenhouse Gases, OTA-0-482, Washington DC, U.S. Government Printing Office, February 1991, p. 122.

Energy Information Administration, Lighting in Commercial Buildings, DOE/EIA-0555(92)/1, Washington - DC, March 1992, p. 41.

Energy Information Administration, Energy Consumption and Conservation Potential: Supporting Analysis for the National Energy Strategy, SR/NES/90-02, Washington DC, December 1990, p. 52.

U.S. Congress, House of Representatives. Energy Policy Act of 1992: Conference Report to Accompany H.R. 776, 102nd Cong., 2d sess. October 5, 1992. 
MODELINTUUT:

YARIABLENAME:

MODEL COMPONENT:

DEFINTION:

CLASSIJICATTON:
Adjustment to SEDS to match NEMS sectoral definitions TranfromsEDS

Benchmarking

Commercial-rate energy consumption for transportation purposes attributable to the transportation sector

Input from file KCALTRN

\section{DISCUSSTON:}

- There are several differences between the sectoral classification definitions used by NQES and those employed for SEDS reporting. In particular, sectoral classification in SEDS is based on supplier classifications of customer accounts, by whatever means suppliers choose to use. As a result, where SEDS quantities include contributions known to properly belong to NEMS sectors other than the commercial sector, adjustments are made to the SEDS data prior to benchmarking the Commercial Sector Demand Module forecasts.' TranfromSEDS contains fuel quantities included by SEDS in the commercial sector, because they were purchased at commercial rates, but which were purchased for activities that properly belong to the transportation sector; such as fuel consumption by AMTRAK. They are input to the Commercial Module from file KCALTRN, and subtracted from corresponding SEDS consumption figures in the appropriate Census divisions.

\section{SOURCES:}

David Chien, Energy Information Administration. Personal communication, October 1995. 


\section{Appendix B. Mathematical Description}

This section provides the formulae and associated mathematical description which represent the detailed solution algorithms arranged by sequential submodule as executed in the NEMS Commercial Sector Demand Module. Certain conventions, nomenclature, and symbols used in the equations are defined below.

In general, the following conventions for subscript usage are observed in this section. Additional subscripts are defined later in this appendix where necessary. Discrete values assumed by the subscripts, and categories of such values, are described in Table 2 of Chapter 2: .

\footnotetext{
Subscript Description of Dimension Represented by Subscript

I Census Division

b - NEMS Commercial Module building type

$b^{\prime} \quad$ NEMS MAM building type

$s \quad$ End-use service

f Fuel

d Equipment decision type (values of 1 through 3 correspond, respectively, to the New, Replacement, and Retrofit decision types)

t Technology class

v. Vintage or model of floorspace or equipment, depending upon usage

$t^{\prime}$ Alternate technology class, for comparison with technology class $t$

$v^{\prime} \quad$ Alternate vintage or model of floorspace or equipment, depending on usage

p Consumer time preference premium segment

y Year designation (unless otherwise indicated, year ranges from 1993 through 2020, with the year 1993 indexed to the value 4 in the FORTRAN code. The equations below treat $y$ as the calendar year.)

$x$ Building stock designation (a value of 1 corresponds to existing buildings, a value of 2 corresponds to new construction)
} 
In addition, the following standard mathematical symbols are used in the formulae, primarily to indicate over which values of the subscripts the formula is evaluated:'

\section{Symbol Meaning}

$\begin{array}{ll}\forall & \text { for all : } \\ \epsilon & \text { belonging to the category of } \\ \exists & \text { such that } \\ \exists & \text { there exists } \\ \text { or } x & \text { multiplication }\end{array}$

Use is also made of several variables that represent 'flags', indicating conditions observed by the model during input of certain data. These flag variables and their definitions are:

FuelByTech ${ }_{L f}=1$ if technology $t$ uses fuel $f$, and is 0 otherwise.

TechbyService $_{\mathrm{s}, \mathrm{t}}=1$ if technology $\mathrm{t}$ provides service $\mathrm{s}$, and is 0 otherwise.

Most formulae are evaluated only for the current year of the forecasts. Subscripts appearing on the left side of the equal sign $\Leftrightarrow$ without explicit restrictions indicate that the formula is evaluated for every combination of applicable values of those subscripts. The variables over which summations are performed are indicated, but often without restriction. In those cases, as with the subśctipts, they assume all applicable values. Applicable values are generally all major and minor fuels for the fuel subscript, $f$; all major services for the end-use subscript, $s$; and all possible values for the remaining subscripts. In any event, fuels and services involved in calculations where technologies are explicitly referenced are always restricted to the major categories.

The equations follow the logic of the FORTRAN source code very closely to facilitate an understanding of the code. and its structure. In several instances, a variable name will appear on both sides of an equation. This is a FORTRAN programming device that allows a previous calculation to be updated (for example, multiplied by a factor) and re-stored under the same variable name: The equations are discussed in the text of Chapter 4 . The variables appearing in the equations are cross-referenced and fully defined in Appendix A, Table A-1. 


\section{Floorspace Equations}

\section{Logistic Building Survival Function:}

$$
\begin{aligned}
& \text { CMSurvRate }\left(b, y-y_{0}\right) \equiv \frac{1}{1+\left(\frac{y-y_{0}}{C M A v g A g e(b)}\right)^{\text {CMGanma }(b)}} \\
& y_{0} \equiv \text { year of construction. }
\end{aligned}
$$

Backcast 1992 existing floorspace to new construction in original year of construction:

$$
\begin{gathered}
\text { CMNewFloorSpace }_{r, b, y^{\prime}}=\frac{C B E C S F l r S p c_{r, b, v}}{C M S u r v R a t e\left(b, C B E C S y e a r-y^{\prime}\right)} \\
y^{\prime} \equiv \text { original year of construction }=\text { CMVintage }{ }_{r, b, v}
\end{gathered}
$$

where $\mathrm{v}$ ranges over each of the nine floorspace vintage ranges and represents the median year of construction within the intervals.of: 1) prior to 1899 ; 2) $1900-1919$; 3) 1920-1945; 4) 1946-1959; 5) 1960-1969; 6) 1970-1979; 7) 1980 1986; 8) 1987-1989; and 9) 1990-1992. In this case, y' ranges from 1825 through 1992.

Previously-constructed floorspace surviving Into the current year:

$$
\text { SurvFloorTotal }_{r, b, y}=\sum_{y^{\prime}=\text { CMOLdestBldgVint }}^{y^{-1}}\left[\text { CMNewFloorSpace, }{ }_{r, b, y^{\prime}} \cdot \operatorname{CMSurvRate}\left(b, y-y^{\prime}\right)\right]
$$

First estimate of n̈ew floorspace construction:

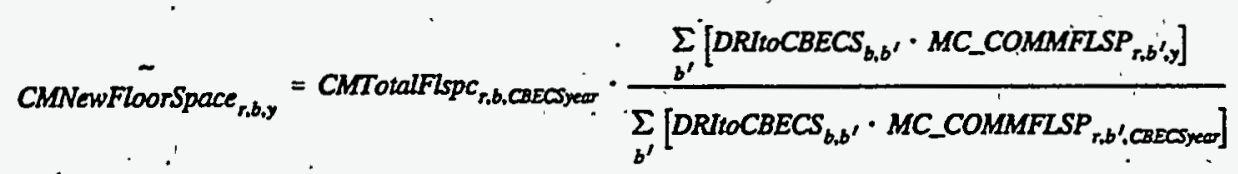

$$
\begin{aligned}
& \text { - SurvFloorTotal }{ }_{r, b, y} \text {, }
\end{aligned}
$$

Where the tilde $(\sim)$ indicates the first estimate of a variable that is iteratively calculated twice in the system of equations B-4 through B-10. 


$$
\underset{\text { CMNewFioorSpace }_{r, b, y}}{\sim}=\dot{M A X X}\left(\underset{\text { CMNewFloorSpace }_{r, b, y}}{\tilde{n}}, 0\right)
$$

First estimate of total commerclal floorepace:

$$
{\tilde{C M T o t a l F l s p c_{r, b, y}}}^{\text {SurvFloorTotal }_{r, b, y}}+\text { CMNewFloorSpace }_{r, b, y}
$$

Ratio between Macro Model and first estimate Commerclal Module floorspace growth rates:

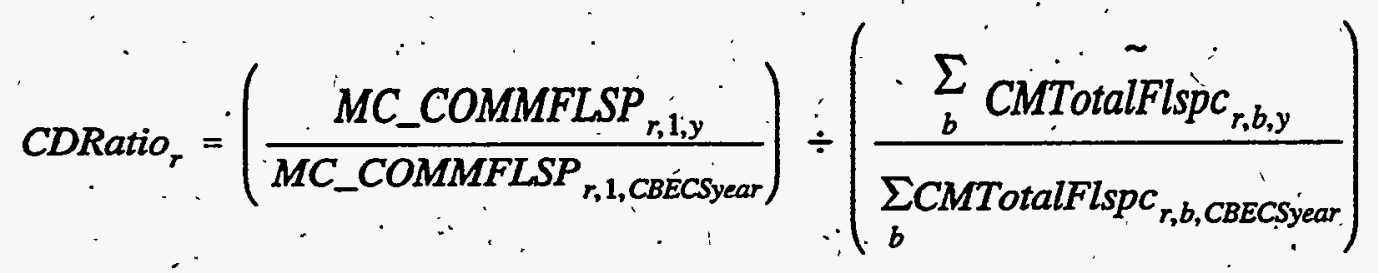

Where the value of 1 for the middle subscript of MC_COMMFiSP denotes the Census Division total commercial floorspace, across all NEMS MAM (DRI) building types.

Revised forecast of new commercial floorspace construction and total floorspace: .

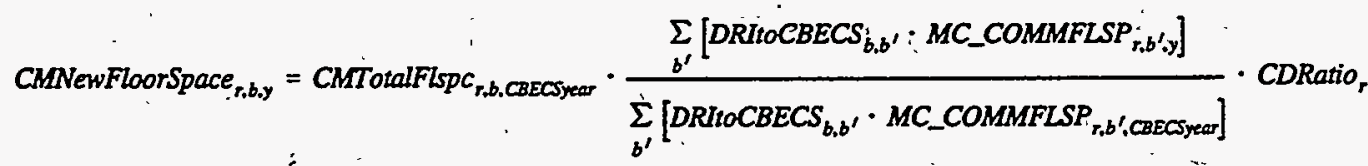

$$
\begin{aligned}
& \text { - SurvFloorTotal } r, b, y \\
& \text { CMNewFloorSpace }_{r, b, y}=\operatorname{MAX}\left(\text { CMNewFloorSpace }_{r, b, y}, 0\right)
\end{aligned}
$$

$$
\text { CMTotalFlspc }_{r, b, y}=\text { SurvFloorTotal }_{r, b, y}+\text { CMNewFloorSpace }{ }_{r, b, y}
$$


Service Demand Equations

Total Enorgy Use Intensities:

$$
\begin{aligned}
& \operatorname{ComEUI}_{r, b, s, F}=\sum_{f \in\{\text { Major Fuels }\} .} \operatorname{ComEUI}_{r, b, s, f} \\
& F \equiv \text { "total across major fuels" }=\text { CMnumMajFl }+1
\end{aligned}
$$$$
(B-11)
$$

Split Office Equlpment EUI Into PC and Non-PC If not speclfied separately:

If BaseYrPCShrofOffE $q E U I \geq 0$ Then

$$
\begin{aligned}
& \text { ComEUI }{ }_{r, b, s=\text { NonPCOff } q, f}=\operatorname{ComEUI}_{r, b, s=P C O f E q, f} \cdot(1-\text { BaseYrPCShrofOffE } q E U I) \\
& \text { ComEUI }_{r, b, s=P C O f E q, f}=\operatorname{ComEUI}_{r, b, s=P C O f E q, f} \cdot \text { BaseYrPCShrofoffEqEUI } \cdot(\mathrm{B} \text { - 12) } \\
& f \in\{\text { MajorFuels }\}
\end{aligned}
$$

Otherwise, unchanged

Total consumption by end-use in 1992:

CforStotal $_{[r, s]}=\sum_{b}\left[\right.$ ComEUI $_{r, b, s, F} \cdot$ CMTotalFlspc $\left._{r, b, C B E C S y e a r}\right]$ (B - 13)

End-use fuel consumptlon in 1992 in bulldings to which particular equipment is restricted:

CforSrestrict $_{[l, v, r, s]}=\sum_{b}\left[\operatorname{ComEUI}_{r, b, s, F} \cdot{ }^{\circ}\right.$ CMTotalFlspc $_{r, b, C B E C S y e a r} \cdot\left(1-\right.$ EquipRestriction $\left.\left._{t, v, b, r}\right)\right]$ (B - 14)

Techavailability $_{t, v, 1} \leq$ CBECSyear

Energy Information Administration

NEMS Commercial Module Documentation Report

B-5 
Revise initial equipment market shares to reflect buliding restrictions:

TechShareofServiceBASE $_{r, b, s, r, v}=$ TechShareofServiceBASE $E_{r, b, s, z, v} \cdot \frac{\text { CforStotal }}{\text { CforSrestrict }}$, if EquipRestriction ${ }_{z, v, b, r}=0$

0 , otherwise

(B - 1.5)

TechAvailability $_{\text {Lv.1 }} \leq$ CḄECSyear

TechShareofServiceBASE $E_{r, b, s, t, v}$

TechShareofService $_{r, b, s, t, v}=\sum_{b^{\prime}} \sum_{t^{\prime}, v^{\prime}}$ TechShareofServiceBASE $_{r, b^{\prime}, s, t^{\prime}, v^{\prime}}$

TechAvailability ${ }_{t^{\prime}, v^{\prime}, 1} \leq$ CBECSyear.

$(B$ - 16)

TechAvailability $_{t, v, 1} \leq$ CBECSyear

Here, $b$ is used as an alternative NEMS Commercial Module building type index rather than as a NEMS MAM (DRI) building type index, in order to represent an expression that depends both on a particular building type and a summation over all building types.

Apply fuel-specific factor to bring 1992 equipment market shares and EUI's into agreement:

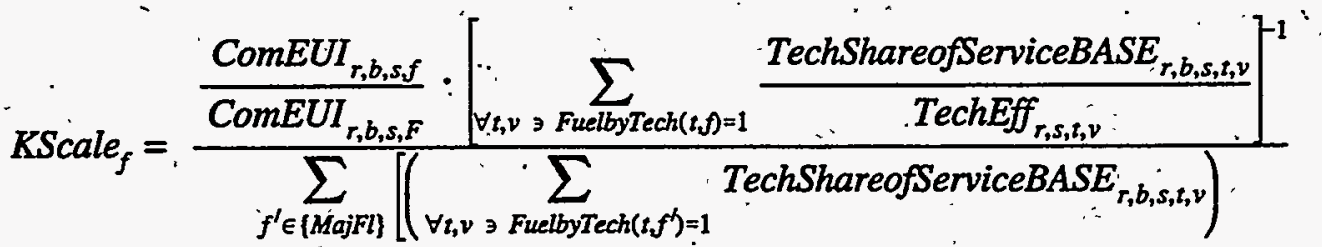

$$
\begin{aligned}
& \cdot \frac{\operatorname{ComEUI}}{\operatorname{ComEUI} I_{r, b, s, F}} \\
& \left.\therefore \sum_{\forall t, v>}\left(\frac{\text { TechShareofServiceBASE }}{\text { TechEf }_{r, b, s, t, v}} f_{r, f^{\prime}, t, v}\right)\right]
\end{aligned}
$$


TechShareofServiceBASE $E_{r, b, s, t, v}^{\cdot}=$ TechShareofServiceBASE $E_{r, b, s, i, v} \cdot K_{\text {Scale }} \cdot$ $f \in\{$ Major Fuels $\} ; \forall t, v \rightarrow$ FuelbyTech $t_{t, f}=1$

Service Deimand Intensities (SDI) prevaling in 1992:

$$
\operatorname{ServDmdIntenBASE_{s,b,r}}=\frac{\operatorname{ComEUI}_{r, b, s, F}}{\sum_{\forall t, v} \sum_{\operatorname{TechEf}_{r s, i, v} \neq 0}\left(\frac{\text { TechShareofServiceBASE }}{r, b, s, t, v}\right)}
$$

$s \in\{$ Major Services $\} ; F \equiv$ "total across fuels" $=$ CMnumMajFì +1

ServDmdIntenBASE ${ }_{s, b, r}=\operatorname{ComEUI}_{r, b, s, \dot{F}}$

$s \in\{$ Minor Services $\} ; F \equiv$ "total across fuels" = CMnumMajFl +1

Basic forecast of service demands in floorspace surviving into current year:

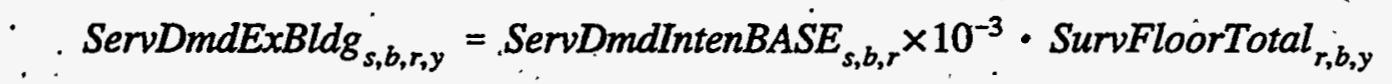
$s \in\{$ Major Services $\}$

Calculate the current year effliency of surviving base-year floorspace (upper bound is new shell efficlency):

$$
\text { ExistShBaseStock } \left._{s, b, r, y}=\left(\text { Maximum(ExistImprov,ShellEffIndex }{ }_{b, r, 2}\right)^{\frac{1}{(2015-C B E C S y e a r)}}\right)^{(v-C B E C S y e a r)}
$$

$s \in\{$ SpHeat, SpCool $\}$ 
Compute the heating efficlericy index of surviving floorspace as woighted average of surviving base-year stock and post base-year additions: .

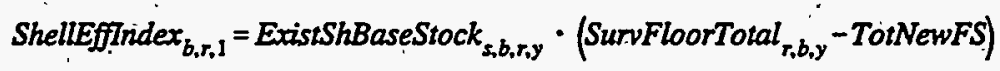

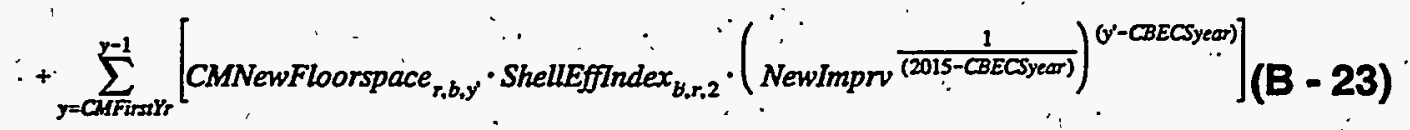

$$
\begin{aligned}
& s \in\{\text { SpḦeat, } S p \dot{C} \text { Cool }\}
\end{aligned}
$$

Interpolate effect of improving shell efficlencles on service demands in surviving floorspace:

$$
\begin{aligned}
& \operatorname{ServDimdExBldg}_{s, b, r, y}=\operatorname{ServDmdExBldg}_{s, b, r, y} \cdot \dot{S}_{\text {ShellEffIndex }_{b, r, 1}} \\
& \text {. } s \in\{\text { SpHeat }\} \\
& {\operatorname{ServDmdEx} B l d g_{s, b, r, y}}=\operatorname{ServDmdExBldg}_{s, b, r, y} \cdot\left[\left(\text { ShellEffIndex }_{b, r, 1}-1.0\right) \cdot(-0.1)+1.002\right] \\
& s \in\{S p C o o l\}
\end{aligned}
$$

Basic forecast of service demands in new floorspace construction:

$$
\begin{aligned}
& \text { NewServDmd }_{s, b, r, y}=\text { ServDmdIntenBASE }_{s, b, r} \times 10^{-3} \cdot \text { CMNewFloorspace }_{r, b, y} \\
& s \in \text { MMajor Services }
\end{aligned}
$$

Calculate the current year improvement to new heating shell efficlency:

$$
\begin{aligned}
& \text { NewShAdj }=\left(\text { NewImprv } \frac{\left.\because \cdot \frac{1}{(2015-C B E C S y e a r)}\right)}{(y-C B E C S y e a r)}\right. \\
& s \in\{\text { SpHeat, SpCool }\}
\end{aligned}
$$

Interpolate effect of Improving shell efficiencies on service demands in néw fioorspace:

$$
\begin{aligned}
& \text { NewServDmd }_{s, b, r, y}=\text { NewServDmd }_{s, b, r, y} \cdot \text { ShellEffIndex }_{b, r, 2} \cdot \text { NewShAdj } \\
& s \in\{\text { SpHeat }\} .
\end{aligned}
$$


NewServDmd $_{s, b, r, y}=N e w S e r v D m d_{s, b, r, y} \cdot\left[\left(\right.\right.$ ShellEffIndex $\left.\left._{b, r, 2} \cdot \operatorname{NewShAdj}_{-1.0}\right) \cdot(-0.0309)+1.0315\right]$ $s \in\{S p C o o l\}$

$(B-29)$

Effect of serviced floorepace proportion difference between surviving and new construction:

$$
\begin{aligned}
& \text { NewServDmd }_{s, b, r, y}=\text { NewServDmd } d_{s, b, r, y} \cdot \frac{\text { ServicedFlspcProp }_{b, s, n e w}}{\text { ServicedFlspcProp }_{b, s, \text { existing }}} \cdot(\mathrm{B}-\mathbf{3 0}) \\
& s \leq \text { CMnumVarSDI }
\end{aligned}
$$

Minor service demand forecast with 1992 average efficiency indexed to one:

$\operatorname{ServDmdExBldg}_{s, b, r, y}=\operatorname{ServDmdIntenBASE_{s,b,r}} \times 10^{-3} \cdot$ SurvFlooṙTotal $_{r, b, y}$

$s \in\{$ MinorServices\}

(B - 31)

$\operatorname{NewServDmd}_{s, b, r, y}=\operatorname{ServDmdIntenBASE}_{s, b, r}^{\prime} \times 10^{-3} \cdot$ CMNewFloorspace $_{r, b, y}$

$s \in\{$ Minor Services $\}$

Effect of continuing market penetration on demands for certain services:

$$
\operatorname{ServDmdExBldg_{s,b,r,y}}=\operatorname{ServDmdExBldg_{s,b,r,y}} \cdot \text { MarketPenetration }_{s, y}
$$$$
s \in\{\text { OfficeEquipment:PC, OfficeEquipment:NonPC, Other\} }
$$

$\operatorname{NewServDmd}_{s, b, r, y}=$ NewServDmd $_{s, b, r, y}^{:} \cdot$ MarketPenetration $_{s, y}$

$s \in\{$ OfficeEauipment:PC. OfficeEauipment:NonPC. Other)

Reduce demands by amounts satisfied using solar energy directly:

$$
\operatorname{ServDmdExBLdg_{s,b,r,y}}=\operatorname{ServDmdExBldg}_{s, b, r, y}-\left(\frac{\text { SolarRenewableContrib }_{r, s, y}}{\text { CMNumBldg }} \cdot \frac{\text { SurvFloorTotal }_{r, b, y}}{\text { TotalFloorspace }_{r, b, y}}\right)
$$

$s \in\{$ Solar Services $\}$ 
Amount of service demand requiring replacement equipment due to equipment failure:

NewServDmd $_{s, b, r, y}=$ NewServDmd $_{s, b, r, y}-\left(\frac{\text { SolarRenewableContrib }_{r, s, y}}{C M N u m B l d g} \cdot \frac{\text { CMNewFloorspace }_{r, b, y}}{\text { TotalFloorspace }_{r, b, y}}\right)(\mathbf{B}-36)$ $s \in\{$ Solar Services $\}$.

RetireServDmd $_{s, b, r, y}=\operatorname{ServDmdExBLdg}_{s, b, r, y} \cdot \sum\left(\frac{\text { PrevYrTechShareofService }_{r, b, s, l, v}}{\text { TechLife }_{t, v}}\right)$

(B - 37)

$\forall t, \ni$ TechbyService $_{s, t}=1$

Amount of service demand satisfled by working equipment, but subject to the retrofit decision:

ServDmdSurv $_{s, b, r, y}=\operatorname{ServDmdExBldg}_{s, b, r, y}-$ RetireServDmd $_{s ; b, r, y}$

$y>$ CMFirstYr 


\section{Technology Choice Equations}

Proportion of service demand affected by falled equipment:

$$
\text { ReplacementProportion }_{r, b, s}=\sum\left(\frac{\text { PrevYrTechShareofService }_{r, b, s, t, v}}{\text { TechLife }_{t, v} \ldots}\right)
$$

$$
\forall t, v \ni \text { TechbyService }_{s, t}^{\cdot}=1
$$

Equipment share of service demand not requiring equipment replacement:

$$
\begin{aligned}
& \text { SurvivingShareofService }_{r, b, s, t, v}=\text { PrevYrTechShareofService }_{r, b, s, t, v} \cdot \frac{\left(1-\frac{1}{\text { Techlife }_{h, v}}\right)}{1-\text { ReplacementProportion } r, b, s} \text { (B - 40) } \\
& \forall t, v \ni \text { TechbyService }_{s, t}=1
\end{aligned}
$$

Fuel shares of service demand not requiring equipment replacement:

$$
\text { SurvivingFuelShäreofService } \left._{r, b, s, f}=\sum_{\forall t, v \geqslant \text { TechbyService }(s, t)=1_{r, b, s, t, v}} \text { SüvivingShareofService } \cdot \text { FuelbyTech }_{t, f}\right]
$$

Failed equipment shares of service demand requiring equipment replacement:

$$
\text { ReplacementShareofService }_{r, b, s, t, v}=\cdot \frac{\text { PrevYrTechShareofService }_{r, b, s, t, v} \cdot\left[\frac{1}{\text { TechLife }_{t, v}}\right]}{\text { ReplacementProportion }_{r, b, s}}
$$


Fuel shares of service demand requiring equipment replacement:

$$
\begin{gathered}
\text { ReplacementFuelShareofService }_{r, b, s, f}=\sum_{\forall t, v \geqslant \text { TechbyService }_{-s, t}=1}\left(\text { ReplacementShareofService }_{r, b, s, t, v} \cdot \text { FuelbyTech }_{t, f}\right) \\
\forall
\end{gathered}
$$

Incremental cost of heat pump to provide heating over cost of standard cooling equipment:

$$
\begin{aligned}
& \text { TechCost }{ }_{t, v, 1}=\text { TechCost }_{t, v, 1}-\text { TechCost }_{\text {CoolingTechindexHP,v, }} \\
& t, v \in\{\text { Heatpumps for SpHeat }\}
\end{aligned}
$$

This is a one-time adjustment performed following the input of TechCost from the KTECH file.

\section{Cost Trend Function when flag CostTrendSwitch is set to one:}

$$
\begin{aligned}
& \text { KEqCost }\left(t, v, y, " C A P^{\prime \prime}\right) \equiv \frac{\text { TechCost }_{t, v, 1} \cdot \delta}{1+\left(\frac{y-y_{1}}{y_{0}-y_{1}}\right)^{\gamma}}+(1-\delta) \cdot \text { TechCost }_{t, v, 1}, \quad \text { for Infant technologies } \\
& \frac{\text { TechCost }_{t, v, 1}-2 \cdot \delta}{1+\left(\frac{y-y_{1}}{y_{0}-y_{1}}\right)^{\gamma}}+(1-\delta) \cdot \text { TechCost }_{t, v, 1} \text {, for Adolescent technologies }
\end{aligned}
$$

$$
\text { TechCost } t_{t, v, 1} \text {, for Mature technologies. }
$$

$\gamma \equiv$ shape parameter corresponding to the rate of price decline,

$\delta \equiv$ total anticipated percentage decline in real cost from the initial value,

$y_{0} \equiv$ year dictating the curve's inflection point,

$y_{1} \equiv$ effective year of introduction for the given technology:

TechCost $_{h, 1,1}$ is used if CostTrendSwitch is set to zero. 
Calculate the shell efficlency factor for space heating equipment directly from the shell efficlency indices calculated in the Service Demand Submodule:

$$
\begin{aligned}
& \text { ShellEffFactor }_{x}=\text { ShellEffIndex }_{b, r, x} \\
& s \in\{\text { SpHeat }\}
\end{aligned}
$$

Modlfy the space heating Indices by the adjustment for thermal integrity to obtain the space cooling shell efficlency factor:

$$
\begin{aligned}
& \text { ShellEffFactor }_{1}=\left(\text { ShellEffIndex }_{b, r, 1}-1\right) \cdot-0.1+1.002 \\
& \text { ShellEffFactor }_{2}=\left(\text { ShellEffIndex }_{b, r, 2} \cdot \text { NewShAdj }^{-1}\right) \cdot-0.0309+1.0315 \\
& s \in\{\text { SpCool }\}
\end{aligned}
$$

\section{Annualized cost of new equipment:}

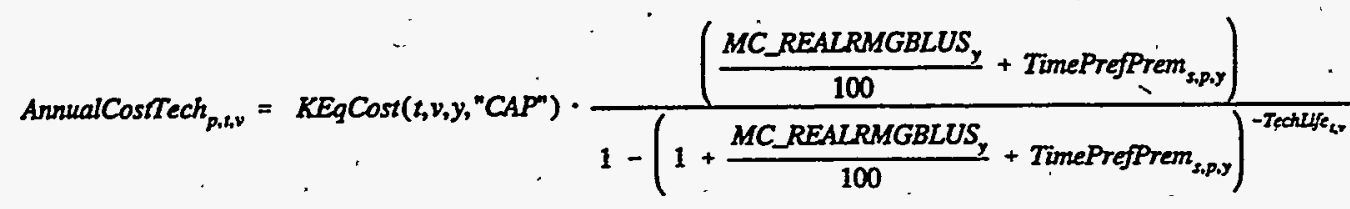

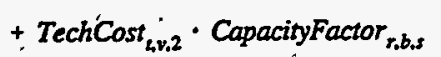

$$
\begin{aligned}
& + \text { ShellEffFactor }_{x} \cdot \frac{\text { ConvFactor }_{\text {TechEff }}}{\text { Th,s, }_{\text {. }}} \cdot \text { CapacityFactor }_{r, b, s} \cdot \text { FuelCost }_{f_{r, r y, s}} \\
& \text { ConvFactor } \equiv 8.76 \text { for } s \text { * lighting; } 0.3343^{-1} \text { for } s=\text { lighting } \\
& f_{t} \equiv \text { fuel used by } t
\end{aligned}
$$

where the third subscript of TechCost is 1 for annual capital cost per unit of service demand and is 2 for annual operating and maintenance costs (excluding fuel costs). The variable ShellEffFactor is involved in the calculation only for space heating and space cooling. Because only the relative costs of choices are important within a given building, to simplify the calculation actually evaluated by the model the equation above is divided by CapacityFactor, which has the same value for all equipment providing a given service in a given building type and Census Division. FuelCost $t_{f, r y s}$ is the price of fuel $f$ in Census Division $r$ during year $y$ for end-use service $s$ (the subscript $s$ is only applicable for electricity prices) for the default mode of myopic foresight and the expression in Equation B-49 when optional price expectations modeling is used. 
Expression for FuelCost when optlonal price expectations àre used:

$$
\text { FuelCost }_{f_{s} r, y, s} \equiv \frac{1}{\text { TechLife }_{t, v}} \cdot \sum_{y^{\prime}=y}^{y+\text { TechLife }_{z, v}-1} \text { Xprice }_{f_{t}, r, y}
$$

$$
f_{t} \equiv \text { fuel used by } t
$$

Lesst Cost Decision Rule- - Identify least cost equipment:

Find $t, v$ such that AnnualCostTech ${ }_{p, t, v} \leq$ AnnualCostTech ${ }_{p, t^{\prime}, v^{\prime}} \forall t^{\prime}, v^{\prime}$ then $L C T N R A F_{p, 1}=t$ and $L C T N R A F_{p, 2}=v$

LCTNRAF $F_{\mathrm{p}, 1}$ represents the technology class with the least annualized cost.

LCTNRAF $F_{\mathrm{p} 2}$ represents the technology model with the least annualized cost.

Same Fuel Decision Rule - fdentify least cost equipment using the same fuel as the existing stock

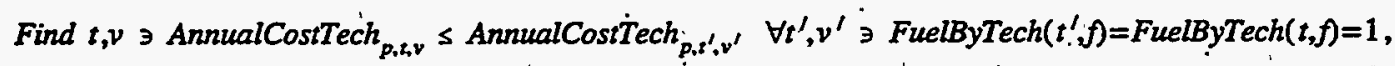
then LCTNRSF $_{p f .1}=t$ and LCTNRSF $F_{p f, 2}=\varphi$

If $\nexists t \rightarrow$ FuelByTech $(t, f)=1$, then $\operatorname{LCTNRSF}_{p f, 1}=L C T N R S F_{p f, 2}=0$

$(B-51):$

$f \in\{$ Major Fuels $\}$

where LCTNRSF $_{\mathrm{p} f, 1}$ represents the technology class with the least annualized cost, and

LCTNRSF $_{\mathrm{p}, \mathrm{f} 2}$ represents the technology model with the least annualized cost.

Same Technology Decision Rule - Identify least cost model in current technology class:

Find $v$ such that AnnualCostTech ${ }_{p, t, v} \leq$ AnnualCostTech $_{p, t, v}, \forall v^{\prime}$ then LCVNRST $_{p, t}=v$

LCVNRST $_{\mathrm{pf}}$ represents the technology model with the least annualized cost. 
Market shares of equipment within least cost behavior segment of new and replacement declsion types:

$$
\begin{aligned}
& \text { LCMSNR }_{t, \nu}=\sum_{\dot{p}} \text { TimePrefProp }_{s, p, y} \\
& \forall p \ni L C T N R A F_{p, 1}=t^{i} \text { and } L C T N R A F_{p, 2}=v
\end{aligned}
$$

Equipment market shares within same fuel behavior segment of new decision type:

$$
\text { SFMSN }_{t, v}=\sum_{\forall p \ni \operatorname{LCTNRSF}_{p, f, 1}\left[\text { TimePrefProp }_{s, p, y} \cdot \text { PrevYrFuelShareofService }_{r, b, s, f}\right]} \text { and LCTNRSF } F_{p, f, 2}=v ; f \in\{\text { MajFuels }\}
$$
',

Equipment market shares within same fuel segment of replacement declsion type:

$$
\begin{aligned}
& \text { SFMSR } \left._{t, v}=\sum \text { [TimePrefProp }_{s, p, y} \cdot \text { ReplacementFuelShareofService }_{r, b, s, f}\right] \\
& \forall p \ni \text { LCTNRSF }_{p, f, 1}=t \text {, and LCTNRSF } F_{p, f, 2}=v ; f \in\{\text { MajFuels }\}
\end{aligned}
$$

Equipment market shares within same technology of new decision type:

$$
\operatorname{STMSN}_{t, v}^{\prime}=\left[\sum_{\forall p} \sum_{L C V N R S T_{p, s^{\prime}}=v} \text { TimePrefProp }_{s, p, y, y}\right] \cdot\left[\sum_{\forall v^{\prime}} \text { PrevYrTechShareofService }_{r, b s, t, v^{\prime}}\right]
$$

Equipment market shares within same technology behavior segment of replacement declsion type:

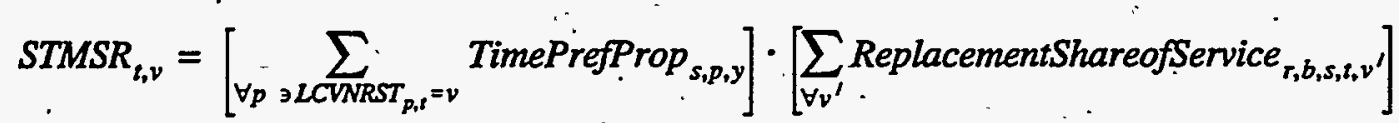


Equipment market shares within new decision type, consolidated across behavior segments:

$$
\begin{aligned}
M_{b, s, 1, t, v} & =\text { BehaviorShare }_{s, b, 1,1} \cdot \overline{L C M S N R}_{t, v} \\
& + \text { BehaviorShare }_{s, b, 1,2} \cdot \text { SFMSN }_{t, v} \\
& + \text { BehaviorShare }_{s, b, 1,3} \cdot S T M S N_{t, v}
\end{aligned}
$$

Where the subscript ' 1 ' appearing in $M S$ and the next, to last subscript of BehaviorShare represents the decision type, and, in' this case, corresponds to the 'new' decision. The last subscript of BehaviorShare represents the behavior rule.

Equipment market shares within replacement decislon type, consolidated across behavior segments:

$$
\begin{aligned}
M_{b, s, 2, t, v} & =\text { BehaviorShare }_{s, b, 2,1} \cdot \text { LCMSNR }_{t, v} \\
& + \text { BehaviorShare }_{s, b, 2,2} \cdot S F M S R_{t, v} \\
& + \text { BehaviorShare }_{s, b, 2,3} \cdot S T M S R_{t, v}
\end{aligned}
$$

Where the subscript ' 2 ' appearing in $M S$ and the next to last subscript of BehaviorShare represents the decision type, '। and, in this case, corresponds to the 'replacement' decision. The last subscript of BehaviorShare represents the 'behavior rule. 


$$
\begin{aligned}
& A C E_{h, v, p}=\operatorname{TechCost}_{h, v, 2} \cdot \text { CapacityFacior }_{s, b, s}
\end{aligned}
$$

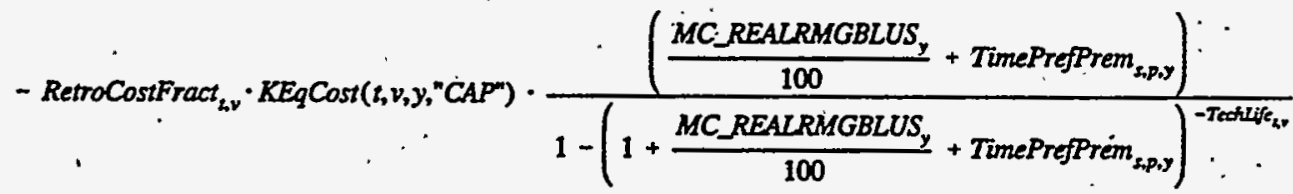

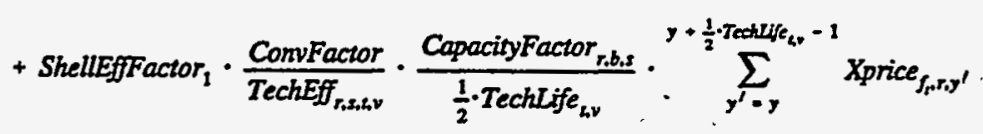

ConvFactor $=8.76$ for $s *$ lighting; $0.3343^{-1}$ for $s=$ lighting

$f_{t} \equiv$ fuel used by $t$

The variable ShellEffFactor is involved in the calculation only for space heating and space cooling. Because only the relative costs of choices are important within a given building, the equation above is divided by CapacityFactor, which has the same value for all equipment providing a given service in a given building type and Census Division,

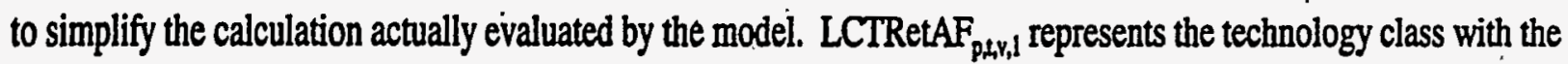

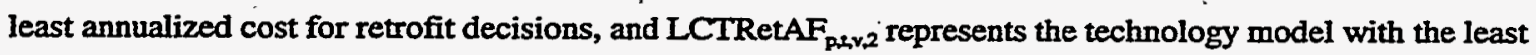
annualized cost for retrofit decisions.

Identffy lesst cost alternative for retrofft decision, following least cost behavior:

Find $t^{\prime}, v^{\prime}$ such that AnnualCostTech $h_{p, t^{\prime}, v^{\prime}} \leq A C E_{t, v, p}$

if none found, set $t^{\prime}=t, v^{\prime}=v$.

If $t, v$ unavailable, set $t^{\prime}=v^{\prime}=0$

then $\operatorname{LCTRetAF}_{p, t, v, 1}=t^{\prime}, \operatorname{LCTRetAF} F_{p, t, v, 2}=v^{\prime}$

Identify least cost retrofit alternative for same fuel behavior:

Find $t^{\prime}, v^{\prime} \ni$ AnnualCostTech ${ }_{p, t^{\prime}, v^{\prime}} \leq A C E_{t, v_{p}, p}, f_{t^{\prime}}=f_{i}$

If $\nexists t^{\prime}, v^{\prime}$, set $t^{\prime}=t, v^{\prime}=v^{\prime}$

If $\nexists t, v$, set $t^{\prime}=v^{\prime}=0$

(B - 62)

then $\operatorname{LCTRetSF}_{p, L, v, 1}=t^{\prime}$, LCTRetSF $F_{p, t, v, 2}=v^{\prime}$ 
Identify least cost retrofit alternative for same technology behavior, when optional retrofiting is allowed:

Find $v^{\prime} \ni$ AnnualCostTech $h_{p, i, v^{\prime}} \leq A C E_{t, v, p}, \forall v^{\prime}$

If $\nexists v^{\prime}$, set $v^{\prime}=v$.

$(B-63)$

then $\dot{L} C V R e t S T_{p, t, \nu}=v^{\prime}$

Equipment market shares within least cost behavior segment of retrofit decision type:

$$
\begin{aligned}
\text { LCMSRet }_{t, v}= & \left.\sum_{\forall t^{\prime}, v^{\prime}} \text { TimePrefProp }_{s, p, y} \cdot \text { SurvivingShareofService }_{t^{\prime}, v^{\prime}}\right] \\
& \text { SCRetAF }_{p, t^{\prime}, v^{\prime}, 1}=t, \operatorname{LCTRetAF}_{p, t^{\prime}, v^{\prime}, 2}=v ; \forall p
\end{aligned}
$$

Equipment market shares within same fuel behavior segment of retrofft decision type:

$$
\begin{aligned}
\text { SFMSRet }_{t, v} & \left.=\sum_{\forall \text { TimePrefProp }_{s, p, y}} \text {. SurvivingShareofService } t_{t^{\prime}, v^{\prime}}\right] \\
& \forall t^{\prime}, v^{\prime} \ni \operatorname{LCTRetSF}_{p, t^{\prime}, v^{\prime}, 1}=t, \text { LCTRetSF }_{p, t^{\prime}, v^{\prime}, 2}=v ; \forall p
\end{aligned}
$$

LCTRetSF $_{\text {prv, }, 1}$ represents the technology class with the least annualized cost for retrofit decisions, and

LCTRetSF $_{p, 1,2,2}$ represents the technology model with the least annualized cost for retrofit decisions.

Equipment market shares within same technology behavior segment of retroftt decision type:

$$
\begin{aligned}
& \text { STMSRet } \left._{t, v}=\sum \text { TimePrefProp }_{s, p, y} \cdot \text { SunvivingShareofService }_{t, v}\right] \\
& \forall v^{\prime} \operatorname{LCVRetST}_{p, t, v^{\prime}}=v ; \forall p, \quad \text { if STRetBehav }=1 \\
& \text { SurvivingShareofService }_{t, v},{ }^{\prime}, \quad \text { if STRetBehav }=0
\end{aligned}
$$

LCVRetST $_{p, i v}$ represents the technology model with the least annualized cost for retrofit decisions 
.Equipment market shares within retrofit decision type, consolidated across behavior segments:

$$
\begin{aligned}
\text { MS }_{b, s, 3, t, v} & =\text { BehaviorShare }_{s, b, 3,1} \times \text { LCMSRet }_{t, v} \\
& + \text { BehaviorShare }_{s, b, 3,2} \times \text { SFMSRet }_{t, v} \\
& + \text { BehaviorShare }_{s, b, 3,3} \times \text { STMSRet }_{t, v}
\end{aligned}
$$

Where the subscript. ' 3 ' appearing in $M S$ and the next to last subscript of BehaviorShare represents the decision type, and, in this case, corresponds to the 'retrofit' decision. The last subscript of BehaviorShare represents the behavior rule.

Heat pump market shares of space cooling service demand:

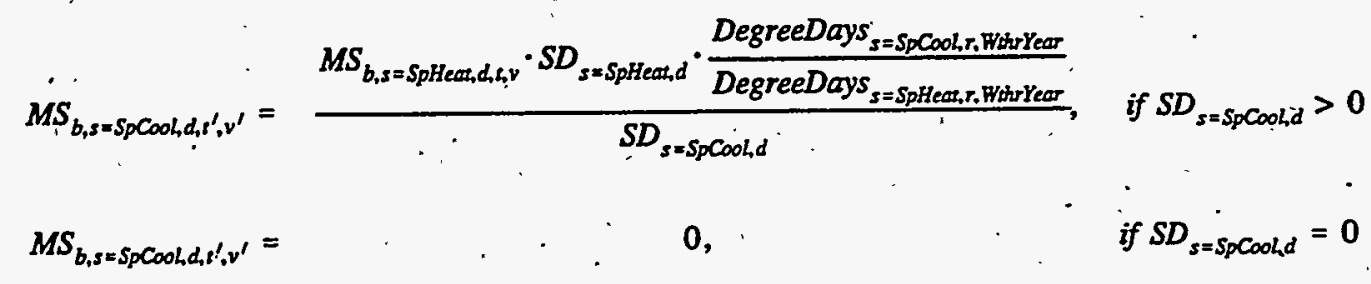

for $t, v \in\{$,Heatpumps for SpHeat $\}$

$t^{\prime}, v^{\prime} \equiv$ same equip as $t, v$, except for SpCool

$$
\begin{array}{r}
S D_{s, d} \equiv N S D_{r, b, s, y}, \text { if } d=1 \\
R S D_{r, b, s, y}, \text { if } d=2 \\
S S D_{r, b, s, y}, \text { if } d=3
\end{array}
$$

WhirYear $\equiv y$ (current year), if $y \leq K S T E O Y R$ KSTEOYR, otherwise

Amount of cooling service demand satisfied by heat pumps:

$$
\begin{aligned}
& \text { HeatPumpCoolingSD } d_{d}=S D_{s=S p \text { Cool, } d} \cdot \sum_{t, v \in\{\text { Heatpunps for } S p C o o l\}} M S_{b, s=S p \text { Coold,t,v }} \\
& \text { Normalizer }_{d}=\sum_{t, v \in[S p \operatorname{Cool} \text { equip other than heatpumps }\}} M S_{b, s=S p \operatorname{Cooh}, \boldsymbol{t}, v}
\end{aligned}
$$$$
\text { (B - 69) }
$$ 
Adjusted market shares of space cooling equipment other than heat pumps:

$$
M S_{b, s=S p \text { Cool,d,t,v}}=\frac{M S_{b,=S p \text { Coold }, t, v}}{\text { Normalizer }_{d}} \cdot \frac{\left.\left(S D_{s=S p C o o h d}-\text { HeatPumpCoolingSD }\right)_{d}\right)}{S D_{s=S p C o o l, d}}
$$

$t, v \in\{$ SpCool equipment other than heatpumps $\}$

Fuel shares by fuel, declsion type, service, bullding, and Census Division:

$$
\begin{aligned}
& F S_{r, b, s, d f}=\sum_{t} \sum_{v}\left[M S_{b, s, d, t, v} \times \text { Fuelbytech }_{t f}\right] ; \text { where FuelbyTech } t_{t, f}=1 \text { if } t \text { uses } f \\
& f \in\{\text { Major Fuels }\}
\end{aligned}
$$

Average equipment efficiency by fuel, decision type, service, bullding, and Census Division:

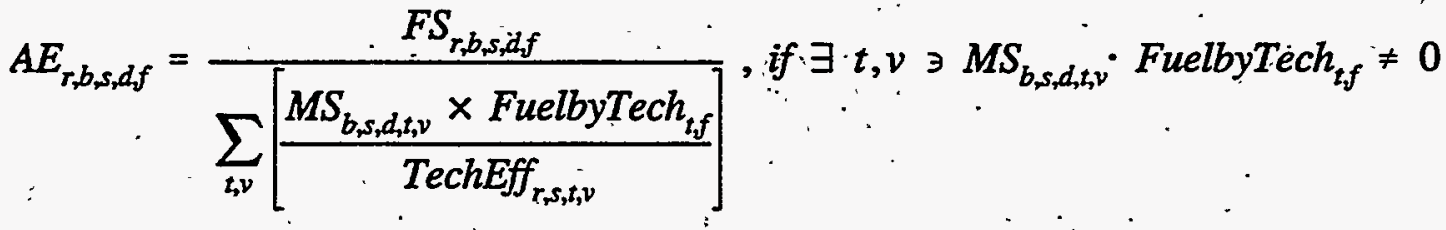

$$
\begin{aligned}
& 0 \text {, otherwise }
\end{aligned}
$$

$$
f \in\{\text { MajorFuels }\}
$$

Fuel shares by fuel, end-use, building, and Census Division:

$$
\begin{aligned}
\text { FuelShareofService }_{r, b, s, j} & =\frac{N S D_{r, b, s, y} \times F S_{r, b s, 1, f}}{T S D_{r, b, s y}} \\
& +\frac{R S D_{r, b s, y} \times F S_{r, b s, 2 f}}{T S D_{r, b s, y}}+\frac{S S D_{r, s, b y} \times F S_{r, b s, 3 f}}{T S D_{r, b, s y}}
\end{aligned}
$$

where $T S D_{r, b s y}>0,0$ elsewhere

$$
f \in\{\text { MajFuel }\}
$$

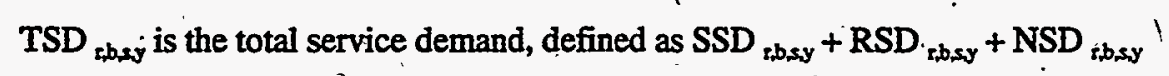


Equipment market shares by equipment, end-use, bullding, and Census Divislon:

$$
\begin{aligned}
& \text { TechShareofService }_{r, b, s, t, v}=\frac{N S D_{r, b, s, y} \times M S_{r, b, s, 1, t, v}}{T S D_{r, b, s, y}} \\
& +\frac{R S D_{r, b, s, y} \times M S_{r, b, s, 2, i, y}}{T S D_{r, b, s, y}}+\frac{S S D_{r, s, b, y} \times M S_{r, b, s, 3, t, v}}{T S D_{r, b, s, y}} \\
& \text { where } T S D_{r, b, s, y}>0,0 \text { elsewhere } \\
& \forall t, v .
\end{aligned}
$$

Average equipment efficiency by fuel, end-use, building, and Census Division:

$$
\begin{aligned}
& \text { AverageEfficiency }_{r, b, s, f}=\frac{\text { FuelShareofService }_{r, b, s, f}}{\sum_{t, v}\left[\frac{\text { TechShareofService }_{r, b, s, i, v} \times \text { FuelbyTech }_{t, f}}{\text { TechEff }_{r, s, t, v}}\right]} \\
& \text { if } \exists t \ni \text { TechShareofService } r, b, s, t, v . \text { FuelbyTech }_{t, f} \neq 0 \\
& 0 \text {, otherwise } \\
& f \in\{\text { MajFuels }\}
\end{aligned}
$$

Average equipment efficlency for new declsion type by fuel, end-use, and Census Dlvision:

$$
\operatorname{DecAvgEff}_{r, s, 1, f, y}=\frac{\sum_{b}\left[F S_{r, b, s, 1, f} \times N S D_{r, b, s, y}\right]}{\sum_{b}\left[\frac{F S_{r, b, s, 1, f} \times N S D_{r, b, s, y}}{A E_{r, b, s, 1, f}}\right]}
$$

$$
f \in\{\text { MajFuels }\} \text {; }
$$

The third subscript of DecAvgEff represents the equipment decision type, $d$. 
Average equipment efficlency for replacement declsion type, by fuel, end-use, and Census Division:

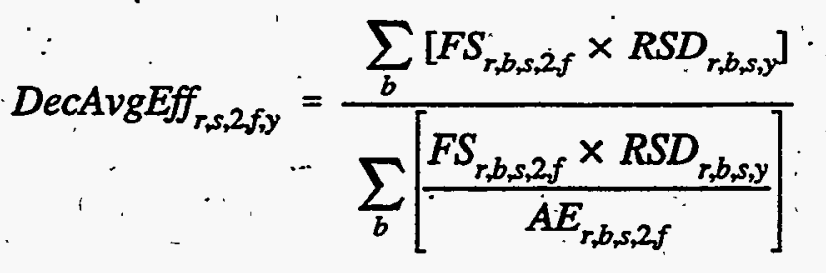

$$
\begin{aligned}
& f \in\{\text { MajFuels }\}
\end{aligned}
$$

Average equipment efficiency for retrofit decision type, by fuel, end-usè, and Census Division:

$$
\begin{aligned}
& \text { DecAvgEff } f_{r, s, 3, y, y}=\frac{\sum_{b}\left[F S_{r, b, s, 3, f} \times S S D_{r, b, s, y}\right]}{\sum_{b}\left[\frac{F S_{r, b, s, 3, f} \times S S D_{r, b, b, y}}{A E_{r, b s, 3, f}}\right]} \\
& f \in\{\text { MajFuels }\}
\end{aligned}
$$

Fuel shares within new declsion type, by fuel; end-use, and Census Division:

$$
\begin{aligned}
& \text { DecFuelShare }_{r, s, 1, f y}=\frac{\sum_{b}\left[F S_{r, b s, 1,1_{f}} \times N S D_{r, b, s, y}\right]}{\sum_{b} N S D_{r, b, b s}} \\
& f \in\{\text { MajFuels }\}
\end{aligned}
$$

The third subscript of DecFuelShare represents decision type, d.

Fuel shares within replacement decision type; by fuel, end-use, and Census Division:

$$
\text { DecFuelShare }_{r, s, 2 f, y}=\frac{\sum_{b}\left[F S_{r, b, s, 2 f} \times R S D_{r, b, s, y}\right]}{\sum_{b} R S D_{r, b s, y}}
$$

$$
f \in\{\text { MajFuelș }
$$


Fual shares within retrofft decision type, by fusl, end-use, and Census Dhtalon:

$$
\begin{gathered}
\text { DecFuelShare }_{r, s, 3 f, y} \\
\ldots \in\{\text { MajFuels }\}
\end{gathered}=\frac{\sum_{b}\left[F S_{r, b, s, 3 f} \times S S D_{r, b s, y}\right]}{\sum_{\cdot b} S S D_{r, b, s, y}}
$$

Nattoinal average equipment officlency, by fusl and end-use:

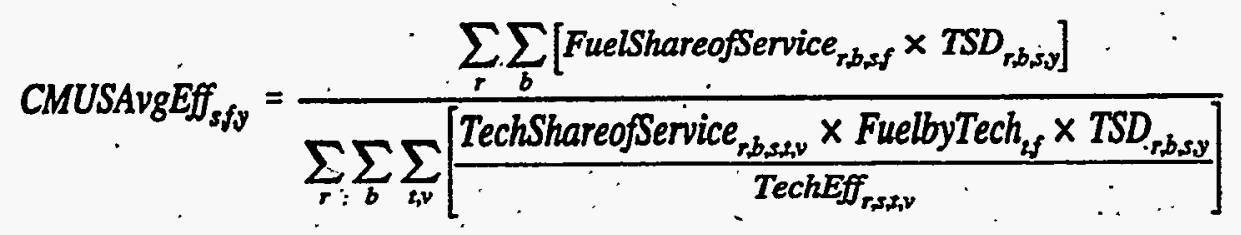

$s \in\{$ MajServ\},$f \in\{$ MajFuels $\}$

Minor cervice average efticlency by fuel, end-use, bullding, and Census Division:

$$
\begin{aligned}
& \text { AverageEfficiency }_{r, b, s, f}=\text { PrevYrAverageEfficiency }_{r, b, s, f} \times\left(1+\text { EffGrowthRate }_{s}\right) \\
& s \in\{\text { MinServ\} }, f=\text { electricity. }
\end{aligned}
$$

Ulnor service average efficlency and fuel shạe by deciston type, fuci, end-use, and Census. Dhision:

$$
\begin{aligned}
& \text { DecAvgEff }_{r, s, d_{j}, y}=\text { AverageEfficiency }_{r, b, s, 1} \\
& \text { DecFueiShare }_{r, s, d f, y}=\text { FuelShrofService }_{r, b, s, 1} \\
& s \in\left\{\text { MinServ }^{\prime}\right.
\end{aligned}
$$




\section{End-Use Fuel Consumption Equations}

Baslc estimate of fusl consumption to moet eniduse demands other than lighting:

$$
\begin{aligned}
& \text { EndUseConsump }_{f, s, b, r}=\frac{\text { FuelShareofService }_{r, b, s, f} \times \text { TSD }_{r, b, s, y}}{\text { AverageEfficiéncy }_{r, b, s, y}} \text {, if Average Efficiency }>0 \\
& s \neq \text { lighting }, f \in\{\text { MajFuels\} } \\
& 0 \text {, otherwise }
\end{aligned}
$$

Basle estimate of tual conisumption by lighting equipment:

$$
\begin{aligned}
& \text { EndUseConsump }_{f_{s, b}, r}=\frac{\text { FuelShareofService }{ }_{r, b, s, f} \times T_{r_{r, b}, y}}{\text { AverageEfficiency }_{r, b, s, y}} \div 0.03343 \\
& s=\text { lighting }
\end{aligned}
$$

where $0.03343 \frac{G W Y}{T B t u}$ converts units used in lighting to Btu units

\section{Modification of fuel consumption by Price Elasticlty and Rebound Effect:}

$$
\begin{aligned}
& \text { EndUseConsump }_{f, s, b, r, y}=\text { EndUseConsump }_{f, s, b, r, y} \cdot\left(1+\left[\frac{\operatorname{Pr}_{f, r, y, s}-\operatorname{Pr}_{f, r, \text { CBECSyear,s }}}{\operatorname{Pr}_{f, r, C B E C \text { year,s }}}\right]\right) \\
& \text {-. } \quad\left(1+\left[1-\frac{\text { AveragéEficiency }_{r, b, s, f}}{\text { AverageEfficiencyBASE } r, b, s, f}\right]\right) \\
& \cdot\left(\begin{array}{c}
1+\left[\left(\text { ShellEffindex }_{b, r, 1}-1\right) \cdot \frac{(y-C B E C \text { Syear })}{(2015-C B E C \text { Syear })}\right] \\
-[
\end{array}\right)
\end{aligned}
$$

- $f \in\{$ MajFuels $\}$.

$s \in\{S p H e a t+S p C o o l\}$

evaluated without building shell effect (third term) for

$s \in\{$ water htg, ventilation, cooking, and lighting \}

Where $P r_{f r y s}$ is the price of fuel $f$ in Census Division $r$ during year $y$ for end-use service $s$ (the subscript $s$ is only applicable for electricity prices). $y$ is expressed as a'calendar year in the third term. 
EndUseConsump $_{f, s, b, r, y}=$ EndUseConsump $_{f, s, b, r, y} \cdot \frac{\text { DegreeDays }_{s, r, w \text { thyr }}}{\text { DegreeDays }_{s, r, C B E C S y e a r}}$. $s^{*} \in\{$ SpHeat, $S p C o o l\}$ $f \in\{$ MajFuels $\}$ wthryr $\equiv . \quad y, \cdot$ if $y \leq K S T E O Y R$ KSTEOYR, if $y>$ KSTEOYR

Total fual consumption acrose end-use services:

$$
\begin{aligned}
& \text { FinalEndUseCon }_{f, b, r, y}=\sum_{s} \text { EndUseConsump }_{f, s, b, r} \\
& f \in\{\text { MajFuels }\}
\end{aligned}
$$

Unbenchmarked fuil consumption forecast by Census Divislon and bullding type:

$$
\begin{aligned}
& \text { UnBenchCon }_{f, r, b, y}=\text { FinalEndUseCon }_{f, b, r, y} \\
& f \in\{\text { MajFuels }\}
\end{aligned}
$$

U.S. total fual consumption by end-use (quadrillion Btu):

$$
\begin{aligned}
& \text { CMUSConsump }_{s, f, y}=\left[\sum_{r} \sum_{b} \text { EndUseConsump } f_{f, b, b, r y}\right] \times 10^{-3} \\
& f \in\{\text { MajFuels }\}
\end{aligned}
$$


U.S. average minor service equipment efficiency by enduse and fual:

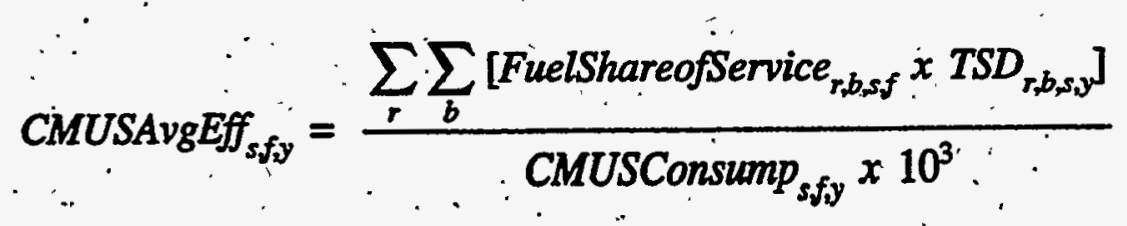

$\forall s \in\{$ MinServ $\}, f \in\{$ MajFuel $\}$

Consumption of minor fuals other than motor gasoline:

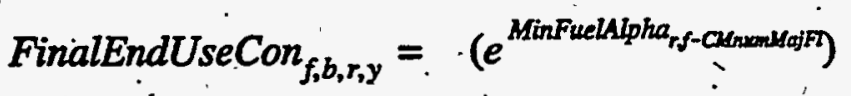

$$
\begin{aligned}
& x \text { Price }_{f, r y}^{\text {MinFuelBeta }}, \text { : } \\
& x \quad 10^{-6} \\
& \left.x \text { (SurvFloorTotal }_{r, b, y}+\text { CMNewFloorSpace }_{r, b, y}\right) \text {. }
\end{aligned}
$$

$\forall f \in\{$ MinFuels $\} ;\{$ MotorGasoline $\}, b, r, y$

Consurription of motor gasoline during historical and near term periods:

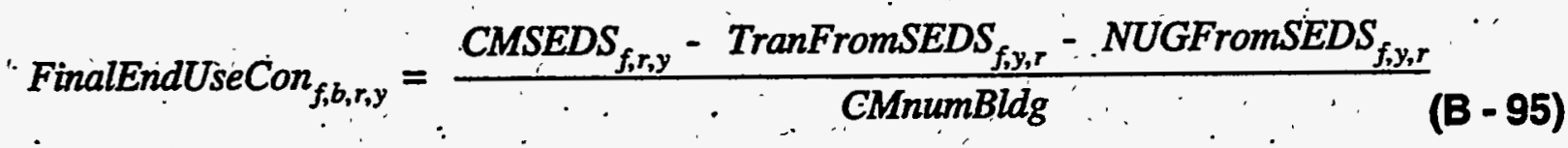
$f=$ MotorGásoline; $y \leq$ KSTEOYR

Consumption of motor gasoline beyoind near term period:

FinalEndUseCon ${ }_{f, b, r, y}=$ FinalEndUseCon $_{f, b, r, y-1} \cdot\left(1+\right.$ MinFuelBeta $\left._{r, f-c \dot{M} \text { numMajFl }}\right)$

$f \in\{$ MotorGasoline $\} ; y>$ KSTEOYR 
Quantlty of eloctriclty produced by cogeneration using fudis subject to cross-price elasticlty considerations:

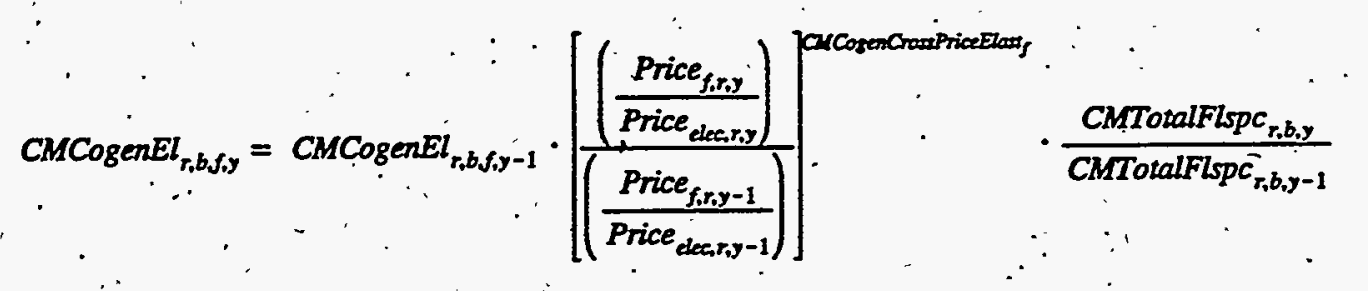

$f \in\{$ Major+Minor Fuels $\} ; y>C M F i r s t Y r+1$.

CMCogenEl ${ }_{\text {rbffy }}$ input from files KCOG93 \&.KCOG94 for y = 1993 \& 1994, respectively.

Quantity of electriclty produced by cogeneration using fuels not subject to cross-price elasticlty considerations:

$$
\begin{aligned}
& \text { CMCogenEl }_{r, b, f, y}=\operatorname{CMCogenEl}_{r, b, f, y-1} \cdot \frac{C M T \text { TotalFlspc }}{C M \text { Totalf,y }} \\
& f \in\{\text { Renewable + Other Fuels }\}
\end{aligned}
$$

Amount of cogeneration capacity that was planned:

$$
C G C O M C A P_{r, y, F, p l a n n e d}=C G C O M G E N_{r, y, F} \cdot \frac{1000 \frac{M W}{G W}}{8760 \frac{\mathrm{hr}}{\mathrm{yr}}} \cdot\left(1-C M C o g U_{n p l a n P r o p}\right) \quad(B-99)
$$

Where CMCOMGEN is an Electricity Market Module (EMM) variable representing commercial sector cogenerated electricity, to which CMCogenEl is mapped. F represents the EMM fuel categories defined by that module. A units conversion from trillion Bta to gigawatthours is also performed during the mapping.

Amount of unplanned cogeneration capacity:

$C G C O M C A P_{r, y, F, \text { unplanned }}=C G C O M G E N_{r, y, F} \cdot \frac{1000 \frac{M W}{G W}}{8760 \frac{\mathrm{hr}}{\mathrm{yr}}} \cdot C M C o g$ UnplanProp $(\mathrm{B}-100)$ 
Proportion of cogenerated electricity sold to the grid:

$$
\text { GRIDSHR }_{r, y}=1
$$

Consumption of fuels to produce cogenerated electriclty:

$$
\begin{aligned}
\text { CMCogenConsump }_{r, b, f} & =\left(C M \text { CogenEl }_{r, b f}\right. \\
\times & \text { CMCogenTEtoELratio } \left._{f}\right) \\
& \times \text { CMDeltaRecipEffic }_{f} \\
& f \in\{\text { Major }+ \text { Minor }+ \text { Renewable }+ \text { Other Fuels }\}
\end{aligned}
$$

Consumption of tuels acrose end-uses, including consumption for cogeneration of electricity:

$$
\begin{aligned}
& \text { FinalEndUseCon } n_{f, b, r, y}=\text { FinalEndUseCon }{ }_{f, b, r, y}+C M C o g e n C o n s u m p \\
& f \in\{\text { Major }+ \text { Renewable Füls }\}
\end{aligned}
$$

Consumption of fuels to provide district services, by Censius Division, bullding type, fuel, and service:

$$
\begin{aligned}
& \text { DistServConsump } p_{r, b, s_{j}, j y}=\text { DistServSteamEUI }_{r, b, s,} \\
& \left.x \text { (SurvFloorTotal }{ }_{r, b, y}+\text { CMNewFloorSpace }_{r, b, y}\right) \\
& x\left(\frac{\text { DistServFuelShr }_{b_{f} f}}{\text { DistServBoilerEff }}\right) \\
& \text {. } 10^{-3}
\end{aligned}
$$

$s \in\{$ DistServ\}; f $\in\{$ MajFuels $\}$ 
U.S. total fuel consumption to provido district services (quadrillion Btu):

$$
\text { CMUSDistServ }_{s, f, y}=\left[\sum_{r} \sum_{b} \text { DistServ Consump }_{r, b, s, f, y}\right] \times 10^{-3}
$$

$s \in\{$ DistServ $\} ; f \in\{$ MajFuels $\}$

Consumption of tuds across end-uses, Including cogeneration and district services:

$$
\begin{gathered}
\text { FinalEndUseCon }_{f, b, r, y}=\text { FinalEndUseCon }{ }_{f, b, r, y} \\
\therefore \\
f \in\left\{\sum_{\forall s \in\{\text { Disserv }\}} \text { DistServConsump }_{r, b, s, f, y}\right.
\end{gathered}
$$

Unbenchmarked consumption of fuels across end-uses, by Census Division:

$$
\begin{aligned}
& \text { CMFinalUnbenchCon }_{f, r, y}=\sum_{b} \text { UnBenchCon }_{f, b, r, y} \\
& \forall f \in \text { MMajFueis\} }^{.}
\end{aligned}
$$

Consumption of fuols across end-uses, including cogeneration and district services, by Census Dhislon:

$$
\begin{gathered}
\text { CMFinalEndUse }_{f, r, y}=\sum_{b} \text { FinalEndUseCon }_{f, b, r, y} \\
f \in\{\text { MajFuels }+ \text { MinFuels }+ \text { RenewableFuels }\}
\end{gathered}
$$


U.S. total consumption by building type, across end-uies, including cogeneration, district services, ind solar thermal:

$$
\begin{aligned}
& \text { CMFinalEndUseCon }_{b, y}=\sum_{r} \sum_{f} \text { FinalEndUseCon }_{f, b, r, y} \\
& \forall f \in\{\text { MajFuels }+ \text { MinFuels + RenewableFuels }\}
\end{aligned}
$$

$$
\begin{aligned}
& +\sum_{r} \sum_{s} \frac{\text { SolarRenewableContrib }_{r, s, y}}{\text { CMnumBldg }} \\
& \forall s \in\{\text { Space Htg }+ \text { Water Htg }\}
\end{aligned}
$$




\section{Benchmarking Equations}

Difference between forecast and SEDS fuel consumption data ("SEDS mistle") for historleal years:

$$
\begin{aligned}
\text { SEDSMistie }_{f, r,[y]} & =\left(C M S E D S_{f, r, y}-\text { TräFromSEDS }_{f, r, y}-\text { NUGFromSEDS }_{f, r, y}\right) \\
: & -C M F i n a l E n d U s e_{f, r, y}
\end{aligned}
$$

y $\leq$ MSEDYR + 1

$f \in\{$ MajFuels + MinFuels $\}$

The brackets around the year index indicate that SEDSMistie implicitly possesses a year dimension, although it is not explicitly declared as having one.

Nonbullding fuel use forecast for historical years:

$$
\begin{aligned}
& \text { CMNonBLIgUse }_{f, r, y}=\text { SEDSMistie }_{f, r,[y]} \\
& y \leq M S E D Y R+1
\end{aligned}
$$

Difference betwoen forecastod fuel consumption (nondistillate) with SEDS nonbullding component, and STEO forecast:

$$
\begin{aligned}
& \text { STEOMistie }_{f, r,[y]}=\left(\text { CMSEDS }_{f, r, y}-\text { TranFromSEDS }_{f, r, y}-\text { NUGFromSEDS }_{f, r, y}\right) \\
& \text { - (CMFinalEndUse } f_{f, r, y}+\text { SEDSMistie } e_{f, r,[\text { LSEDYR }+1]}+ \\
& \left.\frac{\left(M C_{-} C O M M F L S P_{r, 1, y}-M C \_C O M M F L S P_{r, 1, y^{\prime}=\text { LSEDYR+1 }}\right)}{M C C O M M F L S P_{r, 1, y^{\prime}=M S E D Y R+1}} \cdot \mid S E D S M i s t i e_{f, r,\{L S E D Y R+1]}\right)(B-112)
\end{aligned}
$$

MSEDYR + $1<y \leq$ KSTEOYR

$f \in\{$ MinFuels + MajFuels except Distillate $\}$ 
SEDS-based component of nonbullding fual consumption (ñondistillate) after last year of avallable SEDS data:

$$
\begin{aligned}
& \text { CMNOnBLdgUse } \left._{f, r, y}=\text { SEDSMistie }_{f, r,[\text { MSED }}+1\right]+
\end{aligned}
$$

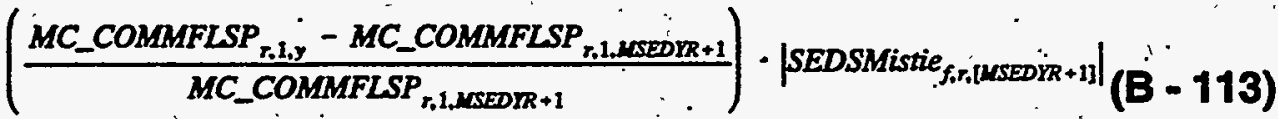

$y>M S E D Y R+1$

$f \in$ \{MinFuels + MajFuels except Distillate\}.

Difference between forecasted dlstillate fuel consumption with SEDS nonbuilding componient, and STEO forecast:

$$
\begin{aligned}
\text { STEOMistie }_{f, r,[y]}= & \left(\text { CMSEDS }_{f, r, y}-\text { TranFromSEDS }_{f, r, y}-\text { NUGFromSEDS }_{f, r, y}\right) \\
& -\left(\text { CMFinalEndUSe }_{f, r ; y}+\text { SEDSMistie }_{f, r,[M S E D Y R+1]}\right)
\end{aligned}
$$

MSEDYR $+1<y \leq K S T E O Y R$

$\cdot f=$ Distillate

SEDS-based component of nonbuliding distillate fuel consumption:

$$
\begin{aligned}
& \text { CMNonBldgUse }_{f, r, y}=\text { SEDSMistie }_{f, r,[M S E D Y R+1]} \\
& y>\text { MSEDYR }+1 \\
& f=\text { Distillate }
\end{aligned}
$$

Optional benchmarking to STEO forecast for years where STEO data is avallable:

$$
\begin{gathered}
\text { CMNonBldgUse }_{f, r, y}=\text { CMNonBldgUse }_{f, r, y}+\text { STEOMistie }_{f, r,[y]}, \text { if } S T E O B M=1 \\
\ddots
\end{gathered}
$$

MSEDYR $+1<y \leq$ KSTEOYR

$f \in\{$ Major and minor fuels $\}$ 
Optional docay factor to apply to final STEO mistio for optional benchmarking to STEO after last year of STEO data:

$$
\begin{aligned}
& \text { STEOTieDecayFactor }_{[y]} \equiv \quad 1, \quad \text { if DecayBM }=0 \\
& 1-\frac{(y-K S T E O Y R)}{(\text { FirstNonBenchYr-KSTEOYR })}, \text { if DecayBM }=1 \\
& 0 \text {, if DecayBM } 1 \text { and } \\
& y \geq \text { FirstNonBenchYr }
\end{aligned}
$$

Where FirstNonBenchYr is converted from a calendar year to a year index prior to use.

Optional STEO-based component of nonbuilding fuel consumption forecast after last year of avallable STEO data:

$$
\begin{aligned}
& \text { CMNOnBldgUse }_{f, r, y}=\text { CMNonBldgUse }_{f, r, y}+\operatorname{STEOMistie}_{f, r,[\mathrm{KSTEOYR]}} \cdot S T E O T i e D e c a y F a c t o r_{[y]} \text {, } \\
& \text { if } S T E O B M=1 \text {; } \\
& \text { unchanged, otherwise }
\end{aligned}
$$

Final benchmarked fuel consumption forecast by fuel, Census Dhision, and year:

$$
\text { CMFinalEndUse }_{f, r, y}=\text { CMFinalEndUse } e_{f, r, y}+C M N o n B l d g U_{s e_{f, r, y}}
$$

$f \in\{$ Major and minor fuels $\}$ 
[This page intentionally left blank]

j 


\section{Appendix C}

\section{Introduction}

This Appendix provides a bibliography citing literature used in the theoretical and analytical design, development, implementation, and evaluation of the NEMS Commercial Module. The references supplied hiere are sipplemented by additional detail regarding page citations, both in the body of this report and in the references provided in Appendix A, starting at Table A-1. 


\section{References}

Al-Sahlawi, M., "The Demand for Natural Gas: A Survey of Price and Income Elasticities, The Enerey Joumal, (Jan 1989).

Artur D. Little; Inc., "Discussion Charts; Task 1: Technology Stamus - Residential/ Commercial End-Use Equipment and Advariced Power Cycles, " ADL reference 64460-09, prepared for U.S. Deparment of Energy; Energy Information Administration, March 1990.

Arthir D. Littie, Inc., "Technical Memorandum for Technology Advances and Forecasts - Residential/Commercial EndUse Equipment," April 1990.

Belzer, D., L. Wrench and T. Marsh, End-Use Energy Estimates for U.S. Commercial Buildings. 1989, Pacific Northwest Laboratory, PNL-8946, UC-35̣0, November 1993.

Berenyi, E. and R. Gould, 1991 Resource Recovery Yearbook: Directory and Guide, Government Advisory Associates; 1991.

Bloomquist, R. et al, District Heating Developmen Guide: Legal Instiutional and Marketing Issues, Vol. 1, Washington State Energy Office, October 1988.

"Citicorp Maragers Call Efficiency Key to Tenant Draw," Energy User News, June 1991, p. 18.

Cowing, T. and D. McFadden, Microeconomic Modeling and Policy Analusis: Studies in Residential Energy Demand, Orlando: Academic Press, Inc. 1984.

Data Resources Inc., Energy Review, Lexington, Massachusetts, Fall-Winter 1992-1993.

Data Resources Incorporated, U.S. Energy Model Technical Documentation, Lexington MA, November 1980.

Decision Analysis Corporation of Virginia and Science Applications International Corporation, "Alternative Methodologies for NEMS Builaing Sector Model Development: Draft Report," prepared for EIA under Contract No. DE-AC01-92El21946, Task 92-009, Subtask 4, Vienna VA, August 1992.

DRI-McGraw Hill, Compact Model of the U.S. Esonomy, Version US90A, Lexington MA, January 1991.

Electric Power Research Institute, A Compendium of Utility-Sponsored Energu Efficiency Rebate Programs, 1987.

Electric Power Research Instiute, Commercial End-Üse: Data Development Handbook: COMMEND Market Profiles and Parameters, Vol. 2: COMMEND Data and Parameter Development Techniques, Régional Economic Research, Inc., EM5703, Sạ Diego CA, April 1988.

Energy Information Administration, U.S. Department of Energy, Amual Energy Outlook 1993, DOE/EIA-0383(93), Washington, DC, Jamary 1993.

Energy Information Administration, U.S. Deparment of Energy, Commercial Buildings Characteristics 1992, DOE/EIA0246(92), Washington DC; April 1994.

Energy. Information Administration, U.S. Department of Energy, Commercial Buildings Consumption and Expenditures 1992, DOE/EIA-0318(92), Washington DC, April 1995. 
Energy Information Administration, U.S. Deparmemt of Energy, Characteristics of Commercial Bujidings 1989, DOE/EIA-0246(89), Washington DC, June 1991.

Eriergy Information Administration, U.S. Department of Energy, Commercial Buildings Consumption and Expendinures 1986, DOE/EIA-0318(86), Washington DC, May 1989.

Energy Information Administration, U.S. Department of Energy, Energy Consumption and Conservation Potential: Supporting Analysis for the National Energy Strategy, Washington DC, December 1990.

Energy Information Administration, U.S. Deparment of Energy, Lighting in Commercial Buildings, Washington DC, i , March 1992.

Energy Information Administration, U.S. Department of Energy, "Nonutility Power Producers," Electric Power Monthiy, April 1992.

Energy Information Administration, U.S. Department of Energy, PC-AEO Forecasting. Model for the Ammal Energy Qutlook-1990. Model Documentation, (Section 3, Commercial Energy Demand) and Technical Notes, DOE/EIAMO36(90), Washington DC, March 1990.

Energy Information Adrninistration, U.S. Department of Energy, State Energy Data Report: Consumption Estimates 19601989, DOE/EIA-0214(89), Washington DC, May 1991.

Energy Information Administration, U.S. Department of Energy, State Energy Data Report: Consumption Estimates. 1960-1992, DOE/EIA-0214(90), Washington DC, May 1992.

Gas Research Institute, Baseline Projection Data Book: GRI Baseline Projection of U.S. Eneroy Supply and Demand to 2010,-1992 edition, vol. I.

Gordon, F., et. al., "Úse of Commercial Energy Efficiency Measure Service Life Estimates in Program and Resource Plaming," Procedings of the 1988 ACEEE Summer Study on Energy Efficiency in Buildings, vol. 3. Commercial and Industrial Building Technologies, Washington DC, American Council for an Energy Efficient Economy, August 1988.

Hazilla, M. and R. Kopp, "Systematic Effects of Capital Service Price Definition on Perceptions of Input Substitution," Joumal of Business änd Esonomic Statistics, April 1986.

Hirst, E. and R. Lee, "Independent Expert Review of the EIA Residential End-Use Model (REEM) and the Building Energy End-Use Model (BEEM)", Oak Ridge National Laboratory, June 1991: -

Jackson, J. et al, The Commercial Demand for Energy: A Disagregated Approach, Oak Ridge National Laboratory, April 1978.

Jerry Jackson and Associates, NPPC Commercial Energy Demand Medel, Pacific Northwest Electric Power and Conservation Power Planning Council, Portland OR, November 1982..

Komor; P. and R. Katzev, "Behavioral Determinants of Energy Use in Small Commercial Buildings: Implications for Energy Efficiency," Energy Systems and Policy, vol. 12, 1988.

Koomey, J., "Energy Efficiency Choices in New Office Buildings: An Investigation of Market Faihures and Corrective · Policies," Ph.D. dissertation, University of California at Berkeley, 1990.

Koomey, J., et. al., The Potential for Electricity Efficiency Improvements in the U.S.Residential Sector, Lawrence Berkeley Laboratory, Applied Science Division, Prepared for DOE, Contract No. DE-AC03-76SF00098, Berkeley CA, 
July 1991.

Lamarre, L., "Shaping DSM," EPRIJournal, Octobei/November 1991.

Lamarre, L., "New Push for Energy Efficiency," EPRI Joumal, April/May 1990.

Lewis, J. and A. Clarke, Easton Consultants, Replacement. Market for Selected Commercial Energy Service Equipment: Topical Report. Phase 1B-Commercial, Prepared for Gas Research Institute, Jume 1990.

"Lighting the Commercial World," EPRI Joumal, vol. 14, No. 8, December 1989.

Lowe, M., Shaping Cities: The Envirommental and Human Dimensions, Worldwatch Paper 105, October 1991.

Mahoney, D., "Phase I of a Project to Enhance the Commercial Sector Analysis of the GRI Baseline Modeling System; Topical Report \#1: Data Enhancements," prepared for Gas Research Institute under Contract No: 5085-800-1175, DRI Energy Division, Lexingtọ MA, July 19897.

National Analysts, Synergic Resources Corp.; QEI, Inc., Residential Customer Preference and Bèhavior: Market Segmentation Using CLASSIFY, EPRI EM-5908, Palo Alto CA: EPRI, March 1989.

National Economic Research Associates, NERA Energy Outlook, White Plains, New York, February 1993.

Piette, M., J: Eto, and J. Harris, "Office Equipment Energy Use and Trends," Energy and Environment Division, Lawrence Berkeley Laboratory, September 1991.

Prete, L., J. Gordon, and L. Bromiey, "Electric Utility Demand-Side Management, " Electric Power Monthly, April 1992.

Regional Economic Research, Commercial End-Use Data Dévelopment Handbook: COMMEND Market Profiles and Parameters, Vol. 1: COMMEND Market Profiles and Model Structure, EPRI EM-5703, April 1988.

Regional Economic Research, Commercial End-Use Data Development Handbook: COMMEND Market Profiles and Parameters, Vol. 2: COMMEND Data and Parameter Development Techniques, EPRI EM-5703, April 1988. .

Temple, Barker and Sloane, Inc., Xenergy, Inc., Market Research on Demand-Side Management Programs, EPRI EM5252, Palo Alto CA: EPRI, June 1987.

U.S. Congiess, Office of Technology Assessment, Building Energy Efficiency, OTA-E-518, Washington DC: U.S. Government Printing Office, May 1992.

U.S. Congress, Office of Technology Assessment, Changing by Derrees: Steps to Reduce Greenhouse:Gases, OTA-O482, Washington DC, U.S. Goverment Printing Office, February 1991.

U.S. Department of Commerce, Bureau of the Census, Statistical Abstract of the United States 1920 (110ih ed.), Washington DC, 1990.

U.S. Department of Energy, Office of Coal and Electricity Policy, Emergine Issues in PURPA Implementation, DOE/PE70404-H1, Pfeffer, Lindsay, and Assoc., Inc, March 1986.

U.S. Envirommental Protection Agency, "Green Lights Financing Directory Database," Version 2.0, Jamuary 1992.

"Utility Rebate Gưide," Energiy User News, Vol. 17, No. 4, April 1992.

C-4

Energy Information Administration NEMS Commercial Model Documentation Report 
Vine, E., and J. Harris, "Implementing Energy Conservation Programs for New Residential and Commercial Buildings," Energy Systems and Policy, vol. 13, no. 2, 1989.

Wharton Economic Forecasting Associates, Energy Analysis Quarterly, Winter 1992.

Westley, G., "The Demand for Electricity in Latin America," Inter-American Development Bank Papers on Project Amalysis No. 35, Economic and Social Development Deparment, Country Studies Division, Washington, D.C., February 1989.

Z, Inc., IPL Codebook for 1986 Consumption and Expendiures Tables. NBECS 86, Z, Inc., Contract No. DE-AC0185E19693, Silver Spring MD, April 1989. 
[This page intentionally left blank] 


\section{Appendix D. Model Abstract}

\section{Model Name:}

Commercial Sector Demand Model

\section{Model Acronym:}

None

\section{Description:}

The NEMS Commercial Sector Demand Module is a simulation tool based upor economic and engineering relationships that models commercial sector energy demands at the nine Census Division level of detail for eleven distinct categories of commercial buildings. Commercial equipment selections are performed for the major fuels of èlectricity, natural gas, and distillate fuel, for the major services of space heating, space cooling, water heating, ventilation, cooking, refrigeration, and lighting. The market segment level of detail is modeled using a constrained life-cycle cost minimization algorithm that considers commercial sector consumer behavior and time preference premiums. The algorithm also models the minor fuels of residual oil, liquefied petroleum gas, steam coal, motor gasoline, and kerosene, the renewable fuel sources of wood and municipal solid waste, and the minor services of office equipment (with a separate breakout of personal computers), and "other" in less detail than the major fuels and services. Numerous specialized considerations are incorporated, including the effects of changing building shell . efficiencies, the relationship between nonutility generation of electricity and the relative prices of fuels, and consumption to provide district services.

\section{Purpose of the Model:}

As a component of the National Energy Modeling System integrated forecasting tool, the NEMS Commercial Module generates mid-term forecasts of commercial sector energy demand. The model facilitates policy analysis of energy markets, technological development, environmental issues, and regulatory development as they impact commercial sector energy demand.

\section{Most Recent Model Update:}

October 1997. 


\section{Part of Another Model?}

National Energy Modeling System (NEMS)

\section{Model Interfaces:}

Receives inputs from the Electricity Market Module, Natural Gas Transmission and Distribution Module, Petroleum Market Module, Coal Market Module, and Macroeconomic Activity Module within NEMS. Outputs are provided to the Electricity Market Module, Natural Gas Transmission and Distribution Module, Petroleum Market Module, Coal Market Module Oil, and Integrating Module.

\section{Official Model Representative:}

Erin Boedecker

Office of Integrated Analysis and Forecasting

Energy Demand and Integrated Analysis Division

Energy Demand Analysis Branch

United States Department of Energy; James Forrestal Building

1000 Independence Avenue, S.W.

Washington, D.C. 20585

(202) 586-4791

\section{Documentation:}

Energy Information Administration, U.S. Department of Energy, Model Documentation Report: Commercial Sector Demand Model of the National Energy Modeling System, DOEJEIA-MO66(97) (Wähington, D.C., January, 1997).

\section{Archive Media and Installation Manual(s):}

The Module will be archived on magnetic tape storage compatible with the IBM RS/6000 computing platform upon completion of the NEMS production runs to generate the Annual Energy Outlook for 1998 (AEO98).

\section{Energy System Described:}

Domestic commercial sector energy consumption.

\section{Coverage:}

- Geographic: Nine Census Divisions: New England, Mid Atlantic, East North Central, West North Central, 
South Atlantic, East South Central, West South Central, Mountain, Pacific

Time UnitFrequency: Annual, 1990 through 2020

Products: Electricity, natural gas, distillate, residual oil, liquefied petroleum gas, coal, motor gasoline, kerosene, wood, municipal solid waste

- Economic Sectors: Eleven Building Categories: Assembly, Education; Food Sales, Food Services, Health Care, Lodging, Large Office, Śmall Office, Mercantile \& Service, Warehouse, Other. Nine Services: Space Heating, Space Cooling, Water Heating, Ventilation, Cooking, Lighting, Office Equipment, . :Refrigeration, Other.

\section{Modeling Features.}

- : Model Structure: Sequential calculation of forecasted commercial fioorspace, service demand, technology choice, and end-use consumption.

- Modeling Technique: Simulation of technology choice by decision type, within a service, within a building and Census Division, for the current year of the forecast. Commercial Buildings Energy Consumption Survey 1992 data are used for initial floorspace, market shares, fuel shares, district service shares. Engineering analyses used for initial efficiency estimates.

- Special Features: Technology choice data base and simulation technique is capable of accommodating an extensive range of policy analyses, including but not limited to demand-side management capital incentives, tax credits, and equipment efficiency standards.

\section{Model Inputs}

- Historical commercial sector floorspace by Census Division and building type, for the years 1970-1990

- Historical floorspace retirement proportion by Census Region for the year 1990

Description of floorspace categorization to enable mapping to DOE sources

Commercial sector existing equipment characteristics, including typical equipment capacity, installed capital cost, operating and maintenance (O\&M) cost, expected physical lifetime

- Equipment research and development (R\&D) advances and projected dates of model introduction

- Base year floorspace by Census Division, building type, building age cohort, energy-consuming characteristics

- Base year district service consumption totals and relative shares

- Base year Energy Use Intensity (EUI) by Census Division, building type, and energy service

- Base year equipment stock characteristics by Census Division and energy service

- : Base year energy consumption for calculation of nonbuilding consumption to benchmark

Energy Information Administration NEMS Commercial-Model Documentation Report 
- Historical commercial sector quantities of cogenerated electricity by Census Division, generating fuel, and building type

Annual consumption of fuels for cogeneration by Census Division and building type

Current status of commercial sector generating facilities

Current oútlook for commercial sector generating capacity, to determine planned and unplanned additions to capacity.

- Forecasted commercial sector renewable energy demand, by renewable source and energy service

\section{Non-DOE Input Sources:}

\section{Datá Resoưces Inc. (DRD), F.W. Dodge}

- Historical commercial sector floorspace by Census.Division and building type, for the years 1970-1990

- Historical floorspace retirement proportion by Census Region for the year 1990

- Description of floorspace categorization to enable mapping to DOE sources

Arthur D. Little.Technical Reports, EPRI Technical Assessment Guide, GRI Baseline Data Book (references provided in Appendix $\mathrm{C}$ to this report)

- Commercial séctor existing equipment characteristics, including typical equipment capacity, installed capital cost, operating and maintenance (O\&M) cost, expected physical lifetime, based on data from the years 1986-1993

- Equipment research and development (R\&D) advances and projected dates of model introduction, projections for technology availability encompassing the years 1995-2010

\section{DOE Input Sources:}

Commercial Building Energy Consumption Survey 1992 (CBECS 1992)

- . Base year floorspace by Census Dịvision, building type, building age cohort, energy-consuming characteristics

- Base year district service consumption totals and relative shares

- Base year Energy Use Intensity (EUI) by Census Division, building type, and energy service

- Base year equipment stock characteristics by Census Division and energy service

- Base year energy consumption for calculation of nonbuilding consumption to benchmark

Form EI-867: - Survey of.Independent Power Producers, forms for years 1993-1994

- Historical commercial sector quantities of cogenerated electricity by Census Division, generating fuel, and 
building type

- Annual consumption of fuels for cogeneration by Census Division and building type

- Current status of commercial sector generating facilities

-.... Current outlook for commercial sector generating capacity, to determine planned and unplanned additions to capacity.

National Renewable Energy Laboratory (NREL) Interlaboratory Documentation, 1990

- Forecasted commercial sector renewablé energy demand, by renewable source and energy service

\section{Computing Environment:}

- Hardware Used: IBM RS/6000.

- Operating System: UNIXJAIX

- Language/Software Used: FORTRAN

- Memory Requirement: 4,000K

- Storage Requirement: Model has not yet been archived. It will require an as-yet undetermined number of tracks of an IBM 3380 disk pack

- Estimated Run Time: 3.5 minutes for a 1990-2020 run in non-iterating NEMS mode on an IBM RS/6000

- Special Features: None.

\section{Independent Expert Reviews Conducted:}

Independent Expert Reviews of Commercial Sector Component Design Report, July 31, 1992 conducted by David Belzer, Pacific Northwest Laboratory; Richard E. Jones, Office of Building Technologies, Conservation and Renewable Energy; James E. McMahon, Ph.D., Lawrence Berkeley Laboratory; Robert P. Trost, Ph.D., and Inderjit Kundra, Office of Statistical Standards.

\section{Status of Evaluation Efforts by Sponsor:}

None. 
[This page intentionally left blank] 


\section{Appendix E}

\section{Introduction}

The NEMS Commercial Sector Demand Module develops forecasts of commercial sector energy consumption based upon the data elements as detailed in Appendix $\mathrm{A}$ of this report. The module input data, parameter estimates, and module variables are described in Appendix A, inchuding the transformations, estimation methodologies, and resulting inputs required to implement the model algorithms. The quality of the principal sources of imput data is discussed in Appendix E. Information regarding the quality of parameter estimates and user inputs is provided where available. This appendix discusses quality of data used in preparing the $A E O 95$, and has not been updated to reflect changes in data used to prepare the AEO96.

\section{Quality of Input Data}

\section{Commercial Buildings Energy Consumption Survey 1989 (CBECS 1989)}

EIA's Commercial Buildings Energy Consumption Survey 1989 (CBECS 1989) is the principal data source for the NEMS Commercial Moctule forecast of energy consumption. This section discusses the quality of the CBECS 1989 data set as described in Commercial Buildings Consumption and Expendinures $1989^{\circ}$.

CBECS 1989 implementation. EIA conducts the CBECS survey to provide basic statistical information on consumption of, and expenditures for, energy in U.S. commercial buildings, along with data on energy related characteristics of these buildings. CBECS is based upon a sample of commercial buildings selected according to the sample design described in Commercial Buildings Consumption and Expenditures 1989.

The CBECS methodology consists of two major stages. In the first stage, information about the selected buildings is collected in the Buildings Characteristics Survey through voluntary personal interviews with the buildings' owners, managers, or tenants. Building energy consumption records are provided through the use of an Authorization Form to release this confidential data. In the second stage, the Energy Suppliers Survey, data concerning the actual consumption of energy is obtained through a mail survey conducted by a survey research firm under EIA 's mandatory data collection authority.

1. U.S. Department of Energy, Eñergy Informätion Administration, Commercial Buildings Consumption and Expenditures 1989, DOE/EIA-0318 (89), pp. 275-35़9. 
CBECS 1989 samples 8,791 buildings, selected based upon an area probability sample supplemented by lists of large brildings. The source previously cited provides additional detail regarding the area probability sampling methodology. The sampling methodology relies upon the 1986 sampling methodology and inchudes some of the large and/or specialized commercial briildings previously sampled. Except for these few brildings, the 1989 sample does not overlap. with previous CBECS. Primary differences between the CBECS 1989 sampling method and the CBECS 1986 sampling method are further described in the report previously cited.

Building Characteristics Survey (Stage ). Target Population. The target population of CBECS 1989. is domestic commercial buildings greater than $1,000 \mathrm{ft}^{2}$ in area. (All buildings in the sample satisfy three criteria: 1.$)$ each meets the survey definition of a "building", 2.) each is used primarily for commercial purposes, and 3.) each measures $1,001 \mathrm{fl}^{2}$ or more. As described in the report previously cited, building eligibility is evaluated at multiple points throughout the survey purpose to ensure data accuracy, and quality:

Response Rates. The total sample of CBECS 1989 is 8,791 buildings, composed of 6,659 from the area sample and 2,132 from a list sample. Of these, 6,352 buildings are interviewed, 4,770 from the area sample and 1,582 from the list sample: Successful interviews for $92.5 \%$ of the eligible buildings $(5,277)$ are contained in CBECS 1989. Similar success .rates for Authorization Form completion are observed in the sample.

Data Collection. As previously described, the Buildings Characteristics Survey consists of personal interviews with buildings' owners, managers, and tenants. A limited mumber of these interviews are telephone interviews, either due to a nomresponse conversion effort or lack of access to a building representative in the same PSU as the site. In all cases, a physical site visit is included.

The Interview Process. Each interview contains screening questions to verify building eligibility, followed by the survey questions. Data are collected by contractor field staff trained in data collection, field office procectures, and quality control. This training inchudes background information on the CBECS, the definition of a building, finding the sampled building, specific review of the questionnaire, and administrative information. This information is supplemented by general information on interviewing techniques for new interviewers. Trainee performance is monitored and evaluated by supervisory personmel tiroughout the performance period and only those judged qualified contribute to the survey.

Completed questionnaires are edited twice, in conjunction with random sample validation of $17 \%$ of respondents by supervisory persomel. These edits check for completeness and logical consistency, identifying cases with missing data. Key data items are pursued through telephone data retrieval procedures. Additional detail on these procecures is provided in the repoit previously cited. 
Energy Suppliers Survey (Stage I). Target Pojulation. Each supplier of electricity, natural gas, fuel oil,. district steam, hot water, and chilled water to a sampled building, provides consumption and expenditures data on a mailed survey form for this stage of CBECS 1989. The survey forms request data summed across several customers, either within a building or across a group of buildings, depending on whether individual biilding or district services are supplied.

Response Rates. The oyerall response rate for the Stage II survey is $86.7 \%$. Each record obtained from this survey corresponds to a single energy supplier for a particular energy source to a particular building.

Data Colection. Prenotification through a mailed form to natural gas and electric suppliers that were previous CBECS participants is one facet of the data collection effort. This form reported the results of CBECS 1986, alerted suppliers that a 1989 effort would soon commence, and requested notification of updates to supplier information. Second, prenotification was followed by mailed survey forms to energy suppliers based upon Stage I response patterns from the Building Characteristics Survey. The third facet of the Stage II effort consists of thank-you letters mailed to participants and requests for feedback regarding survey procectures, to be incorporated in future CBECS surveys.

Data Qunlity Verification. At the conciusion of the input and editing procedure, additional data quality verification consists of the following steps:

- A mamual review of the completeness of the discrete fuel sources, including review of sporadic records;

- A comparison of energy-source record accounts with the mumber of energy sources indicated for the building by the building respondent;

- A comparison of prices for standardized quantities with all bill records to detect price errors;

- An identification process through a program to flag overridden data written to the file in error, accompanied by review of these errors.

This process ensures the quality of the CBECS 1989 input data, which is the principal source of initial floorspace levels and age cohorts, appliance stock composition, district service shares, and unbenchmarked 1989 end-use consumption.

\section{Energy Use Intensity (EUI) Data Source}

The EUI estimates discussed in Appendix A of this report (referenced in Table A-1) are based upon preliminary results . generated in advance of the November 1993 study published by Pacific Northwest Laboratory (PNL) and referenced in Appendix $\mathrm{C}$ of this report. Data quality issues are addressed in the PNL report, specifically related to sampling 
considerations and the appropriate level of statistically significant disaggregation.

\section{Technology Characterization Data Sources}

The EPRI, Arthur D. Little, and GRI data sources used to develop technology characterization profiles for the NEMS Commercial Module do not provide discussions of data quality: The EIA report, Lighting in Commercial Buildings ${ }^{2}$ provides extensive discussion of the quality of the data used to develop lighting equipment profiles.

\section{Historical Energy Consumption Data: State Energy Data System (SEDS), 1990}

SEDS provides estimated energy consumption for the domestic commercial sector. Much of the SEDS published information is developed from data collected at the state level, and maintaining a reliable time series of consistent consumption data from the state sources is difficult. Some of the consumption estimates provided in SEDS are based on a variety of proxy measures, selected primarily based upon availability, applicability, contimuity, and consistency. These general considerations, along with the fuel-specific considerations discussed in the SEDS documentation ${ }^{3}$ render it impossible to develop meaningful mumerical estimates of overall errors associated with the published SEDS data.

\section{User-Defined Parameters}

The principal user-defined parameters in the Commercial Module are the initial proportions of commercial consumers . that behave according to each of the eleven time preference premium segments and three behavior rules described in the body of this report. The time preference preminms are developed based on analysis of survey and utility data as described below. The behavior rules represent the proportion of consumers following the Least Cost, Same Fuel, and Same Techrology rules. These parameters are designed to be calibration parameters, and as such are available to align model results with observed historical consumption results and professional expectations.

The initial behavior rule proportions are estimated by building type and decision type in order to create relationships between the different types of decisionmakers and different types of decisions. For existing buildings (replacement and retrofit decision types), the decisionmakers are divided into government, private sector companies occupying self-owned

2 U.S. Departiment of Energy, Energy Information Administration, Lighting in Commercial Buildings, DOE/EIA0555(92)/1, March 1992, pp. 72-88.

$\therefore 3$ U.S. Department of Energy, Energy Informátion Administration, State Energy Data Report. Consumption Estimates: 1960-1990, DOE/EIA-0214(90); Máy 1992; pp. 437-461. 
building space, and private sector companies occupying rented building space. For new buildings, decisionmakers are divided into organizations building space for their orin occupancy and speculative developers building space for sale upon completion. These proportions are developed by building type based on the interpretation of several qualitative descriptions of energy efficiericy related decisionmaking as described in Appendix A (referenced in Table A-1).

The actual assumptions for the behavior rule proportions associated with government, private sector companies occupying self-owned building space, organizations building space for their own occupancy, and speculative developers are listed by decision type are provided in Table E-4. Data quality analysis was not performed in the data sources providing this information.

\section{Time Preference Premium Distribution}

The literature surveyed provides five quantified distributions of commercial sector consumer payback requirements. These show considerable variation, which reflect the uncertainty in this area. These studies have been converted to consumer time preference interest rate preminums, and averaged to yield a time preference premium distriburion with that is used in the NEMS Commercial Module.

Insufficient data were available to disaggregate consumer discount rates by Census Division or by technology (i.e., the sample size was too small). As documented in the published data sources, the variance of each estimate was far greater than the difference between the sudies by technology or region. Therefore, a single distribution is applied to all technologies and all Census Divisions:

The five distributions of commercial sector payback requirements from the literature were first converted to discount rates assuming mid-year cash flows and 30 year lives. Next, the zero-risk interest rate for the years in which the five studies were performed were subtracted from the distributions to yield the consumer preference premiums implied by each source. The zero risk interest rate used was the 10 year Treasury bond yield (nominal). Finally the proportions of consumers at each step in the payback distribution were averaged, and the associated consumer preference premiums were - averaged weighted by proportions of commercial consumers. Each study was given equal weight since they represented, in general, the utilities' estimates of commercial consumer discount rates, rather than specific statistical studies. The. resulting average commercial consumer time preference premium distribution is: 


\section{Table E-1. Consumer Time Preférence Premium Distribution}

\begin{tabular}{|c|c|}
\hline Percent of Commercial Sector Consumers & $\begin{array}{l}\text { Commercial Consumers' Time Preference Premium to } \\
\text { the Risk-Free Inierest Rate }\end{array}$ \\
\hline $12.4 \%$ & $\infty$ \\
\hline $14.4 \%$ & $152.9 \%$ \\
\hline $16.4 \%$ & $55.4 \%$ \\
\hline $19.2 \%$ & $30.9 \%$ \\
\hline $19.6 \%$ & $19.9 \%$ \\
\hline $10.4 \%$ & $.13 .7 \%$ \\
\hline $3.4 \%$ & $9.4 \%$ \\
\hline 1. $1.2 \%$ & $6.4 \%$ \\
\hline $1.0 \%$ & $4.5 \%$ \\
\hline $1.0 \%$ & $2.9 \%$ \\
\hline $1.0 \%$ &.$\quad 1.5 \%$ \\
\hline
\end{tabular}

Sources:

Koomey, Jonathan G., "Energy Efficiency Choices in New Office Buildings: Án Investigation of Market Faihures and Corrective Policies," dissertation, University of California át Berkeley; 1990.

- This dissertation includes a distribution of commercial consumer payback period requirements from a 1986 PEPCO study. This study was not technology specific.

DAC and SAIC, "Alternative Methodologies for NEMS Building Seçtor Model Development," draft report, prepared under Contract No. DE-AC01-92EI21946, August 3, 1992, p. 14.

- This report lists four commercial consumer payback requirement distributions. Three of these are from electric utilities and the fourth is from an EIA market penetration model for rooftop photovoltaic systems. Three of these sources were téhnology specific and one was not. 
Table E-2. Commercial Customer Payback Period (PEPCO)

\begin{tabular}{|c|c|c|}
\hline $\begin{array}{l}\text { Preferred Payback Period - } \\
\text { (Years) }\end{array}$ & $\begin{array}{l}\text { Percent of Respondents } \\
\quad(N=659) \quad,\end{array}$ & $\begin{array}{l}\text { Implied Real Internal Rate of } \\
\text {. Return (Percent) }\end{array}$ \\
\hline 1 & 17 & 161.8 \\
\hline 2 & 17 & 64.0 \\
\hline 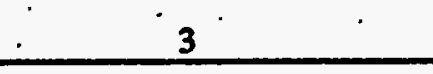 & 18 & 39.3 \\
\hline 4: & 6 & 28.3 \\
\hline$\therefore>4$ & 10. & 19.8 \\
\hline Don't Know & 33. & - or $\infty$ \\
\hline
\end{tabular}

Source:" Koomey, Janthan G., Energy Efficiency Cboices in New Office Buildings: An Investigation of Market Failures and Corrective Policies," dissertation, University of California at Berkeley; 1990, p. 16. 
-Table E-3: Commercial Consumer Payback Requirement Distributions

\begin{tabular}{|c|c|c|c|c|}
\hline $\begin{array}{c}\text { Payback } \\
\text { Period } \\
\text { (vears) }\end{array}$ & \multicolumn{3}{|c|}{ Cumulative Percent of Consumers with Payback Requirement } \\
\hline 1 & Con Ed & SCE & [proprietary] & EIA \\
\hline 2 & 100 & 100 & 70 & 100 \\
\hline 3 & 85 & 100 & 45 & 85 \\
\hline 4 & 70 & 85 & 25 & 70 \\
\hline 5 & 45 & 70 & 12 & 45 \\
\hline 6 & 25 & 50 & 5 & 0 \\
\hline 7 & 0 & 35 & 3 & 0 \\
\hline 8 & 0 & 20 & 1 & 0 \\
\hline 9 & 0 & 15 & 0 & 0 \\
\hline 10 & 0 & 10 & 0 & 0 \\
\hline 0 & 5 & 5 & 0 & 0 \\
\hline
\end{tabular}

Scurce: DAC and SAIC, "Altermative Methodologies for NEMS Building Sector Model Development," draft repor, prepared under Contract No. DE-AC01-92ED21946, August 3, 1992, p. 14. 
Behavior Rule Proportions: Supporting Documentation

Table E-4. Floorspace Ownership and Occupancy Patterns

\begin{tabular}{|l||c|c|c|}
\hline \multicolumn{1}{|c|}{$\begin{array}{c}\text { Guilding Type } \\
\text { (percent) }\end{array}$} & $\begin{array}{c}\text { Nön-government Owner } \\
\text { Occupied } \\
\text { (percent) }\end{array}$ & $\begin{array}{c}\text { Non-government } \\
\text { Non-owner Occupied } \\
\text { (percent) }\end{array}$ \\
\hline Assembly & $20.4 \%$ & $74.8 \%$ & $4.8 \%$ \\
\hline Education & $77.5 \%$ & $22.4 \%$ & $0.2 \%$ \\
\hline Food Sales & $0.6 \%$ & $77.0 \%$ & $22.3 \%$ \\
\hline Food Service & $9.3 \%$ & $79.9 \%$ & $10.8 \%$ \\
\hline Health Care & $24.1 \%$ & $70.9 \%$ & $5.0 \%$ \\
\hline Lodging & $17.9 \%$ & $72.4 \%$ & $9.7 \%$ \\
\hline Mercantile/Service & $3.2 \%$ & $64.6 \%$ & $32.2 \%$ \\
\hline Office & $19.9 \%$ & $56.3 \%$ & $23.8 \%$ \\
\hline Warehouse & $6.5 \%$ & $63.4 \%$ & $30.1 \%$ \\
\hline Other & $22.2 \%$ & $44.4 \%$ & $33.4 \%$ \\
\hline- & $22.0 \%$ & $57.4 \%$ & $20.6 \%$ \\
\hline
\end{tabular}




\section{References}

Belzer, D., L. Wrench and T. Marsh, End-Use Energy Eśtimates for U.S.Commercial Buildings, 1989, Pacific Northwest Laboratory, PNL-8946,UC-350, November 1993.

Feldmain, S., "Why is it So Hard to Sell 'Savings' as a Reason for Energy Coniservation?" Energy Efficiency: Perspectives on Individual Behavior, Willett Kempton and Max Neiman eds., American Council for an Energy-Efficient Economy, Washington, D.C., 1987.

Komor, P. and R. Katzev, "Behavioral Determinants of Energy Use in Small Commercial Buildings: Implications for Energy Efficiency," Energy Systems and Policy, Vol. 12; 1988.

Komor, P., and L. Wiggins, "Predieting Conservation Choice: Beyond the Cost-Minimization Assumption," Energy, Vol. 13, No. 8, 1988:

Koomey, J.. "Energy Efficiency Choices in New Office Buildings: An Investigation of Market Faihures and Corrective Policies," doctoral dissertation, University of California at Berkeley, 1990.

Lamarre, L., "Lighting the Commercial World," EPRIJoumal, December 1989.

Lamarre, L., "New Pụsh for Energy Efficiency," ERRI Joumai," AprilMay' 1990.

Office of Technology Assessment, Building Energy Efficiency, OTS-E-518, U.S. Government Printing Office, Washington, D.C., 1992.

U.S. Deparment of Energy, Energy Information Administration, Lighting in Commercial Buildings, DOE/EIA0555(92)/1, March 1992.

U.S. Department of Energy, Energy Information Administration, State Energy Data Report. Consumption Estimates: 1960-1990, DOE/EIA-0214(90), May 1992.

Vine, E. and J. Harris, "Implementing Energy Conservation Programs for New Residential and Commercial Buildings," Energy Systems and Policy, Vol. 13, No. 2, 1989. 


\section{Appendix F: Model Sensitivities}

\section{Solution Methodology}

The NEMS Commercial Module simulates the behavior of commercial energy consumers through a dynamic flow process. A sequential calculation of floorspace, service.demand, and technology choice is employed to yield estimates of end-use consumption. The mathematical . equations provide meaningful results because of the detail level of the input for each submodule and the modeling approach chosen.

\section{Theoretical Considerations}

\section{Domain of Module Solution}

The module is a sequential structured algorithm that solves recursively. The domain of the solution is the positive orthant for the solution variables of commercial sector fuel consumption by Census Division, building.type, fuel and year; and commercial sector airborne emissions by pollutant and year. In addition, the intermediate module outputs of interest to.the Load and Demand Side Management Submodule (LDSM) of the NEMS Electricity Market Module (EMM), specifically the fuel proportions of service demand and marketplace equipment performance characteristics calculated in the Technology Choice Submodule of the Commercial Module, also assume values within the positive orthant.

\section{Module Stability}

A frequently employed method of model assessment is to investigate output response to a variety of different input data and parameter assumptions. The structure of the model should be such that the output responds in a manner that reflects the underlying physical and behavioral tenets of 
the model. This implies that reasonable changes in inputs do not cause catastrophic model results indicating a structural flaw in the model design. This section presents the input parameters for each Submodule of the NEMS Commercial Module. A realistic range for each parameter is discussed as well as extreme and counter-factual parameter values. Because the effects of each parameter ultimately affect the final output of the module, the sign of the effect is noted if the effect is not ambiguous. In some cases changes to user inputs can result in numerous conflicting impacts of unknown relative magnitudes, rendering the final outcome on final energy consumption unclear. 


\section{Commercial Module Empirical Basis}

This section presents preliminary module results. The empirical basis of the Commercial Module is initially reviewed by comparing results to historical data and the forecasts produced by the Department of Energy and alternative sources. In order to analyze module stability, numerous scenarios in which key input values and assumptions vary are also presented. It must be emphasized that the forecasts presented in this volume are preliminary and are not the official-EIA forecasts. These forecasts are used only for examining the responsiveness of the NEMS Commercial Module.

In order to place the NEMS forecast in perspective, some inspection of the historical trends of consumption should be considered. Figure 1 extrapolates the historical values of total commercial energy consumption data reported in the State Data Energy System (SEDS). For comparison, Figure 1 includes the preliminary NEMS forecast to the year 2015. The historical data shows an upward trend in aggregate consumption. The NEMS forecast continues this upward trend and is slightly higher than the SEDS projection.

The NEMS forecast of commercial electricity consumption evenly continues the historical consumption path over the forecast horizon. Figure 2 displays the time path of the consumption along.with NEMS forecasts and a naive extrapolation of the historical SEDS data. The historical series displays very stable growth in consumption with relatively little variation. In addition, the NEMS forecast lies below the linear extrapolation of the SEDS data.

The historical consumption of natural gas in the commercial sector is depicted in Figure 3. Natural gas projections display greater variation than either total or electricity consumption. As apparent in Figure 3, the NEMS forecast continues the rising trend in consumption 


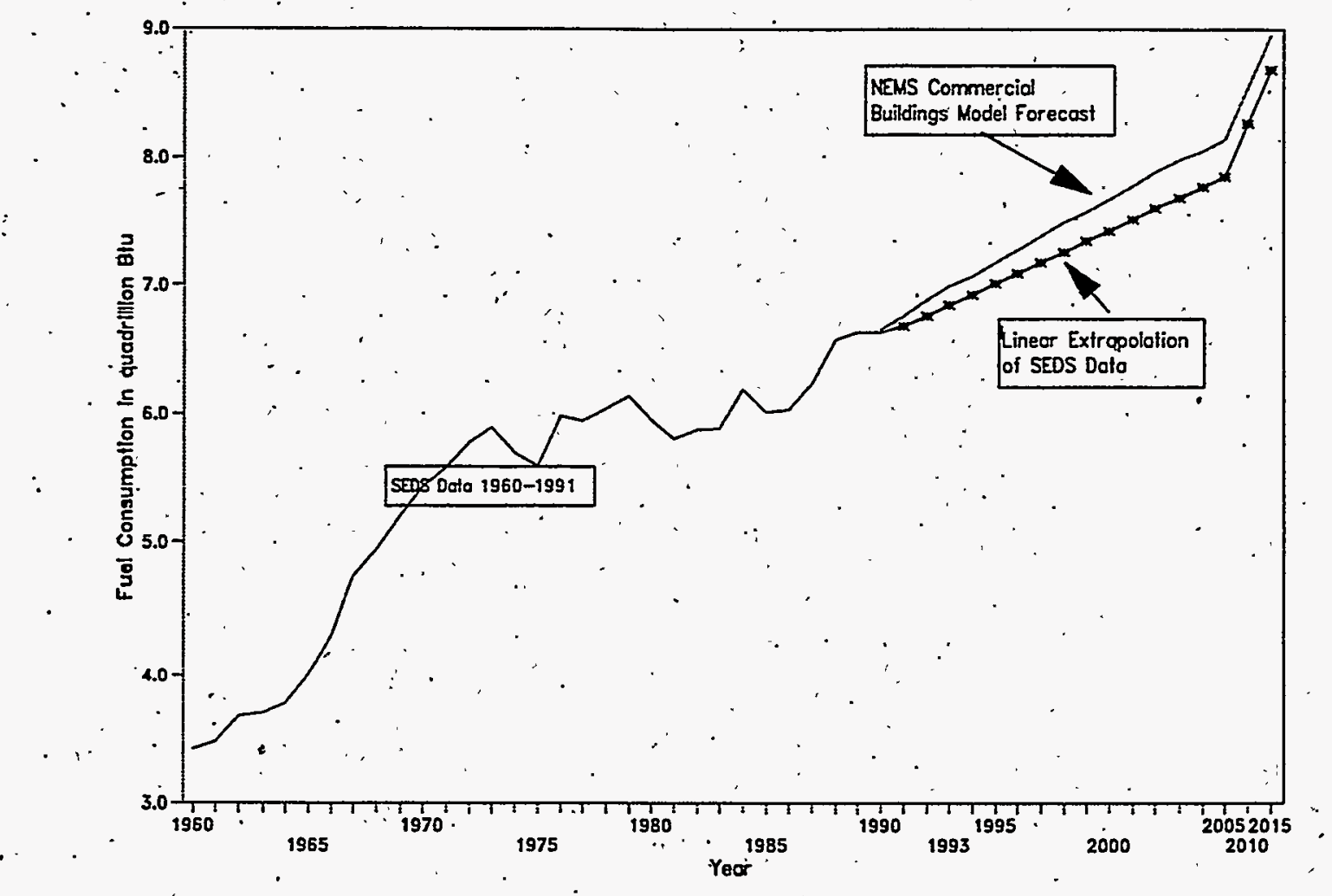

Figure 1. Total Energy Consumption: SEDS and NEMS

throughout the forecast horizon, although it is lower than the linear extrapolation of SEDS. 


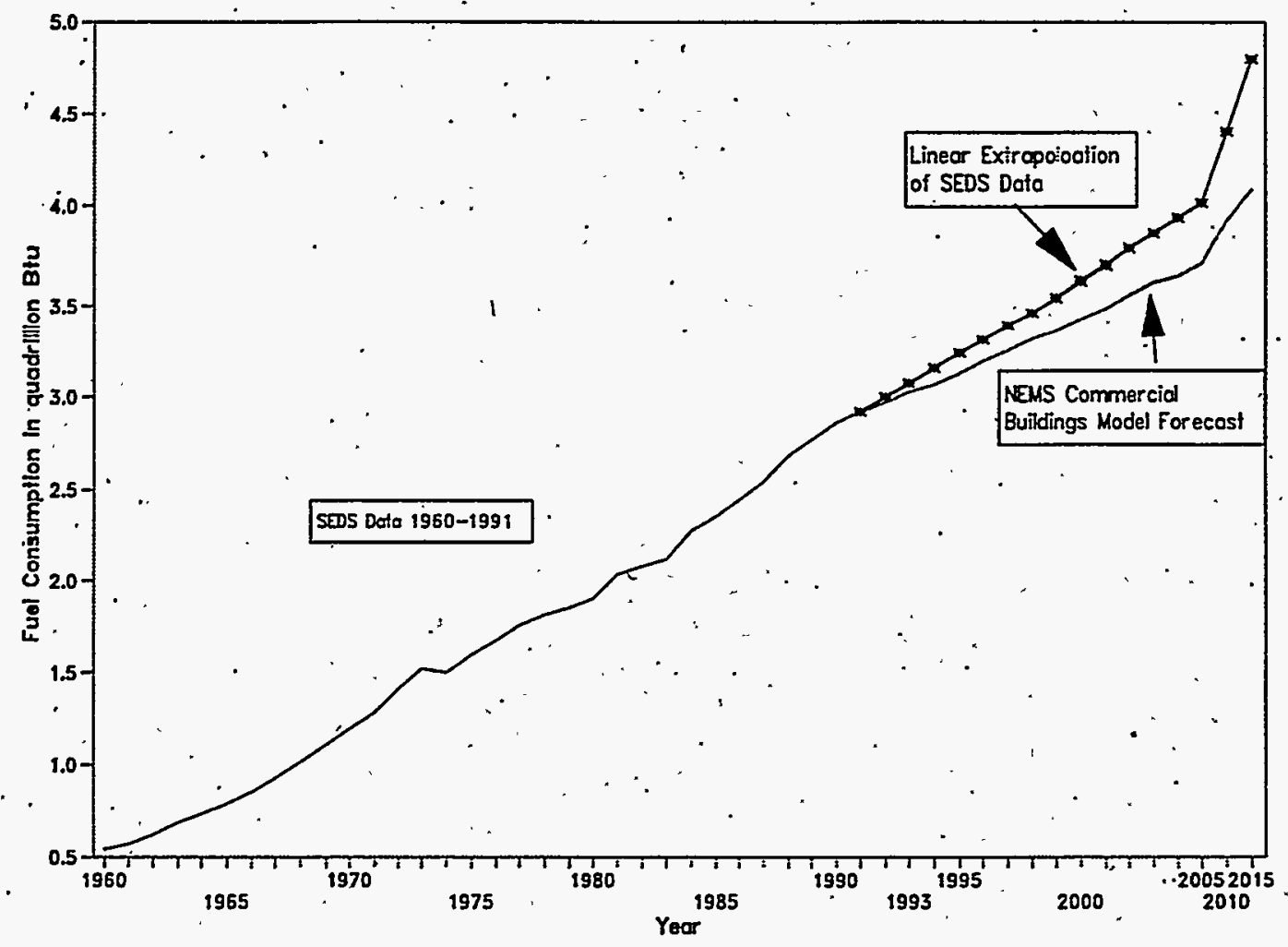

Figure 2. Commercial Sector Electricity Consumption: SEDS and NEMS

Energy Information Administration 


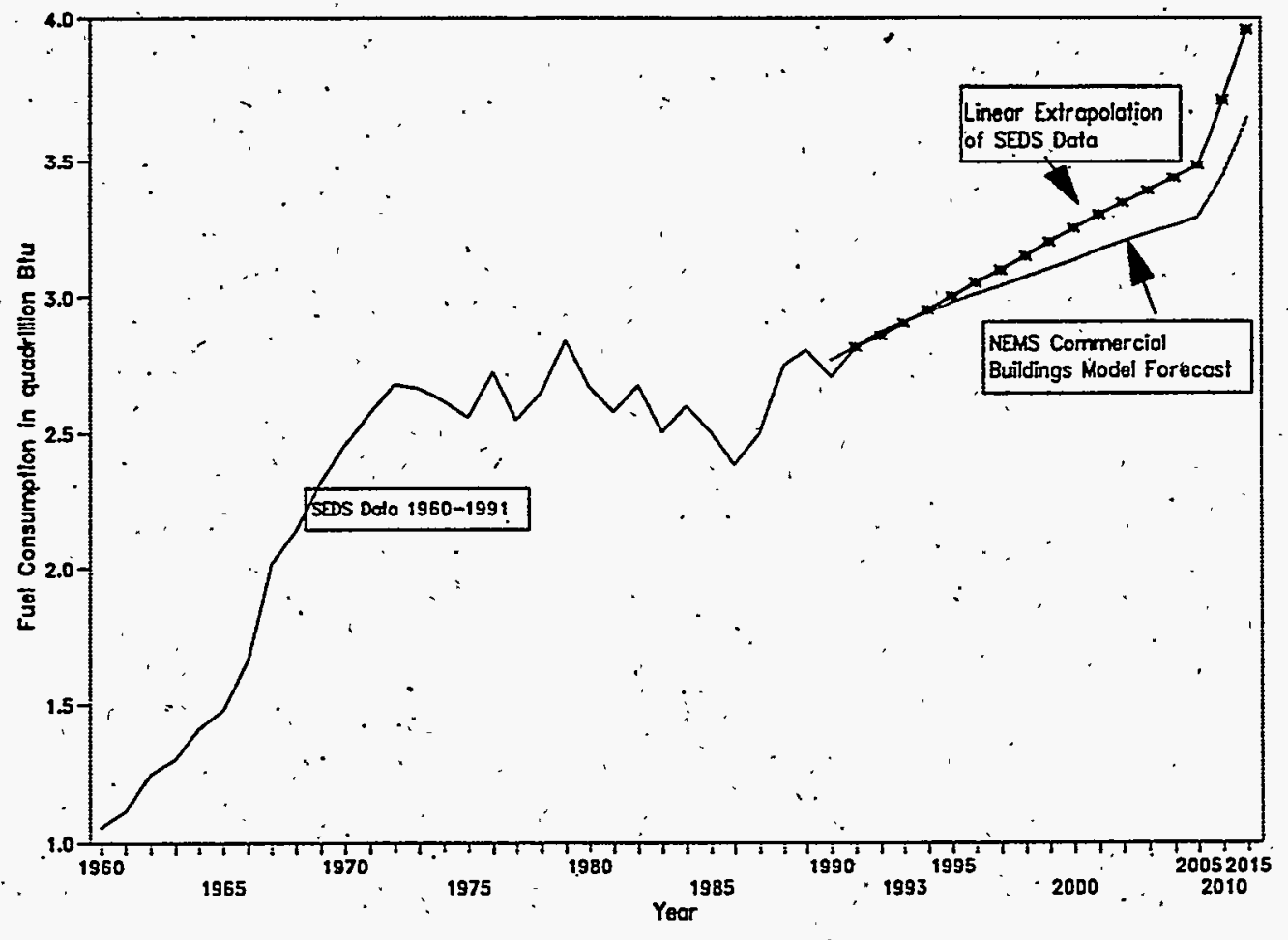

Figure 3. Commercial Sector Gás Consumption: SEDS and NEMS

\section{Comparison with the Annual Energy Outlook 1993}

The AEO93 is the most recent commercial energy demand forecast prepared by EIA. This section compares the preliminary NEMS forecast with the AEO93 forecast as well as the Wharton Econometric Forecasting Associates Group (WEFA):forecast and DRIMCGraw-Hill (DRI) forecast. The AEO93 forecasts were developed using the BEEM Model. ${ }^{1}$ WEFA and DRI

Energy Information Administration, PC-AEO Forecasting Model for the Annual Energy Outlook 1990, Model Documentation, DOE/EIA-036(90), March 1990. 
have developed and maintained integrated modeling systems. The NEMS forecasts presented in this section are preliminary, and are presented to illustrate a frame of reference for the module and the likely range of the final AEO94 forecasts.

Table 1 contains a comparison of the available forecasts for the commercial sector. In 1995, NEMS forecasts 7.18 quads compared to 7.42 in the AEO for a difference of 0.24 .quads or $3.2 \%$. The NEMS forecast rises to 8.55 quads for the year 2010 compared to AEO93's reference case • of 8.27 quads for a difference of 0.28 quads or $3.4 \%$. The DRI forecast is consistently lower than either the NEMS or AEO93 forecasts. The DRI aggregation of energy demand in the commercial sector may not be comparable to the definitions used by EIA. WEFA forecasts increase more rapidly than either NEMS or the AEO93 cases. Figure 4 illustrates the forecasts for total energy demand in the commercial buildings sector for the forecasts horizon 1995 to 2010. The WEFA projection reaches 8.75 quads by the year 2010 while the NEMS forecast is 8.55 quads, a divergence of 0.20 quads from the NEMS forecast. The difference in forecasts of total energy demand is partly attributable to differing fuel price forecasts as discussed in further detail in this section. 


\section{Table 1. Forecast Comparison: Commercial Sector Energy Demand}

\section{by Fuel: Quadrillion Btu}

Electricity Forecasts

\begin{tabular}{|l|l|l|l|l|}
\hline \multicolumn{1}{|c|}{$\therefore$} & 1995 & 2000 & $2005:$ & 2010 \\
\hline NEMS & 3.13 & 3.43 & 3.71 & 3.92 \\
\hline AEO93 High Economic Growth & 3.12 & 3.42 & 3.68 & 3.88 \\
\hline AEO93 Reference Case & 3.12 & 3.40 & 3.64 & 3.83 \\
\hline AEO93 Low Economic Growth & 3.12 & 3.38 & 3.61 & 3.77 \\
\hline WEEFA & 3.12 & 3.40 & 3.73 & 4.07 \\
\hline DRI & 3.12 & 3.39 & 3.64 & 3.85 \\
\hline
\end{tabular}

Natural Gas Forecasts

\begin{tabular}{|l|l|l|l|l|}
\hline & 1995 & 2000 & 2005 & 2010 \\
\hline NEMS & 2.98 & 3.13 & 3.28 & 3.44 \\
\hline AEO93 High Economic Growth & 3.07 & 3.18 & 3.26 & 3.31 \\
\hline AEO93 Reference Case & 3.08 & 3.17 & 3.23 & 3.25 \\
\hline AEO93 Low Economic Growth & 3.07 & 3.15 & 3.20 & 3.20 \\
\hline WEFA & 3.00 & 3.13 & 3.36 & 3.58 \\
\hline DRI & 3.08 & 3.17 & 3.23 & 3.32 \\
\hline
\end{tabular}

Distillate Fuel Forecasts

\begin{tabular}{|l|l|l|l|l|}
\hline & 1995 & 2000 & 2005 & 2010 \\
\hline NEMS & 0.53 & 0.57 & 0.60 & 0.62 \\
\hline AEO93 High Economic Growth & 0.57 & 0.53 & 0.49 & 0.45 \\
\hline AEO93 Reference Case & 0.57 & 0.53 & 0.49 & 0.44 \\
\hline AEO93 Low Economic Growth & 0.57 & 0.53 & 0.48 & 0.44 \\
\hline
\end{tabular}




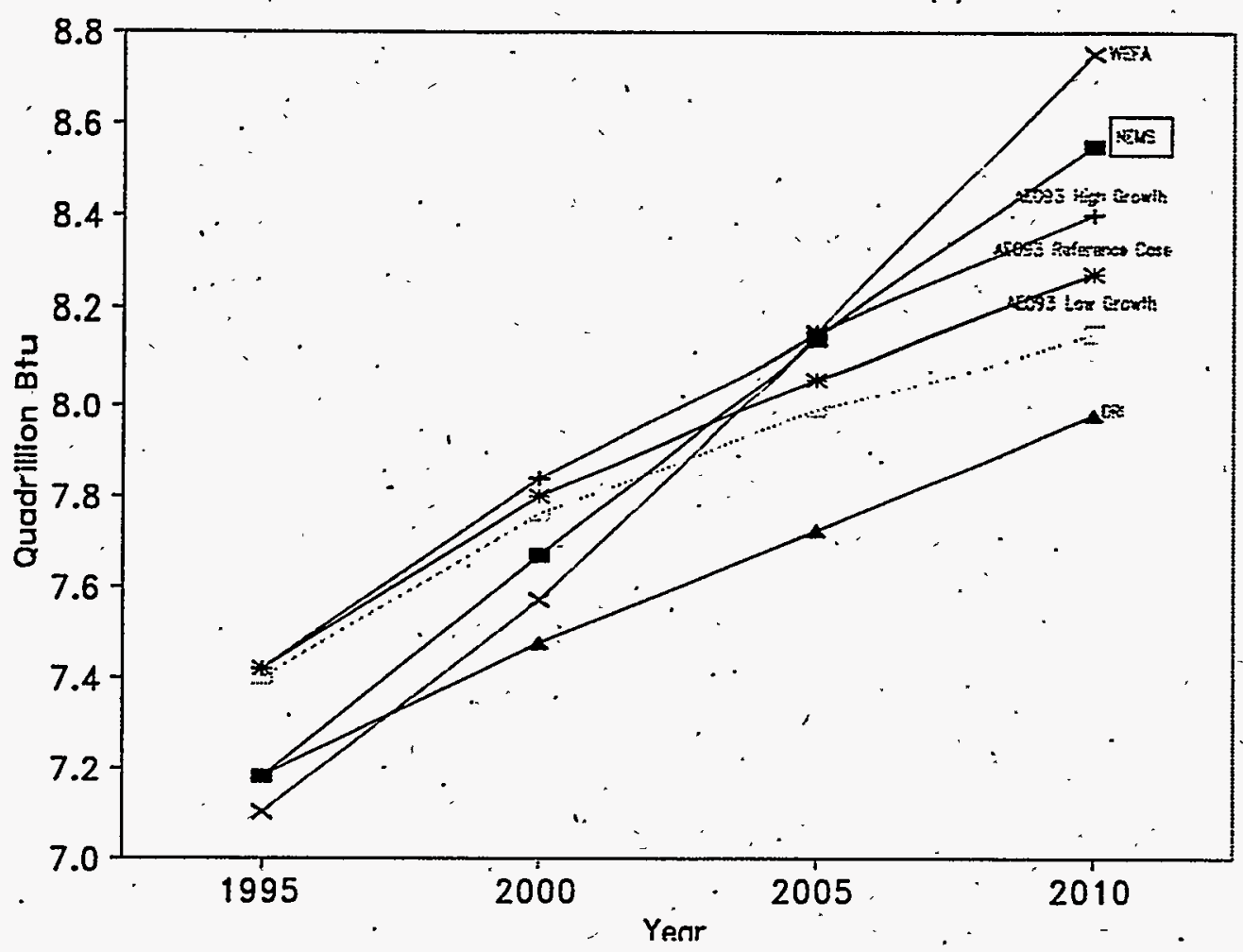

Figure 4. Total Forecasted Commercial Sector Energy Demand

Forecasts by major fuel are compared in Table 2. The distillate fuel forecasts rises in the NEMS forecast from 0.49 to 0.64 quads and falls in the AEO93 reference forecast from 0.49 to 0.44 quads.

Electricity forecasts display more similar projected trends. This is illustrated in Figure 5. The : NEMS forecast projects 3.92 quads in 2010. This is higher than the AEO93 scenarios and the DRI forecasts, although the forecasted fuel prices are significantly different for each of these projections. The AEO93 reference case prices for electricity rise from \$19.94/MMBtu in 1990 to \$20.19/MMBtu in 2010, while the NEMS electricity prices fall over the same period from $\$ 20.69 / M M B t u$ to $\$ 19.52 / M M B t u$. The DRI electricity price forecast falls over the 1990 to 
2010 period from $\$ 23.84 / \mathrm{MMBtu}$ to $\$ 20.07 / \mathrm{MMBtu}$ as well. This price forecast may explain the comparability of the DRI forecast and the NEMS forecast. In general, falling electricity prices and constant (or increasing) prices for alternative fuels should increase electricity demand. Therefore, none of these forecasts appear to contradict with bäsic economic intuition.

Figure 6 suggests that natural gas demand forecasts diverge more drastically than the electricity demand forecasts. The NEMS module forecasts natural gas demand of 3.44 quads in 2010 as compared to the reference case AEO93 forecast of 3.25 quads. The NEMS forecast displays an increasing trend in natural gas consumption, as do the WEFA and DRI forecasts while the AEO93 scenarios show consumption leveling off after 2005.

The NEMS natural gas consumption is rising because more attractively priced, high efficiency gas equipment becomes available over the forecast horizon and because gas penetration rises due to behavior rule assumptions and displacement of distillate fuel consumption. 


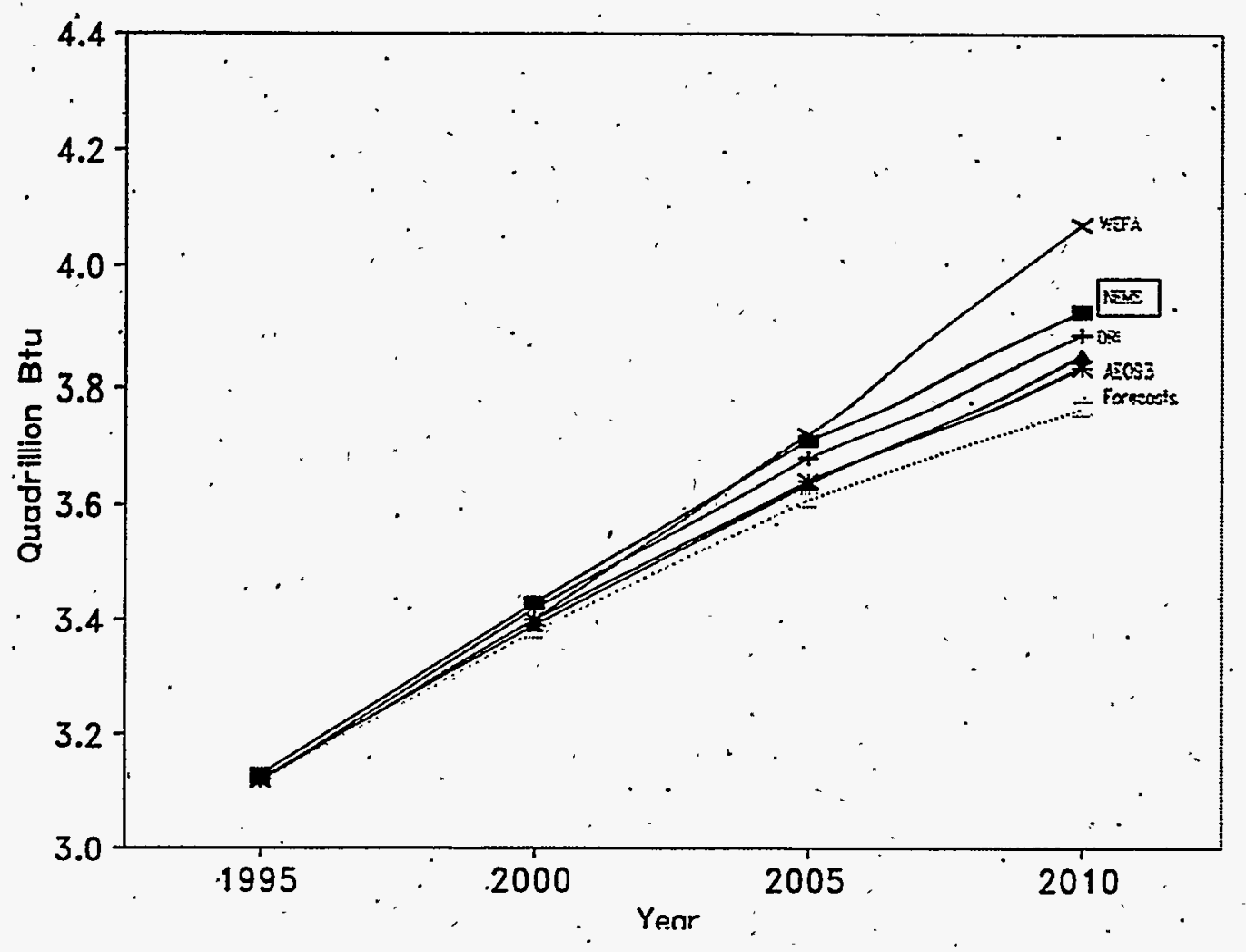

Figure 5. Comparison of Forecasted Commercial Sector Electricity Demand 


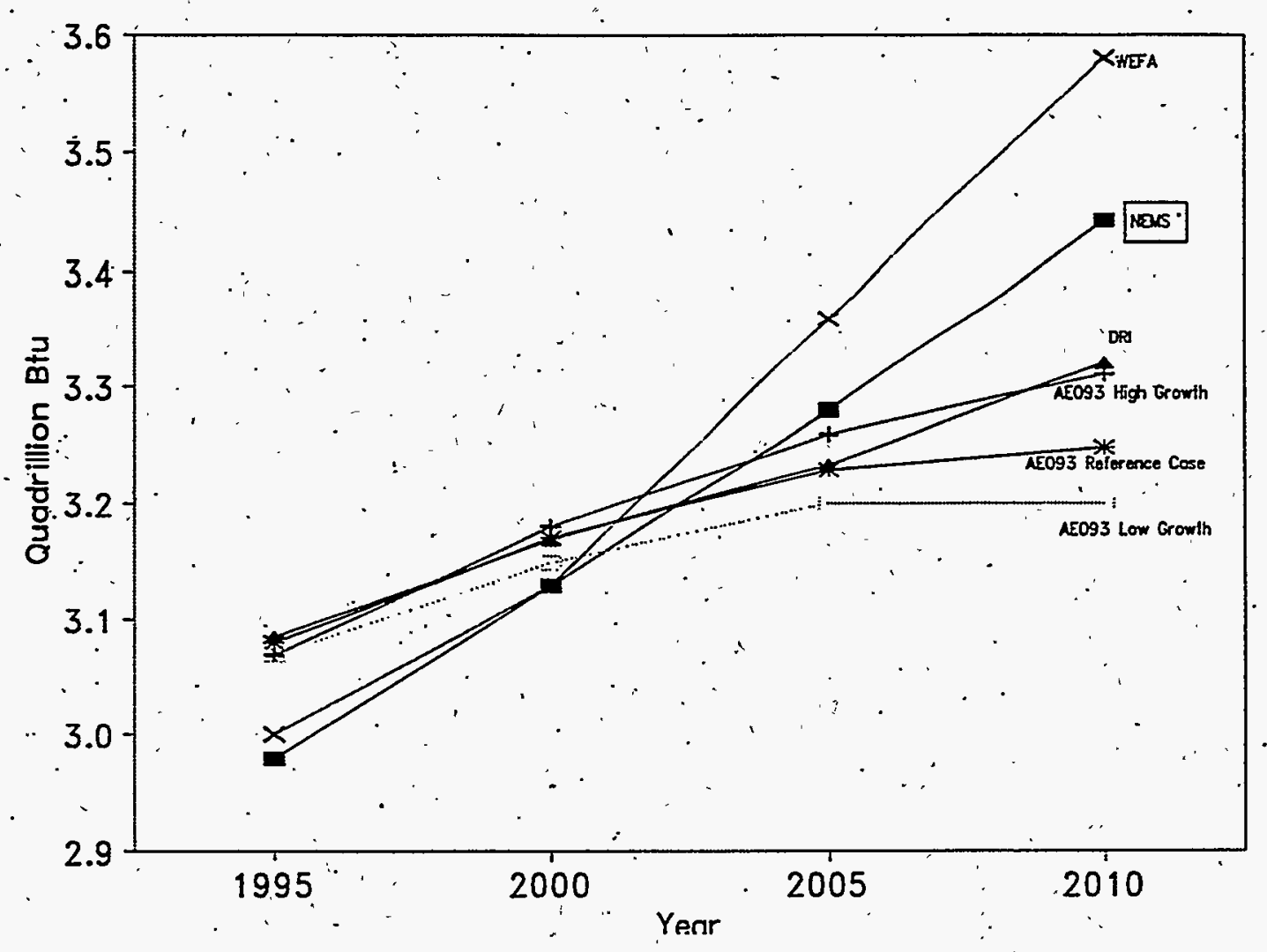

Figure 6. Comparison of Forecasted Commercial Sector Natural Gas Demand 


\section{One-at-a-time Module Sensitivity Analysis}

The NEMS Commercial Module is composed of five Submodules as described in the Module Documentation Report: Floorspace, Service Demand, Technology Choice, End-Use

Consumption, and Benchmarking. The five submodules are executed sequentially in the order presented, and the outputs of each submodule are inputs to subsequently executed submodules. As a result, key forecast drivers for the Floorspace submodule are key drivers for the Service Demand submodule, etc. This section examines the module's responsiveness to range of changes in economic activity, input prices, and assumptions regarding the behavior of commercial consumers.

The exogenous forecast of commercial floorspace provided by the NEMS Macroeconomic. Activity Module (MAM) is the primary driver of the floorspace submodule. Projected floorspace, along with year to year changes in the composition of the stock by Census Division and building type, determine the size and energy-consuming characteristics of the commercial buildings sector. ${ }^{2}$ The key output of the Floorspace Submodule is projected commercial floorspace by Census Division, building type, and floorspace category for new, retiring, and șurviving buildings.

The projections calculated in the Floorspace Submodule are utilized to develop service demands by Census Division, building type; and service. This direct linkage between the Floorspace and Service Demand Submodules ensures that projected changes in the characteristics of the floorspace stock are reflected ir calculated service demands.

As described in the Module Documentation Report, the Technology Choice Submodule calculates the results of the capital stock decisions for the major fuels of electricity, natural gas,

Energy Information Administration. Component Design Report Commercial Sector Energy Demand. .prepared by Decision Analysis Corporation of Virginia, Contract No. DE-AC01-92EI21946, January 20,1993. 
and distillate fuel; for the current year of the forecast. Capital stock decisions are driven by commercial consumer behavioral rule assumptions, fuel prices, relative individual technology capital costs and operating and maintenance (O\&M) costs. The primary outputs of the Technology Choice Submodule are the market shares of service demand met by each available technology, and the corresponding average equipment coefficient of performance by (end-use) service.

End-use consumption is developed using the calculated service demands from the Service Demand Submodule, along with the market share and equipment characteristic outputs of the Technology Choice Submodule. End-use consumption is then benchmarked to known historical data for the commercial sector, in order to account for nonbuilding use and other energy consumption that is not modeled within the buildings component.

As described previously, commercial floorspace, fuel prices; and behavioral rule ássumptions are key drivers of the module. Sensitivity analysis is therefore focused upon testing module responsiveness under varying assumptions regarding these key drivers. Table 2 summarizes the scenario descriptions that are presented in this report. 


\section{. Table 2. Scenario Descriptions for Sensitivity Analysis}

.

$\therefore \frac{\text { Scenario Tile }}{\text { 1. Reference Case }}$

2. High Floorspace ' ,

3. Low Foorspace

4. High Electricity Price

5. Low Electricity Price

6. Extreme Electricity Price(High)

7. Extreme Electricity Price(Low)

8. High Matural Gas Price

9. Low Natural Gas Price

10. High Distillate Price

11. All Least Cost Capital Decisions

12. All Same Fuel Capital Decisions

13. All Same Technology Capital Decisions Scensrio Description

Base scenario: MAM default floorspace, NEMS defanlt fuel prices, NEMS Commercial Module default - behavioial rule assumptions.

Increase commiercial sector floosspace by $10 \%$ eacti year of the forecast. Use Reference Case default fuel prices and behavioral mile assumptions.

Decrease commercial sector floorspace by $10 \%$ each year of the forecast. Use Reference Case default

fuel prices and behavional rule assumptions.

Increase commercial sector electricity price by $10 \%$ each year of the forecast. Use Reference Case defaults for floorspace, additional fuel prices, behavioral rule assumptions.

Decrease commercial sector electricity price by $10 \%$ each year of the forecast. Use Reference Case defanlts for floorspace, additional fuel prices, behavioral rule assumptions.

Quadruple commercial sector electricity price esch year of the forecast. Use Reference Case defaults for floorspace, additional fivel prices, behsvioral rule assomptions.

Decrease commercial sector electricity price by $75 \%$ each year of the forecast. Use Reference Case defaults for floorspace, additional fuel prices, behavioral rale assumptions.

Increase commercial sector natural gas price by $10 \%$ each year of the forecast. Use Reference Case defanits for floorspace, additional fuel prices, behavioral nule assumptions.

Decrease commercial sector natural gas price by $10 \%$ each year of the forecast. Use Reference Case defauits for floorspace, additional fuel prices, behavioral rule assumpions.

Increase commercial sector distillate price by $10 \%$ each jear of the forecast. Use Reference Case defaiuts for floorspace, additional fuel prices, behavioral rule assumptions.

Set behavioral rule proportions to 1.0 for Least Cost, 0.0 for Same Fuel and Same Technology rules. Use Reference Case defauth for floorspace and fuel prices.

Set behavioral rule proportions to 1.0 for Same Fuel, 0.0 for Least Cost and Same Technology rules. Use Refereace Case defanits for floorspace and fuel prices.

Set behavior rule proportions to 1.0 for Same Technology, 0.0 for Least Cost and Same Fuel rules. Use

Reference, Case defanlts for floorspace and fuel prices.

Energy Information Administration

NEMS Commercial Demand Module Documentation Report 


\section{Reference Case Scenario}

The Reference Case scenario employs the MAM default floorspace forecast, the NEMS Restart File fuel price series, and the NEMS Commercial Module default assumptions for all remaining module parameters, including behavioral rule proportions.

The Reference Case forecast of total commercial floorspace is projected to increase annually, beginning with an annual rate of increase of $1.7 \%$, and tapering off to an annual growth rate of $0.8 \%$ by the end of the forecast period. Census Division-specific floorspace trends are more volatile than national floorspace trends, especially in the Mountain Census Division, which accelerates to an annual growth rate of $6.7 \%$ by 2015 .

Reference Case fuel prices vary relative to each other throughout the forecast period. Initially, the price of distillate fuel is greater than the price of natural gas (measuring all fuels in 1990 dollars/million Btu for equivalence); but this relationship reverses over the forecast period. Forecasted electricity prices fall gradually through 2000 , and rise slightly after 2000 , for an average annual growth rate of $0.2 \%$ over the forecast period.

As described previously, fuel prices are key drivers in the capital stock decision process modeled in the Technology Choice Submodule. The observed changes in the fuel proportions of service demand reflect changes in the relative fuel price series over the forecast period. As anticipated, market equipment performance for the major services of space heating, space cooling, and water . heating improves over the forecast period; reflecting the implementation of energy efficiency standards and the gradual trend of the commercial market - equipment manufacturers and commercial consumers - toward the installation of higher efficiency equipment. 
The initial behavioral rule assumptions indicate that differing proportions of commercial consumers both across and within building types and decision types (new, replacement, or retrofit) consider characteristics of their existing equipment (type of fuel used or type of equipment), in addition to equipment costs, in the capital decision-making process.

Reference Case projections of energy consumption by fuel type are presented in these forecasts, electricity consumption increases from 2.9 quadrillion Btu (quads) in 1990 to 3.3 quads in 2015, for an average annual growth rate of $0.6 \%$ over the forecast period. Natural gas consumption increases from 2.8 quads in 1990 to 3.3 quads in 2015 , resulting in $0.7 \%$ average annual growth over the twenty-five years. Distillate consumption remains at 0.5 quads over the forecast period. 


\section{Alternate Floorspace Scenarios}

The alternate floorspace scenarios employ the BASE92 NEMS Restart File fuel price series, and the NEMS Commercial Module default assumptions for all remaining user inputs, including behavioral rule proportions. The incremental floorspace scenario increases the MAM floorspace. forecast by $10 \%$ for each year of the forecast period. The decremented floorspace scenario decreases the MAM floorspace by $10 \%$ for each year of the forecast.

\section{Incremented Floorspace Scenario}

The expected result of increasing commercial floorspace is increased energy consumption projections for all fuels; since increasing floorspace effectively expands the commercial sector market for all fuels. This expectation is realized, as demonstrated in the energy consumption forecasts. In this consumption forecast, electricity demand rises from 2.9 quads in 1990 to 3.4 quads in 2015, an increase of 0.1 quads over the reference electricity forecast. Similarly, natural gas demand rises from 2.76 quads in 1990 to 3.5 quads in 2015, an increase of 0.2 quads over the Reference Case. Distillate fuel demand falls from 0.5 quads in 1990 to 0.4 quads in 2015, as compared to a steady reference forecast. This last trend reflects the decline of distillate fuel penetration in new commercial floorspace.

\section{Decremented Floorspace Scenario}

The primary expected result of decreasing commercial floorspace is a corresponding decrease in energy consumption compared to the Reference Case, since decreasing floorspace effectively: reduces the size of the commercial market. This expectation is realized, as demonstrated in the energy consumption forecasts. In this consumption forecast, electricity demand rises from 2.9 quads in 1990 to only 3.1 quads in $2015,0.2$ quads less than the reference electricity forecast in 2015. Similarly, natural gas demand rises from 2.8 quads in 1990 to.3.2 quads in $2015,0.1$ quads less than the Reference Case. Distillate fuel demand falls from 0.5 quads in 1990 to 0.4 quads in 2015, as compared to a steady Reference Case forecast. As in the incremental 
floorspace scenario, this last trend reflects the declining distillate fuel penetration in new commercial floorspace. 


\section{Alternate Fuel Price Scenarios}

The fuel price scenarios discussed in this section are generated using price series constructed from the. NEMS Restart file. All other default module assumptions as described in the Reference Case forecast are retained in the fuel price scenarios. High and low fuel prices are individually tested and presented, for the major fuels of electricity and natural gas. A high distillate fuel price scenario, holding all other fuel prices at Reference Case levels, is also tested. In order to analyze module performance under dramatic price changes, two extreme cases are analyzed. The first extreme case increases the annual electricity price to $400 \%$ of the Reference Case value, for each forecast year. The second extreme case decreases annual electricity prices to $25 \%$ of the Reference Case value.

\section{Expected Results}

The definition of a normal good states that an increase in the price of a good results in a reduction in the quantity demanded of that good. In addition, the substitution effect postulates that an increase in the relative price of good $x$ results in an increase in the demand for goods that are substitutes for good $x$. Assuming that the energy services provided by the fuels under consideration are normal, and recognizing that NEMS Commercial Module permits fuel switching through the Technology Choice submodule, these principles translate into expected changes in demand across all major fuels resulting from alternate fuel price assumptions for individual fuels.

Specifically, the fuel price scenarios performed for this analysis modify individual fuel price projections, holding remaining fuel prices at Reference Case levels. This type of scenario specification alters relative fuel prices; facilitating the analysis of both own-fuel and cróss-fuel impacts. The expected results of increasing the price of fuel $f$ are a decrease in the quantity demanded of fuel $f$ and an increase in the quantity demanded of other major fuels. Analogous to the price increase scenario, price reduction scenarios are expected to result in increases in 
quantity demanded of the fuel experiencing the price reduction, accompanied by decreases in the quantity. demanded of other major fuels whose relative prices rise under the alternate scenario. Minor fuel consumption forecasts are expected to remain at Reference Case levels, since fuel substitution is permitted only across the major fuels that compete to meet service demands within : the Technology Choice submodule as described in Volume I of this report

\section{Electricity Price Scenarios}

The four alternate electricity price scenarios performed for this analysis are: $110 \%$ Reference Case, 90\% Reference Case, 400\% Reference Case, and 25\% Reference Case. Each of these scenario specifications tests a different aspect of module performance. The first two scenarios test a normal range of module sensitivity, and the latter two scenarios test module response under extreme circumstances.

Forecasted energy prices for the $110 \%$ Reference Case scenario are provided in Table 3 along with the forecasted consumption for each price scenario. As expected, projected electricity demand rises at an average annual growth rate of $0.6 \%$ over the forecast period, as compared to $0.7 \%$ in the Reference Case. In addition, natural gas demand rises from 2.8 quads to 3.3 quads over the forecast period, for an increase of 0.1 quads over the Reference Case projection. Projected distillate fuel consumption remains steady under this scenario, reflecting the trend away from the installation of distillate-fired equipment in new commercial floorspace. These trends are also reflected in the fuel proportions of service demand that support this scenario.

Energy price projections for the $90 \%$ Reference Case scenario and the corresponding energy demand forecasts by fuel type for this scenario are also found in. The reduction in Table 3 forecasted electricity prices results in the expected increase in projected electricity consumption over the Reference Case forecast. The increase is slight (only 0:01 quads by 2015) over the Reference Case. Similarly, the corresponding comparison between forecasted natural gas 
Table 3. NEMS Forecast: Alternative Electricity Prices

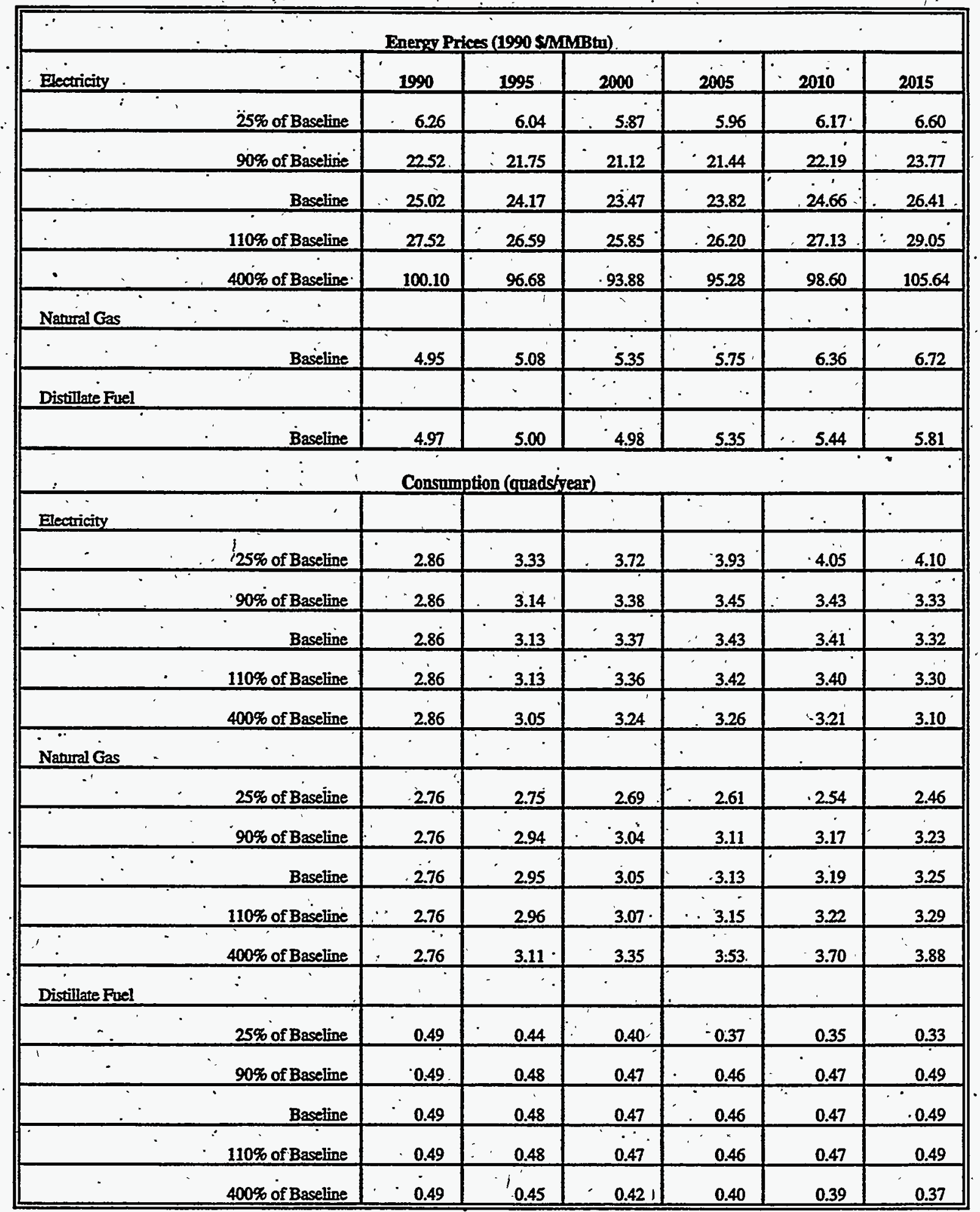

Energy Information Administration

NEMS Commercial Demand Module Documentation Report 
consumption in 2015 for the alternate case and the Reference Case is also slight (a difference of 0.02 quads). Distillate fuel consumption remains steady under this scenario. The $400 \%$. Reference Case and 25\% Reference Case scenarios test the responsiveness of the module under more dramatic price assumptions. As expected, the extremely high electricity price dampens the upward trend of electricity consumption growth, resulting in an average annual growth rate of

. $0.3 \%$ as compared to $0.6 \%$ in the Reference Case. The natural gas consumption forecast increases significantly over Reference Cașe levels under this scenario, growing at an average annual rate of $1.4 \%$, compared to $0.7 \%$ under Reference Case assumptions. Distillate fuel consumption falls at an annual average rate of $1.1 \%$ over the forecast period, reflecting the continued steady penetration of natural gas equipment under the $400 \%$ scenario. The forecast trends observed in the $400 \%$ Reference Case scenario are reversed under the $25 \%$ Reference Case scenario, with projected electricity consumption growing at an annual average rate of $1.4 \%$ over the forecast period (compared to $0.6 \%$ under Reference Case assumptions), and natural gas consumption declining at an average annual rate of $0.5 \%$. Distillate fuel consumption declines even more steeply (1.6\% average annual decline from 1990 to 2015), again reflecting market. trends away from distillate equipment and relative price disadvantages compared to the other major fuels.

Figure 7 and Figure 8 provide a graphical comparison of the alternative electricity price scenarios and the effect on the levels of consumption in electricity and natural gas, the substitute energy source. 


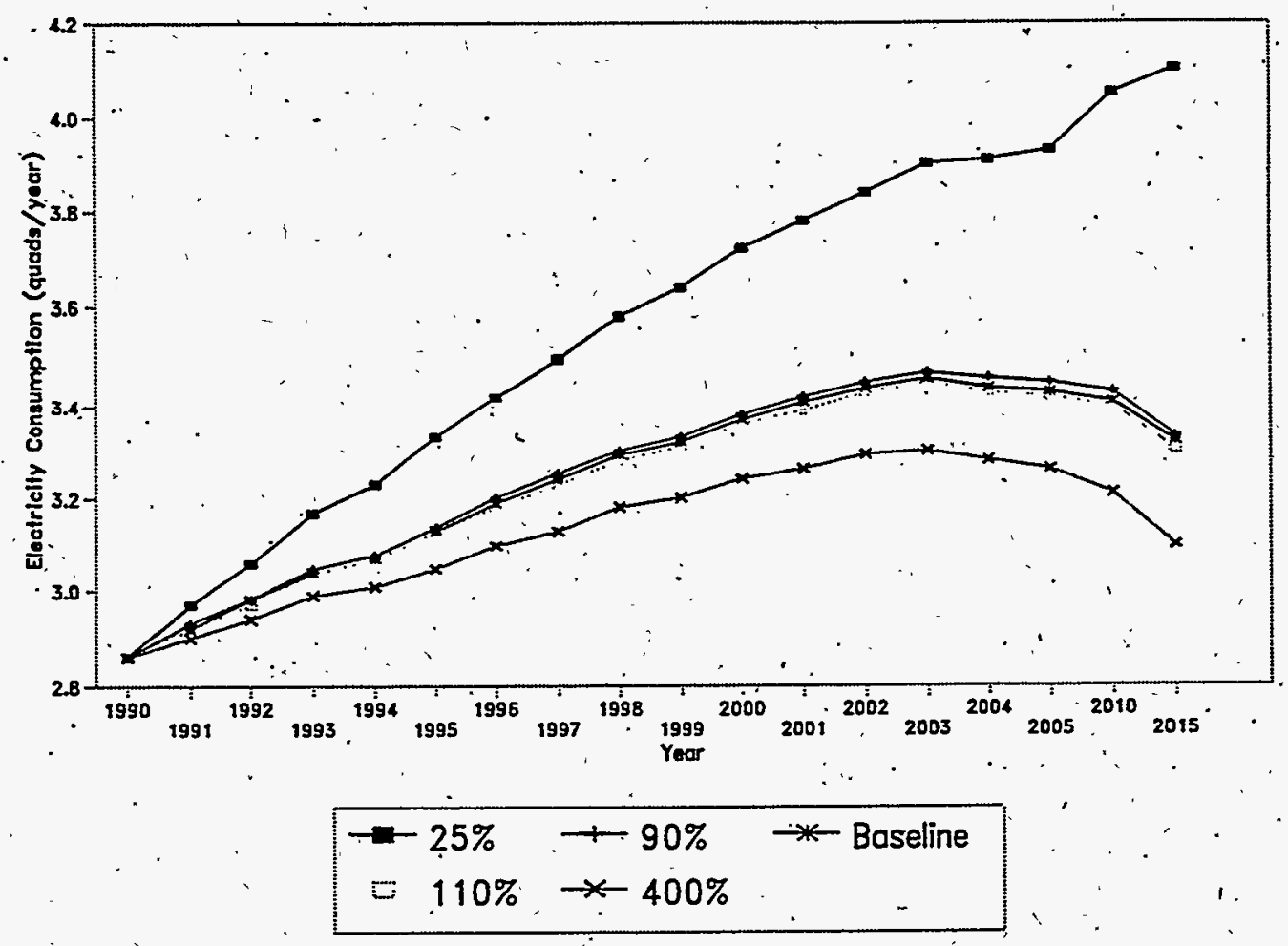

Figure 7. NEMS Forecast under Alternative Electricity Price Assumptions 


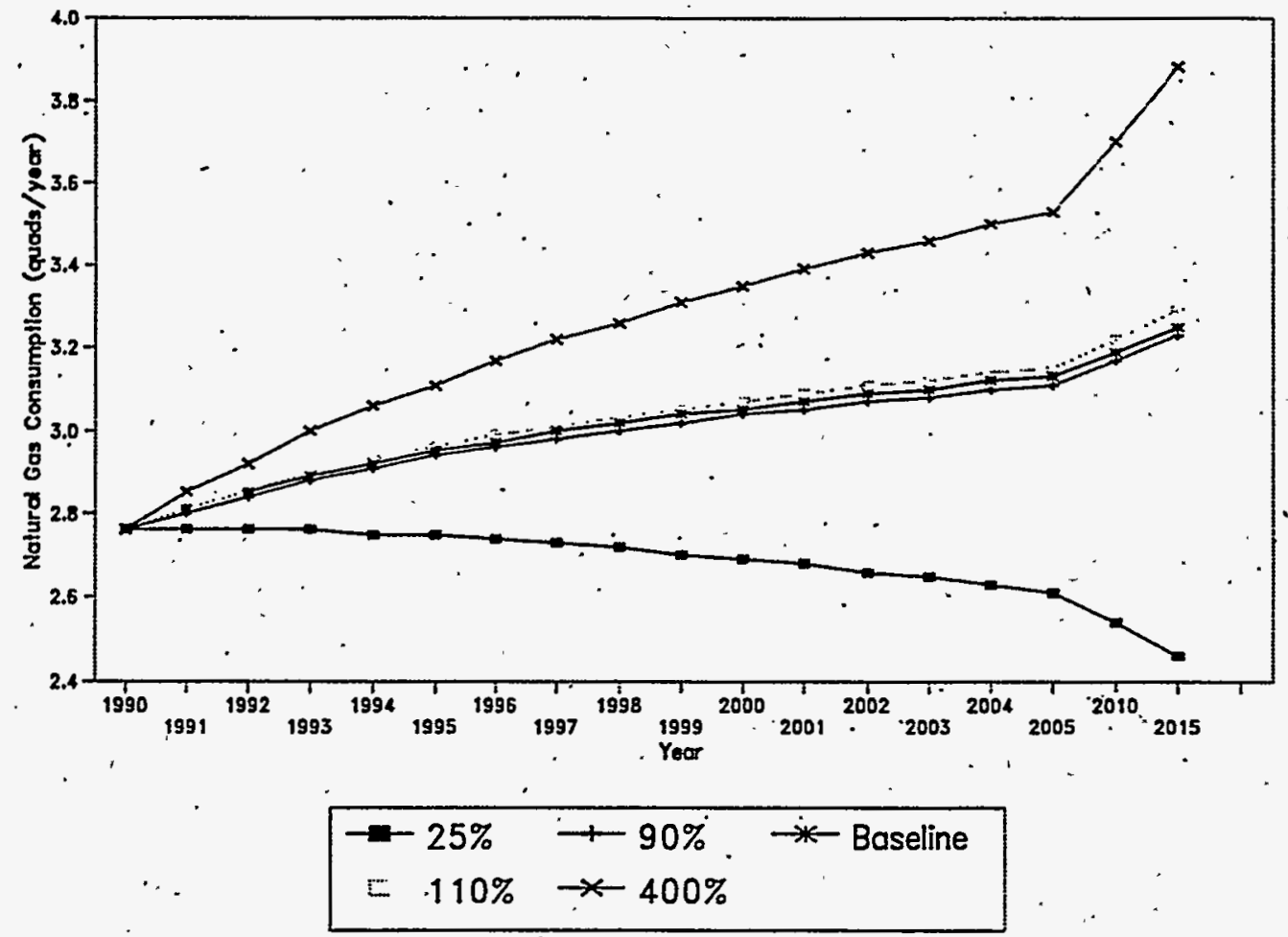

Figure 8. NEMS Commercial Natural Gas Forecast under Alternative Electricity Prices

\section{Natural Gas Price Scenarios}

Two alternate natural gas price scenarios are presented in this report: $110 \%$ Reference Case and 90\% Reference Case. Similar to the electricity price scenarios, these two cases are designed to evaluate module responsiveness in projecting energy consumption and fuel proportions of service demand under alternate price forecast assumptions. As in the electricity price scenarios, all other major fuel prices are held at Reference Case levels while natural gas prices vary, in order to analyze own-price and cross-price impacts.

Energy price projections and the forecasted consumption for the natural gas price scenarios are presented in Table 4. As expected, the increase in the relative price of natural gas over Reference 
Case levels results in reduced average annual growth in projected natural gas consumption over the forecast period ( $0.5 \%$ compared to $0.7 \%$ in the Reference Case). Projected electricity consumption remains at Reference Case levels, and projected distillate fuel consumption rises at an average annual growth rate of $1.1 \%$ over the forecast period, indicating that fuel substitution is occurring from natural gas equipment into distillate equipment, since the relative price of natural gas to distillate becomes higher under this scenario. The corresponding results of the Technology Choice submodule for this scenario support the relative price theory.

As expected, the reduction in natural gas prices compared to Reference Case levels results in increased projected natural gas consumption growth, at an average annual growth rate of $0.8 \%$, compared to $0.7 \%$ in the Reference Case. Projected electricity consumption is slightly lower than the Reference Case in 2015 (by 0.01 quads), reflecting the increased relative price advantage of natural gas under this scenario. Similarly, distillate consumption falls from 0.5 quads in 1990 - to 0.4 quads in 2015, also reflecting the relative price advantage of natural gas under this scenario.

Figure 9 illustrates the response of the demand for natural gas under the varying price scenarios. Electricity consumption figures are excluded since the graphical presentation does not significantly add to the analysis. This is because electricity consumption is not as sensitive to changes in natural gas prices over the forecast horizon due to the minor effects of cross-price consideration, which are discussed further in the elasticities section of this report. In addition, electricity is the sole energy source for several types of equipment such as lighting, office equipment, etc. . 
Table 4. NEMS Forecast: Alternative Natural Gas Prices

\begin{tabular}{|c|c|c|c|c|c|}
\hline \multicolumn{6}{|c|}{ Energy Prices (1990 \$MMMtu) } \\
\hline Natural Gas & 1990 & 1995 & 2000 & 2005 & 2010 \\
\hline$\therefore 90 \%$ of Baseline Gas Price & 4.46 & 4.57 & 4.82 & 5.18 & 5.72 \\
\hline Baseline Gas Price & 4.95 & 5.08 & 5.35 & 5.75 & 6.36 \\
\hline $110 \%$ of Baseline Gas Price & $5: 45$ & 5.59 & 5.89 & 6.33 & 7.00 \\
\hline Electricity & & & 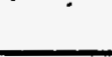 & & \\
\hline Baseline & 25.02 & 24.17 & $23.47^{\circ}$ & 23.82 & 24.66 \\
\hline Distillate Fuel & 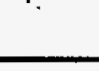 & & & & . \\
\hline Baseline & 4.97 & 5.00 & 4.98 & 5.35 & 5.44 \\
\hline \multicolumn{6}{|c|}{ Consumption (quads'year) } \\
\hline Electricity & & - & & & \\
\hline $90 \%$ of Baseline Gas Price & 2.86 & 3.13 & 3.37 & 3.43 & 3.40 \\
\hline Baseline Gas Price & 2.86 & 3.13 & 3.37 & 3.43 & 3.41 \\
\hline $110 \%$ of Baseline Gas Price & 2.86 & $3.14^{\circ}$ & 3.37 & 3.44 & 3.42 \\
\hline Natural Gas & & & & & \\
\hline $90 \%$ of Baseline Gas Price & 2.76 & 2.97 & 3.09 & 3.18 & 3.27 \\
\hline Baseline Gas Price & 2.76 & 2.95 & 3.05 & 3.13 & 3.19 \\
\hline $.110 \%$ of Baseline Gas Price & 2.76 & 2.91 & 2.98 & 3.03 & 3.06 \\
\hline Distillate Fuel & & & & & \\
\hline $90 \%$ of Baseline & 0.49 & 0.48 & 0.47 & 0.46 & 0.47 \\
\hline Baseline & 0.49 & 0.48 & .0 .47 & 0.46 & 0.47 \\
\hline $110 \%$ of Baseline & 0.49 & 0.48 & 0.47 & 0.46 & 0.47 \\
\hline
\end{tabular}




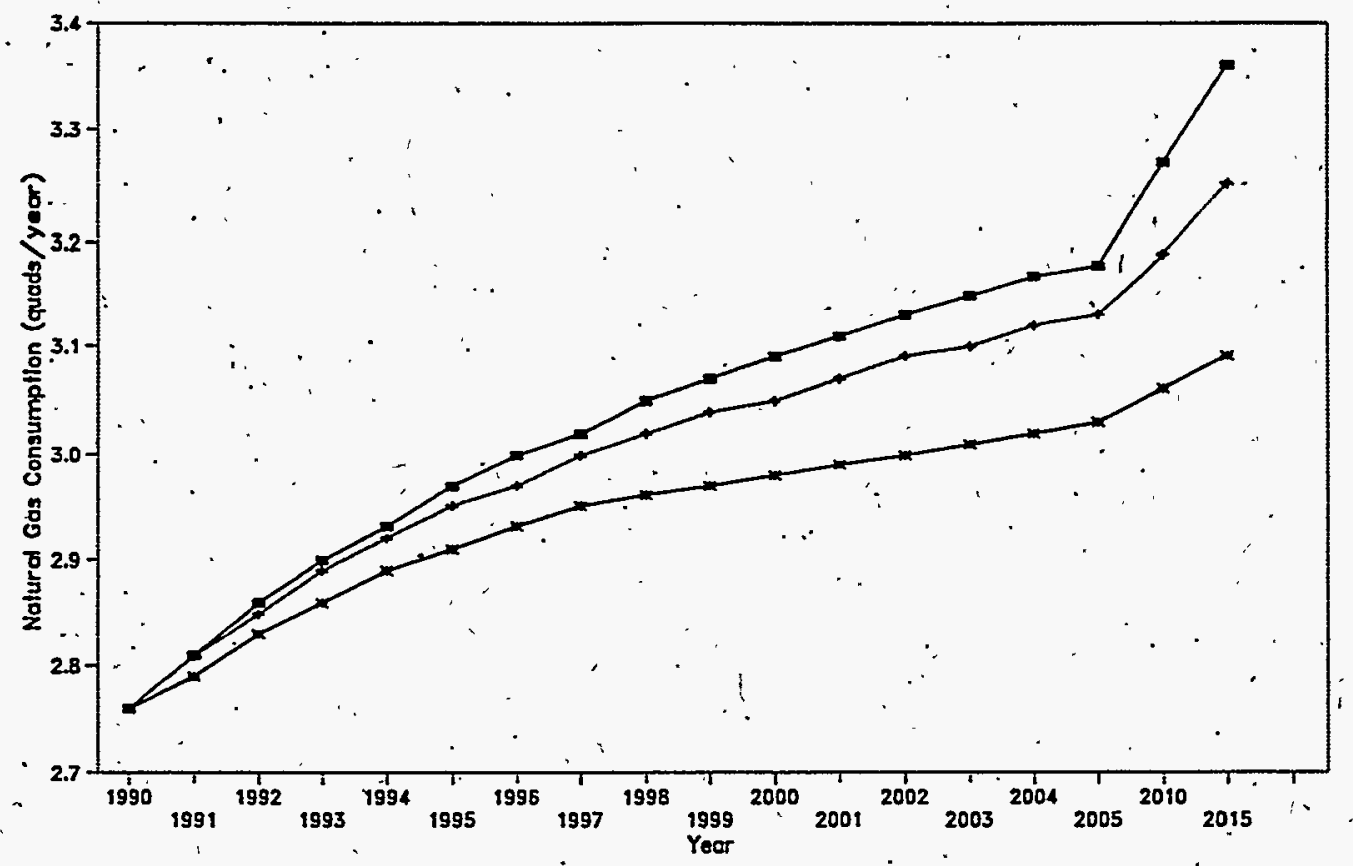

$90 \%+$ Baseline $* 110 \%$

Figure 9. NEMS Forecast of Commercial Sector Natural Gas Demand under Alternative Natural Gas Price Assumptions

\section{Distillate Price Scenario}

For completeness in testing module sensitivity under major fuel price assumptions; a $110 \%$

Reference Case is presented for distillate fuel. As illustrated in the consumption forecasts, increased distillate prices result in reduced consumption of distillate fuel over the forecast period. Distillate consumption falls from 0.5 quads in 1990 to 0.4 quads in 2015, for an average annual decline of $0.6 \%$ over the forecast period, compared to a steady forecast under Reference Case 'prices. Projected electricity consumption remains at Reference Case levels under this scenario, and projected natural gas consumption rises by $0.7 \%$, compared to $0.6 \%$ under Reference Case 
assumptions. As in the $110 \%$ Reference Case scenario for natural gas, this scenario illustrates the fuel substitution that occurs between distillate and natural gas.

\section{Price Elasticity of Demand Calculation}

The economic description of the long run is that period in which all inputs vary, including the capital stock. The Technology Choice submodule of NEMS Commercial Buildings Module ensures that capital stock is permitted to vary, since all-service demand is subjected to the decision-making process, for each year of the forecast period. This effectively ensures that the price elasticity of demand estimates computed by comparing alternate price scenarios of the NEMS Commercial Module are long-run. For purposes of this analysis, long-run price elasticity estimates are computed both within and across fuels, for the three major fuels of electricity, natural gas, and distillate.

The estimated own-price and cross-price demand elasticities are presented in Table 5. As illustrated in the table, the own-price impact for electricity appears small in comparison to the own-price impacts for natural gas and distillate fuel. The primary factor underlying this result is the presence and steady penetration of solely electric end uses such as ventilation systems, office equipment, and refrigeration systems in commercial buildings. In addition, all new commercial floorspace utilizes electricity to meet lighting service demand, increasing the complexity of evaluating long-run trends in electricity consumption. In spite of this complication, the ownprice elasticity estimates for all three major fuels fall within the range observed in documented analyses.

Cross-price elasticities are not significant for electric and distillate fuel pairs, due to the limited variation across price scenarios. Natural gas consumption displays a symmetric cross-price elasticity with respect to electricity and distillate prices, rising approximately $0.7 \%$ for each $1 \%$ rise in electricity or distillate price. Distillate displays a comparably large cross-price elasticity of nearly $1.3 \%$ for each $1 \%$ rise in natural gas price, illustrating fuel substitution behavior. 
Table 5. Long-Run Price Elasticity of Demand Estimates

\begin{tabular}{|c|c|c|c|}
\hline \multicolumn{2}{|l|}{ Fuel } & \multicolumn{2}{|c|}{ Long-Run Price Elasticity of Demand } \\
\hline \multicolumn{2}{|l|}{ Electricity. } & \multicolumn{2}{|l|}{$=0.030$} \\
\hline \multicolumn{2}{|c|}{$\therefore$} & \multicolumn{2}{|l|}{-0.230} \\
\hline \multicolumn{2}{|l|}{ Distillate } & \multicolumn{2}{|l|}{-0.426} \\
\hline Cross-Price Elasticity of Demand & Electricity & Natural Gas & Distillate \\
\hline Electricity & & n.s. & n.s., . \\
\hline Natural Gas & 0.066 & $\therefore$ & 0.066 \\
\hline Distillate & n.s. & 1.277 & \\
\hline
\end{tabular}




\section{Alternate Behavioral Rule Proportion Scenarios}

The assumed proportions of commercial consumers that follow the three behavioral rules are key drivers of the NEMS Commercial Module. The Reference Case assumptions are derived from studies pertaining to consumer characteristics, building characteristics, behavioral patterns, and professional júdgement to align the initial proportions as closely as possible with known historical information and expectations. One test of module performance in capital stock decision-making involves assuming that all consumers follow a single behavior rule, holding all other module inputs at Reference Case levels.

\section{All Least Cost Behavior}

The Least Cost behavioral rule assumes that commercial consumers consider all pieces of equipment that meet a given service, across all fuels, when faced with a capital stock decision. The consumer chooses the piece of equipment that meets the service at the lowest annualized lifetime cost. The "All Least Cost" scenario sets the ratio of consumers following this rule to 1.00 , removing all fuel-specific considerations in the decision process. This scenario effectively assumes that decisions are independent of the fuel proportions of the existing equipment stock.

The theory underlying this scenario does not accurately reflect observed market behavior and professional expectations; a certain proportion of consumers are expected to base capital decisions in part on the fuel currently being used to meet that service demand. For example, a commercial consumer that is satisfied with the performance of a natural gas boiler may give greater preference to purchasing another natural gas boiler, as compared to an electric furnace, when the current boiler wears out, possibly due to reasons such as perceived comfort or reliability, that may be independent of relative technology costs. 
In this forecast, projected electricity consumption rises at an annual average growth rate of $0.7 \%$, as compared to $0.6 \%$ in the Reference Case. Forecasted natural gas consumption rises at only $0.2 \%$ on an average annual basis, compared to $0.7 \%$ in the Reference Case, and distillate consumption rises at an annual average rate of $0.9 \%$, compared to a steady Reference Case forecast. These trends indicate that, under the Reference Case relative price projections, electric and distillate-fired equipment enjoy cost advantages that are not fully realized when the majority of commercial consumers are assumed to follow the Same Fuel and Same Technology behavioral rules.

The module performs as expectèd under this alternate scenario, given the projected price trends for the major fuels. Under the Reference Case scenario, electricity prices are expected to rise at an annual average rate of $0.2 \%$ over the forecast period. Natural gas prices are forecasted to rise $.1 .2 \%$ on an annual average basis, and distillate prices are projected to rise at $0.6 \%$ annually. The 'disparity in price growth rates, along with the reversal of the relative price relationship between natural gas and distillate fuel during the forecast period, drive the results of the Least Cost scenario.

\section{All Same Fuel Behavior.}

The Same Fuel behavioral rule restricts the capital stock decision to the set of technologies that consume the same fuel that currently meets the decision-maker's.service demand. The consumer chooses from this subset of available technologies the specific equipment that meets the service at the lowest annualized lifetime cost. The assumption of all Same Fuel behavior effectively eliminates fuel substitution from the Technology Choice submodule.

As in the Least Cost scenario, projected electricity consumption rises at an annual average growth rate of $0.7 \%$, compared to $0.6 \%$ in the Reference Case. Forecasted natural gas consumption rises at only $0.2 \%$ on an average annual basis, compared to $0.7 \%$ in the Reference Case, and distillate consumption rises at a significantly higher annual average rate of $2.0 \%$, compared to a steady Reference Case forecast. 
- Two primary.conclusions can be drawn from this exclusion of fuel substitution. First, the movement of the commercial market away from electric and distillate space heating and water - heating equipment in favor of natural gas equipment is eliminated, resulting in persistence of electric and distillate service demand for these services. This trend contributes to increased growth in the electricity and distillate forecasts at the cost of slower growth in the natural gas forecast compared to the Reference Case. Second, the long lifetimes associated with distillatefired equipment also contribute to the pẹrsistence of distillate market share.

\section{All Same Technology Behavior}

Under the Same Technology tule, commercial consumers consider only the available models of the same technology and fuel that currently meets service demand, when facing a capital stock: decision. Equipment choices are therefore.restricted to the subset of models of equipment available that use the same fuel as existing equipment. For example, a commercial consumer currently using a medium efficiency distillate-fired furnace chooses as its replacement the available distillate furnace model (e.g., medium-efficiency, high efficiency, very high efficiency) that meets the space heating service demand at the lowest annualized cost. The assumption of all Same Technology behavior eliminates both fuel substitution and technology substitution. This is the most restrictive behavioral rule assumption tested in this analysis.

Under the Same Technology assumption, electricity consumption is forecast to be 3.5 quads in 2015 , with a forecast annual average growth rate of $0.9 \%$, compared to $0.6 \%$ in the Reference Case. Forecasted natural gas consumption rises at $0.1 \%$ on an average annual basis, compared to $0.7 \%$ in the Reference Case. Distillate fuel consumption falls slightly over the forecast period, at an average annual decline of $0.2 \%$, compared to a steady Reference Case scenario.

\section{Reference Case Forecast}

The forecasted increase in electricity consumption compared to the Reference Case (and the Same Fuel scenario) results from the interfuel and intrafuel restrictions.imposed under the Same Technology rule. Under the Same. Fuel rule, consumers are permitted to choose more efficient 
technologies using the same fuel currently in place. For example, consumers using inefficient electric resistance space heating equipment are capable of choosing high efficiency electric boilers (that meet the same amount of heating service demand and consume less electricity than resistance equipment) under the Sàme Fuel rule. In contrast, the Same Technology rule restricts the choice set to the available electric resistance equipment, potentially resulting in a choice that uses more fuel than other electric technologies to meet the same service demand. Projected natural gas consumption trends under this scenario follow the gradual introduction over the forecast period of more efficient natural gas space heating, space cooling, and water heating equipment with competitive capital costs. This trend reflects the movement of the market toward higher efficiency equipment as existing equipment retires, when restricting the choice to the same class of technology. 


\section{Bibliography}

Energy Review, Data Resources Inc., Lexington, Mass., Fall-Winter 1992-1993, Table 4, p. 151.

NERA Energy Outlook, National Economic Research Associates, White Plains, New York, February 15,1993, p. 3.

Energy Analysis Quarterly, Wharton Economic Forecasting Associates, Winter 1992, pp. 10-12 to $10-15$.

U.S. Department of Energy, Energy Information Administration, Annual Energy Outlook 1993, DOE/EIA-0383(93), Washington, DC, January 1993, appendices A through C.

Commercial Buildings Energy Consumption and Expenditures 1989. Energy Information Administration, Office of Energy Markets and End Use, U.S. Department of Energy, Washington, DC, April 1992, pp. 1-4:

State Energy Data Report: Consumption Estimates 1960-1990, Energy Information . Administration, Office of Energy Markets and End Use, U.S. Department of Energy, Washington, DC, May 1992, pp. 1-3. 